\title{
Amphiphilic carbohydrate-containing compounds for multifunctional nano/macro structures
}

\author{
Dissertation \\ to attain the doctoral degree (Dr. rer. nat.)* \\ of the Faculty of Forest Sciences and Forest Ecology \\ Georg-August-Universität Göttingen
}

Submitted by

Shuang Wang

born on 05-01-1989 in P.R. China

Göttingen, 11, 2020 
1st Referee: Prof. Dr. Kai Zhang, Department of Wood Technology and Wood-based Composites, Georg-August-Universität Göttingen

2nd Referee: Prof. Dr. med Michael P. Schön, Department of Dermatology, Venereology and Allergology, Georg-August-Universität Göttingen

3rd Referee: Prof. Dr. Thomas Heinze, Institute for Organic Chemistry and Macromolecular Chemistry (IOMC), Friedrich Schiller University Jena

Date of the oral examination: 29-09-2020 


\section{Acknowledgment}

First of all, I would like to thank my supervisor Prof. Dr. Kai Zhang for his priceless guidance and strong support in my Ph.D. research. His advice on scientific research, life, and further career are invaluable and meaningful. It's very fortunate for me to have the opportunity to pursue my Ph.D. degree with a smart, responsible, and enthusiastic scientist.

Then I would like to thank two other professors in my supervising committee: Prof. Dr. med Michael P. Schön and Prof. Dr. Philipp Vana. I deeply appreciate their generous help in equipment supporting and inspirational comments. Especially, I would like to thank Prof. Dr. med Michael P. Schön for his valuable time for reviewing my thesis. I would also like to thank the other members of my oral examination board, Prof. Dr. Carsten Mai, for his time, helpful comments, and insightful questions.

Moreover, I sincerely thank all my collaborators including Dr. Loren Andreas, Mr. Marcel C. Forster, Dr. med. Katharina Amschler and Dr. Florian Ehlers for their stimulating inspiration, valuable discussion, and valuable time for testing. I also thank all colleagues in Wood Technology and Wood Chemistry and all my friends for their kindness and the fun we have had, making the stay in Germany so memorable.

I also thank the China Scholarship Council (CSC) for the financial support that made my Ph.D. study possible in Germany.

Last but not the least, I would like to thank my parents and siblings for their unconditional love, care, support, and encouragement. 


\begin{abstract}
In living organisms, carbohydrate-containing compounds, such as glycoproteins, glycopeptides, and glycolipids, play key roles in numerous physiological and pathological events via carbohydrate-protein interactions amplified by "glycol-cluster effect". Inspired by the multifunctional natural glycoconjugates, huge synthetical carbohydrate-containing compounds in the form of polymers and surfactants have been produced and applied in our daily life.
\end{abstract}

In this study, renewable and biodegradable cellulose had been chosen as the biopolymer backbone during the synthesis of carbohydrate-containing polymers. Novel cellulose derivatives with regioselective distributions of pendant glucose moieties were successfully synthesized via a series of essential reactions: nucleophilic reaction to introduce primary hydroxyl groups with the longer chain at C6 position; further sequential TEMPO/[bis(acetoxy)iodo]benzene (BAIB)-mediated oxidation of primary hydroxy groups, Schiff base formation and reduction reactions in one-pot to introduce free thiol groups; thiol-ene click reaction to introduce glucose moieties. The glycosylated cellulose derivatives with a degree of substitution ascribed to glucose moieties of 0.6 could reversibly bind with 1,4-benzenediboronic acid (BDBA) in DMSO with the assistance of $\mathrm{NaOH}$ and form nanoparticles via nanoprecipitation. Besides, novel fluorescence cellulose derivatives bearing mannose moieties were synthesized via photo- and thermal- initiated thiol-ene click reactions by sequentially conjugating hydrophilic mannose-oxyethoxylpropane-thiol (Mann-SH) and fluorescent coumarin-oxyhexyl-thiol (Coum-SH) and rhodamine B-ethyl-thiol (RhB-SH) to cellulose backbone with terminal double bonds. The amphiphilic fluorescence cellulose derivatives formed uniform nanoparticles with average sizes ranging from 240-554 nm in low ionic strength solutions $(<0.085 \mathrm{M})$. The thermal-stable uniform nanoparticles bearing mannose moieties exhibited excellent dispersion stability in $\mathrm{NaOH}$ solution even at elevated temperature via binding to BDBA.

Moreover, carbohydrate-containing bolaamphiphiles (CHO-Bolas) were synthesized and exhibited interesting reversible temperature- and $\mathrm{pH}$-responsive micelle-to-vesicle transition 
(MVT). Micelles of $20-55 \mathrm{~nm}$ turned into vesicles of up to $1.5 \mu \mathrm{m}$ reaching the MVT transition temperatures $\left(T_{\mathrm{MVT}}\right)$ in acidic or neutral aqueous solutions. In alkaline aqueous solution, CHO-Bolas coassembled with BDBA into microsized helix structures upon cooling. In general, the carbohydrate-containing compounds in the form of polymer and surfactants displayed boronic acid-sensitivity due to the clustered carbohydrate moieties and formed nano/macro structures.

This thesis is a cumulative work including 3 publications. All papers were prepared to submit/published in peer-reviewed journals, one was already published and two of them are in manuscripts and prepared to submit. The background, the objective of the study, results and discussion of the three publications and the conclusion are presented in Section 1-4. 


\section{Zusammenfassung}

In lebenden Organismen spielen kohlenhydrathaltige Verbindungen wie Glykoproteine, Glykopeptide und Glykolipide eine Schlüsselrolle bei zahlreichen physiologischen und pathologischen Ereignissen über Kohlenhydrat-Protein-Wechselwirkungen, die durch den „Glykol-Cluster-Effekt" verstärkt werden. Inspiriert von den multifunktionalen natürlichen Glykokonjugaten werden riesige synthetische kohlenhydrathaltige Verbindungen in Form von Polymeren und Tensiden hergestellt und in unserem täglichen Leben angewendet.

In dieser Studie wurde erneuerbare und biologisch abbaubare Cellulose als Biopolymergrundgerüst während der Synthese von kohlenhydrathaltigen Polymeren ausgewählt. Neuartige Cellulosederivate mit regioselektiven Verteilungen anhängender Glucoseeinheiten wurden über eine Reihe wesentlicher Reaktionen erfolgreich synthetisiert: nukleophile Reaktion zur Einführung primärer Hydroxylgruppen mit der längeren Kette an der C6-Position; weitere sequentielle TEMPO / [Bis (acetoxy) iod] benzol (BAIB) -vermittelte Oxidation von primären Hydroxygruppen, Schiffsche Basenbildung und Reduktionsreaktionen im Eintopfverfahren zur Einführung freier Thiolgruppen; Thiol-En-Klick-Reaktion zur Einführung von Glucoseeinheiten. Die glykosylierten Cellulosederivate, die durch die Glucoseeinheiten einen Substitutionsgrad von 0,6 aufweisen, konnen mithilfe von $\mathrm{NaOH}$ reversibel an 1,4-Benzoldiboronsäure (BDBA) in DMSO binden und durch Nanopräzipitation Nanopartikel bilden. Außerdem wurden neuartige, mannosehaltige Fluoreszenzcellulosederivate über photo- und thermisch initiierte Thiol-En-Klick-Reaktionen synthetisiert, indem nacheinander hydrophiles Mannose-Oxyethoxylpropan-Thiol (Mann-SH) und fluoreszierendes Cumarin-Oxyhexyl-Thiol (Coum-SH) und Rhodamin B-Ethylthiol (RhB-SH) zum Cellulosegerüst mit terminalen Doppelbindungen konjugiert wurden. Die amphiphilen Fluoreszenzcellulosederivate bildeten einheitliche Nanopartikel mit durchschnittlichen Größen im Bereich von $240 \mathrm{~nm}$ bis $554 \mathrm{~nm}$ in Lösungen mit niedriger Ionenstärke $(<0,085$ M). Die thermisch stabilen, einheitlichen Nanopartikel, die Mannoseeinheiten tragen, zeigten durch die Bindung an BDBA selbst bei erhöhter Temperatur eine ausgezeichnete 
Dispersionsstabilität in NaOH-Lösung.

Darüber hinaus wurden kohlenhydrathaltige Bolaamphiphile (CHO-Bolas) synthetisiert, die einen interessanten reversiblen, auf Temperatur und $\mathrm{pH}$-Wert reagierenden Übergang von Mizelle zu Vesikel (MVT) aufwiesen. Bei Erreichen der MVT-Übergangstemperaturen (TMVT) in sauren oder neutralen wässrigen Lösungen verwandelten sich die $20 \mathrm{~nm}-55 \mathrm{~nm}$ großen Mizellen in Vesikel mit einer Größe von bis zu 1,5 $\mu \mathrm{m}$. Beim Abkühlen in alkalischer wässriger Lösung setzten sich die CHO-Bolas mit BDBA zu Helixstrukturen in Mikrogröße zusammen.

Im Allgemeinen zeigten die kohlenhydrathaltigen Verbindungen in Form von Polymeren und Tensiden aufgrund der gruppierten Kohlenhydrateinheiten eine Boronsäureempfindlichkeit und bildeten Nano / Makro-Strukturen.

Diese Arbeit ist eine kumulative Arbeit mit 3 Publikationen. Alle Beiträge wurden zur Einreichung vorbereitet/sind in Fachzeitschriften veröffentlicht, eine wurde bereits veröffentlicht und zwei davon befinden sich in Manuskripten und sind zur Einreichung vorbereitet. Der Hintergrund, das Ziel der Studie, die Ergebnisse und die Diskussion der drei Veröffentlichungen sowie die Schlussfolgerung sind in Abschnitt 1-4 dargestellt. 


\section{Table of Contents}

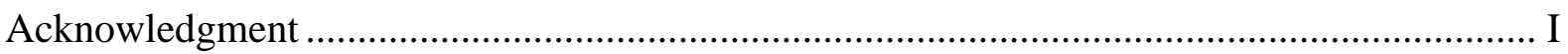

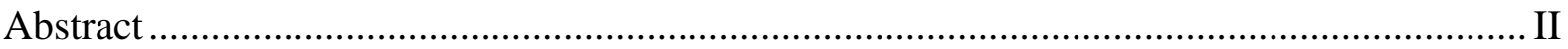

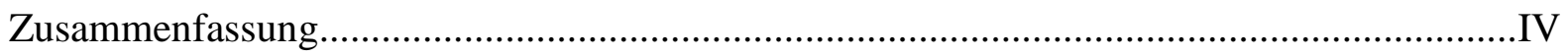

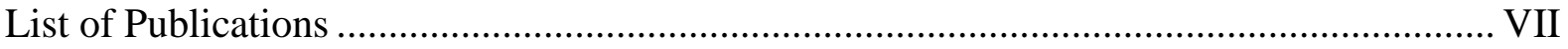

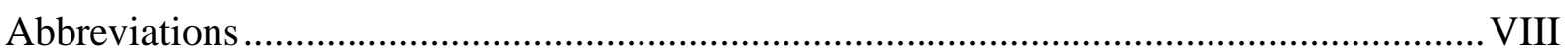

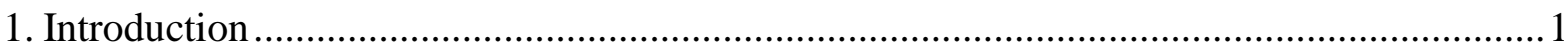

1.1. Chemical glycosylation for constructing carbohydrate-based glycomonomers ............2

1.2. Synthetic carbohydrate-containing polymers....................................................

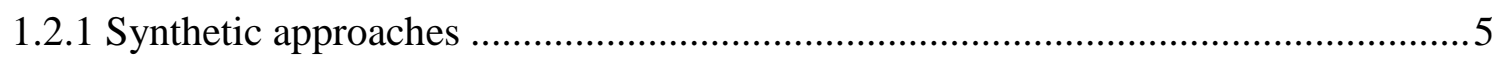

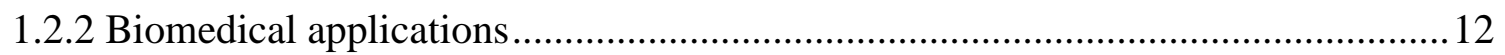

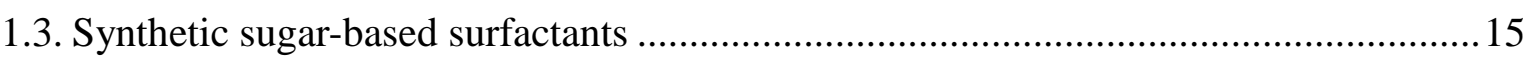

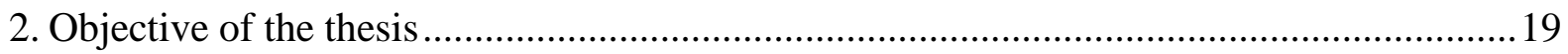

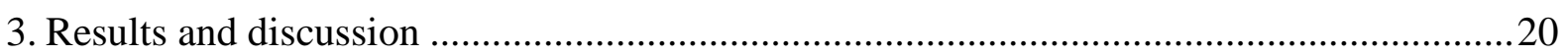

3.1. Celluose derivatives with regioselective distributions of glucose moieties .................20

3.2. Sugar-based bola-amphiphiles displaying unique properties ..................................25

3.3. Fluorescent cellulose derivatives bearing mannose moieties .................................... 31

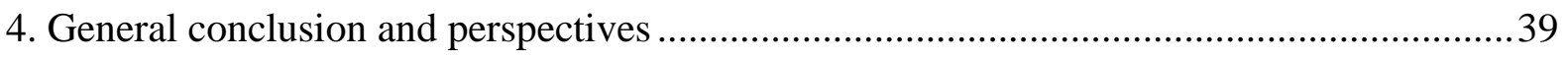

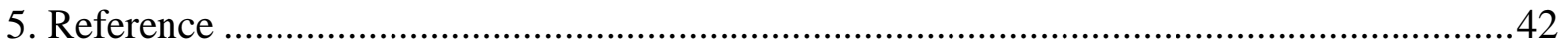

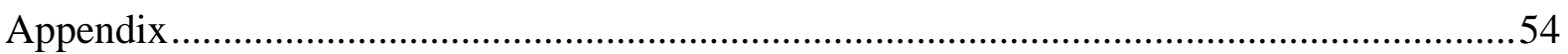

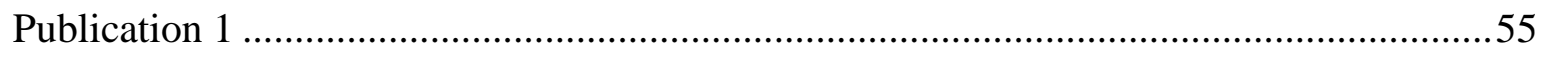

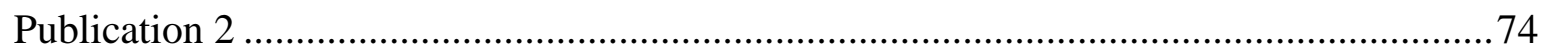

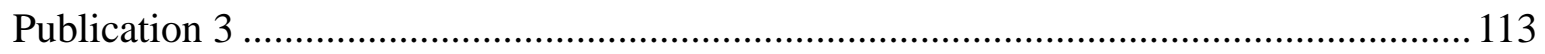




\section{List of Publications}

Publication 1

Glycosylated cellulose derivatives with regioselective distributions of pendant glucose moieties

Shuang Wang, Kai Zhang*

Carbohydrate Polymers, 2018, 196, 154-161.

Publication 2

Macro-scale helices induced by temperature-responsive carbohydrate-based bolaamphiphiles from assembled phenylboronic acid

Shuang Wang, ${ }^{+}$Marcel C. Forster, ${ }^{+}$Kai Xue, Florian Ehlers, Bo Pang, Loren B. Andreas, Philipp Vana and Kai Zhang*

Prepared to submit 2020.

Publication 3

Mannosylated fluorescent cellulose-based glycopolymers for stable uniform nanoparticles

Shuang Wang, Philipp Vana, Kai Zhang*

Prepared to submit 2020. 


\begin{tabular}{|c|c|}
\hline \multicolumn{2}{|c|}{ Abbreviations } \\
\hline CDs & Cyclodextrins \\
\hline Lg & Leaving group \\
\hline FRP & Free-radical polymerization \\
\hline ROMP & Ring-opening metathesis polymerization \\
\hline CRP & Controlled free-radical polymerization \\
\hline NMP & Nitroxide-mediated controlled free-radical polymerization \\
\hline CMP & Cyanoxyl-mediated polymerization \\
\hline ATRP & Atom transfer radical polymerization \\
\hline RAFT & Reversible addition-fragment chain transfer \\
\hline NHS & $N$-hydroxysuccinimide \\
\hline $\mathrm{CuAAC}$ & Copper-catalyzed azide-alkyne cycloaddition \\
\hline $\mathrm{S}_{\mathrm{N}}$ & Nucleophilic displacement \\
\hline TosC & $p$-Toluenesulfonylation of cellulose leading to tosylcellulose \\
\hline TosCC & Carbanilation of tosylcellulose leading to tosylcellulose carbanilate \\
\hline $\mathrm{EaCC}$ & 6-Deoxy-6-ethanolamino cellulose carbanilate \\
\hline ThiolCC & 6-Deoxy-6-(2-thiolethylamino)ethylamino cellulose carbanilate \\
\hline GlcThiolCC & $\begin{array}{l}\text { Glycosylated 6-deoxy-6-(2-thiolethylamino) ethylamino cellulose } \\
\text { carbanilate }\end{array}$ \\
\hline BDBA & 1,4-Benzenediboronic acid \\
\hline CHO-Bolas & Bolaamphiphiles with carbohydrate headgroups \\
\hline GCCG-12 & D- (+)-glucose-based coumarin dimer \\
\hline MCCM-12 & D- (+)-mannose-based coumarin dimer \\
\hline DI water & Deionized water \\
\hline NMR & Nuclear magnetic resonance \\
\hline DLS & Dynamic Light Scattering Measurement \\
\hline TEM & Transmission electron microscopy \\
\hline SEM & Scanning electron microscopy \\
\hline
\end{tabular}


PLM

PDI

Mann-SH

Coum-SH

RhB-SH

CUE

NPs

AGUs

DS

BAIB

TEMPO

MVT

$T_{\mathrm{MVT}}$

THF

UV-VIS

FTIR

DMA

DMF

DCM

CUE-MCR
Polarized light microscopy

Polydipersity index

Mannose-oxyethoxylpropane-thiol

Coumarin-oxyhexyl-thiol

Rhodamine B-ethyl-thiol

Cellulose 10-undecenoyl ester

Nanoparticle dispersions

Anhydroglucose units

Degree of substitution

[Bis(acetoxy)iodo] benzene

2,2,6,6-Tetramethyl-1-piperidinyloxy

Micelle-to-vesicle transition

The MVT transition temperatures

Tetrahydrofuran

Ultraviolet-visible spectroscopy

Fourier transform infrared spectroscopy

Dimethylacetamide

Dimethylformamide

Dichloromethanes

11-(mannoseoxyethoxylpropane)(coumarinoxyhexyl)(rhodamineethyl)

thiolundecanoate 10-undecenoly ester of cellulose 


\section{Introduction}

Carbohydrates (or called saccharides)-together with proteins, nucleic acids and lipids called the four major biomolecules in living organisms-are the most abundant organic molecules in nature, which can be classified into monosaccharides, oligosaccharides, and polysaccharides according to molecular size. ${ }^{1}$

Monosaccharides and oligosaccharides are low-molecular-weight carbohydrates. Generally, oligosaccharides are defined as saccharides composed of 2-20 monosaccharide residues linked to each other by glycosidic linkages. ${ }^{2,3}$ However, oligosaccharides in living cells often exist in the form of glycoconjugates linked to other macromolecules proteins (called glycoproteins or lipids (called glycolipids), which play important roles in mediating a variety of physiological and pathological processes (Figure 1).$^{4-7}$ In nature, the most classic oligosaccharides in the free form are cyclodextrins (CDs) composed of 6-8 $\alpha-(1 \rightarrow 4)$-linked D-glucopyranose units. ${ }^{8}$
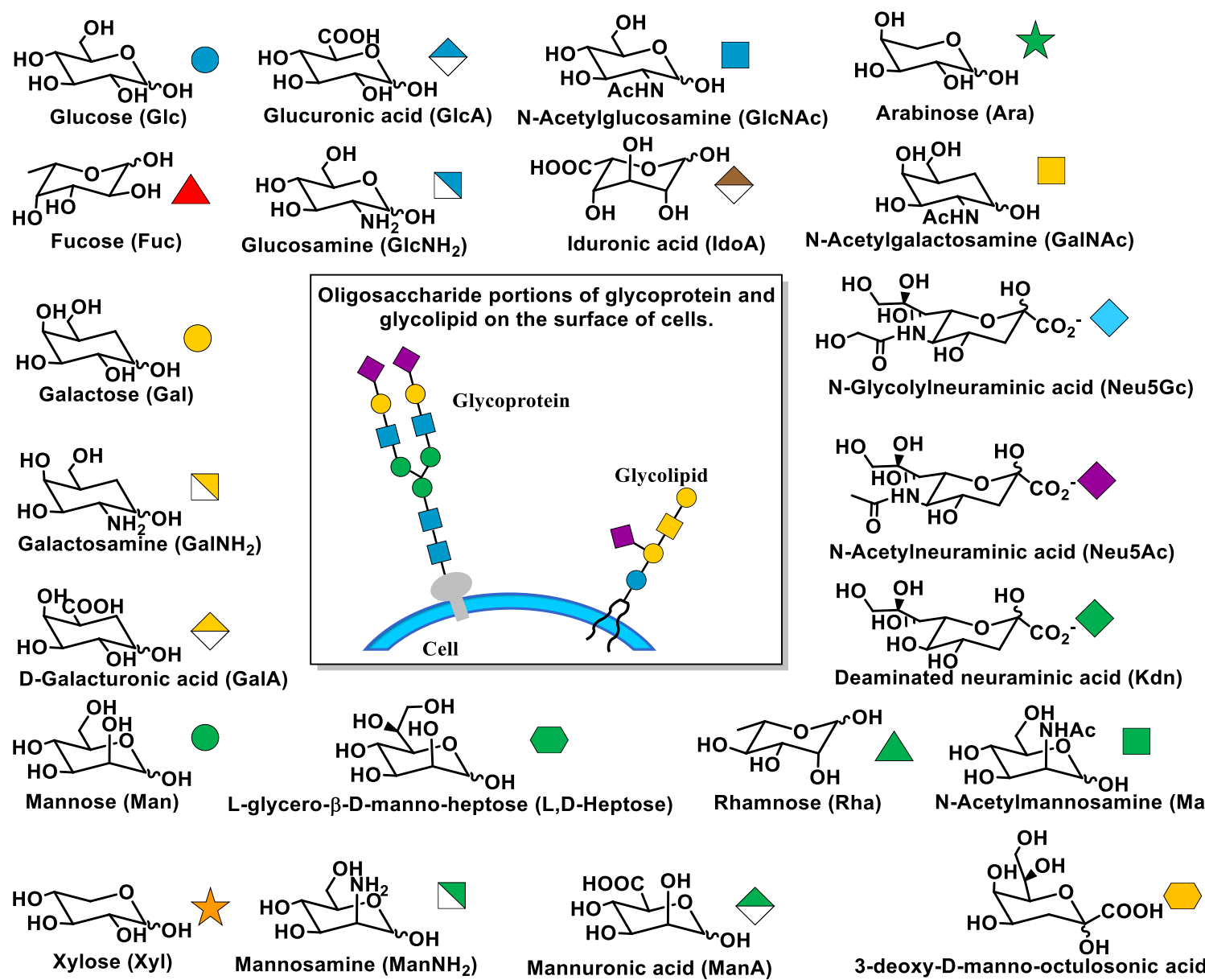

N-Acetylmannosamine (ManNAc)

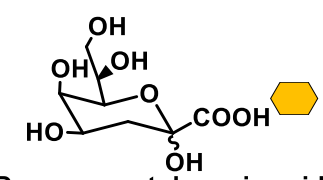

3-deoxy-D-manno-octulosonic acid (Kdo) 
Figure 1. Common monosaccharides that occur as building blocks in oligosaccharides and their symbols (Reproduced with modification from Wen et al. ${ }^{4}$ Copyright from American Chemical Society 2018).

Polysaccharides, as natural carbohydrate-containing polymers, are widely distributed in the plants, animals, microorganisms, and algae, which display a variety of biological functions, such as providing nature's energy source (glycogen and starch), acting as structural materials (cellulose, collagen, chitin, and proteoglycans), and conferring specific biological properties (hyaluronan and chondroitin sulfate of anti-inflammatory, heparin in blood coagulation ). ${ }^{9,10}$ In comparison with other two major natural polymers polynucleotides and polyamides, polysaccharides are complicated polymers composed of diverse monosaccharide residues joined to each other by glycosidic linkages of different stereo- and regioselectivity (Figure 2). ${ }^{11,12}$
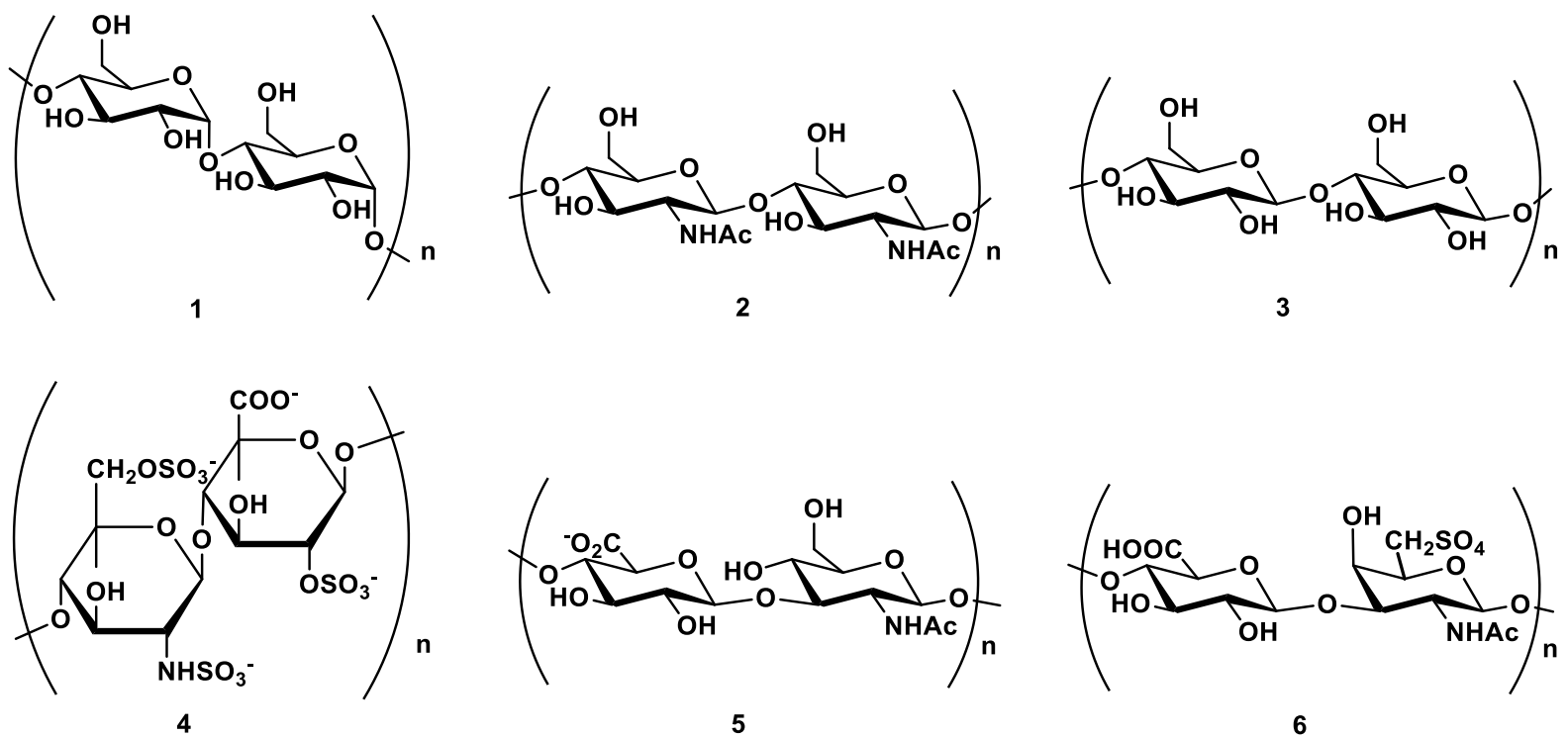

Figure 2. Structures of natural carbohydrate-containing polymers. (1) Starch; (2) chitin; (3) cellulose; (4) heparin; (5) hyaluronan; (6) chondroitin sulfate. (Reproduced from Ladmiral et $a l .{ }^{9}$ Copyright from Elsevier Science Ltd. 2003)

\subsection{Chemical glycosylation for constructing carbohydrate-based glycomonomers}

Carbohydrate chemistry was first established by Emil Fischer in the late $19^{\text {th }}$ century ${ }^{13,14}$ 
and the cyclic structure of carbohydrates was later further elucidated by Norman Haworth and colleagues in the 1930s. ${ }^{15}$ Soon afterward, the macromolecular structures of polysaccharides were discovered. In modern scientific research, synthetic glycomolecules that mimic biological structures have attracted considerable attention in the fields of chemistry, biology, and material science. In carbohydrate chemistry, glycosylation is a crucial organic synthetic method to obtain glycomolecules by attaching saccharides to other molecules. It has been more than a century since Wilhelm Koenigs and Edward Knorr discovered one of the oldest and simplest glycosylation reaction-the Koenigs-Knorr reaction, which fueled the field of carbohydrate chemistry and has been widely used to prepare aryl and alkyl glycosides (Figure 3). ${ }^{16,17}$

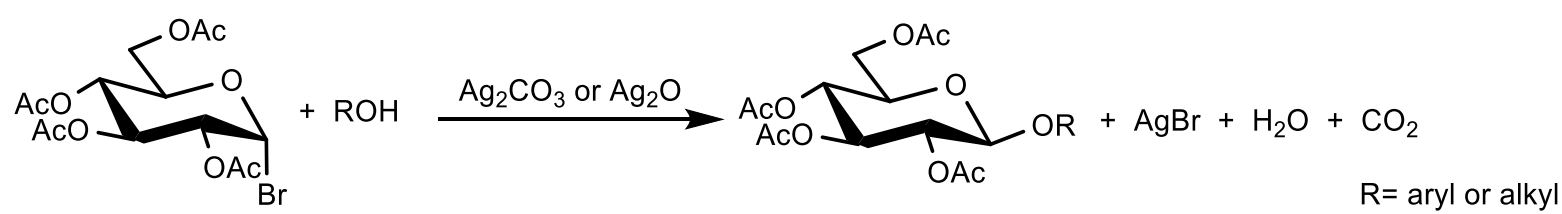

Figure 3. The Koenigs-Knorr glycosylation reaction. (Reproduced with modification from Igarashi. ${ }^{17}$ Copyright from Academic Press, Inc. 1997)

Since then, countless researchers have devoted to the discovery of improved glycosylation methods. Generally, the chemical glycosylation strategies for the formation of glycosidic linkages are acetal exchange and glycal oxidation, both involving glycosyl donor as an electrophile and glycosyl acceptor as a nucleophile (Figure 4). ${ }^{18-20}$ In acetal exchange method, the chemical glycosylation transforms the carbohydrate into a fully protected glycosyl donor with a latent leaving group $(\mathrm{Lg})$ at its anomeric center, possessing highly electron-deficient with the assistant of electrophilic "activator" $\left(\mathrm{EI}^{+}\right)$and following attacking by the nucleophilic glycosyl acceptor $(\mathrm{Nu}-\mathrm{H})$ (Figure 4a). This method has been widely and effectively used for simple/complex glycomolecules synthesis. In the glycal oxidation approach, the chemical glycosylation uses enol ether nucleophile glycal as glycosyl donor, forming a three-membered ring with electrophilic oxidants $\left(\mathrm{EI}^{+}\right)$and finally ring-opening with nucleophilic glycosyl acceptor $(\mathrm{Nu}-\mathrm{H})$ (Figure 4b). This method allows the synthesis of 
various 2-deoxyglycosides, such as C2-acyloxyglycosides, C2-azidoglycosides and C2-sulphonamideglycosides. Through these two glycosylation methods, many carbohydrate-based glycomonomers have been synthesized, such as amino carbohydrates, thiol carbohydrates, azido carbohydrates, alkenyl carbohydrate and alkyne carbohydrates, which be commonly used for the synthesis of corresponding carbohydrate-containing polymers and surfactants (Figure 4c).

a) Actal-exchange

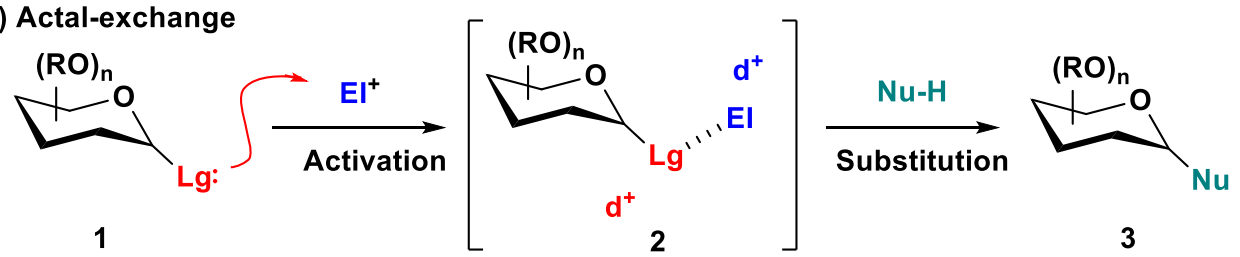

b) Glycal oxidation

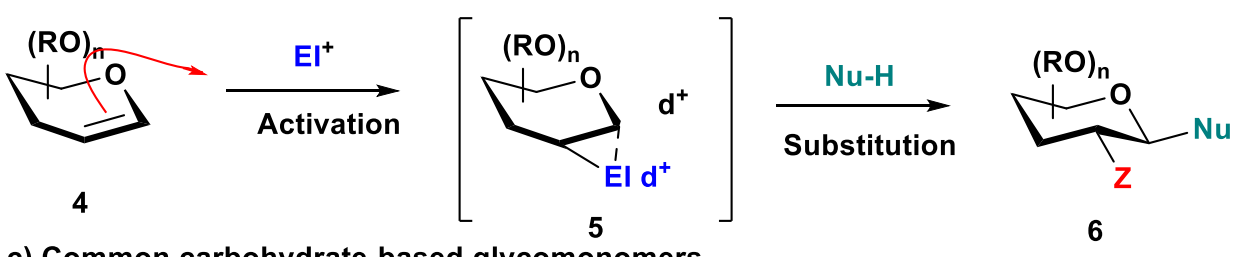

c) Common carbohydrate-based glycomonomers

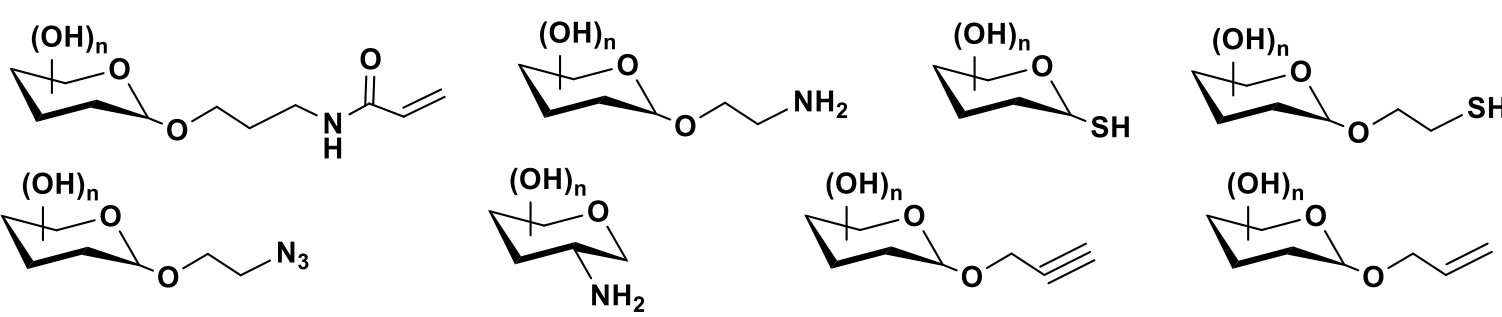

Figure 4. Glycosylation methods: a) acetal exchange; b) glycal oxidation; c) common sugar-containing monomers ( Reproduced with modification from Galonić et al ${ }^{18}$ Copyright from Springer Nature 2007)

\subsection{Synthetic carbohydrate-containing polymers}

In living organisms, the strong carbohydrate-protein interactions have participated in numerous biological events, such as cellular recognition, cancer cell metastasis, and adhesion, due to the so-called "glycol-cluster effect". ${ }^{21}$ The synthetic carbohydrate-containing polymers, mimicking natural glycoconjugate, have attracted considerable interest in some fields such as biology, medicine and chemistry. ${ }^{22-26}$ 


\subsubsection{Synthetic approaches}

Just like glycoconjugates in living cells as the products of cotranslational or post-translational modification, synthetic carbohydrate-containing polymers have been prepared through polymerization of sugar-containing monomers or post-polymerization modification using sugar derivatives. ${ }^{27,28}$

\section{Polymerization of sugar-containing monomers}

So far, the polymerization of sugar-containing monomers for well-defined glycopolymers have been realized by various polymerization techniques including free-radical polymerization (FRP), ring-opening metathesis polymerization (ROMP), and controlled free-radical polymerization $(\mathrm{CRP}){ }^{29-35}$

Since the first report of glycopolymer by Horejsi et al. in $1978^{36}$, the conventional free radical polymerization (FRP) as a chain reaction has been commonly used to synthesized carbohydrate-containing polymers via polymerization of unprotected vinyl saccharide monomers. ${ }^{37}$

Ring-opening metathesis polymerization (ROMP) in the assistance of a ruthenium-catalyst is frequently used to synthesize carbohydrate-containing polymers using carbohydrate-containing norbornene derivatives. ${ }^{38-40}$ For example, Cairo et al. used the ROMP of $O$-mannose/galactose norbornene derivatives to synthesize carbohydrate-containing polymers with different mannose/galactose ratio which used to bind to the receptor concanavalin A (Figure 5). ${ }^{41}$
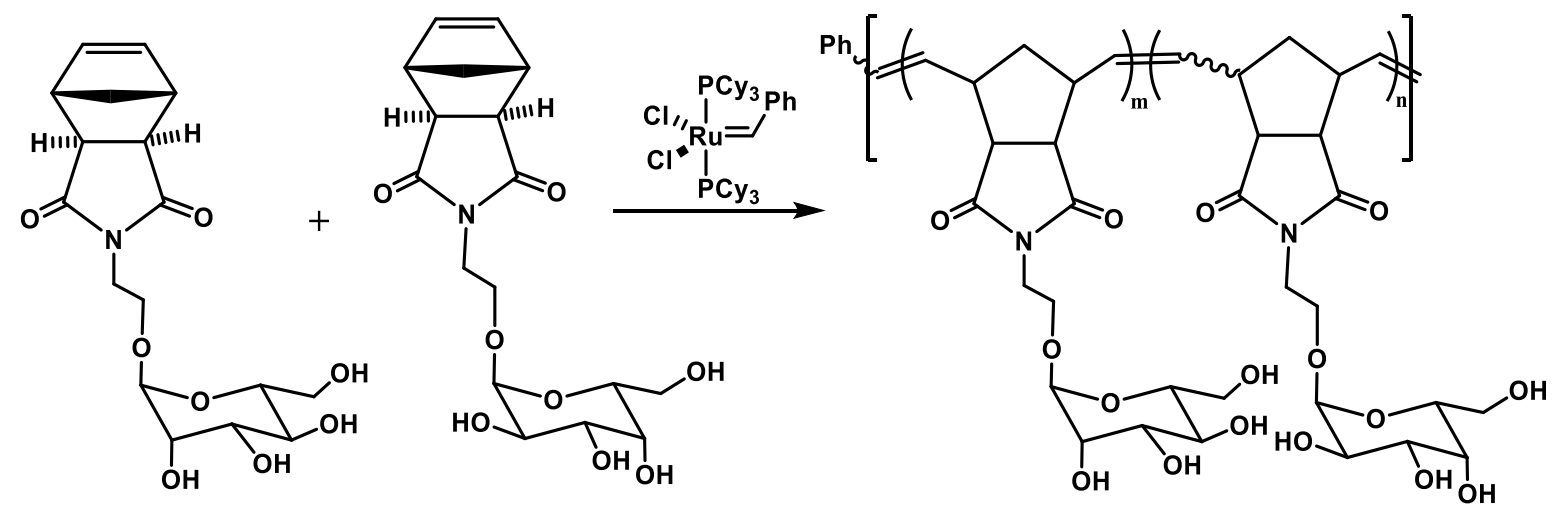

Figure 5. Structures of copolymers. All polymers are of similar length (x), and vary only in 
the proportion of mannose residues $(\mathrm{m})$ to galactose residues (n). (Reproduced from Cairo et $a l .{ }^{41}$ Copyright from American Chemistry Society 2002)

Controlled free-radical polymerization (CRP) techniques have been developed at CRISO for almost 40 years, which include nitroxide-mediated controlled free-radical polymerization (NMP), cyanoxyl-mediated polymerization (CMP), atom transfer radical polymerization (ATRP), and reversible addition-fragment chain transfer (RAFT). ${ }^{42}$ Among them, nitroxide-mediated controlled free-radical polymerization (NMP) as the oldest techniques generally has been used to polymerization of protected glycol-monomers using nitroxide compounds such as TEMPO, TIPNO, and SG1. ${ }^{43,44,28}$ So far, only Babiuch et al. prepared glycopolymer via nitroxide-mediated radical polymerization of unprotected glycol-monomers, which attributed to the water-soluble SG1 and adding water(Figure 6). ${ }^{45}$

a)<smiles>CCOP(=O)(OCC)C(C(C)C)N([O])C(C)(C)C</smiles>

b)<smiles>C=Cc1c(F)c(F)c(F)c(F)c1F</smiles>

Figure 6. a) Structures of commonly used nitroxide compounds; b)synthesis of the gylcopolymer via nitroxide-mediated polymerization (b. Reproduced from Babiuch et al. ${ }^{45}$ Copyright from American Chemistry Society 2011)

Compared to NMP, CMP has been more widely used to the synthesis of well-defined glycopolymers directly using unprotected alkenyl/acryloyl/acrylamido carbohydrate moieties 
under mild reaction conditions. ${ }^{46,47}$ For example, Sun et al. ${ }^{48}$ reported that the Biotin chain-terminated glycopolymers were synthesized via CMP of unprotected lactose-containing acrylamide monomers for carbohydrate-lectin binding (Figure 7).

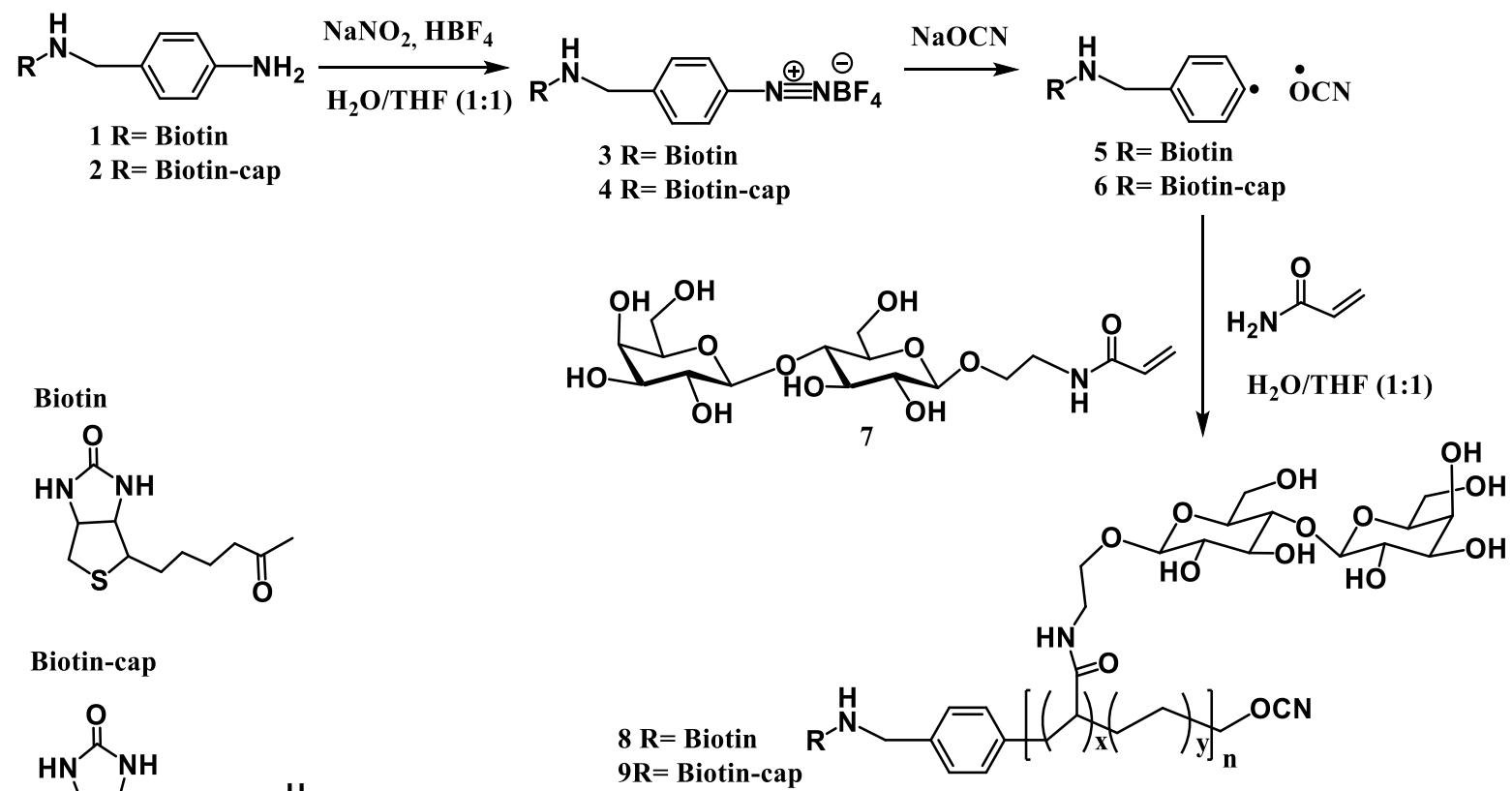

Figure 7. Synthesis of Biotin Chain-Terminated Glycopolymer (Reproduced from Sun et al. ${ }^{48}$ Copyright from American Chemistry Society 2002)

Atom transfer radical polymerization (ATRP) was first reported by Narain et $a l^{49}$ to prepare well-defined carbohydrate-containing polymers via polymerization of unprotected carbohydrate-containing methacrylates in an alkyl halide/copper-complex system under mild conditions, which has a high tolerance to many functional groups (Figure 8).$^{50,30,51}$ 


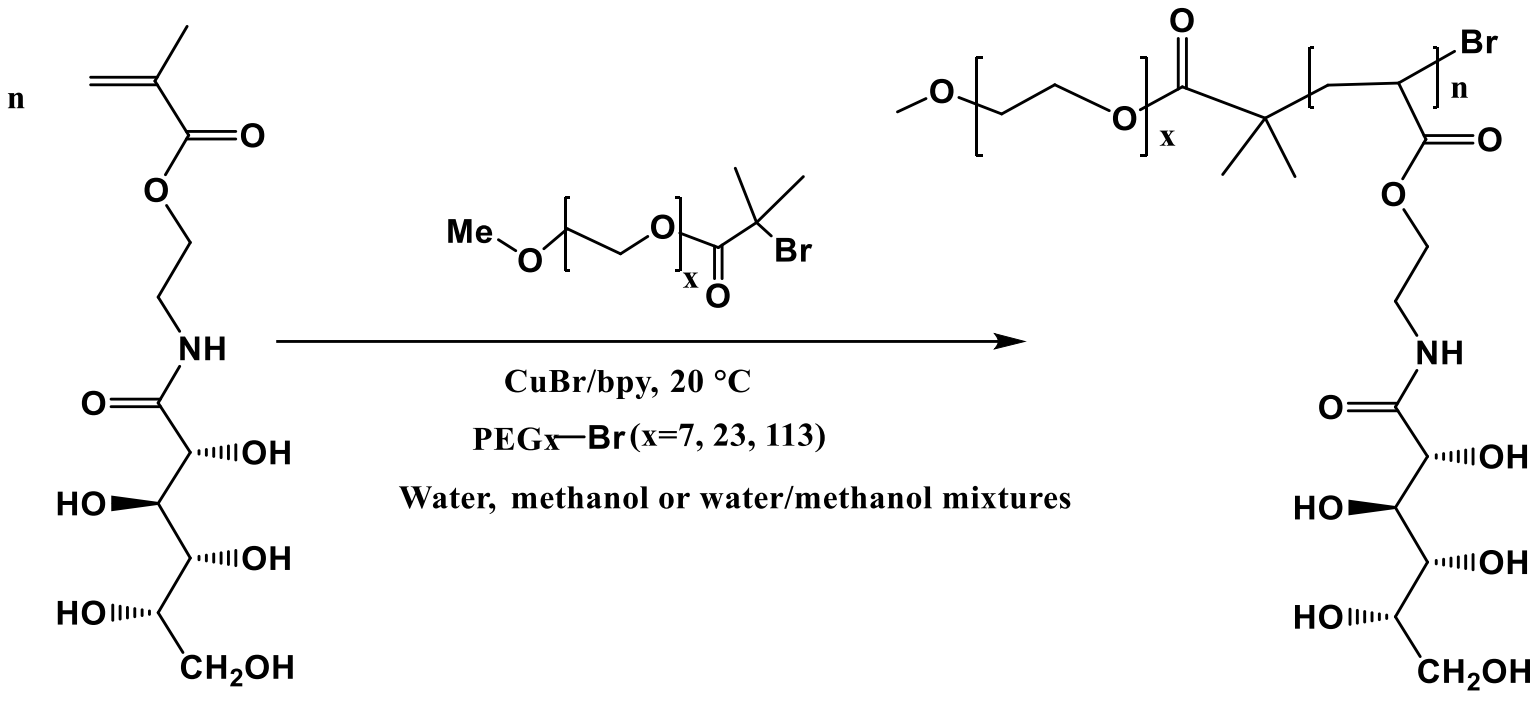

Figure 8. Atom Transfer Radical Polymerization of GAMA in protic media at $20{ }^{\circ} \mathrm{C}$. (Reproduced from Narain et al. ${ }^{49}$ Copyright from Royal Society of Chemistry 2002)

Reversible addition-fragment chain transfer (RAFT) polymerization is the first choice for the synthesis of carbohydrate-containing polymers in aqueous media via polymerization of carbohydrate-containing vinyl ester/methacrylamide monomers using water-soluble chain transfer agents such as dithioester, xanthate, dithiocarbamate, trithiocarbonate under mild condition..$^{52,34,29}$

\section{Post-polymerization modification}

Generally, the post-polymerization modification includes two major types: coupling reactions and click reactions, which have been applied to synthesize carbohydrate-containing polymers by incorporating functional carbohydrate moieties into pre-formed polymer backbones. ${ }^{53,27}$

So far, the most common form of various coupling reactions is the nucleophilic substitution of polymeric active esters such as carboxylic acid, $N$-hydroxysuccinimide (NHS) ester, and anhydrides (Figure 9a). ${ }^{54-58}$ In this high efficient site-specific chemical modifications, amino saccharides as excellent nucleophiles have been most frequently used to synthesis of carbohydrate-containing polymers. For example, $\mathrm{Xu}$ et al. ${ }^{59}$ synthesized glycopolymer by a combination of ring-opening (ROP) and reversible addition-fragmentation 
chain transfer (RAFT) polymerization reaction to construct polymeric active esters and then via nucleophilic substitution reaction to introduce mannose moieties, shown in Figure 9b.

(1)

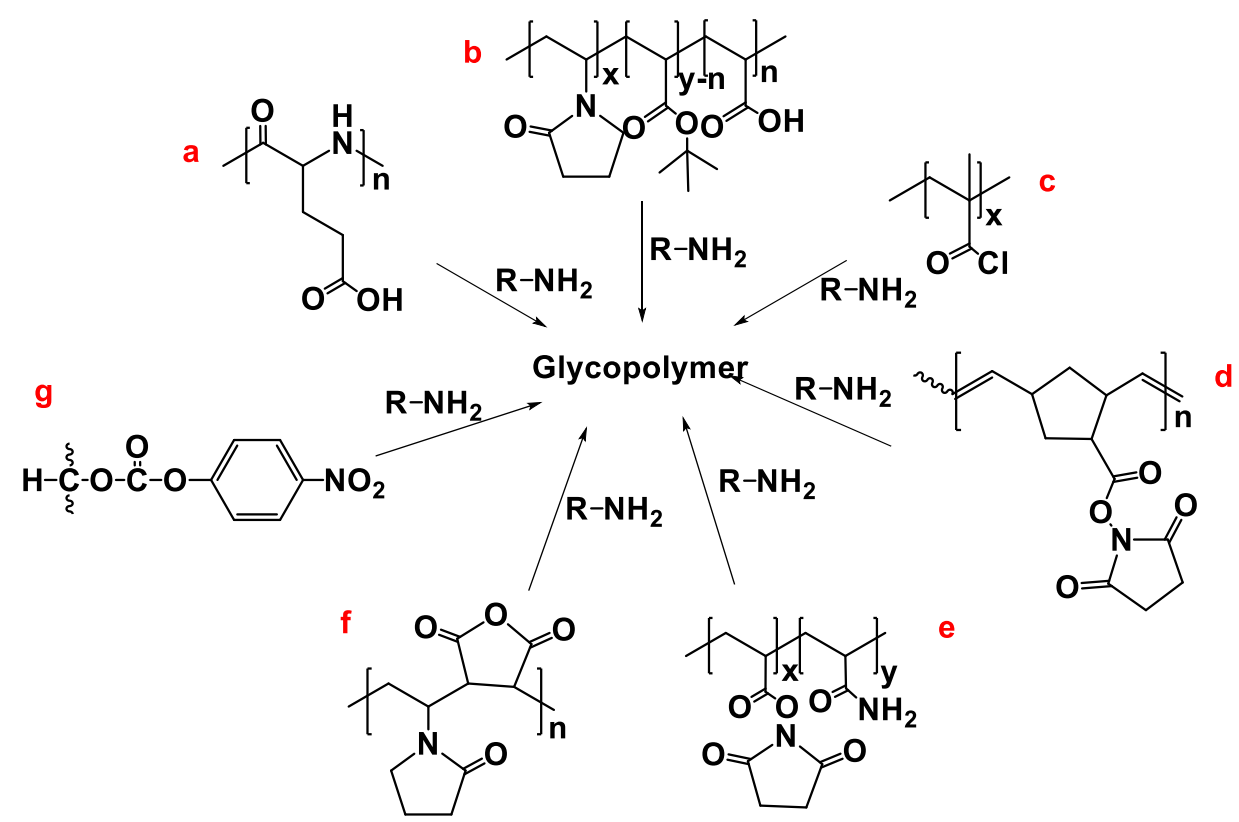

(2)

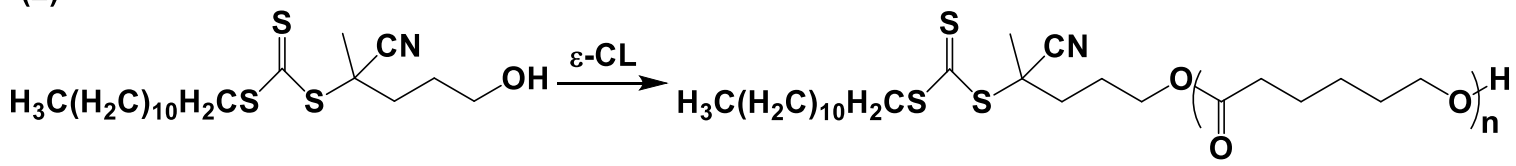

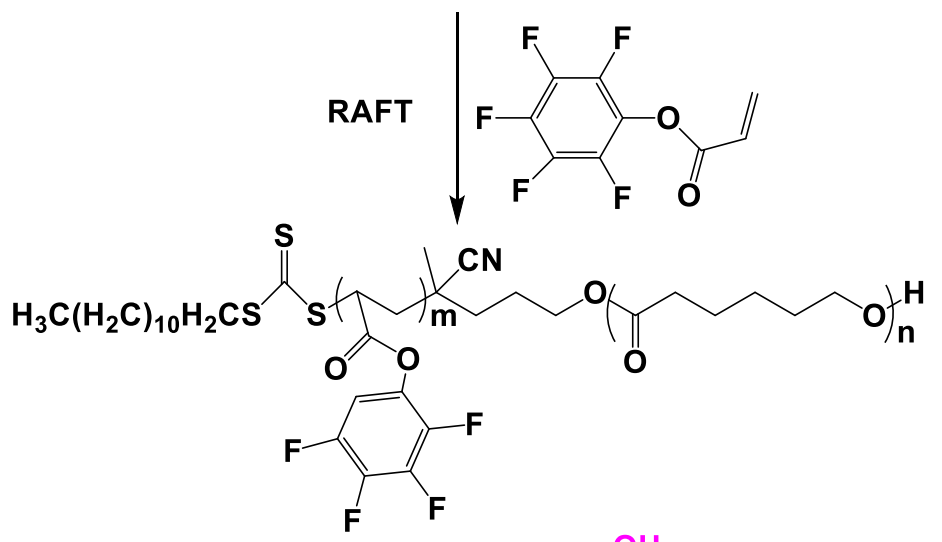

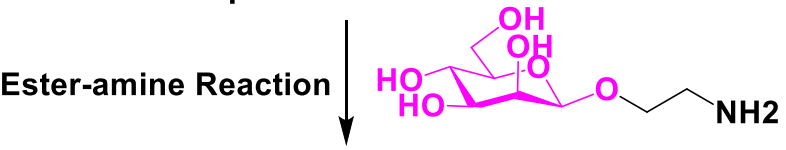

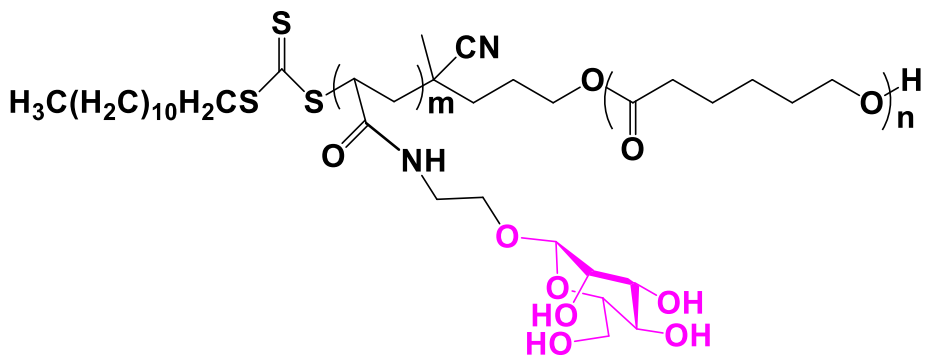


Figure 9. Synthesis of carbohydrate-containing polymers via nucleophilic substitution reaction. (Reproduced with modification from Ting et al. ${ }^{27}$ and $\mathrm{Xu}$ et al. ${ }^{59}$ Copyright from The Royal Society of Chemistry 2010)

Another example, Stenzel et $a l .{ }^{60}$ in 2014 reported that mannose-containing polymer was synthesized by double modification of thiolactione-containing polyacryl-amides. As shown in Figure 10, thiolactione-containing polymer backbone was synthesized via RAFT polymerization, which was further modified by aminolysis with various amines and consequently by nucleophilic substitution with bromoethyl tetra-acetyl-mannopyranoside in one-pot.

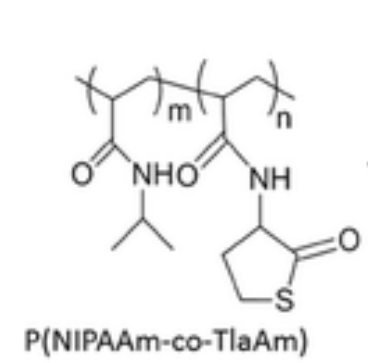

1

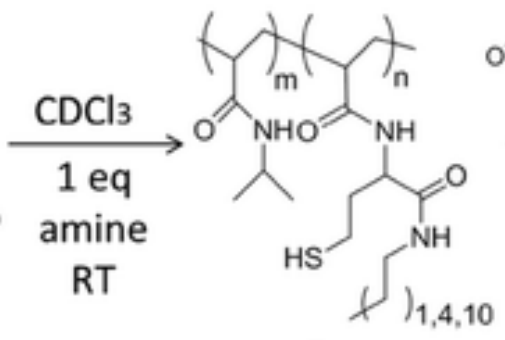

2

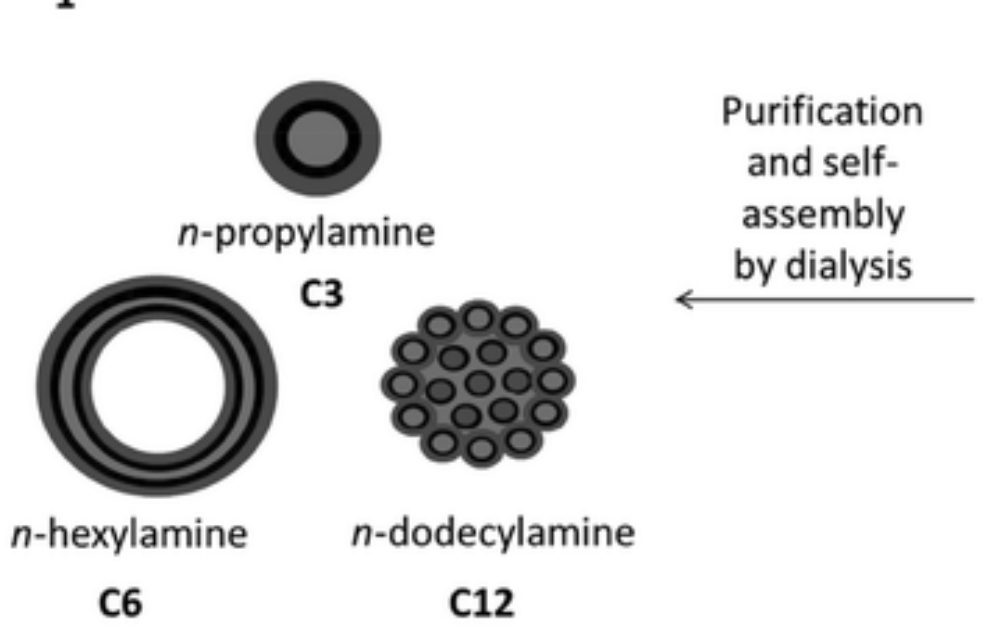

NaOMe

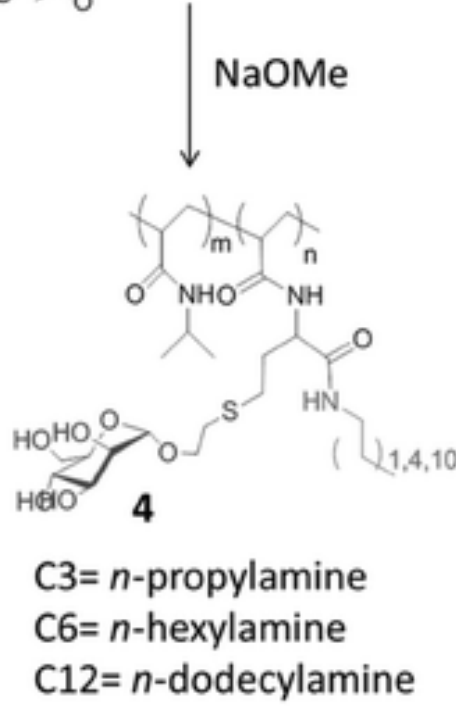

Figure 10. Synthesis of glycopolymer via aminolysis and nucleophilic substitution of thiolactione-containing polyacryl-amides. (Reproduced from Stenzel et al. ${ }^{60}$ Copyright from WILEY-VCH Verlag GmbH \& Co. KGaA, Weinheim 2014)

A significant turning point in glycochemistry has arrived in 2001 when Sharpless and other colleagues first introduced the highly efficient and selective click reactions which also 
have been widely applied in many fields such as chemistry, medicine, and pharmacy. ${ }^{61,62}$ Different types of click reactions allow researchers to prepare carbohydrate-containing polymers via a radical addition or base/nucleophilic substitution, including copper-catalyzed azide-alkyne cycloaddition (CuAAC), thiol-ene click, and thiol-yne click (Figure 11). ${ }^{63,64}$ In general, carbohydrates need to be modified into clickable units with functional groups such as azide, thiol, alkene, alkynes, or halides, which are used as pendants directly clicking onto a polymeric backbone. ${ }^{65}$

Copper catalyzed azide-alkyne cycloaddition (CuAAC)<smiles>[R][R5]O[R10]([R])=C(C)n1cc([R2])nn1</smiles>

Thiol-ene Click: hetero-Michael addition

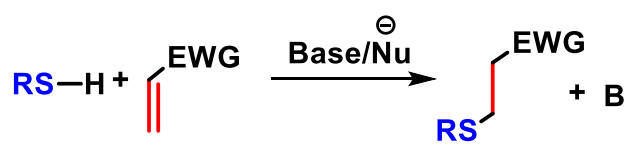

Thiol-yne Click: Radical mechanism<smiles>[R5]CC([R3])[R]([R5])CC</smiles>

Thiol-ene Click: Radical mechanism<smiles>[R]CC[R5]</smiles>

Thiol-halogen Click: $\stackrel{\ominus}{\ominus}$ Substitution

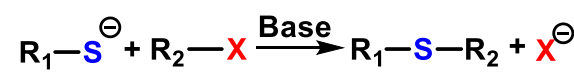

Thiol-para Fluoro Click: Nu Substition<smiles>[R][SH2+][O-]</smiles>

Figure 11. Various click reactions that are employed in the synthesis of carbohydrate-containing polymers. (Reproduced from Slavin et al. ${ }^{63}$ Copyright from Elsevier Ltd. 2010)

For example, Perrier et al. ${ }^{66}$ reported in 2010 that densely functionalized highly and hyperbranched glycopolymers were synthesized by combining living radical polymerization and click chmeisty. As shown in Figure 12, hyperbranched "clickable" polymer backbones with terminal alkynes was synthesized via reversible addition-fragmentation chain transfer (RAFT) polymerization, which were further modified via thiol-yne reaction with Copper-catalyzed azide-alkyne cycloaddition and via thiol-ene reaction, respectively. 


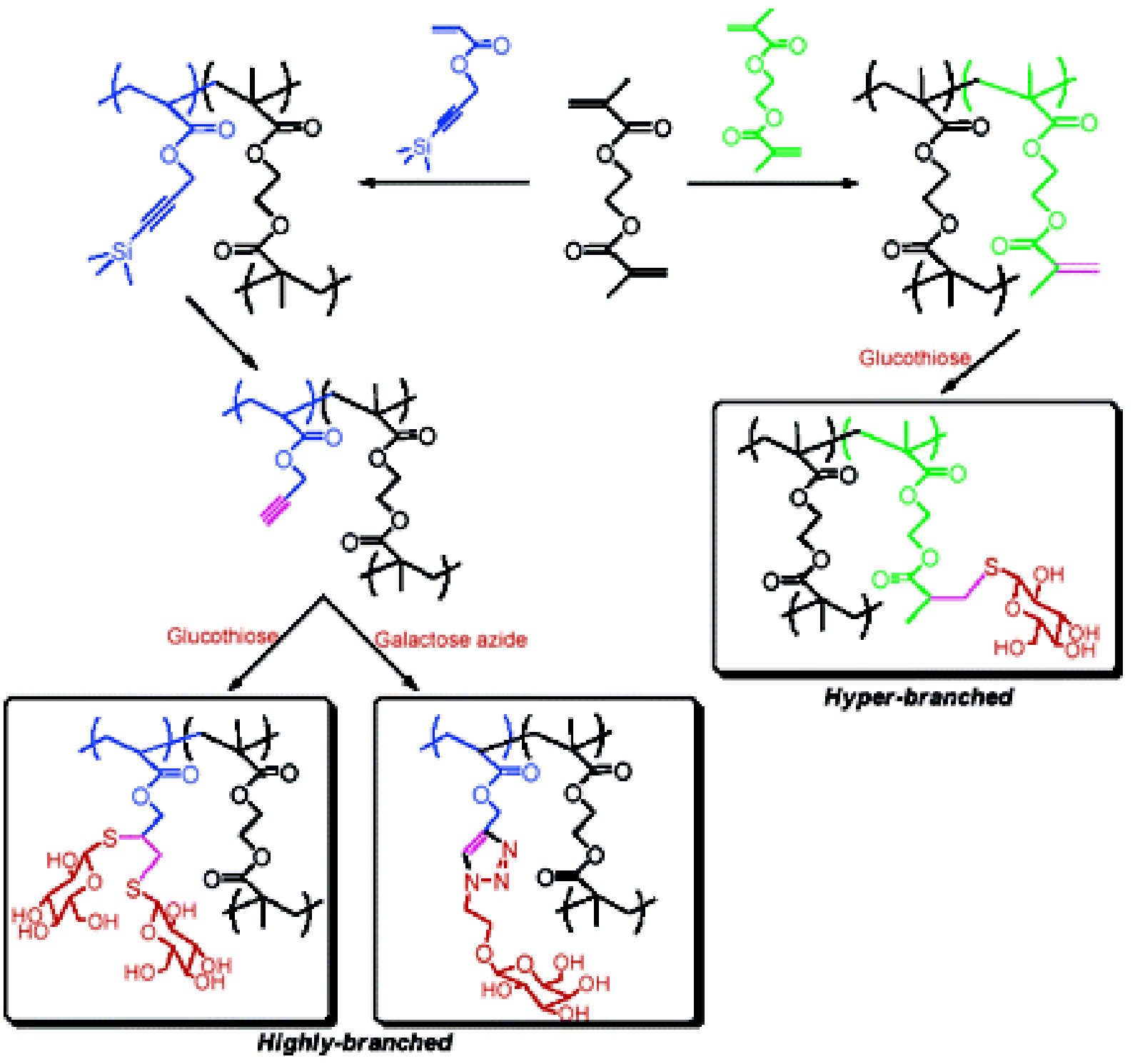

Figure 12. Synthesize of highly branced glycopolymers via "click reactions" (Reproduced from Perrier et al. ${ }^{66}$ Copyright from American Chemistry Society 2010)

\subsubsection{Biomedical applications}

The synthetic carbohydrate-containing polymers have high affinities for diverse saccharide receptors (referring proteins or lectins) via the multivalent effect, which have mainly been used as cell imaging and drug delivery in the biomedicine field.

\section{Cell imaging}

Fluorescence conjugated carbohydrate-containing polymers have been widely used as fluorescent probes for live-cell imaging, due to their good biocompatibility, target-specificity, 
solubility and good photostability. ${ }^{67-69}$ For example, fluorescent cross-linked carbohydrate-containing polymers (R-ITA-Glu) was prepared by Wang et al. ${ }^{70}$ via free radical polymerization and sequential ring-opening polymerization in one-pot (Figure 13). The R-ITA-Glu was amphiphilic glycopolymer, which further self-assembled into nanoparticles. Similar to viruses, nanoparticles bearing carbohydrate moieties had a high surface/volume ratio, which was assimilated by cells for cell imaging.
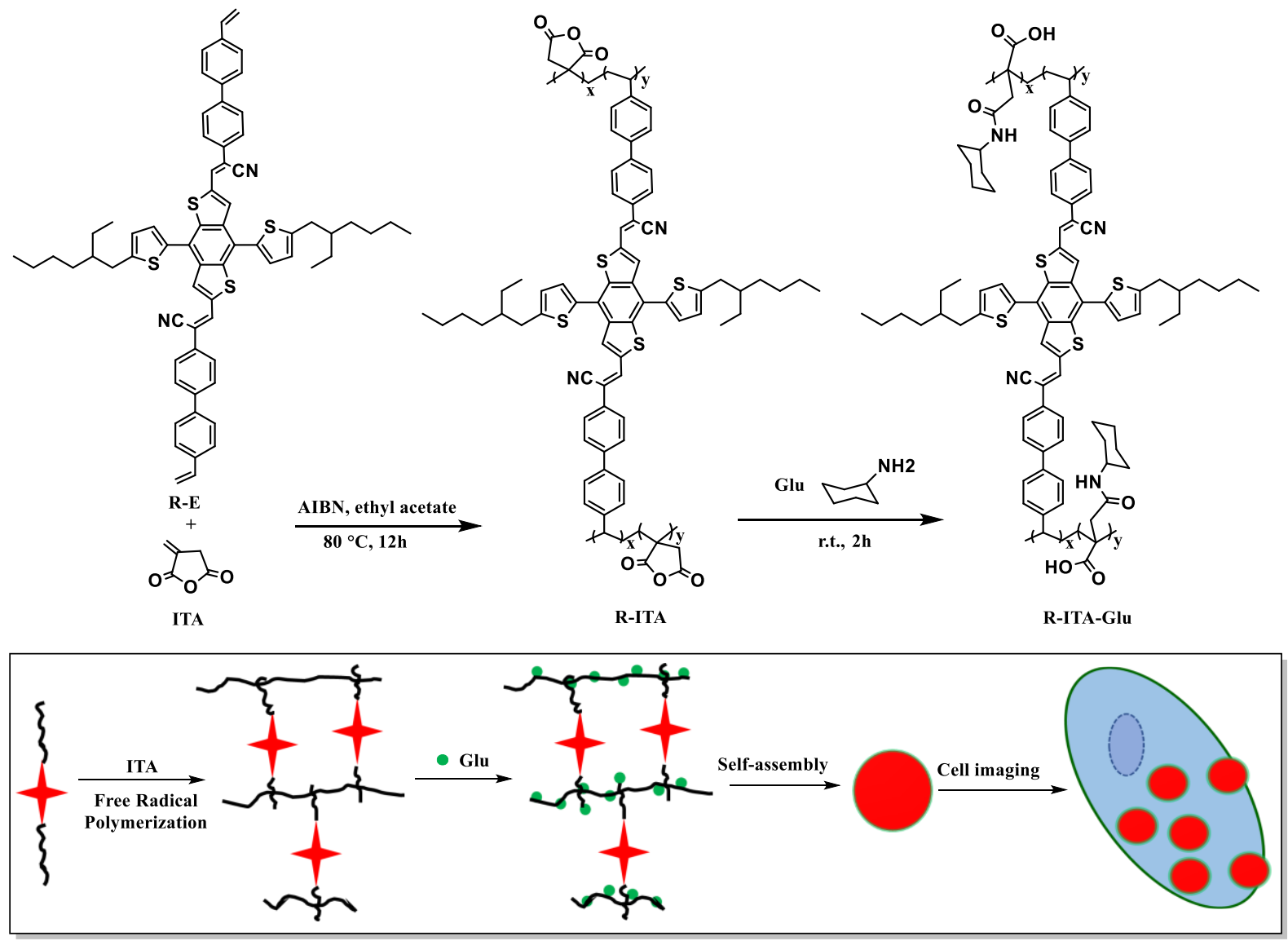

Figure 13. Synthetic route and schematic showing cell imaging applications of R-ITA-Glu. (Reproduced with modification from Wang et al. ${ }^{70}$ Copyright from Royal Society of Chemistry 2015)

Another example, Bertozzi et al. ${ }^{71}$ in 2008 designed fluorescent carbohydrate-containing polymers which can bond and internalized cell membrane when incubated in cell culture. The synthetic glycopolymer behaved like native mucins during the endocytic process (Figure 14). 


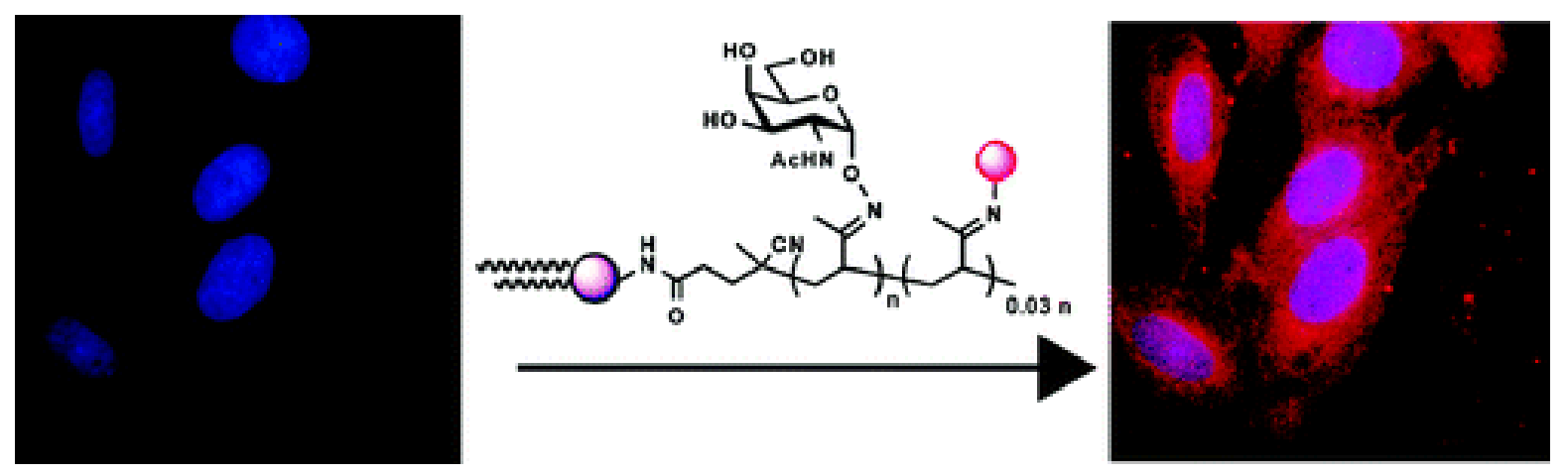

Figure 14. Fluorescence microscopy images of mucin mimic glycopolymer containing a phospholipid end group after incubated in cell culture. (Reproduced from Bertozzi et al. ${ }^{71}$ Copyright from American Chemistry Society 2008)

\section{Drug delivery}

The concept of polymeric drug delivery was first introduced by Ringsdorf in $1975,{ }^{72}$ in which three types of group: a targeting moiety, solubilizing moiety and cleavable linked drug were attached to a polymer backbone. Synthetic carbohydrate-containing polymers can be promising candidates because the carbohydrate moieties have both targeting and solubilizing functions. So far, about 20 drugs in this method have practice applications. ${ }^{73}$ For example, Hashida et al. in 1997 synthesized water-soluble galactosyl-poly[L-glutamic acid]-vatamin K, which was successfully delivered to mice's liver by tail vein injection and displayed an anti-hemorrhagic effect. ${ }^{74}$ Later, Fleming et al. in 2005 constructed polymer bearing galactoses and antioxidants vitamin E moieties, which was delivered to porcine spermatozoa by endocytosis. After treatment with this glycol-polymer delivery system, the viability of porcine spermatozoa had been prolonged, resulting in enhanced fertilization rates (Figure $15)^{75}$ 

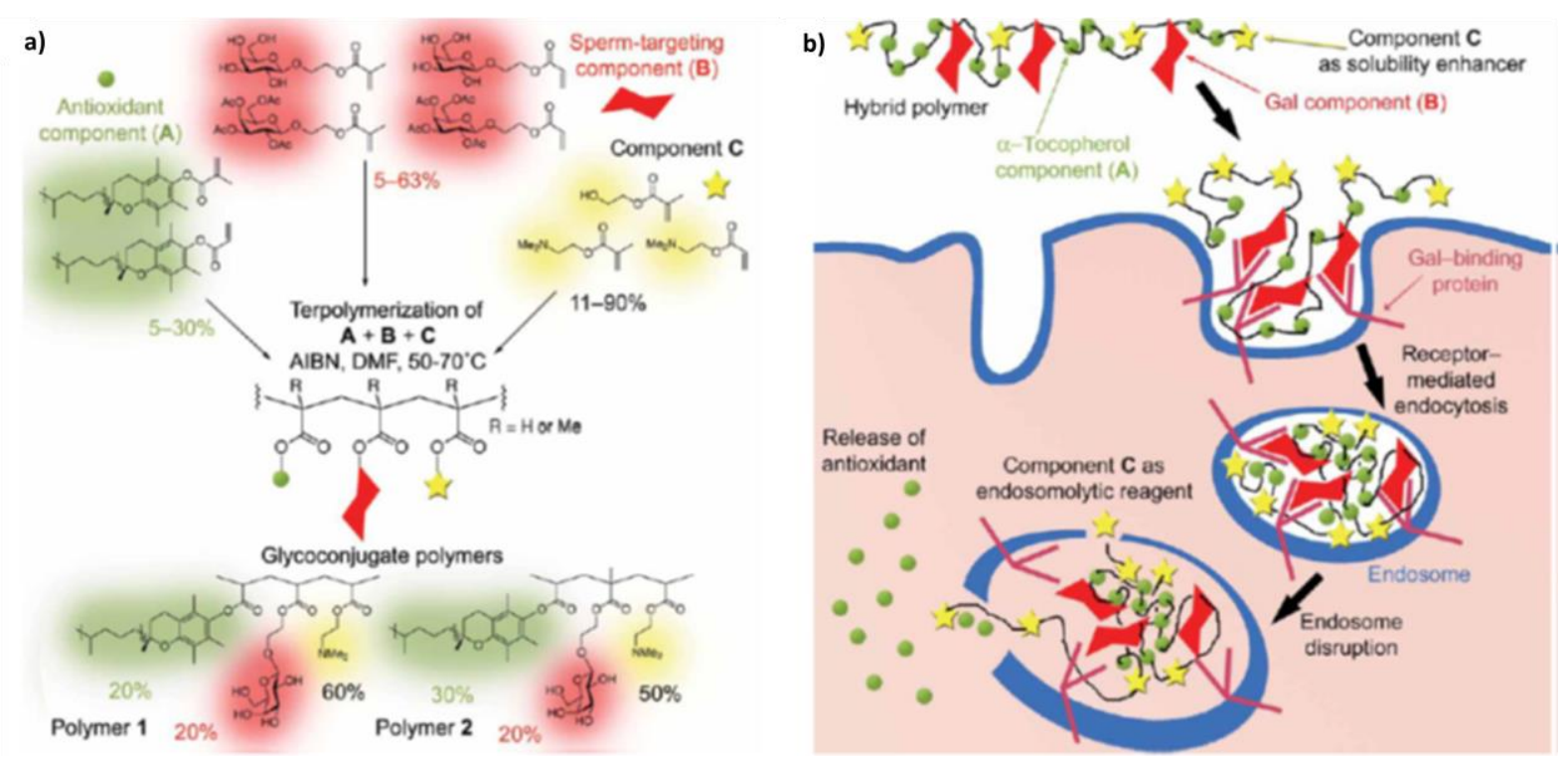

Figure 15. a) The design and construction of the galactoses-vitamin E polymer systems; b) proposed mechanism involving receptor-mediated endocytosis and subsequent vitamin $\mathrm{E}$ releasing. (Reproduced from Fleming et al. ${ }^{75}$ Copyright from Springer Nature Limited 2020)

\subsection{Synthetic sugar-based surfactants}

Since the late $20^{\text {th }}$ century, synthetic sugar-based surfactants have attracted much attention due to their physical-chemical properties. ${ }^{76,77}$ Compared to other nonionic surfactants, sugar-based surfactants have many advantages, such as good biocompatibility, good biodegradability and nontoxicity. ${ }^{78,79}$ Generally, sugar-based surfactants include three types of structural motifs: conventional amphiphiles, Gemini-amphiphiles and bola-amphiphiles.

\section{Conventional sugar-based amphiphiles}

Conventional sugar-based amphiphiles are molecules possessing both a sugar-based headgroup and one or two nonpolar tails, exhibiting excellent surface activity and solubility. The most classical sugar-based amphiphiles are alkyl glycosides and fatty acid glucamides, which have large-scale industrial production from renewable raw materials. ${ }^{79}$

The synthetic alkyl glycosides have existed for more than one century. Generally, glucose reacts with fatty alcohol using acid-catalyst under vacuum at high temperature, producing complex mixture alkyl glycosides (also called alkyl polyglycosides) (Figure 16). Alkyl 
glycosides have many applications, such as cosmetic, dishwashing and detergent, which completely based on renewable resources. ${ }^{80,81}$

Compared with alkyl glycosides, fatty acid glucamides are pure compounds and less soluble, which was synthesized from two steps reduction and alkylation. Generally, glucose reacts with methylamine using nickel-catalyst and subsequently react with fatty acid methyl ester, producing fatty acid glucamides (Figure 16). fatty acid glucamides have been exclusively used as detergents. ${ }^{79,82}$
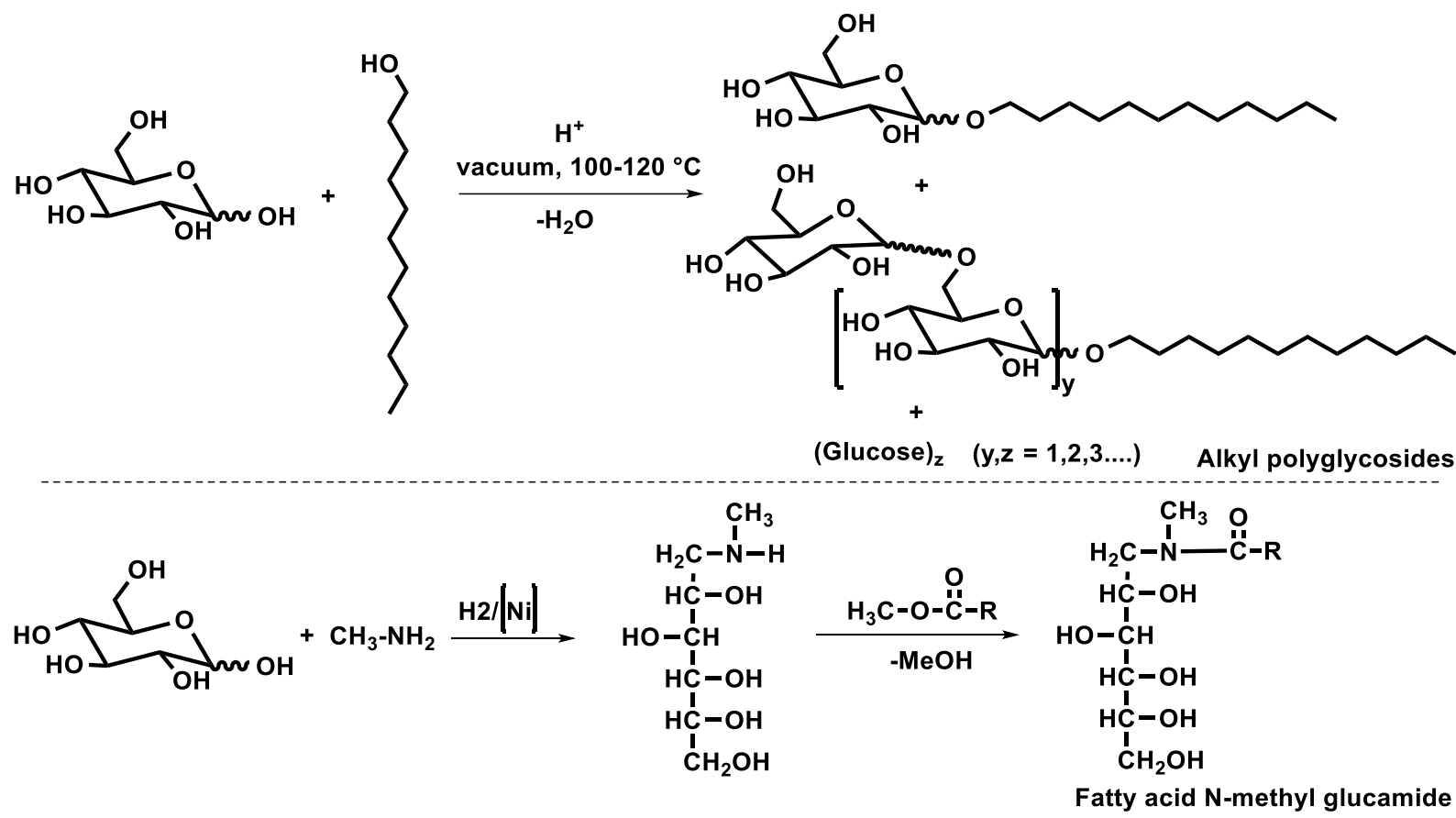

Figure 16. Synthesis of alkyl polyglycosides and fatty acid glucamides. (Reproduced with modification from Hill et al. ${ }^{79}$ Copyright from WILEY-VCH Verlag GmbH, Weinheim, Fed. Rep. Of Germany 1999)

\section{Sugar-based Gemini-amphiphiles}

As a new type of amphiphiles, Gemini-amphiphile consists of two conventional amphiphiles that are covalently linked by a rigid or flexible spacer, which was first reported by Menger et al. in $1991 .^{83}$ Compared to conventional amphiphiles, Gemini-amphiphiles have many advantages, such as lower critical micelle concentration, better solubility in water and enhanced surface activity., ${ }^{84}$ Sugar-based Gemini-amphiphiles refer Gemini-amphiphiles with carbohydrate headgroups, displaying interesting aggregation 
behaviors, such as temperature/pH-induced vesicle-to-micelle transition, ${ }^{85,86}$ and concentration-induced size changing of micelles. ${ }^{87}$ For example, Johnsson et al. in 2003 reported that their synthetic sugar-based Gemini-amphiphile exhibited the vesicle-to-micelle transition within a very narrow $\mathrm{pH}$ region $(\mathrm{pH}$ 6.0-5.6) and the flocculation-to-dispersion transition in the form of vesicle due to the surface charge reversal by increasing the $\mathrm{pH}$ value (Figure 17). ${ }^{88}$ Due to interesting aggregation behaviors and other unique properties, sugar-based Gemini-amphiphiles have many potential applications, such as gene carrier, ${ }^{89-92}$ drug delivery ${ }^{93}$ and oil recovery. ${ }^{94}$
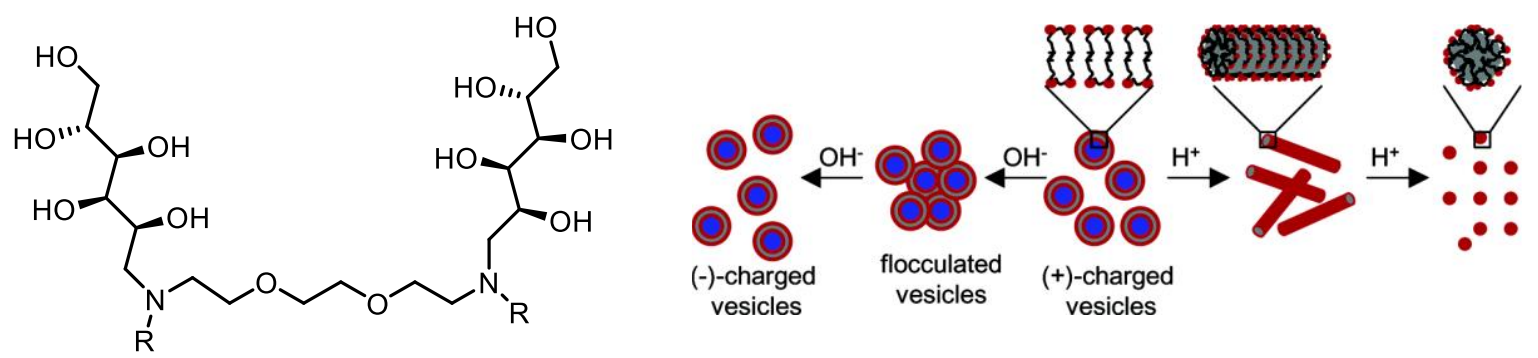

Figure 17. Structure of the sugar-based Gemini-amphiphile which displayed aggregations transition by adjusting $\mathrm{pH}$ value. (Reproduced with modification from Johnsson et al. ${ }^{88}$ Copyright from American Chemistry Society 2003)

\section{Sugar-based bola-amphiphiles}

Bola-amphiphiles are defined as molecules in which two polar functional headgroups are linked covalently by one or more nonpolar hydrocarbon chains, which are found in thermophilic archaebacteria. ${ }^{95}$ Compared to conventional amphiphiles, bola-amphiphiles also have many superiorities including higher solubility in water, increased critical micelle concentration, higher tolerance to physicochemical stress. ${ }^{96}$ Sugar-based bola-amphiphiles refer to bola-amphiphiles containing at least one sugar-based headgroup, which can be divided into symmetric and asymmetric sugar-based bola-amphiphiles. In recent years, sugar-based bola-amphiphiles have attracted much attention due to their interesting aggregation behaviors, such as vesicle-to-fiber transition, ${ }^{97,98}$ and monolayer-to-single-walled tubule transition. ${ }^{99}$ For example, Shimizu et al. in 1997 synthesized glucose-based bola-amphiphiles and obtained different aggregation morphologies by controlling the 
hydrocarbon chain (Figure 18). ${ }^{100}$ Due to their biocompatibility, nontoxicity, biodegradability and interesting aggregation properties, sugar-based bola-amphiphiles have many potential applications, such as sensors, ${ }^{101,102}$ gene delivery, ${ }^{103}$ triggering and immune response, ${ }^{104}$ and drug delivery. ${ }^{105,106}$
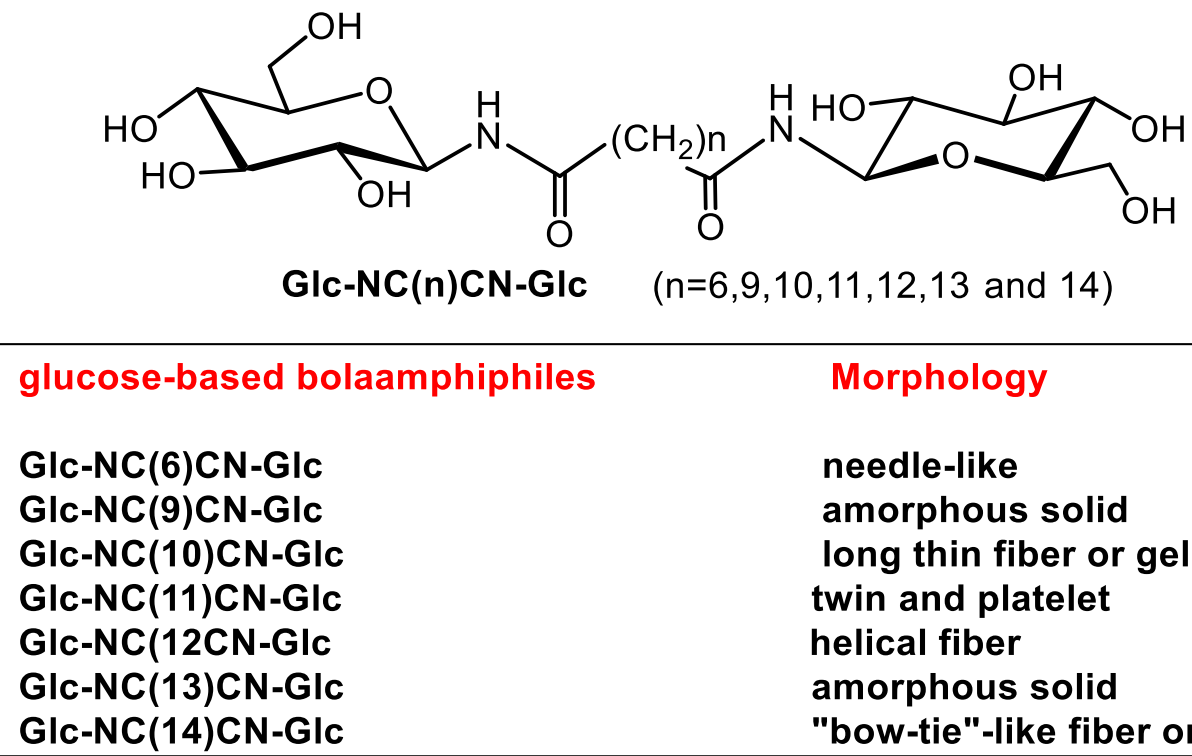

Figure 18. The synthetic 1-glucosamide bola-amphiphiles and diverse morphologies controlled by connecting links. (Reproduced with modification from Shimizu et al. ${ }^{100}$ Copyright from American Chemical Society 1997) 


\section{Objective of the thesis}

Carbohydrate-containing compounds widely exist in nature as important biological substances, which have hydrophilic headgroups. Therefore, carbohydrate-containing compounds are usually amphiphilic. Natural carbohydrate-containing compounds, such as glycoproteins, glycolipids and glycopeptides, participate in important biological events, which inspire scientists to mimic and design synthetic glycopolymers. However, synthetic glycopolymers obtained via post-polymerization modification commonly employed synthetic polymeric backbone, which are not environment friendly.

Cellulose as abundant renewable polymer consists of $\beta$ - $(1 \rightarrow 4)$-linked anhydroglucose units (AGUs) which have three hydroxyl groups in each unit. Chemical modification of cellulose can produce multifunctional cellulose derivatives. So far, carbohydrate-containing cellulose derivatives are still rare, which are good biocompatibility and good biodegradability.

Furthermore, sugar-based surfactants are also very interesting due to their unique properties. Compared to sugar-based conventional and Gemini amphiphiles, there are fewer reports about sugar-based bola-amphiphiles which also have interesting properties.

Therefore, the aim of the present study is to synthesize novel carbohydrate-containing compounds using nature polymer cellulose and also in the form of bola-amphiphiles. The main objective covers the following points:

(1) To develop new synthetic pathways for regioselectively chemical modification of cellulose. (Publication 1).

(2) To prepare fluorescent carbohydrate-containing cellulose derivatives for multifunctional nanostructures. (Publication 1 and 3).

(3) To synthesize novel carbohydrate-containing bola-amphiphiles and explore their new property. (Publication 2) 


\section{Results and discussion}

\subsection{Celluose derivatives with regioselective distributions of glucose moieties}

As reported in Publication 1, cellulose derivatives bearing glucose moieties at C6 position were prepared via nucleophilic displacement $\left(\mathrm{S}_{\mathrm{N}}\right)$ reaction, TEMPO/BAIB-mediated oxidation and subsequent UV-initiated thiol-ene click reaction. As shown in the Scheme 1, the intermediate 6-deoxy-6-ethanolamino cellulose carbanilate $(\mathrm{EaCC})$ with relatively long-chain hydroxy groups at C6 position were synthesized through three-step reactions: (1) tosylation of cellulose under homogenous conditions to produce TosC with a degree of substation ascribed to tosyl groups $\left(\mathrm{DS}_{\text {tosyl }}\right)$ of 1.3 determined by ${ }^{1} \mathrm{H}-\mathrm{NMR}$; (2) carbanilation of TosC to produce TosCC with $\mathrm{DS}_{\text {tosyl }}$ of 1.3 and $\mathrm{DS}_{\text {carbanilate }}$ of 1.6 determined by ${ }^{1} \mathrm{H}-\mathrm{NMR}$; (3) nucleophilic substitution of TosCC at $100{ }^{\circ} \mathrm{C}$ to produce EaCC.

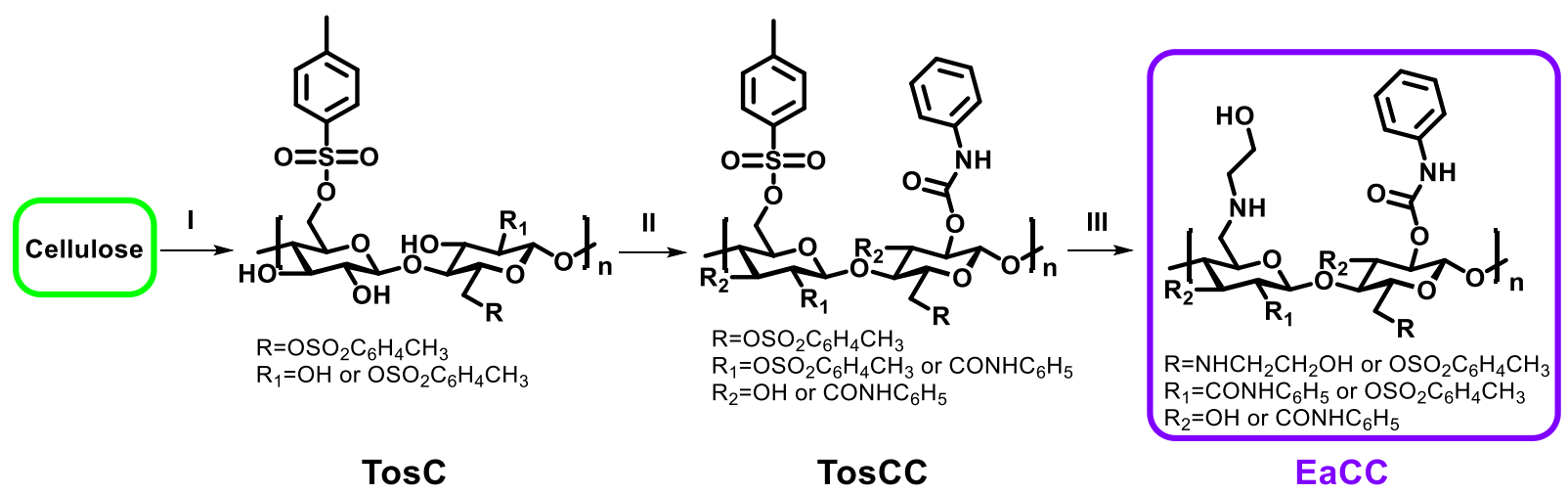

Scheme 1. Schematic representation for the synthesis of 6-deoxy-6-ethanolamino cellulose carbanilate (EaCC): I) Tosyl chloride, triethylamine, $24 \mathrm{~h}, 4{ }^{\circ} \mathrm{C}$; II) Phenyl isocyanate, DMF, $10 \mathrm{~h}, 80{ }^{\circ} \mathrm{C}$; III) Ethanolamine, DMSO, $6 \mathrm{~h}, 100{ }^{\circ} \mathrm{C}$.

The chemical structure of intermediate EaCC was confirmed by FTIR and ${ }^{13} \mathrm{C}$ NMR spectroscopy. The signals of $v(\mathrm{C}-\mathrm{N}-\mathrm{H})$ and $v(\mathrm{C}-\mathrm{N})$ could be observed separately at 1536 and $1445 \mathrm{~cm}^{-1}$, respectively. The characteristic peaks at 51.4 and $60.2 \mathrm{ppm}$ ascribed to 6-deoxy-6-ethanolamino groups (C17 and C18, respectively), as shown in Figure 19. 


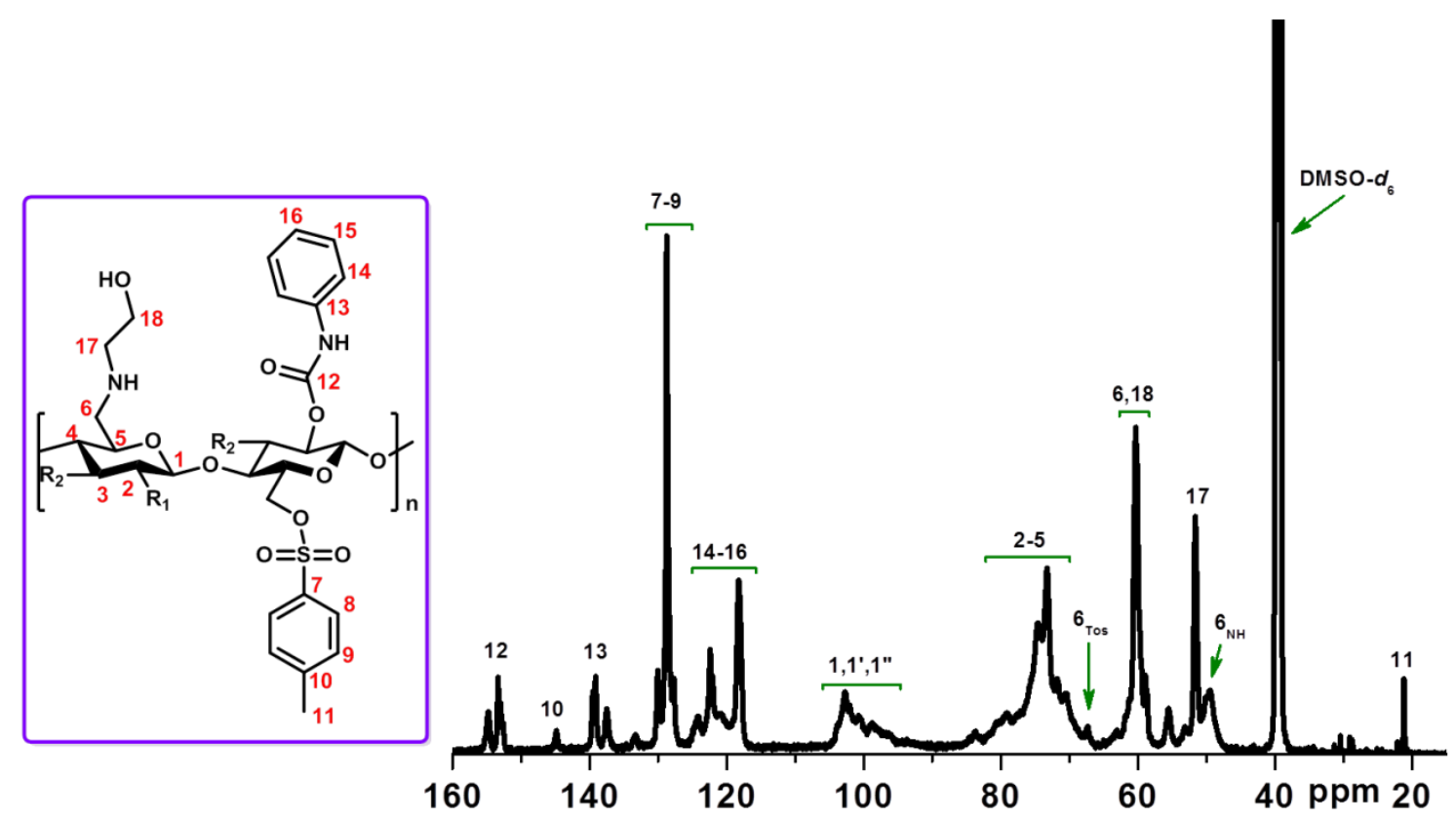

Figure 19. ${ }^{13} \mathrm{C}$ NMR spectrum of 6-deoxy-6-ethanolamino cellulose carbanilate (EaCC) $\left(\mathrm{DS}_{\text {tosyl }}=0.2, \mathrm{DS}_{\text {carbanilate }}=0.5, \mathrm{DS}_{\mathrm{EA}}=0.8\right)$ measured in DMSO- $d_{6}$ at $25^{\circ} \mathrm{C}$. The numbers in the structural formula demonstrate the carbons within EaCC.

The intermediate EaCC with a degree of substitution attributed to ethanolamino groups $\left(\mathrm{DS}_{\mathrm{EA}}\right)$ of 0.8 determined by ${ }^{1} \mathrm{H} \mathrm{NMR}$, as shown in Figure 20. Due to harsh reaction conditions with a high amount of base and high temperature, $\mathrm{DS}_{\text {carbanilate }}$ of EaCC was reduced to 0.5 with still remained $\mathrm{DS}_{\text {tosyl }}$ of 0.2 .
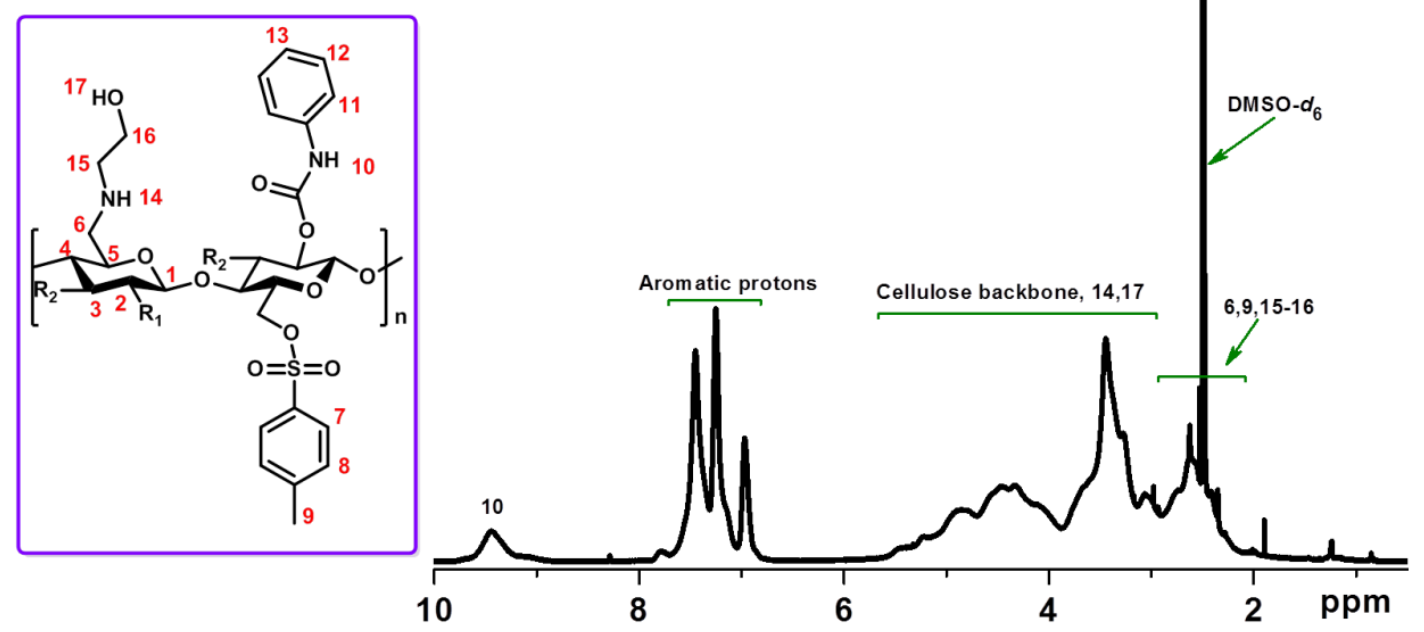
Figure 20. ${ }^{1} \mathrm{H}$ NMR spectrum of 6-deoxy-6-ethanolamino cellulose carbanilate (EaCC) $\left(\mathrm{DS}_{\text {tosyl }}=0.2, \mathrm{DS}_{\text {carbanilate }}=0.5, \mathrm{DS}_{\mathrm{EA}}=0.8\right)$ measured in DMSO- $d_{6}$ at $50{ }^{\circ} \mathrm{C}$. The numbers in the structural formula demonstrate the protons within EaCC.

The final product glycosylated 6-deoxy-6-(2-thiolethylamino)ethylamino cellulose carbanilate (GlcThiolCC) was synthesized via two steps as shown in Scheme 2: (1) novel TEMPO/BAIB-mediate oxidation of primary hydroxy groups of EaCC in DMSO to aldehyde groups which were converted into Schiff base and reduced sequentially in a one-pot reaction, successfully producing intermediate ThiolCC with free thiol groups at C6 position. The new oxidation of the primary hydroxyl groups regioselectively happened at C6 position, moreover, the subsequent treatment with $\mathrm{NaBH} 4$ was not only to reduce the disulfide bridge, but also to reduce the Schiff base; (2) glucose-terminated eugenol was conjugated to intermediate ThiolCC via UV-initiated thiol-ene click reaction, producing the GlcThiolCC.
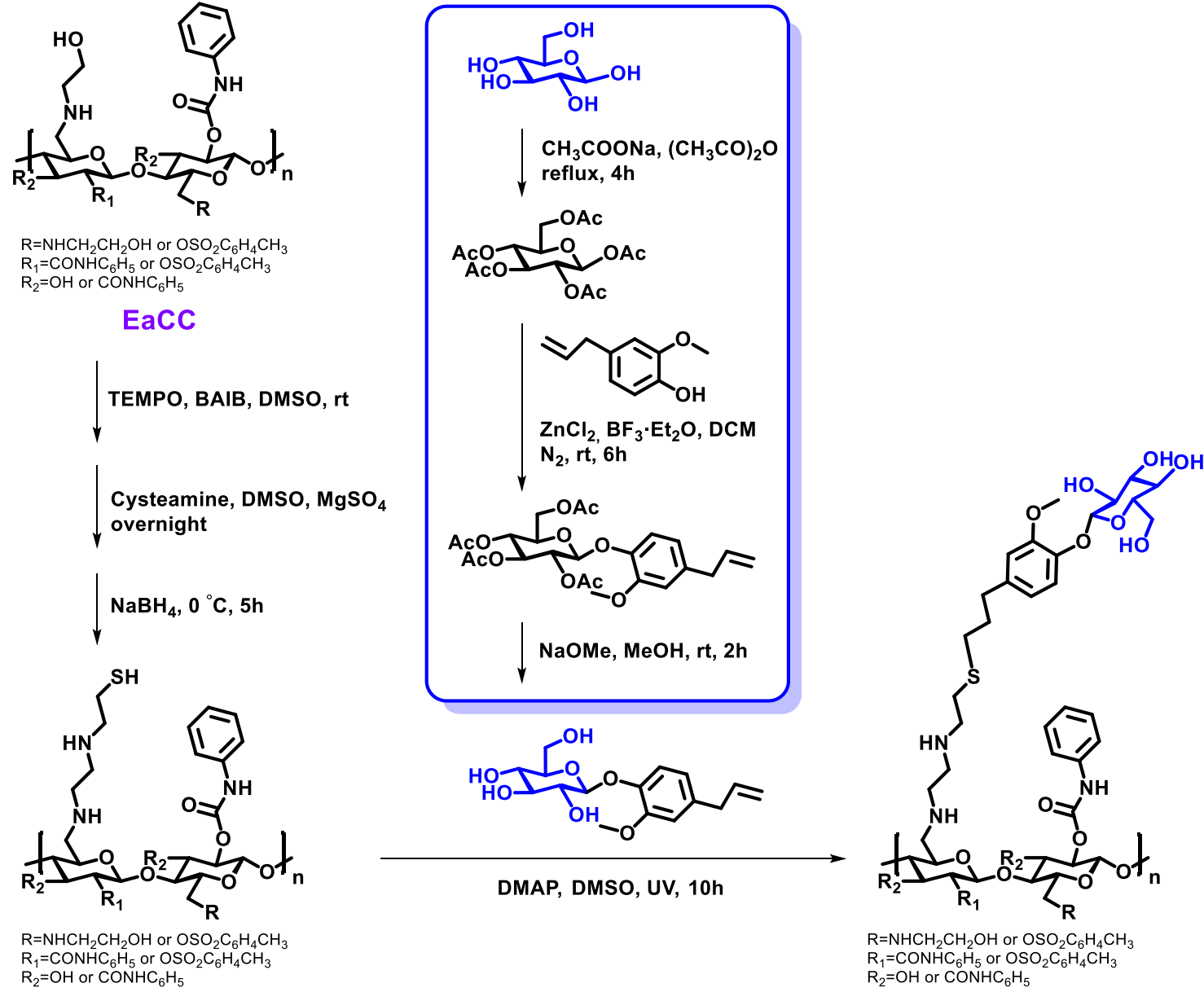

ThiolcC

GIcThiolcC 
Scheme 2. Schematic illustration for the synthesis of glycosylated 6-deoxy-6-(2-thiolethylamino)ethylamino cellulose carbanilate (GlcThiolCC) starting from EaCC.

${ }^{13} \mathrm{C}$ NMR measurement was used to confirm the chemical structure of GlcThiolCC, as shown in Figure 21. Compared to ThiolCC, the GlcThiolCC had better solubility providing more information in ${ }^{13} \mathrm{C}$ NMR spectrum. The characteristic signals of C20/21 at $28 \mathrm{ppm}$, $\mathrm{C} 22 / 23$ at $34.1 \mathrm{ppm}, \mathrm{C}_{\mathrm{NH}}$ with desoxyamino groups at $49.1 \mathrm{ppm}$ and $\mathrm{C} 30 / 36$ around 60.5 ppm were observed.
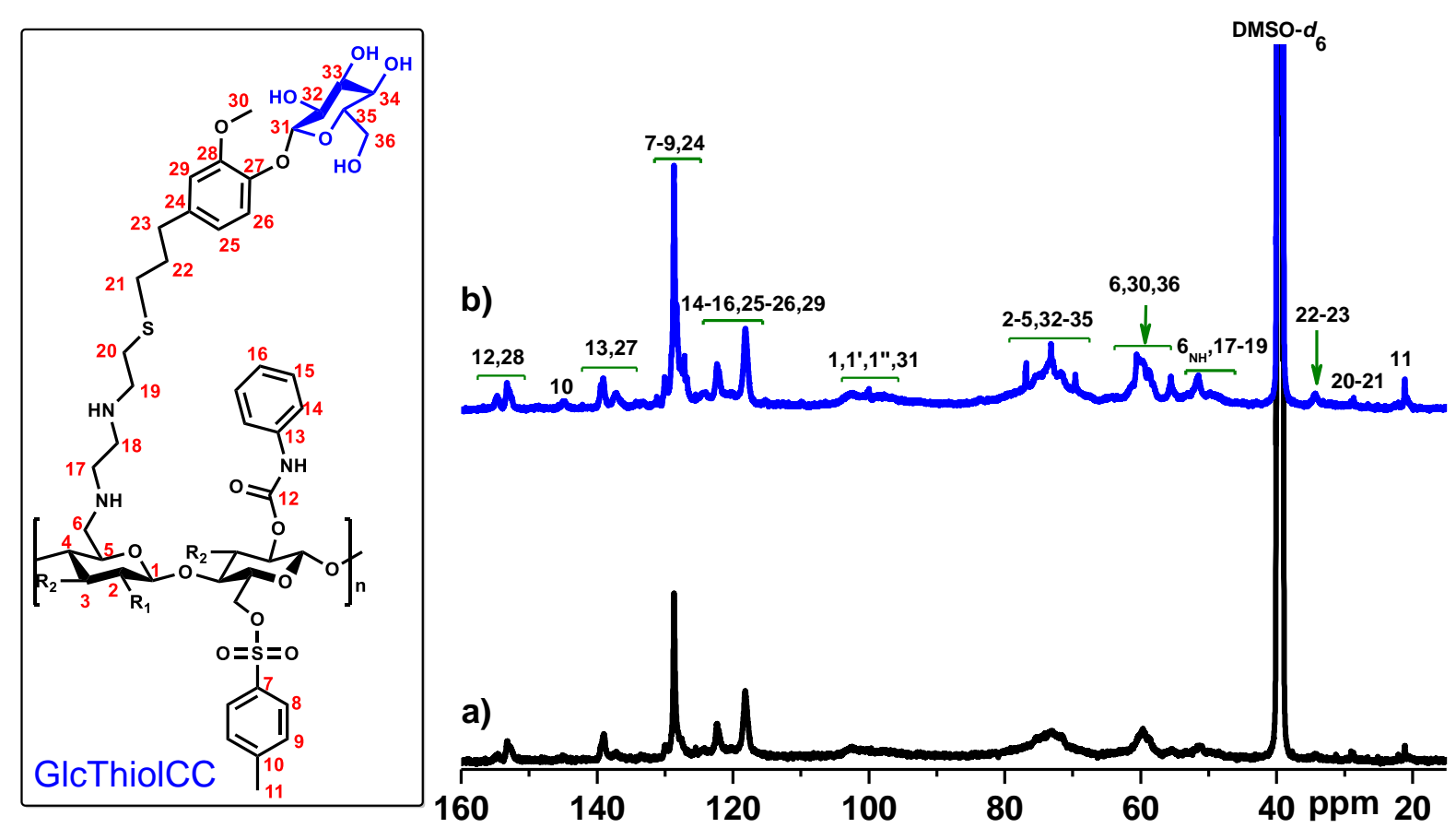

Figure 21. ${ }^{13} \mathrm{C}$ NMR spectrum of a) ThiolCC $\left(\mathrm{DS}_{\text {tosyl }}=0.2, \mathrm{DS}_{\text {carbanilate }}=0.5, \mathrm{DS}_{\mathrm{SH}}=0.6\right)$ and $\left.\mathrm{b}\right)$ GlcThiolCC $\left(\mathrm{DS}_{\text {tosyl }}=0.2, \mathrm{DS}_{\text {carbanilate }}=0.5, \mathrm{DS}_{\text {glucose }}=0.6\right)$ measured in DMSO- $d_{6}$ at $25{ }^{\circ} \mathrm{C}$ with 15000 scans. The numbers in the structural formula of GlcThiolCC display the carbons.

The intermediate ThiolCC with a degree of substitution of thiol groups (DS $\mathrm{SH}_{\mathrm{SH}}$ ) of 0.6 was determined by ${ }^{1} \mathrm{H}$ NMR spectroscopy, due to the obvious signal of secondary amine groups $\left(-\mathrm{NHCH}_{2} \mathrm{CH}_{2} \mathrm{SH}\right)$ at $1.0-1.5 \mathrm{ppm}$ (Figure 22a). Based on the integrals of the signal at 9.5 ppm and signals at 6.8-8.0 ascribed to aromatic protons within the ${ }^{1} \mathrm{H}$ NMR spectrum (Figure 22b), thiol groups in ThiolCC should have completely reacted with vinyl groups in glucose-terminated eugenol, yielding GlcThiolCC with a degree of substitution ascribed to 
glucosyl moieties (DS glucose) of 0.6.
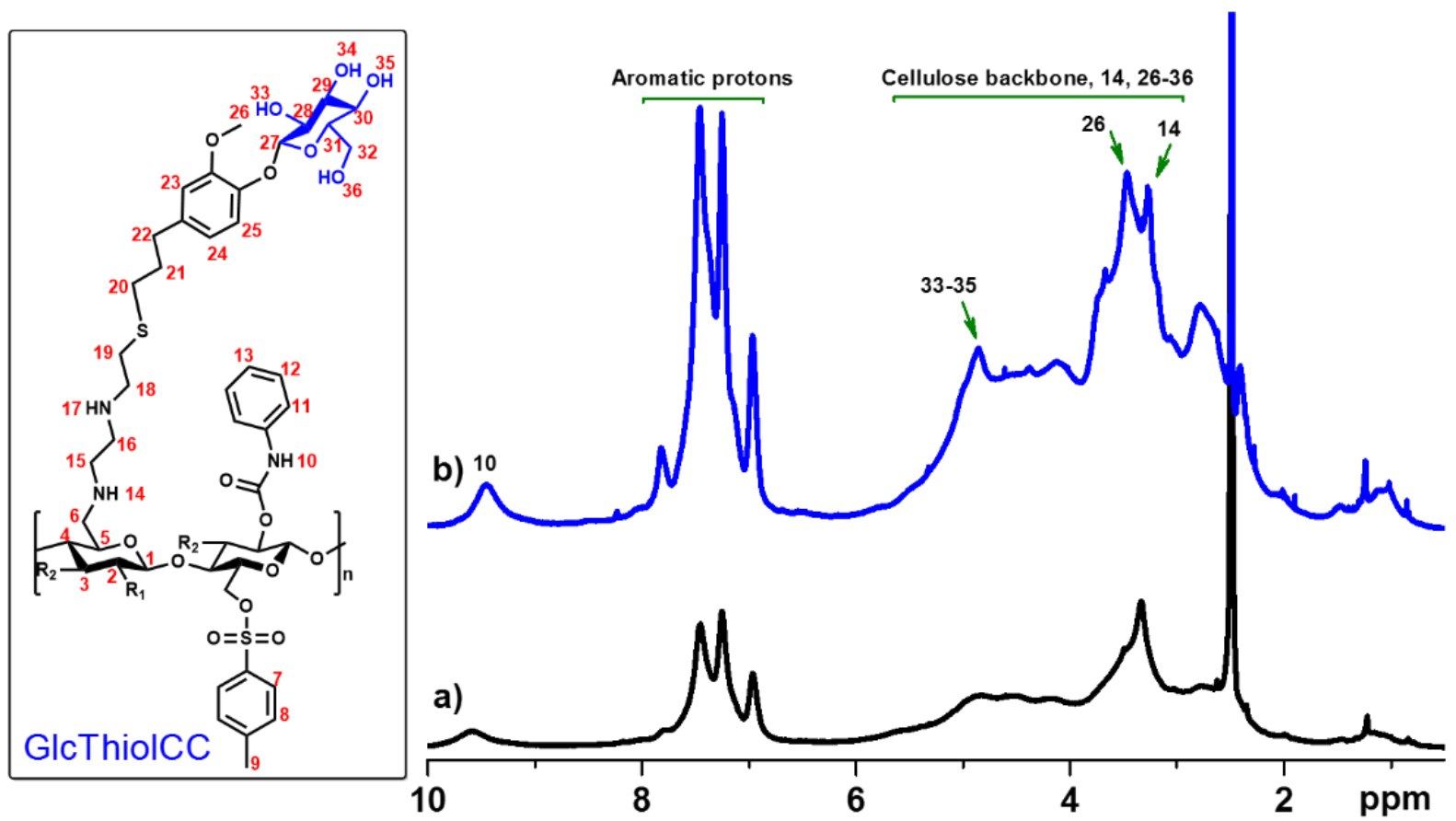

Figure 22. ${ }^{1} \mathrm{H}$ NMR spectrum of a) ThiolCC $\left(\mathrm{DS}_{\mathrm{tosyl}}=0.2, \mathrm{DS}_{\text {carbanilate }}=0.5, \mathrm{DS}_{\mathrm{SH}}=0.6\right)$ and $\left.\mathrm{b}\right)$ GlcThiolCC $\left(\mathrm{DS}_{\text {tosyl }}=0.2, \mathrm{DS}_{\text {carbanilate }}=0.5, \mathrm{DS}_{\text {glucose }}=0.6\right)$ measured in DMSO- $d_{6}$ at $50{ }^{\circ} \mathrm{C}$. The numbers in the structural formula of GlcThiolCC display the protons.

Due to the presence of glucosyl groups with free 4,6-diols at the polymer backbone, the compound GlcThiolCC in DMSO bond with cross-linker 1,4-benzenediboronic acid (BDBA) at $\mathrm{pH} 10$ and a transparent solution became turbid, as shown in Figure 23a. Adding a sufficient amount of glucose, the turbid suspension turned into a transparent solution again, indicating that excess glucose in the base condition can displace GlcThiolCC by binding with 1,4-phenylenediboronic acid. Besides, the average size of NPs formed from dissociated GlcThiolCC solution was $40 \pm 1.2 \mathrm{~nm}$, similar to the average size of NPs formed from the original GlcThiolCC solution, which further confirmed the reversible binding between BDBA and GlcThiolCC (Figure 23b). 

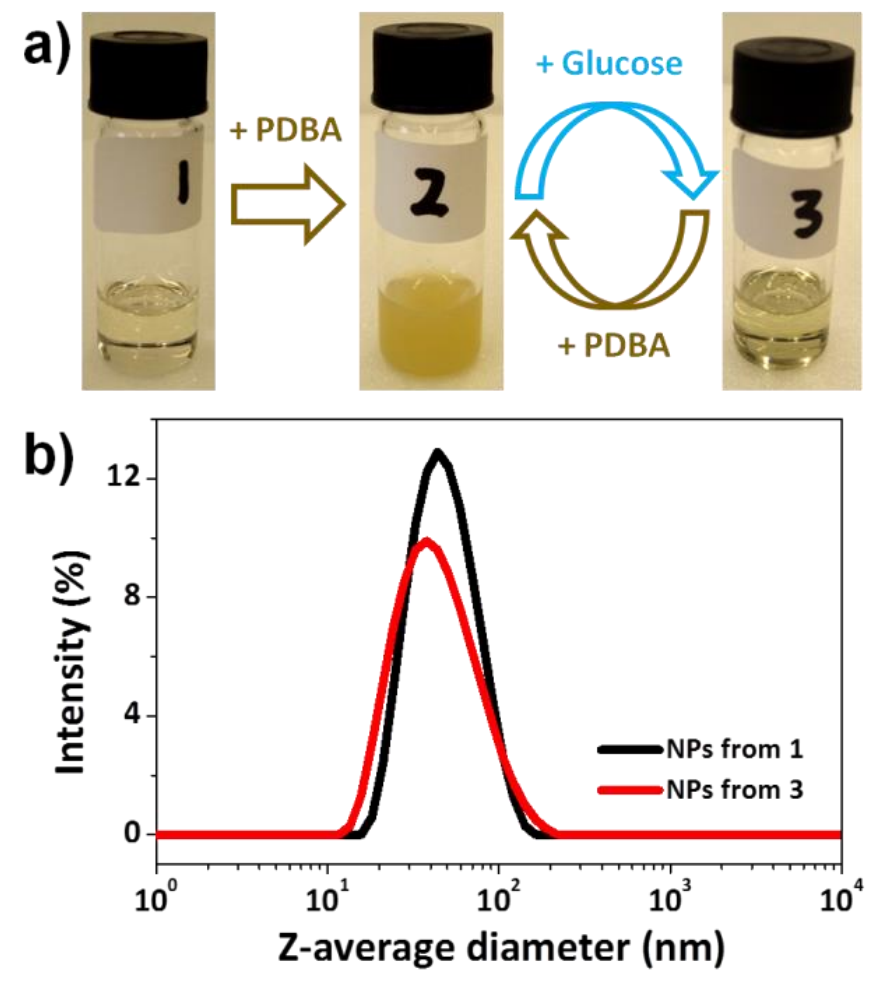

Figure 23. a) Schematic demonstration of the reversible covalent bonding of GlcThiolCC with 1,4-phenylenediboronic acid: (1) GlcThiolCC in DMSO; (2) the cross-linking of GlcThiolCC and 1,4-phenylenediboronic acid (PDBA) and (3) glucose-induced dissociation of the cross-linking complex. b) DLS curves of NPs.

\subsection{Sugar-based bola-amphiphiles displaying unique properties}

Conventional sugar-based amphiphiles have been widely used in our daily life due to the abundant and renewable resources and unique properties. However, sugar-based bola-amphiphiles are rarely reported. In the publication $\mathbf{2}$, novel bola-amphiphiles with carbohydrate headgroups (CHO-Bolas) were synthesized via the simultaneous thio-ene click reaction of 2-allylethoxyl monosaccharides and 7-mercaptohexyloxy-4-methylcoumarin as well as [2+2]-photodimerization reaction of coumarin moieties in the one-pot reaction under 320-400 nm UV irradiation, including D-(+)-glucose-based coumarin dimer (GCCG-12) and D-(+)-mannose-based coumarin dimer (MCCM-12) (Figure 24a). 
a)

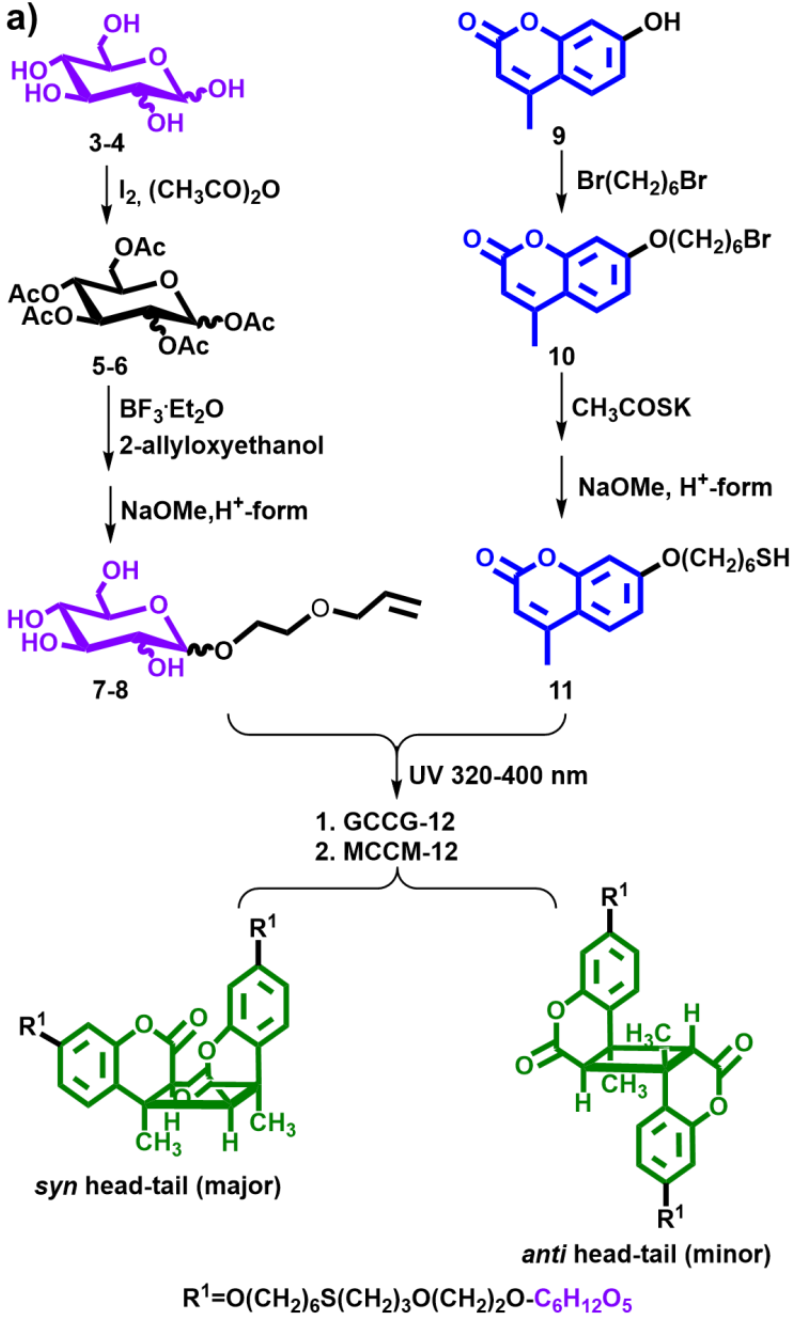

b)

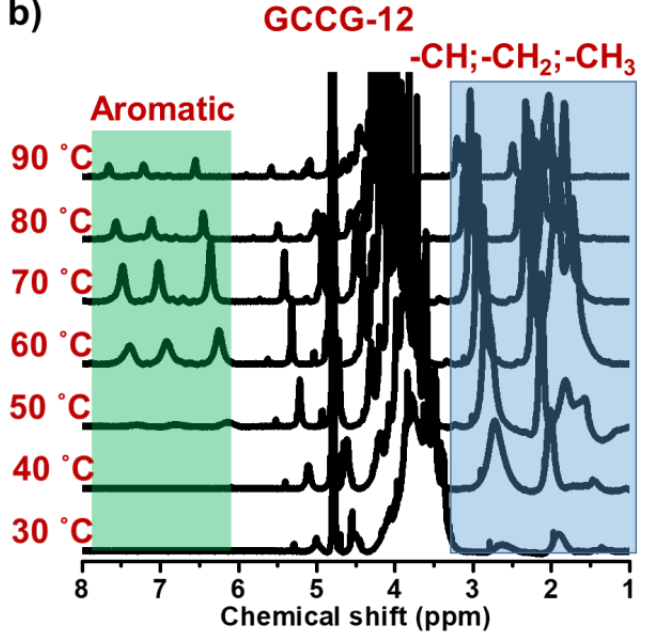

c)

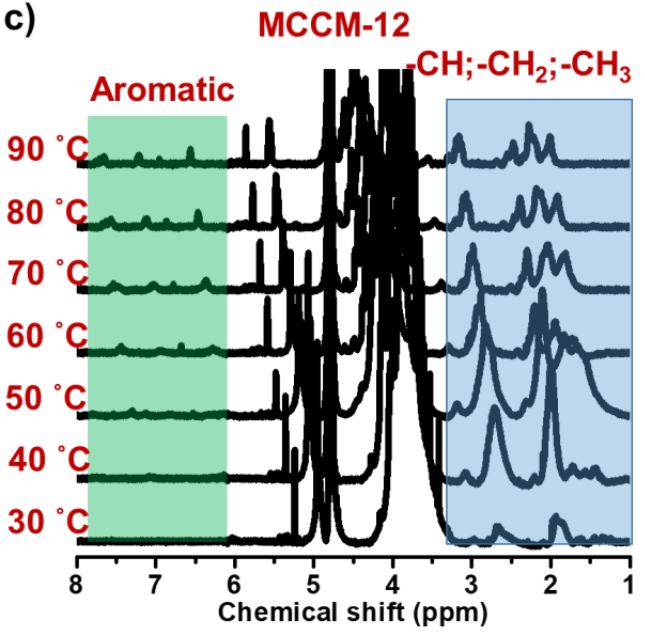

Figure 24. a) Synthesis route for $\mathrm{CHO}-$ Bolas containing glucose and a coumarin dimer (GCCG-12) 1 or mannose and a coumarin dimer (MCCM-12) 2. ${ }^{1} \mathrm{H}-\mathrm{NMR}$ spectra of b) GCCG-12 and c) MCCM-12 recorded in $\mathrm{D}_{2} \mathrm{O}$ at various temperatures between 30 and $90{ }^{\circ} \mathrm{C}$.

${ }^{1} \mathrm{H}$ NMR spectra of GCCG-12 and MCCM-12 recorded in $\mathrm{D}_{2} \mathrm{O}$ at various temperatures were used to further study their thermo-responsive behaviors, as shown in Figure $\mathbf{2 4 b}$ and c. For GCCG-12, the peaks in the aromatic region $(\delta \approx 6-7.5)$ were absent and the peaks related to the alkyl region $(\delta \approx 1-3)$ were significantly diminished at $30{ }^{\circ} \mathrm{C}$, indicating the formation of micelles via $\pi-\pi$ stacking and hydrophobic interaction. The intensities of peaks of aromatic region and alkyl region were greatly enhanced with increased temperature due to the increased molecular mobility and the disaggregation of micelles. When temperature over $80{ }^{\circ} \mathrm{C}$, the intensities of peaks of aromatic region and alkyl region decreased, indicating the 
formation of vesicles via $\pi-\pi$ stacking and hydrophobic interaction. MCCM-12 had similar changes of peaks attributed to aromatic signals $(\delta \approx 6-7.5)$ and alkyl region $(\delta \approx 1-3)$ over a temperature range from 30 to $90{ }^{\circ} \mathrm{C}$ but intensities of peaks were much weaker, due to the much earlier appearance of MVT at a lower temperature with stronger interactions among molecules and other thermodynamic effects including entropic factors.

The GCCG-12 and MCCM-12 aqueous solutions displayed an obvious optical change from clear to turbid with increasing temperature, as shown in Figure 25a. Both GCCG-12 and MCCM-12 aqueous solutions recovered their initial states during the heating-cooling process and maintained a clear solution for several months, suggesting the turbid-transparent transition is totally reversible. The essence of the reversible clear-to-turbid change is the micelle-to-vesicle transition (MVT), which was further confirmed by DLS measurement showing the temperature-induced average size changing of the aggregates (Figure 25b). For GCCG-12 aqueous solution, the average size of the aggregate was $22.2 \pm 2.0 \mathrm{~nm}$ with a narrow size distribution (PDI of $0.152 \pm 0.008$ ) below $80{ }^{\circ} \mathrm{C}$ and increased to $1.5 \pm 0.1 \mu \mathrm{m}$ with a broad size distribution (PDI of $0.815 \pm 0.163$ ) by raising the temperature to $85^{\circ} \mathrm{C}$. For MCCM-12 aqueous solution, the average size of the aggregate was $54.2 \pm 2.9 \mathrm{~nm}$ with a narrow PDI of $0.233 \pm 0.005$ and increased to $917.7 \pm 49.3 \mathrm{~nm}$ with a broad PDI of $0.735 \pm 0.105$ by raising the temperature to $55^{\circ} \mathrm{C}$. Transmission electron microscopy (TEM) and polarized light microscopy (PLM) were used to further confirm the morphologies of aggregates, as shown in Figure 25c-f. The average sizes of the spherical micelles were $5.4 \pm 1.0 \mathrm{~nm}$ and $7.1 \pm 1.1 \mathrm{~nm}$ for GCCG-12 and MCCM-12, respectively. The average size of vesicles formed in GCCG-12 aqueous solution at $95{ }^{\circ} \mathrm{C}$ was $6.2 \pm 1.9 \mu \mathrm{m}$ and the average size of vesicles formed in MCCM-12 aqueous solution at $70{ }^{\circ} \mathrm{C}$ was $9.4 \pm 2.2 \mu \mathrm{m}$. 

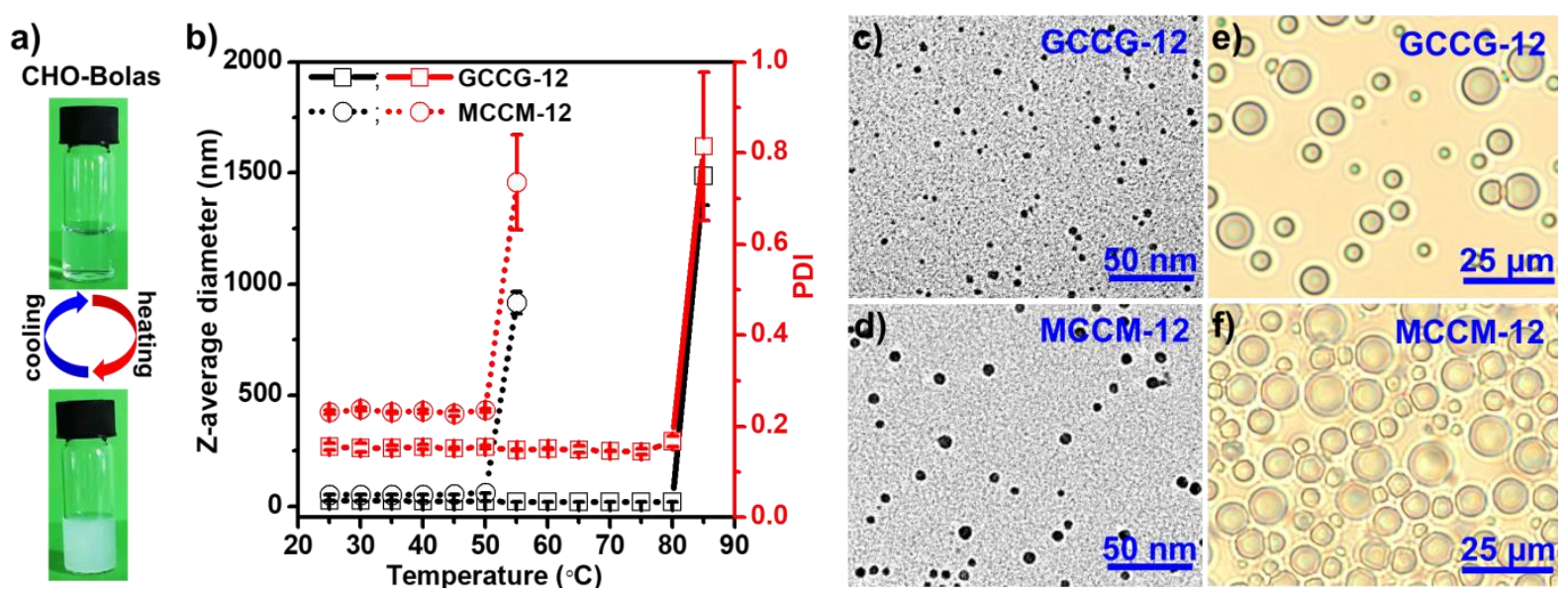

Figure 25. a) Photo images of reversible clear-turbid cycles during heating and cooling of CHO-Bolas in deionized (DI) water. b) Z-average diameters and polydispersity index (PDI) of aggregates formed by GCCG-12 and MCCM-12 in aqueous solutions in correlation with temperature. TEM images of micelles formed by: c) GCCG-12 and d) MCCM-12. Polarized light microscopy (PLM) images of vesicles formed by: e) GCCG-12 at $98{ }^{\circ} \mathrm{C}$ and $\mathrm{f}$ ) $\mathrm{MCCM}-12$ at $70{ }^{\circ} \mathrm{C}$.

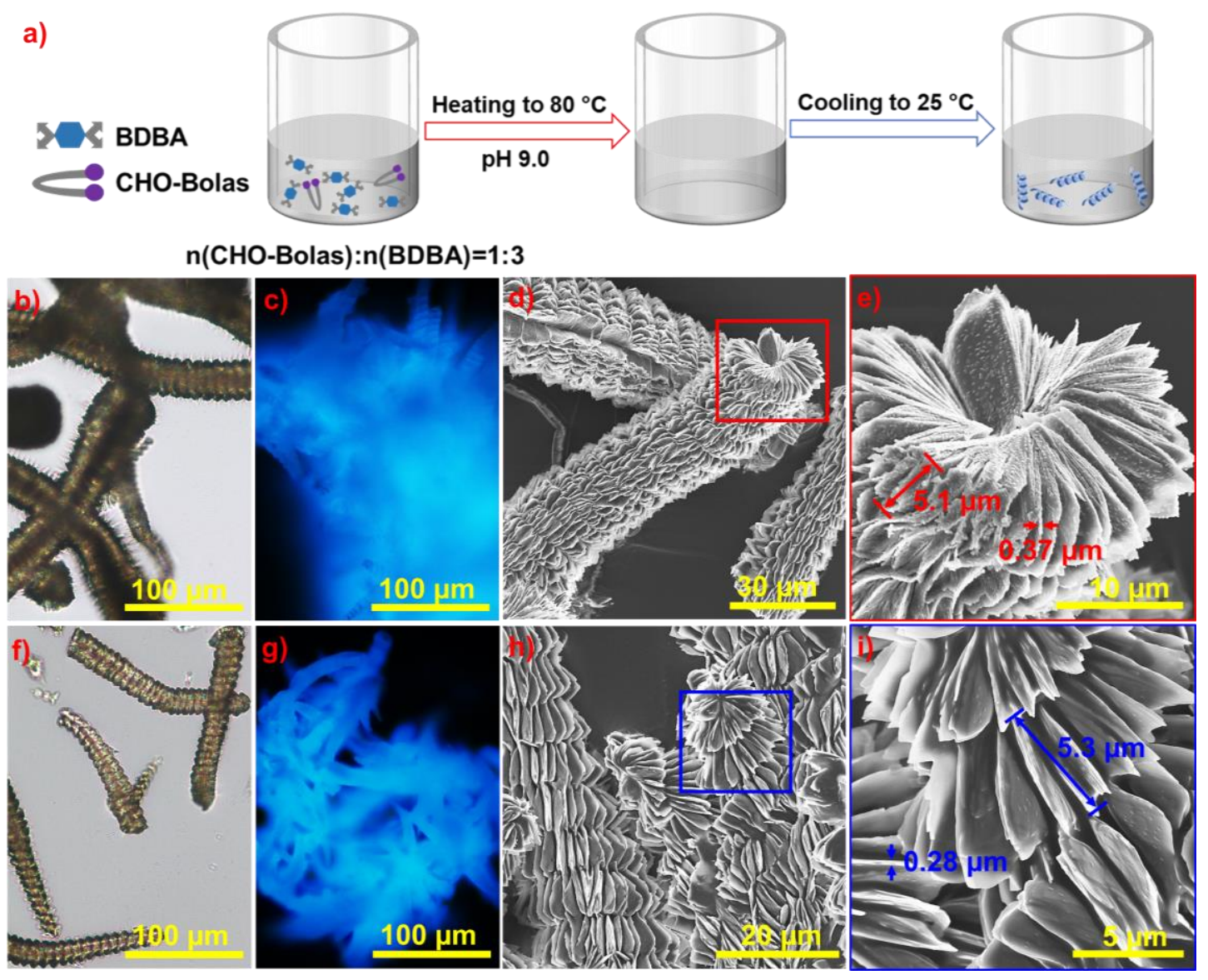


Figure 26. a) Schematic illustration for the formation of helical structures in alkaline aqueous solution of CHO-Bolas and 1,4-benzeneboronic acid (BDBA). Optical light and fluorescence microscopy as well as SEM images of the helices with diverse magnifications: b-e) formed by GCCG-12 and BDBA; f-i) formed by MCCM-12 and BDBA.

Apart from the temperature-responsive behavior of the reversible transition between micelles and vesicles, CHO-Bolas had other characteristic properties, such as chirality and recognition via bonding with lectins or boronic acids through the carbohydrate moieties. ${ }^{107,108}$ As shown in Figure 26a, their accessible carbohydrate headgroups of CHO-Bolas could react with BDBA and co-assembled into microsized helices upon cooling from $80{ }^{\circ} \mathrm{C}$ in alkaline aqueous solutions. With both GCCG-12 and MCCM-12, purified helix aggregates of several hundred microns were obtained as shown by the optical microscopic images (Figure 26b and f). The assembled solid-state helical structures emitted blue luminescence, as observed under the fluorescence microscope with a UV lamp $(\lambda=365 \mathrm{~nm}$ ) (Figure 26c and g). The SEM images of the air-dried samples showed right-handed helices containing packed thin layers (Figure 26d-e and h-i): the helices of coassembled BDBA/GCCG-12 had the helical pitches of $5.37 \pm 1.05 \mu \mathrm{m}$ and the lamellae thickness of $0.27 \pm 0.07 \mu \mathrm{m}$; coassembled helices of BDBA/MCCM-12 had larger helical pitches of $6.29 \pm 0.98 \mu \mathrm{m}$ and thinner lamellae with the thickness of $0.18 \pm 0.06 \mu \mathrm{m}$.
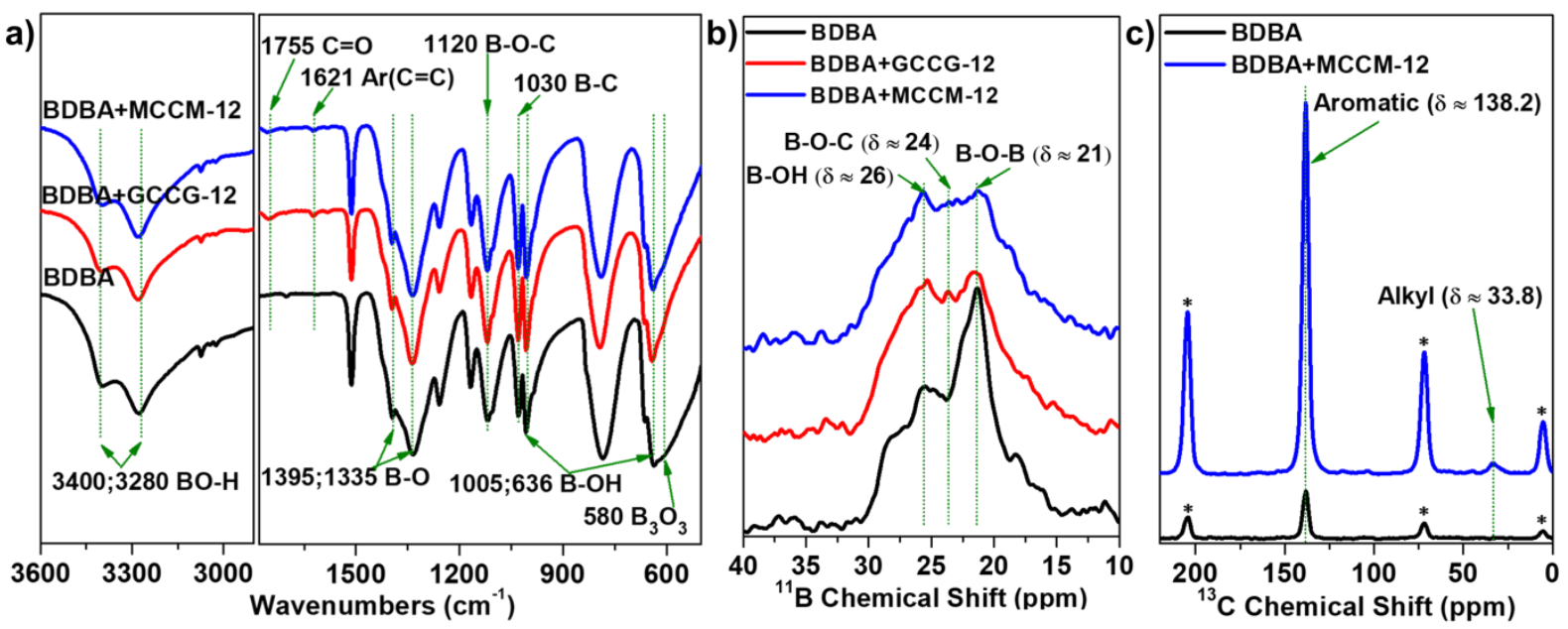

Figure 27. a) FTIR spectra and b) Solid-state ${ }^{11} \mathrm{~B}$ NMR spectra of the helical structures 
formed by the CHO-Bolas and BDBA, as well as brick-shaped structure formed by BDBA alone. c) Solid-state ${ }^{13} \mathrm{C}$ NMR spectra of the helical assembly formed by MCCM-12 and BDBA, as well as brick-shaped structure formed by BDBA alone. Asterisks indicate spinning side-band peaks.

To reveal the chemical compositions of co-assembled helices, they were further analysed with FTIR and solid-state ${ }^{11} \mathrm{~B} /{ }^{13} \mathrm{C}$ NMR spectroscopy. According to the FTIR spectra of the helices and brick-shaped aggregates (Figure 27a), the peaks corresponding to B-OH stretching vibrations at 636 and $1005 \mathrm{~cm}^{-1} \cdot{ }^{109,110}$ The new emerging peaks at 1621 and 1755 $\mathrm{cm}^{-1}$ were assigned to aromatic rings and $\mathrm{C}=\mathrm{O}$ groups of coumarin dimers, respectively. Moreover, the greatly increased peak at $1120 \mathrm{~cm}^{-1}$ was attributed to the symmetric C-O-B-O-C stretching vibration. ${ }^{111}$ All these results indicated the formation of boronate esters between BDBA and CHO-Bolas within the helices. Moreover, brick-shaped aggregates contained much more boroxine anhydrides according to the peak at $580 \mathrm{~cm}^{-1}$ attributed to boroxine anhydrides, ${ }^{112}$ while it should be marginal within helices based on their very weak peaks.

The solid-state ${ }^{11} \mathrm{~B}$ NMR spectrum of the self-assembled helices exhibited overlapping multiplets due to the boron atoms in different structural environments (Figure 27b). Compared to the brick-shaped aggregates formed by BDBA alone, the helical structures formed by BDBA and CHO-Bolas showed a much broader peak, consisting of multiple peaks with roughly the same intensity. This can be explained with the overlap boroxine anhydride at around $21 \mathrm{ppm}$, new emerging boronate ester at around $24 \mathrm{ppm}$ and boronic acid at around 26 ppm, in agreement with the FTIR results shown above. The solid-state ${ }^{13} \mathrm{C}$ NMR spectrum of brick-shaped aggregates exhibited one single and weak resonance for aromatic rings of BDBA at 138 ppm (Figure 27c). In comparison, the solid-state ${ }^{13} \mathrm{C}$ NMR spectrum of helices formed by MCCM-12 and BDBA displayed one stronger and broader resonance at $138 \mathrm{ppm}$ and one weak resonance for alkyl chains of MCCM-12 at $34 \mathrm{ppm}$. Therefore, the helical structures contained high amounts of bulk BDBA, reversible boronate esters formed between 
BDBA and CHO-Bolas, and boroxine anhydrides by self-condensation of BDBA.

\subsection{Fluorescent cellulose derivatives bearing mannose moieties}

Nanostructures of the synthetic fluorescent glycopolymers with the so-called "glycol-cluster effect" can be promising candidates to mimic biological recognition events, such as selectively binding with lectins and targeting cells. In publication 3, the glycopolymer 11-(mannoseoxyethoxylpropane)(coumarinoxyhexyl)(rhodamineethyl) thiolundecanoate 10-undecenoly ester of cellulose (CUE-MCR) was synthesized via two-step thiol-ene click reactions.

First of all, three kinds of mercapto-containing compounds were synthesized: mannose-oxyethoxylpropane-thiol (Mann-SH), coumarin-oxyhexyl-thiol (Coum-SH) and rhodamine B-ethyl-thiol (RhB-SH) (Scheme 3a-c). Besides, esterification of cellulose under homogenous condition was carried out to produce cellulose 10-undecenoyl ester (CUE) with terminal double bonds. Due to the highly hydrophilic Mann-SH and UV-sensitive Coum-SH and RhB-SH, CUE-MCR was prepared via photo-initiated thiol-ene click reaction between Mann-SH and CUE and sequentially thermal-initiated thiol-ene click reaction among Coum-SH, RhB-SH and terminal double bonds of cellulose derivatives (Scheme 3d). According to element analysis, the CUE-MCR had $\mathrm{DS}_{\mathrm{Coum}}$ of $1.0, \mathrm{DS}_{\mathrm{C}=\mathrm{C}}$ of $0.9, \mathrm{DS}_{\mathrm{Mann}}$ of 0.5 and $\mathrm{DS}_{\text {Rhod }}$ of 0.2 , which can be dissolved in several organic solvents such as THF, DCM, DMAc and DMF. 


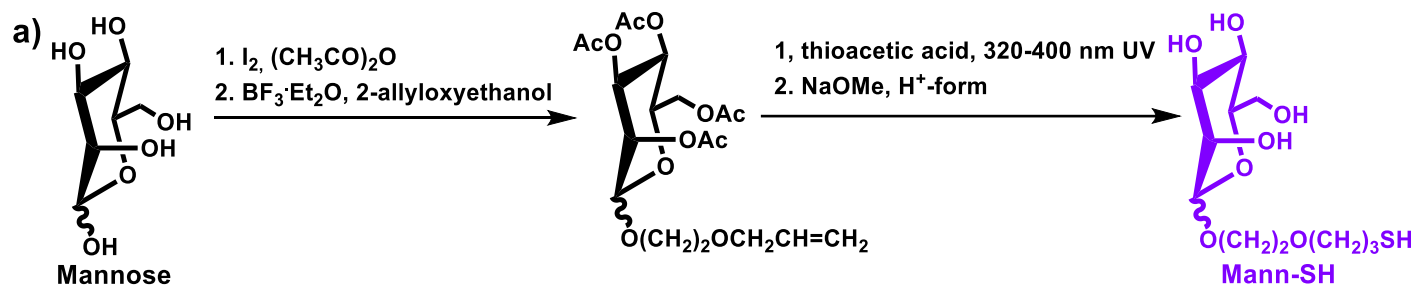

b)

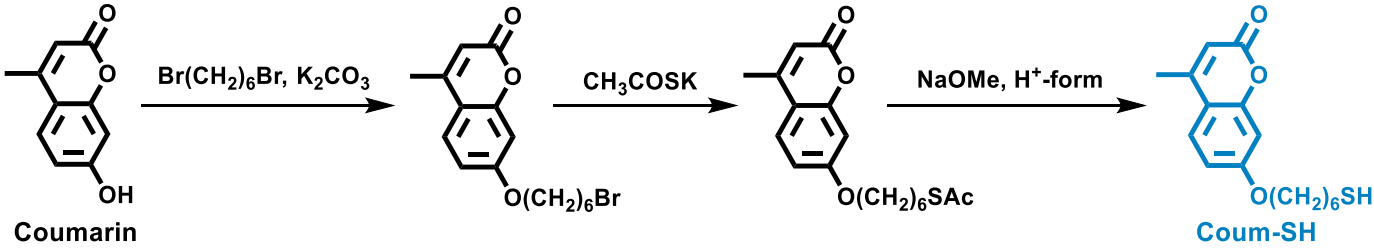

c)
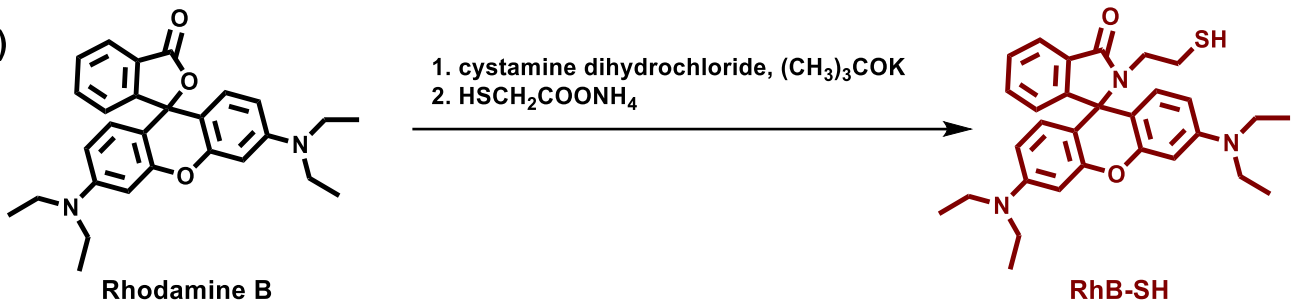

d)
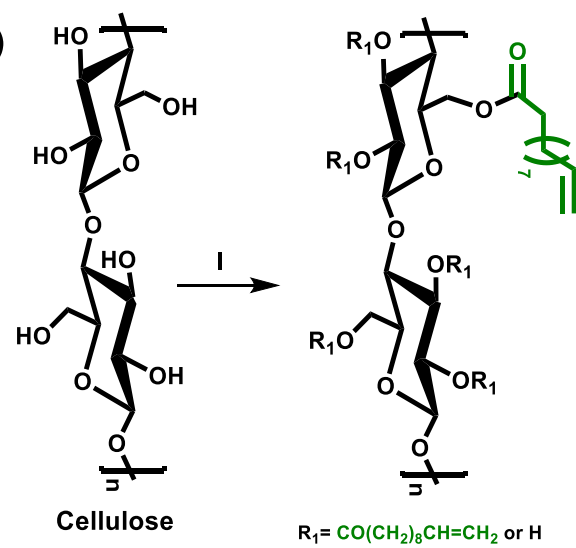

CUE

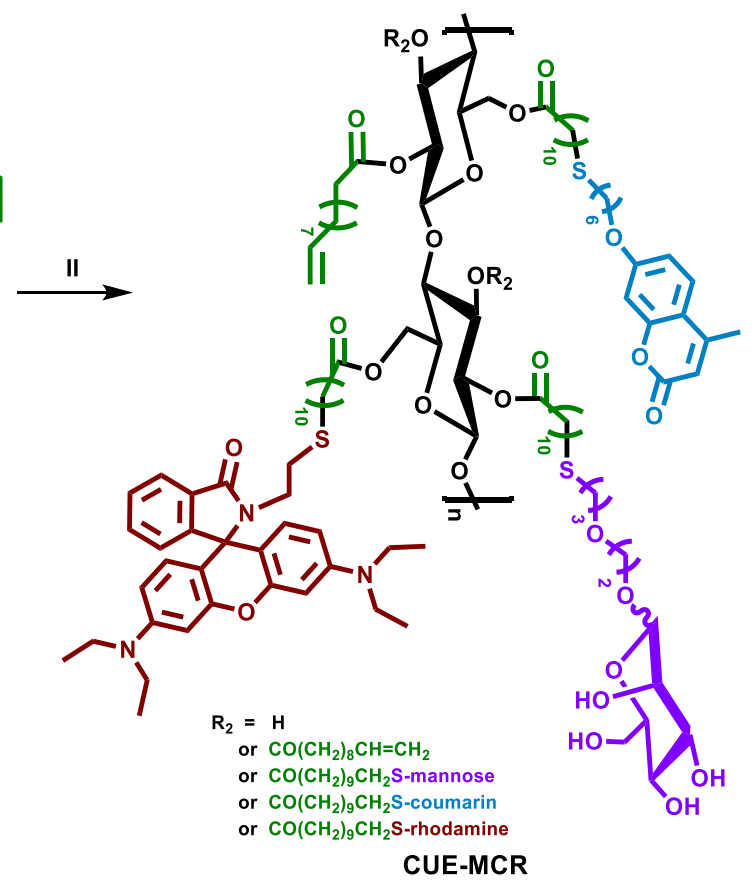

Scheme 3. Synthetic routes of a) Mann-SH; b) Coum-SH; c) RhB-SH and d)

11-(mannose-oxyethoxylpropane)(coumarin-oxyhexyl)(rhodamine-ethyl)thiolundecanoate 10-undecenoyl ester of cellulose (CUE-MCR): I) 10-undecenoyl chloride, pyridine, heating at $50{ }^{\circ} \mathrm{C}$ for 4 hours; II) Mann-SH, 320-400 nm UV irradiation for 6 hours, DMPA; then Coum-SH, RhB-SH, heating at $70{ }^{\circ} \mathrm{C}$ for 10 hours, AIBN.

The chemical structure of CUE-MCR was confirmed by FTIR, as shown in Figure 28. 
The peaks of olefin $\mathrm{C}-\mathrm{H}$ and $\mathrm{C}=\mathrm{C}$ at 3077,1639 and $907 \mathrm{~cm}^{-1}$ greatly decreased, and the peaks of $\mathrm{O}-\mathrm{H}$ and $\mathrm{C}=\mathrm{O}$ at 3483 and $1735 \mathrm{~cm}^{-1}$ broadly increased, indicating the double bonds of CUE were partially consumed and three kinds of mercapto-containing compounds were attached to the CUE. Besides, characteristic peaks of aromatic rings at 1610-1510 and $870-750 \mathrm{~cm}^{-1}$, the peak of $-\mathrm{CH}_{3}$ at $1386 \mathrm{~cm}^{-1}$, the peak of $\mathrm{N}$-aryl at $1280 \mathrm{~cm}^{-1}$ and the peak of $-\mathrm{CH}_{2}-\mathrm{S}-\mathrm{CH}_{2}-$ at 1270 and $693 \mathrm{~cm}^{-1}$ were observed. ${ }^{113,114}$

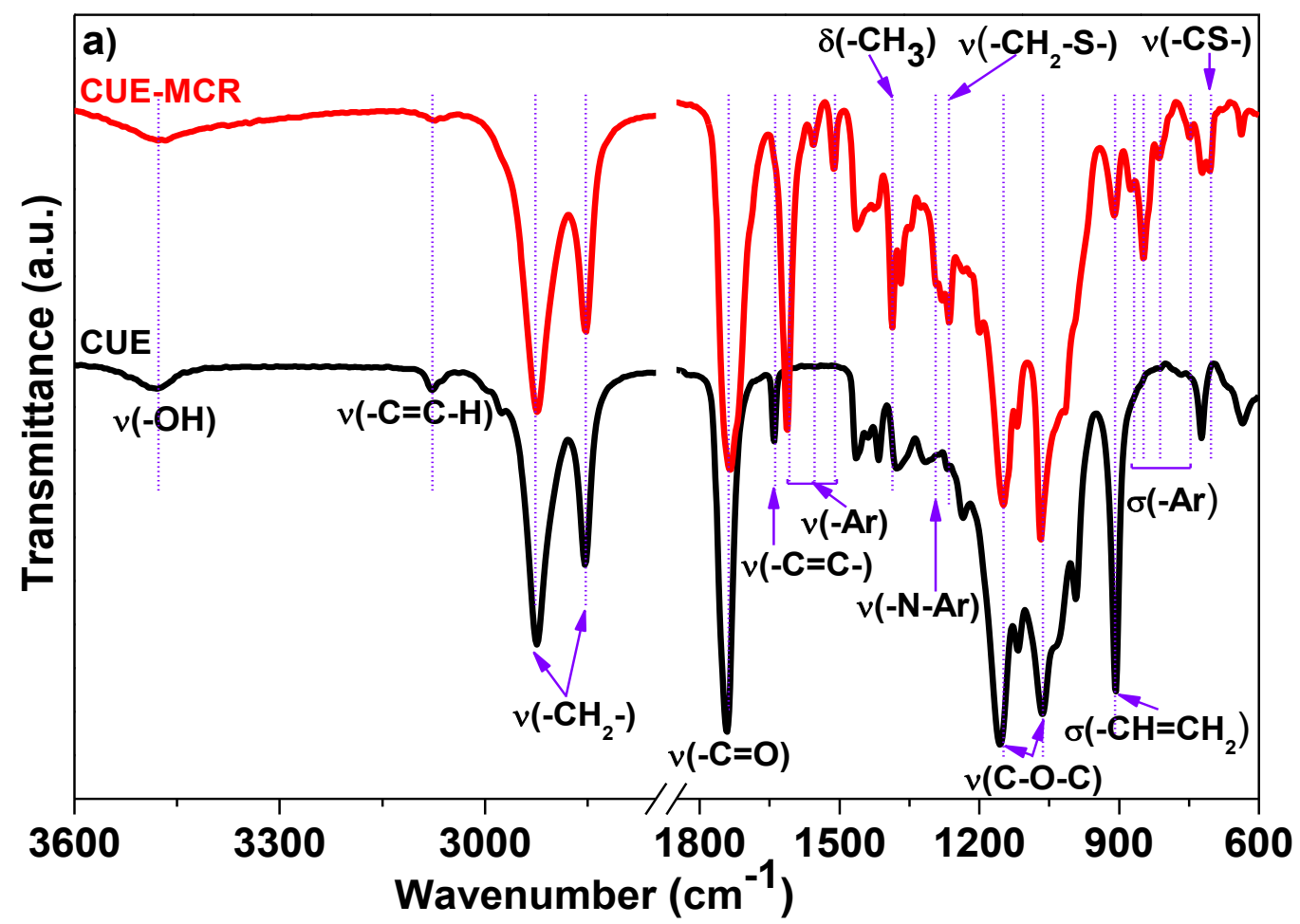

Figure 28. FTIR spectra of cellulose 10-undecenoyl ester (CUE) $\left(\mathrm{DS}_{\mathrm{C}=\mathrm{C}}=2.6\right)$ and 11-(mannose-oxyethoxylpropane)(coumarin-oxyhexyl)(rhodamine-ethyl)thiolundecanoate 10 -undecenoyl ester of cellulose $(\mathrm{CUE}-\mathrm{MCR})\left(\mathrm{DS}_{\mathrm{Mann}}=0.5, \mathrm{DS}_{\mathrm{Coum}}=1.0, \mathrm{DS}_{\mathrm{Rhod}}=0.2\right.$ and $\left.\mathrm{DS}_{\mathrm{C}=\mathrm{C}}=0.9\right)$.

The chemical structure of CUE-MCR was further confirmed by ${ }^{1} \mathrm{H}$ NMR. In Figure 29, the great decrease of olefin resonances at 4.9 and $5.8 \mathrm{ppm}$ and the appearance of new peaks assigned to aromatic protons, enone protons and protons of mannose groups at 8.0, 7.5-7.6, 6.8-7.1, 6.1, 5.4 and 3.3-3.8 ppm, respectively, revealed the most thiol-ene addition and the 
successful incorporation of mannose, coumarin and rhodamine groups. Besides, according to ${ }^{1} \mathrm{H}$ NMR spectrum of CUE-MCR, the integration of typical aromatic peak of rhodamine group at $8.0 \mathrm{ppm}$, enone peak of coumarin group at $6.1 \mathrm{ppm}$, the terminal olefin peak at 5.8 ppm and C-1 peak of mannose group at $5.4 \mathrm{ppm}$ yielded a ratio of 0.24:1.00:0.86:0.48, which was in good accordance with the result of elemental analysis.
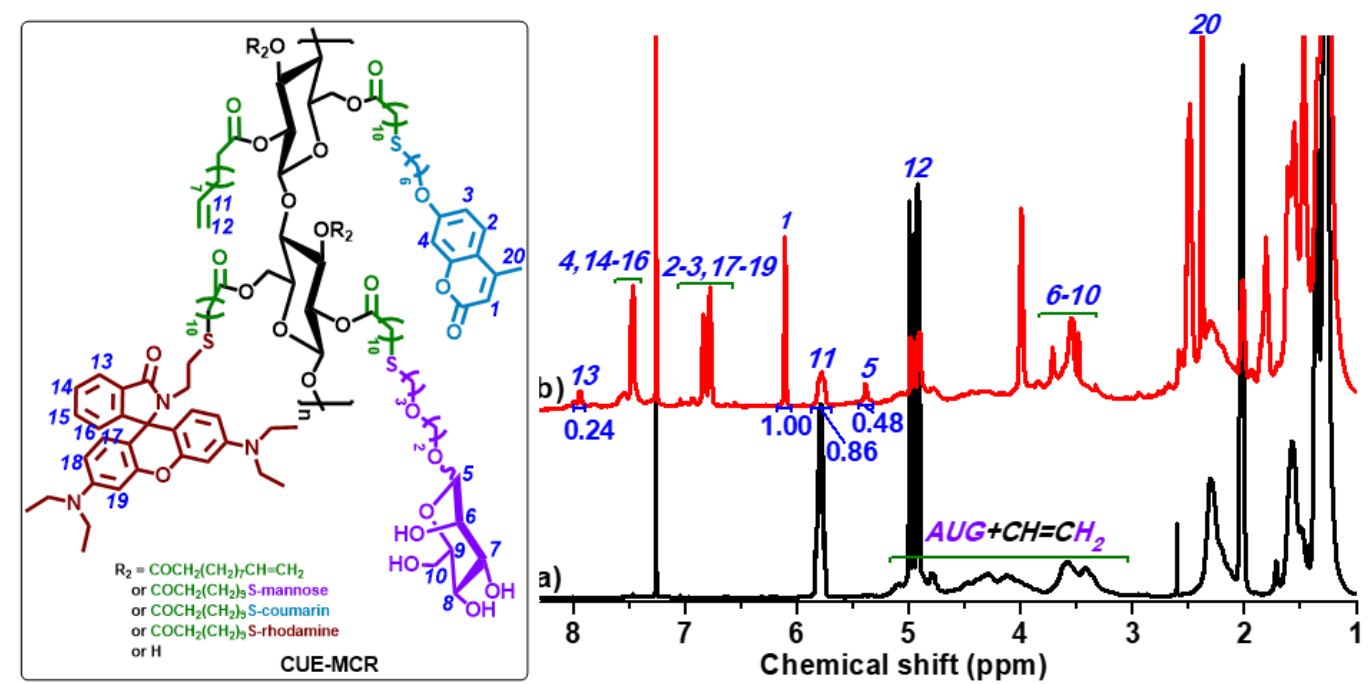

Figure 29. ${ }^{1} \mathrm{H}$ NMR spectra of a) cellulose 10 -undecenoyl ester $(\mathrm{CUE})\left(\mathrm{DS} \mathrm{C}_{\mathrm{C}=\mathrm{C}}=2.6\right)$ and $\left.\mathrm{b}\right)$ 11-(mannose-oxyethoxylpropane)(coumarin-oxyhexyl)(rhodamine-ethyl)thiolundecanoate 10 -undecenoyl ester of cellulose $(\mathrm{CUE}-\mathrm{MCR})\left(\mathrm{DS}_{\mathrm{Mann}}=0.5, \mathrm{DS}_{\mathrm{Coum}}=1.0, \mathrm{DS}_{\mathrm{Rhod}}=0.2\right.$ and $\mathrm{DS}_{\mathrm{C}=\mathrm{C}}=0.9$ ) measured in $\mathrm{CDCl}_{3}$. The numbers in the structural formula of CUE-MCR display the protons of CUE-MCR.

The CUE-MCR in THF solution was converted into NPs via nanoprecipitation (Figure 30a). When dropping CUE-MCR solution into excess DI water containing different electrolytes concentration (0, $17 \mathrm{mM}, 51 \mathrm{mM}, 85 \mathrm{mM}$ of $\mathrm{NH}_{4} \mathrm{Cl}, \mathrm{NaCl}$ and $\left.\mathrm{MgSO}_{4}\right)$, stable, milky NPs were only obtained in low ionic strength solutions $(<0.085 \mathrm{M})$, as shown in Table 1. The average size of NPs formed in pure DI water was $117.8 \pm 1.0 \mathrm{~nm}$ with broad size distribution (PDI=0.29 \pm 0.04 ). Interestingly, uniform NPs were formed in low ionic strength solution and the average sizes of NPs increased with increased ionic strengths. The average size of NPs increased due to small electrostatic screening introduced by low ionic strength but the aggregation of larger nanoparticles was prevented by electrostatic repulsion. The zeta 
potentials of the stable NPs were between -30.9 to $-35.2 \mathrm{mV}$, confirming the negative surface charges and fairly good physical stability.

Furthermore, those NPs exhibited excellent dispersion stability at high-temperature, determined by DLS measurement after incubation at $80{ }^{\circ} \mathrm{C}$ for 36 hours. The average size of NPs decreased along with decreased size distribution after aging. So high-temperature enhanced the dispersion stability of nanoparticles, which can be ascribed to increased surface negative charges. Zeta potential measurements showed that those NPs after aging became more negatively charged.

Table 1. Z-average diameters (d), PDI and zeta potential of NPs formed in aqueous electrolytes solutions of different concentrations using the CUE-MCR solution of $4 \mathrm{mg} \cdot \mathrm{mL}^{-1}$ THF.

\begin{tabular}{|c|c|c|c|c|c|c|c|}
\hline $\begin{array}{c}\text { Dispersan } \\
\mathrm{t}\end{array}$ & $\begin{array}{c}\text { Ionic } \\
\text { strength } \\
(\mathrm{M})^{\mathrm{a}}\end{array}$ & $\begin{array}{c}\mathrm{d} \text { of } \\
\text { as-prepared } \\
\text { NPs } \\
\text { (nm) }\end{array}$ & PDI & $\begin{array}{c}\text { Zeta } \\
\text { potential } \\
(\mathrm{mV})\end{array}$ & $\begin{array}{l}\mathrm{d} \text { of } \mathrm{NPs} \\
\text { at } 80^{\circ} \mathrm{C} \\
\text { for } 36 \mathrm{~h} \\
\quad(\mathrm{~nm})\end{array}$ & PDI & $\begin{array}{c}\text { Zeta } \\
\text { potential } \\
(\mathrm{mV})\end{array}$ \\
\hline DI water & 0 & $117.8 \pm 1.0$ & $0.29 \pm 0.04$ & $-31.9 \pm 0.4$ & $109.8 \pm 5.4$ & $0.26 \pm 0.01$ & $-41.2 \pm 0.6$ \\
\hline $\begin{array}{c}\mathrm{NH}_{4} \mathrm{Cl} \\
(17 \mathrm{mM})\end{array}$ & 0.017 & $239.3 \pm 1.2$ & $0.10 \pm 0.01$ & $-33.1 \pm 0.9$ & $221.9 \pm 1.2$ & $0.10 \pm 0.02$ & $-48.9 \pm 0.6$ \\
\hline $\begin{array}{c}\mathrm{NaCl} \\
(17 \mathrm{mM})\end{array}$ & 0.017 & $196.2 \pm 0.6$ & $0.08 \pm 0.04$ & $-35.0 \pm 0.5$ & $187.8 \pm 4.1$ & $0.06 \pm 0.02$ & $-50.6 \pm 0.8$ \\
\hline $\begin{array}{c}\mathrm{MgSO}_{4} \\
(17 \mathrm{mM})\end{array}$ & 0.068 & $471.4 \pm 4.7$ & $0.05 \pm 0.01$ & $-30.9 \pm 0.1$ & $443.0 \pm 2.4$ & $0.05 \pm 0.02$ & $-39.4 \pm 0.4$ \\
\hline $\begin{array}{c}\mathrm{NH}_{4} \mathrm{Cl} \\
(51 \mathrm{mM})\end{array}$ & 0.051 & $553.7 \pm 7.6$ & $0.12 \pm 0.01$ & $-35.2 \pm 0.2$ & $477.5 \pm 9.1$ & $0.08 \pm 0.04$ & $-53.3 \pm 0.8$ \\
\hline $\begin{array}{c}\mathrm{NaCl} \\
(51 \mathrm{mM})\end{array}$ & 0.051 & $491.0 \pm 4.4$ & $0.10 \pm 0.02$ & $-34.6 \pm 0.6$ & $458.5 \pm 0.3$ & $0.02 \pm 0.02$ & $-49.5 \pm 1.1$ \\
\hline
\end{tabular}

a: the data calculated according the reference ${ }^{115}$. 
The morphologies of those NPs after aging were studied by scanning electron Microscopy (SEM) (Figure 30b). The self-assembly of CUE-MCR by nanoprecipitation produced spherical NPs with a smooth surface, which remained after aging at $80{ }^{\circ} \mathrm{C}$ for 36 hours.

a)

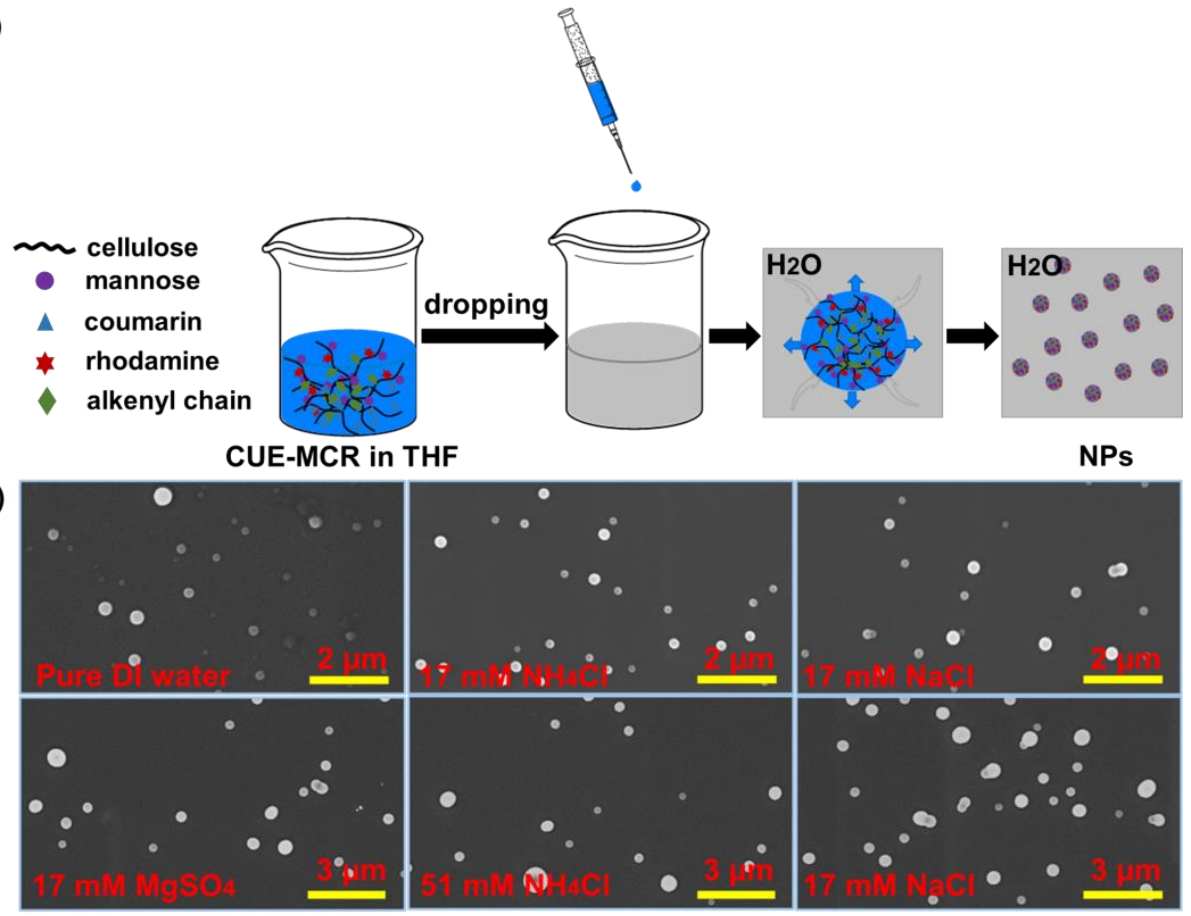

Figure 30. a) Schematic illustration for the nanoprecipitation of CUE-MCR solutions using dropping technique. Blue areas: THF, colorful chains: CUE-MCR chains. b) SEM images of obtained NPs prepared via dropping into aqueous electrolytes solutions of different concentrations after aging at $80{ }^{\circ} \mathrm{C}$ for 36 hours.

The accessibility of pendant mannose moieties on NPs of CUE-MCR was further verified via the interaction of the NPs with 1,4-benzenediboronic acid (BDBA) in alkaline aqueous solutions. As shown in Figure 31c, the NPs mixing with excess BDBA alkaline solution in sample A had good dispersion stability over a period of 100 hours at $60{ }^{\circ} \mathrm{C}$; while the NPs mixing with the same concentration $\mathrm{NaOH}$ aqueous solution in sample $\mathrm{B}$ aggregated at same condition. Moreover, the average diameter of NPs after incubated with BDBA remained and slightly increased compared to original NPs, determined by DLS measurement (Figure 31a and b). The results supported the covalent bond between mannose-containing nanoparticles and BDBA under an alkaline condition, forming boronic acid-cis diol complexes with strong 
boronate ester bonds. ${ }^{116}$ The tetrahedral boronate anions multivalently bond with clustered mannoses existing on the surface of nanoparticles, transforming nonionic NPs into anionic NPs. The negatively charged NPs had great electrostatic repulsion which can stabilize the NPs against electrostatic screening introduced by $\mathrm{NaOH}$. As shown in Figure 31d, compared with initial NPs, the zeta potentials of NPs in sample A were both greatly increased: the zeta potential of $\mathrm{NPs}$ formed in $17 \mathrm{mM} \mathrm{NH}_{4} \mathrm{Cl}$ increased from $-33.1 \mathrm{mV}$ to $-63.1 \mathrm{mV}$, and the zeta potential of NPs formed in $17 \mathrm{mM} \mathrm{MgSO}_{4}$ increased from $-30.9 \mathrm{mV}$ to $-66.6 \mathrm{mV}$. SEM images of NPs incubating with BDBA at $60{ }^{\circ} \mathrm{C}$ under an alkaline condition were shown in Figure 31e and f. The spherical morphology of mono-dispersion nanoparticles maintained but those NPs had an enhanced tendency to agglomerate over incubation time when dried.

a)

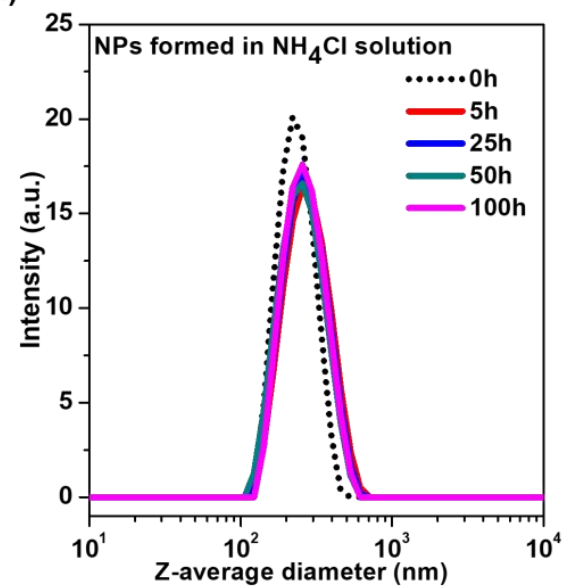

b)

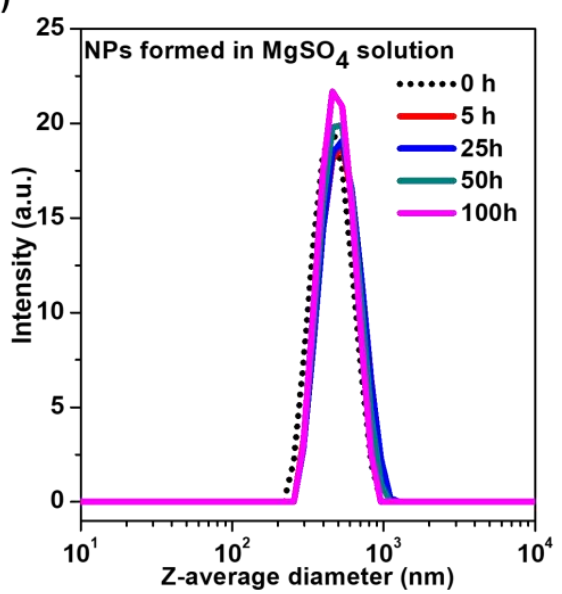

c)

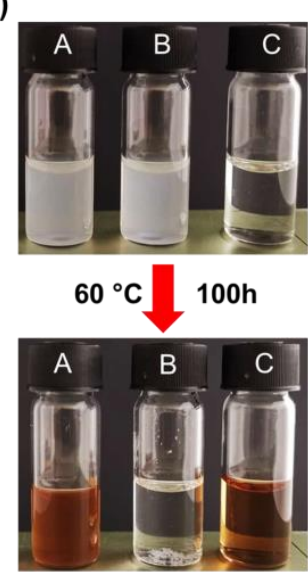

d)

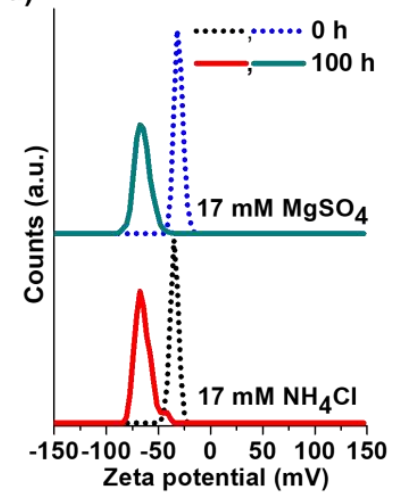

e) NPs formed in $\mathrm{NH}_{4} \mathrm{Cl}$ solution

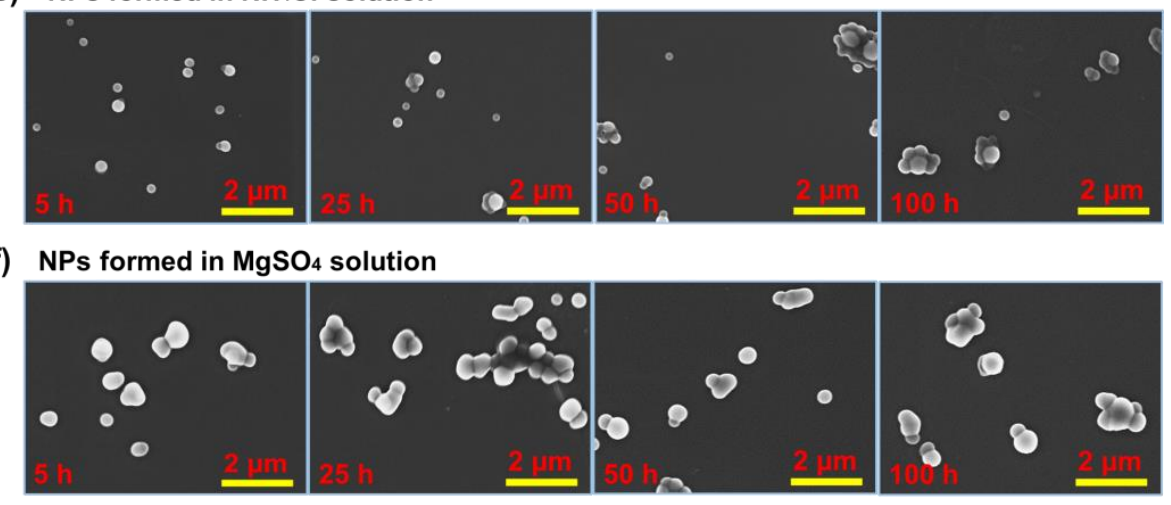

Figure 31. DLS curves and SEM images of NPs after incubation in excess BDBA alkaline solution at $60{ }^{\circ} \mathrm{C}$ for $5,25,50$ and 100 hours: a) and e) NPs formed in $17 \mathrm{mM} \mathrm{NH} 4 \mathrm{Cl}$; b) and f) NPs formed in $17 \mathrm{mM} \mathrm{MgSO}_{4}$. c) Photo image after incubation in $\mathrm{NaOH}$ solution at $60{ }^{\circ} \mathrm{C}$ for 100 hours: sample A containing NPs with excess BDBA, sample B containing NPs 
without BDBA, and sample C containing BDBA without NPs. d) Zeta potential curves of NPs after incubation.

After exposed to $320-400 \mathrm{~nm} \mathrm{UV}$, the coumarin- and rhodamine-functionalized NPs solution turned visible pink. Besides, there were an increase in the fluorescence intensity at $556 \mathrm{~nm}$ due to the structure change of rhodamine and a significant decrease at $328 \mathrm{~nm}$ due to the dimerization of the coumarins, as shown in Figure 32a-c. 320-400 nm UV light exposure was not sufficient enough to change the average diameter of NPs significantly but change the zeta potential of NPs greatly (a change from $-33.1 \pm 0.9 \mathrm{mV}$ to $-41.2 \pm 0.8 \mathrm{mV}$ ), determined by DLS measurement shown in Figure 32d and e.

a)

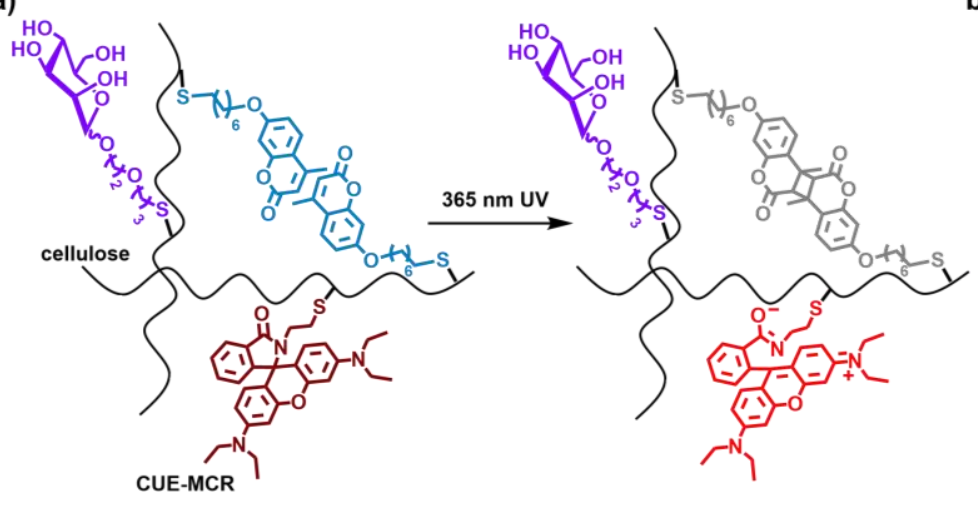

b)

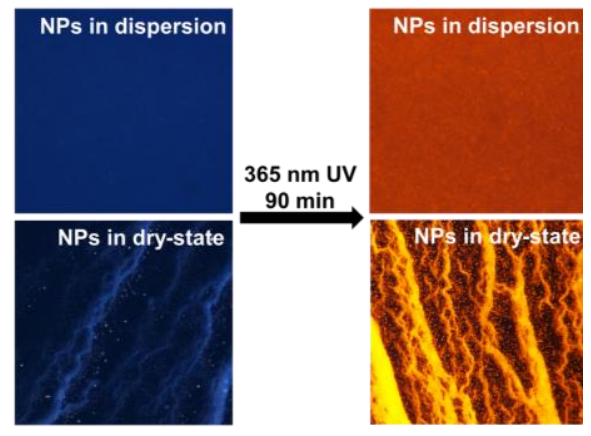

c)

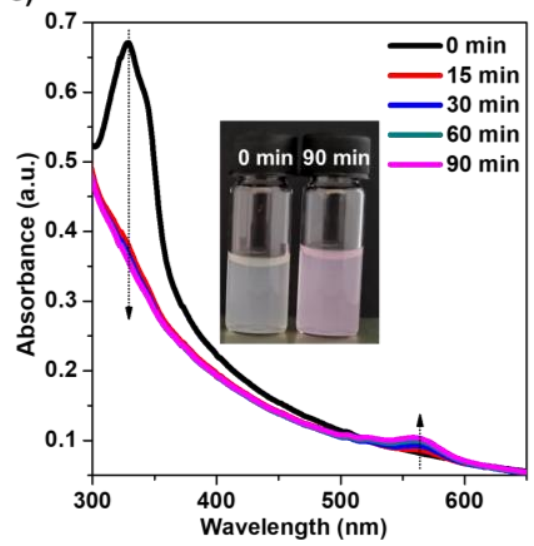

d)

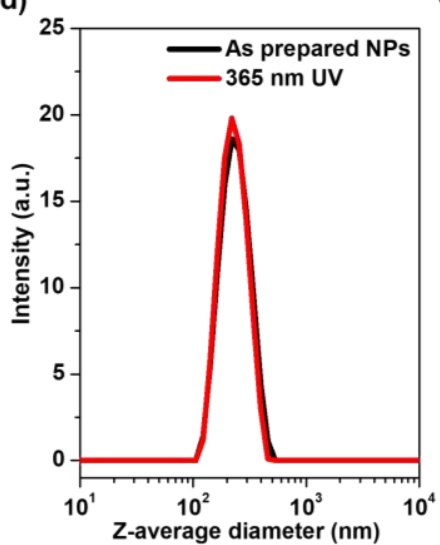

e)

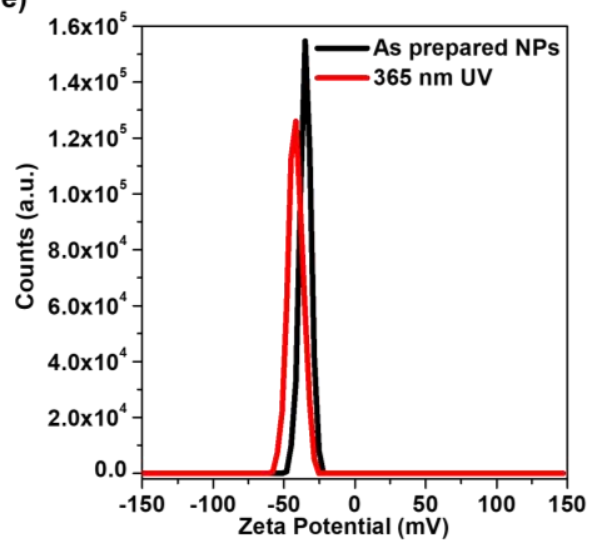

Figure 32. UV (365 nm) irradiation of NPs formed in $17 \mathrm{mM} \mathrm{NH}{ }_{4} \mathrm{Cl}$ solution for $90 \mathrm{~min}$ : a) dimerization of coumarin and structure change of rhodamine; b) fluorescent microscopy images of NPs in dispersion and in dry-state; c) UV-vis spectra, the inset showing the corresponding photographs before and after treatments. d) DLS curves of NPs before and after treatments. e) Zeta potential curves of NPs before and after treatments. 


\section{General conclusion and perspectives}

As mentioned all along with this study, the development of carbohydrate-containing compounds in the form of polymers or surfactants has attracted tremendous attention due to their applications in our daily life. Cellulose as biopolymer has many advantages, such as biocompatibility, nontoxicity, abundance and biodegradability, which can be chemically modified into multifunctional materials for expanded applications. This study particularly focused on the synthesis of carbohydrate-containing cellulose derivatives and sugar-based bola-amphiphiles.

Firstly, in Publication 1, by developing a novel oxidation reaction producing aldehyde groups, we synthesized regioselectively glycosylated and phenylboronic acid-sensitive cellulose derivatives. There were several essential reactions during the preparation: (1) the nucleophilic substitution realized the regioselective and introduced long-chain primary hydroxy groups; (2) the novel sequential TEMPO/BAIB-mediated oxidation, Schiff base formation and reduction in one-pot reaction successfully formed aldehyde groups which subsequently turned into Schiff base and then reduced to amino under mild condition. The reaction was efficient due to the high degree of substitution ascribed to the thiol group $\left(\mathrm{DS}_{\mathrm{SH}}=0.6\right)$, compared to the substance with a degree of substitution ascribed to ethanolamino groups $\left(\mathrm{DS}_{\mathrm{EA}}=0.8\right)$. This whole synthetic procedure containing the one-pot reaction avoided the potential oxidation of aldehyde groups and thiol groups, and the loss of products due to repeated washing; (3) the highly efficient thiol-ene click reaction realized the almost completely introducing of glucose moieties under the mild condition which is also beneficial to protect cellulose backbone. These glycosylated cellulose derivatives displayed significant responsive properties by binding with 1,4-benzenediboronic acid at $\mathrm{pH} 10$, and easy dissociation by extra glucose. These novel glycosylated cellulose derivatives demonstrate a novel group of stimuli-responsive modified biopolymer derivatives.

Then, in Publication 2, we turned to focus on the synthesis of sugar-based bola-amphiphiles. Compared to the last work, we synthesized more hydrophilic sugar moieties bearing terminal double bonds (2-allylethoxyl monosaccharides). Besides, we also 
synthesized UV-sensitive coumarin moieties bearing thiol groups for binding sugar moieties as well as for covalently binding sugar-based amphiphiles via dimerization. Under 320-400 nm UV irradiation, nonionic sugar-based bola-amphiphiles GCCG-12 and MCCM-12 were synthesized through the simultaneous thiol-ene click reaction and [2+2]-photodimerization reaction in one-pot. The GCCG-12 and MCCM-12 displayed reversible temperature-induced MVT in aqueous solutions just by dissolving in water and changing temperature. Due to the different saccharides as headgroups, the GCCG-12 had higher $T_{\mathrm{MVT}}$ than MCCM-12. The morphologies of micelles and vesicles had been recorded by TEM and PLM measurements. Moreover, the CHO-Bolas had chirality and recognizable binding property and further formed helical aggregates by co-assembly with BDBA during cooling-down from a high temperature. The morphologies of the helices had been observed by optical microscopy and SEM, and the chemical structures of the helices consisting of sugar-based bola-amphiphiles and BDBA had been confirmed by FTIR and solid-state ${ }^{11} \mathrm{~B}$ NMR.

Finally, in Publication 3, we continued to use the high hydrophilic sugar moieties bearing thiol groups and coumarin moieties bearing thiol groups, as well as new rhodamine moieties bearing thiol groups. Through photo-and thermal-initiated thiol-ene click reactions, the three mercapto-containing compounds had been successfully conjugated to the cellulose backbone. The obtained fluorescent cellulose derivatives bearing mannose moieties with $\mathrm{DS}_{\text {Mann }}$ of 0.5 , $\mathrm{DS}_{\mathrm{Coum}}$ of $1.0, \mathrm{DS}_{\mathrm{Rhod}}$ of 0.2 and $\mathrm{DS}_{\mathrm{C}=\mathrm{C}}$ of 0.9 had good solubility in most organic solvents and also can be converted into stable NPs via nanoprecipitation. When dropping into low ionic strength aqueous solutions $(<0.085 \mathrm{M})$, the uniformed NPs formed with average size of 196-554 nm depending on the ionic strengths, which also stable at high temperature with the assistance of increased zeta potential. The formed NPs bearing mannose moieties multivalently bond to BDBA in alkaline solution, producing anionic NPs with excellent stabilizing dispersions in $\mathrm{NaOH}$ solution even at elevated temperature. The fluorescence of the NPs bearing mannose moieties can be increased by UV irradiation, which can be suitable candidates for biomedical application.

In conclusion, the studies described in this thesis highlighted the synthesis of 
carbohydrate-containing compounds via the efficient thiol-ene click reactions and their multi-sensitive to BDBA. The novel cellulose derivatives bearing carbohydrate moieties can not only be fabricated regioselectively but also multifunctional. Moreover, the carbohydrate-containing macro-compounds even in the form of NPs can bind to BDBA with good "glycol-cluster effect", which also can recognize typical lectins or cells for further biomedical research. On the other hand, the carbohydrate-containing bola-amphiphiles displayed interesting micelle-to-vesicle transition. Furthermore, the macro-size helices formed by sugar-based bola-amphiphiles and BDBA via chirality transfer had chiral property, which could be potential catalyst applied in chemistry field in the future. 


\section{Reference}

1. Phillips, M. D.; Fyles, T. M.; Barwell, N. P.; James, T. D., Carbohydrate sensing using a fluorescent molecular tweezer. Chem. Commun. 2009, (43), 6557-6559.

2. Slavin, J. L., Resistant oligosaccharides. Handbook of dietary fiber. Marcel Dekker, New York 2001, 125-45.

3. Tian, T.; Freeman, S.; Corey, M.; German, J. B.; Barile, D., Chemical characterization of potentially prebiotic oligosaccharides in brewed coffee and spent coffee grounds. J. Agric. Food Chem. 2017, 65 (13), 2784-2792.

4. Wen, L.; Edmunds, G.; Gibbons, C.; Zhang, J.; Gadi, M. R.; Zhu, H.; Fang, J.; Liu, X.; Kong, Y.; Wang, P. G., Toward automated enzymatic synthesis of oligosaccharides. Chem. Rev. 2018, 118 (17), 8151-8187.

5. Ghazarian, H.; Idoni, B.; Oppenheimer, S. B., A glycobiology review: carbohydrates, lectins and implications in cancer therapeutics. Acta Histochem. 2011, 113 (3), 236-247.

6. Hanson, S.; Best, M.; Bryan, M. C.; Wong, C.-H., Chemoenzymatic synthesis of oligosaccharides and glycoproteins. Trends Biochem. Sci. 2004, 29 (12), 656-663.

7. Toshima, K., Novel glycosylation methods and their application to natural products synthesis. Carbohydr. Res. 2006, 341 (10), 1282-1297.

8. Gattuso, G.; Nepogodiev, S. A.; Stoddart, J. F., Synthetic cyclic oligosaccharides. Chem. Rev. 1998, 98 (5), 1919-1958.

9. Ladmiral, V.; Melia, E.; Haddleton, D. M., Synthetic glycopolymers: an overview. Eur. Polym. J. 2004, 40 (3), 431-449.

10. Shi, L., Bioactivities, isolation and purification methods of polysaccharides from natural products: A review. Int. J. Biol. Macromol. 2016, 92, 37-48.

11. Kadokawa, J.-i., Precision polysaccharide synthesis catalyzed by enzymes. Chem. Rev. 2011, 111 (7), 4308-4345.

12. Wang, Y.; Nie, J.; Fang, W.; Yang, L.; Hu, Q.; Wang, Z.; Sun, J. Z.; Tang, B. Z., Sugar-Based Aggregation-Induced Emission Luminogens: Design, Structures, and Applications. Chem. Rev. 2020. 
13. Hudson, C., Emil Fischer's discovery of the configuration of glucose. A semicentennial retrospect. J. Chem. Educ. 1941, 18 (8), 353.

14. Kunz, H., Emil Fischer - unequalled classicist, master of organic chemistry research, and inspired trailblazer of biological chemistry. Angew. Chem. Int. Ed. Engl. 2002, 41 (23), $4439-4451$.

15. Hudson, C., RELATIONS BETWEEN ROTATORY POWER AND STRUCTURE IN THE SUGAR GROUP. XXVI. THE RING STRUCTURES OF VARIOUS COMPOUND SUGARS1. J. Am. Chem. Soc. 1930, 52 (4), 1707-1718.

16. Koenigs, W.; Knorr, E., Ueber einige Derivate des Traubenzuckers und der Galactose. Ber. Dtsch. Chem. Ges. 1901, 34 (1), 957-981.

17. Igarashi, K., The Koenigs-Knorr reaction. In Adv. Carbohyd. Chem. Biochem., Elsevier: 1977; Vol. 34, pp 243-283.

18. Galonić, D. P.; Gin, D. Y., Chemical glycosylation in the synthesis of glycoconjugate antitumour vaccines. Nature 2007, 446 (7139), 1000-1007.

19. Zhu, X.; Schmidt, R. R., New principles for glycoside-bond formation. Angew. Chem. Int. Ed. 2009, 48 (11), 1900-1934.

20. Yang, Y.; Yu, B., Recent advances in the chemical synthesis of C-glycosides. Chem. Rev. 2017, 117 (19), 12281-12356.

21. Miura, Y., Synthesis and biological application of glycopolymers. J. Polym. Sci. Pol. Chem. 2007, 45 (22), 5031-5036.

22. Aoi, K.; Itoh, K.; Okada, M., Globular carbohydrate macromolecules" Sugar Balls". 1. Synthesis of novel sugar-persubstituted poly (amido amine) dendrimers. Macromolecules 1995, $28(15), 5391-5393$.

23. Sunasee, R.; Adokoh, C. K.; Darkwa, J.; Narain, R., Therapeutic potential of carbohydrate-based polymeric and nanoparticle systems. Expert Opin. Drug Deliv. 2014, 11 (6), 867-884.

24. Gestwicki, J. E.; Cairo, C. W.; Strong, L. E.; Oetjen, K. A.; Kiessling, L. L., Influencing receptor- ligand binding mechanisms with multivalent ligand architecture. J. Am. Chem. Soc. 
2002, 124 (50), 14922-14933.

25. Vázquez-Dorbatt, V.; Lee, J.; Lin, E. W.; Maynard, H. D., Synthesis of glycopolymers by controlled radical polymerization techniques and their applications. ChemBioChem 2012, 13 (17), 2478-2487.

26. Kiessling, L. L.; Grim, J. C., Glycopolymer probes of signal transduction. Chem. Soc. Rev. 2013, 42 (10), 4476-4491.

27. Ting, S. S.; Chen, G.; Stenzel, M. H., Synthesis of glycopolymers and their multivalent recognitions with lectins. Polym. Chem. 2010, 1 (9), 1392-1412.

28. Ting, S. S.; Min, E. H.; Escale, P.; Save, M.; Billon, L.; Stenzel, M. H., Lectin recognizable biomaterials synthesized via nitroxide-mediated polymerization of a methacryloyl galactose monomer. Macromolecules 2009, 42 (24), 9422-9434.

29. Granville, A. M.; Quémener, D.; Davis, T. P.; Barner-Kowollik, C.; Stenzel, M. H. In Chemo-enzymatic Synthesis and RAFT Polymerization of 6-O-Methacryloyl Mannose: A Suitable Glycopolymer for Binding to the Tetrameric Lectin Concanavalin A?, Macromol. Symp., Wiley Online Library: 2007; pp 81-89.

30. Narain, R.; Armes, S. P., Synthesis and aqueous solution properties of novel sugar methacrylate-based homopolymers and block copolymers. Biomacromolecules 2003, 4 (6), 1746-1758.

31. Audebeau, E.; Oikonomou, E. K.; Norvez, S.; Iliopoulos, I., One-pot synthesis and gelation by borax of glycopolymers in water. Polym. Chem. 2014, 5 (7), 2273-2281.

32. Nicolas, J.; Mantovani, G.; Haddleton, D. M., Living radical polymerization as a tool for the synthesis of polymer-protein/peptide bioconjugates. Macromol. Rapid Commun. 2007, 28 (10), 1083-1111.

33. Spain, S. G.; Gibson, M. I.; Cameron, N. R., Recent advances in the synthesis of well-defined glycopolymers. J. Polym. Sci., Part A: Polym. Chem. 2007, 45 (11), 2059-2072.

34. Deng, Z.; Li, S.; Jiang, X.; Narain, R., Well-defined galactose-containing multi-functional copolymers and glyconanoparticles for biomolecular recognition processes. Macromolecules 2009, 42 (17), 6393-6405. 
35. Narumi, A.; Kakuchi, T., Synthesis of glycoconjugated branched macromolecular architectures. Polym. J. 2008, 40 (5), 383-397.

36. Hořejší, V.; Smolek, P.; Kocourek, J., Studies on lectins XXXV. Water-soluble O-glycosyl polyacrylamide derivatives for specific precipitation of lectins. Biochim. Biophys. Acta, Gen. Subj. 1978, 538 (2), 293-298.

37. Furuike, T.; Nishi, N.; Tokura, S.; Nishimura, S.-I., Synthetic glycoconjugates. 6. Preparation and biochemical evaluation of novel cluster-type glycopolymers containing Gal. beta.(1. fwdarw. 4) GlcNAc (N-Acetyllactosamine) residue. Macromolecules 1995, 28 (21), $7241-7247$.

38. Mortell, K. H.; Weatherman, R. V.; Kiessling, L. L., Recognition specificity of neoglycopolymers prepared by ring-opening metathesis polymerization. J. Am. Chem. Soc. 1996, 118 (9), 2297-2298.

39. Manning, D. D.; Hu, X.; Beck, P.; Kiessling, L. L., Synthesis of sulfated neoglycopolymers: selective P-selectin inhibitors. J. Am. Chem. Soc. 1997, 119 (13), 3161-3162.

40. Mortell, K. H.; Gingras, M.; Kiessling, L. L., Synthesis of cell agglutination inhibitors by aqueous ring-opening metathesis polymerization. J. Am. Chem. Soc. 1994, 116 (26), 12053-12054.

41. Cairo, C. W.; Gestwicki, J. E.; Kanai, M.; Kiessling, L. L., Control of multivalent interactions by binding epitope density. J. Am. Chem. Soc. 2002, 124 (8), 1615-1619.

42. Moad, G.; Rizzardo, E.; Thang, S. H., Toward living radical polymerization. Acc. Chem. Res. 2008, 41 (9), 1133-1142.

43. Charleux, B.; Nicolas, J., Water-soluble SG1-based alkoxyamines: A breakthrough in controlled/living free-radical polymerization in aqueous dispersed media. Polymer 2007, 48 (20), 5813-5833.

44. Becer, C. R., The glycopolymer code: synthesis of glycopolymers and multivalent carbohydrate-lectin interactions. Macromol. Rapid Commun. 2012, 33 (9), 742-752.

45. Babiuch, K.; Wyrwa, R.; Wagner, K.; Seemann, T.; Hoeppener, S.; Becer, C. R.; Linke, 
R.; Gottschaldt, M.; Weisser, J. r.; Schnabelrauch, M., Functionalized, biocompatible coating for superparamagnetic nanoparticles by controlled polymerization of a thioglycosidic monomer. Biomacromolecules 2011, 12 (3), 681-691.

46. Grande, D.; Baskaran, S.; Chaikof, E. L., Glycosaminoglycan mimetic biomaterials. 2. Alkene-and acrylate-derivatized glycopolymers via cyanoxyl-mediated free-radical polymerization. Macromolecules 2001, 34 (6), 1640-1646.

47. Baskaran, S.; Grande, D.; Sun, X.-L.; Yayon, A.; Chaikof, E. L., Glycosaminoglycan-mimetic biomaterials. 3. Glycopolymers prepared from alkene-derivatized mono-and disaccharide-based glycomonomers. Bioconjug. Chem. 2002, $13(6), 1309-1313$.

48. Sun, X.-L.; Faucher, K. M.; Houston, M.; Grande, D.; Chaikof, E. L., Design and synthesis of biotin chain-terminated glycopolymers for surface glycoengineering. J. Am. Chem. Soc. 2002, 124 (25), 7258-7259.

49. Narain, R.; Armes, S. P., Synthesis of low polydispersity, controlled-structure sugar methacrylate polymers under mild conditions without protecting group chemistry. Chem. Commun. 2002, (23), 2776-2777.

50. Narain, R.; Armes, S. P., Direct synthesis and aqueous solution properties of well-defined cyclic sugar methacrylate polymers. Macromolecules 2003, 36 (13), 4675-4678.

51. Ohno, K.; Tsujii, Y.; Fukuda, T., Synthesis of a well-defined glycopolymer by atom transfer radical polymerization. J. Polym. Sci., Part A: Polym. Chem. 1998, 36 (14), $2473-2481$.

52. Bernard, J.; Hao, X.; Davis, T. P.; Barner-Kowollik, C.; Stenzel, M. H., Synthesis of various glycopolymer architectures via RAFT polymerization: from block copolymers to stars. Biomacromolecules 2006, 7 (1), 232-238.

53. Gauthier, M. A.; Gibson, M. I.; Klok, H. A., Synthesis of functional polymers by post-polymerization modification. Angew. Chem. Int. Ed. 2009, 48 (1), 48-58.

54. Kobayashi, K.; Tsuchida, A.; Usui, T.; Akaike, T., A new type of artificial glycoconjugate polymer: a convenient synthesis and its interaction with lectins. Macromolecules 1997, 30 (7), 
2016-2020.

55. Martínez, G.; Fernández-García, M.; Sánchez-Chaves, M., Synthesis and characterization of N-vinylpyrrolidone-tert-butyl methacrylate-methacrylic acid terpolymers having amino sugar or bioactive amino side compounds. J. Polym. Sci., Part A: Polym. Chem. 2005, 43 (1), $18-27$.

56. Bahulekar, R.; Tokiwa, T.; Kano, J.; Matsumura, T.; Kojima, I.; Kodama, M., Polyacrylamide containing sugar residues: synthesis, characterization and cell compatibility studies. Carbohydr. Polym. 1998, 37 (1), 71-78.

57. Strong, L. E.; Kiessling, L. L., A general synthetic route to defined, biologically active multivalent arrays. J. Am. Chem. Soc. 1999, 121 (26), 6193-6196.

58. Baek, M. G.; Roy, R., Relative Lectin Binding Properties of T-Antigen-Containing Glycopolymers: Copolymerization of N-Acryloylated T-Antigen Monomer vs. Graft Conjugation of Aminated T-Antigen Ligands onto Poly (N-acryloxysuccinimide). Macromol. Biosci. 2001, 1 (7), 305-311.

59. Li, N. N.; Cai, X. Y.; Chen, J. C.; Hu, X. F.; Xu, L. Q., Conjugation of Lectin to Poly (E-caprolactone)-block-glycopolymer Micelles for In Vitro Intravesical Drug Delivery. Polymers 2016, 8 (11), 379.

60. Chen, Y.; Espeel, P.; Reinicke, S.; Du Prez, F. E.; Stenzel, M. H., Control of Glycopolymer Nanoparticle Morphology by a One-Pot, Double Modification Procedure Using Thiolactones. Macromol. Rapid Commun. 2014, 35 (12), 1128-1134.

61. Kolb, H. C.; Finn, M.; Sharpless, K. B., Click chemistry: diverse chemical function from a few good reactions. Angew. Chem. Int. Ed. 2001, 40 (11), 2004-2021.

62. Kolb, H. C.; Sharpless, K. B., The growing impact of click chemistry on drug discovery. Drug Discov. Today 2003, 8 (24), 1128-1137.

63. Slavin, S.; Burns, J.; Haddleton, D. M.; Becer, C. R., Synthesis of glycopolymers via click reactions. Eur. Polym. J. 2011, 47 (4), 435-446.

64. Hoyle, C. E.; Bowman, C. N., Thiol-ene click chemistry. Angew. Chem. Int. Ed. 2010, 49 (9), 1540-1573. 
65. Diehl, C.; Schlaad, H., Thermo-responsive polyoxazolines with widely tuneable LCST. Macromol. Biosci. 2009, 9 (2), 157-161.

66. Semsarilar, M.; Ladmiral, V.; Perrier, S., Highly branched and hyperbranched glycopolymers via reversible addition- fragmentation chain transfer polymerization and click chemistry. Macromolecules 2010, 43 (3), 1438-1443.

67. Lu, Z.; Mei, L.; Zhang, X.; Wang, Y.; Zhao, Y.; Li, C., Water-soluble BODIPY-conjugated glycopolymers as fluorescent probes for live cell imaging. Polym. Chem. 2013, 4 (24), 5743-5750.

68. Pfaff, A.; Schallon, A.; Ruhland, T. M.; Majewski, A. P.; Schmalz, H.; Freitag, R.; Müller, A. H., Magnetic and fluorescent glycopolymer hybrid nanoparticles for intranuclear optical imaging. Biomacromolecules 2011, 12 (10), 3805-3811.

69. Wang, K.; Zhang, X.; Zhang, X.; Yang, B.; Li, Z.; Zhang, Q.; Huang, Z.; Wei, Y., Fluorescent Glycopolymer Nanoparticles Based on Aggregation-Induced Emission Dyes: Preparation and Bioimaging Applications. Macromol. Chem. Phys. 2015, 216 (6), 678-684.

70. Wang, K.; Zhang, X.; Zhang, X.; Yang, B.; Li, Z.; Zhang, Q.; Huang, Z.; Wei, Y., Red fluorescent cross-linked glycopolymer nanoparticles based on aggregation induced emission dyes for cell imaging. Polym. Chem. 2015, 6 (8), 1360-1366.

71. Rabuka, D.; Forstner, M. B.; Groves, J. T.; Bertozzi, C. R., Noncovalent cell surface engineering: incorporation of bioactive synthetic glycopolymers into cellular membranes. $J$. Am. Chem. Soc. 2008, 130 (18), 5947-5953.

72. Ringsdorf, H. In Structure and properties of pharmacologically active polymers, J. Polym. Sci. Polym. Symp., Wiley Online Library: 1975; pp 135-153.

73. Pasut, G.; Veronese, F., Polymer-drug conjugation, recent achievements and general strategies. Prog. Polym. Sci. 2007, 32 (8-9), 933-961.

74. Hashida, M.; Hirabayashi, H.; Nishikawa, M.; Takakura, Y., Targeted delivery of drugs and proteins to the liver via receptor-mediated endocytosis. J. Control. Release 1997, 46 (1-2), 129-137.

75. Fleming, C.; Maldjian, A.; Da Costa, D.; Rullay, A. K.; Haddleton, D. M.; St John, J.; 
Penny, P.; Noble, R. C.; Cameron, N. R.; Davis, B. G., A carbohydrate-antioxidant hybrid polymer reduces oxidative damage in spermatozoa and enhances fertility. Nat. Chem. Biol. 2005, 1 (5), 270-274.

76. Estroff, L. A.; Hamilton, A. D., Water gelation by small organic molecules. Chem. Rev. 2004, 104 (3), 1201-1218.

77. von Rybinski, W., Alkyl glycosides and polyglycosides. Curr. Opin. Colloid Interface Sci. 1996, 1 (5), 587-597.

78. Aveyard, R.; Binks, B.; Chen, J.; Esquena, J.; Fletcher, P.; Buscall, R.; Davies, S., Surface and colloid chemistry of systems containing pure sugar surfactant. Langmuir 1998, 14 (17), 4699-4709.

79. Hill, K.; Rhode, O., Sugar-based surfactants for consumer products and technical applications. Lipid/Fett 1999, 101 (1), 25-33.

80. Förster, T.; Hensen, H.; Hofmann, R.; Salka, B., Using alkyl polyglycosides in personal-care products. Cosmetics Toiletries 1995, 110 (4), 23-29.

81. Busch, P.; Hensen, H.; Tesmann, H., Alkylpolyglycosides-a new surfactant generation for cosmetic products. Tenside Surfact. Det. 1993, 30, 116-121.

82. Hierrezuelo, J.; Aguiar, J.; Ruiz, C. C., Interactions in binary mixed systems involving a sugar-based surfactant and different n-alkyltrimethylammonium bromides. J. Colloid Interface Sci. 2006, 294 (2), 449-457.

83. Menger, F. M.; Littau, C., Gemini-surfactants: synthesis and properties. J. Am. Chem. Soc. 1991, 113 (4), 1451-1452.

84. Menger, F. M.; Keiper, J. S., Gemini surfactants. Angew. Chem. Int. Ed. 2000, 39 (11), 1906-1920.

85. Pestman, J. M.; Terpstra, K. R.; Stuart, M. C.; van Doren, H. A.; Brisson, A.; Kellogg, R. M.; Engberts, J. B., Nonionic bolaamphiphiles and gemini surfactants based on carbohydrates. Langmuir 1997, 13 (25), 6857-6860.

86. Johnsson, M.; Wagenaar, A.; Stuart, M. C.; Engberts, J. B., Sugar-based gemini surfactants with $\mathrm{pH}$-dependent aggregation behavior: vesicle-to-micelle transition, critical 
micelle concentration, and vesicle surface charge reversal. Langmuir 2003, 19 (11), $4609-4618$.

87. Yoshimura, T.; Ishihara, K.; Esumi, K., Sugar-based gemini surfactants with peptide bonds synthesis, adsorption, micellization, and biodegradability. Langmuir 2005, 21 (23), 10409-10415.

88. Johnsson, M.; Wagenaar, A.; Engberts, J. B., Sugar-based gemini surfactant with a vesicle-to-micelle transition at acidic $\mathrm{pH}$ and a reversible vesicle flocculation near neutral $\mathrm{pH}$. J. Am. Chem. Soc. 2003, 125 (3), 757-760.

89. Wasungu, L.; Scarzello, M.; van Dam, G.; Molema, G.; Wagenaar, A.; Engberts, J. B.; Hoekstra, D., Transfection mediated by $\mathrm{pH}$-sensitive sugar-based gemini surfactants; potential for in vivo gene therapy applications. J. Mol. Med. 2006, 84 (9), 774.

90. Fielden, M. L.; Perrin, C.; Kremer, A.; Bergsma, M.; Stuart, M. C.; Camilleri, P.; Engberts, J. B., Sugar-based tertiary amino gemini surfactants with a vesicle-to-micelle transition in the endosomal $\mathrm{pH}$ range mediate efficient transfection in vitro. Eur. J. Biochem. 2001, 268 (5), 1269-1279.

91. Bell, P. C.; Bergsma, M.; Dolbnya, I. P.; Bras, W.; Stuart, M. C.; Rowan, A. E.; Feiters, M. C.; Engberts, J. B., Transfection mediated by gemini surfactants: engineered escape from the endosomal compartment. J. Am. Chem. Soc. 2003, 125 (6), 1551-1558.

92. Kirby, A. J.; Camilleri, P.; Engberts, J. B.; Feiters, M. C.; Nolte, R. J.; Söderman, O.; Bergsma, M.; Bell, P. C.; Fielden, M. L.; García Rodríguez, C. L., Gemini surfactants: new synthetic vectors for gene transfection. Angew. Chem. Int. Ed. 2003, 42 (13), 1448-1457.

93. Drummond, D. C.; Zignani, M.; Leroux, J.-C., Current status of pH-sensitive liposomes in drug delivery. Prog. Lipid Res. 2000, 5 (39), 409-460.

94. Kamal, M. S., A review of gemini surfactants: potential application in enhanced oil recovery. J. Surfactants Deterg. 2016, 19 (2), 223-236.

95. Escamilla, G. H.; Newkome, G. R., Bolaamphiphiles: from golf balls to fibers. Angew. Chem. Int. Ed. Engl. 1994, 33 (19), 1937-1940.

96. Munoz, S.; Mallen, J.; Nakano, A.; Chen, Z.; Gay, I.; Echegoyen, L.; Gokel, G. W., 
Ultrathin monolayer lipid membranes from a new family of crown ether-based bola-amphiphiles. J. Am. Chem. Soc. 1993, 115 (5), 1705-1711.

97. Kobayashi, H.; Koumoto, K.; Jung, J. H.; Shinkai, S., Sol-gel phase transition induced by fiber-vesicle structural changes in sugar-based bolaamphiphiles. J. Chem. Soc. Perkin Trans. 2 2002, (11), 1930-1936.

98. Jung, J. H.; Rim, J. A.; Cho, E. J.; Lee, S. J.; Jeong, I. Y.; Kameda, N.; Masuda, M.; Shimizu, T., Stabilization of an asymmetric bolaamphiphilic sugar-based crown ether hydrogel by hydrogen bonding interaction and its sol-gel transcription. Tetrahedron 2007, 63 (31), 7449-7456.

99. Gubitosi, M.; Travaglini, L.; D’Annibale, A.; Pavel, N. V.; Vázquez Tato, J.; Obiols-Rabasa, M.; Sennato, S.; Olsson, U.; Schillén, K.; Galantini, L., Sugar-bile acid-based bolaamphiphiles: from scrolls to monodisperse single-walled tubules. Langmuir 2014, 30 (22), 6358-6366.

100. Shimizu, T.; Masuda, M., Stereochemical effect of even- odd connecting links on supramolecular assemblies made of 1-glucosamide bolaamphiphiles. J. Am. Chem. Soc. 1997, $119(12), 2812-2818$

101. Abraham, S.; Paul, S.; Narayan, G.; Prasad, S. K.; Rao, D. S.; Jayaraman, N.; Das, S., Observation of a Chiral Smectic Phase in Azobenzene-Linked Bolaamphiphiles Containing Free Sugars. Adv. Funct. Mater. 2005, 15 (10), 1579-1584.

102. Lee, J. H.; Ahn, J.; Masuda, M.; Jaworski, J.; Jung, J. H., Reinforcement of a sugar-based Bolaamphiphile/functionalized Graphene oxide composite gel: rheological and electrochemical properties. Langmuir 2013, 29 (44), 13535-13541.

103. de Paiva, D. P. S., Cationic nano-systems for DNA transfection. 2013.

104. Luzuriaga-Loaiza, W. P.; Schellenberger, R.; De Gaetano, Y.; Akong, F. O.; Villaume, S.; Crouzet, J.; Haudrechy, A.; Baillieul, F.; Clément, C.; Lins, L., Synthetic Rhamnolipid Bolaforms trigger an innate immune response in Arabidopsis thaliana. Sci. Rep. 2018, 8 (1), $1-13$.

105. Deleu, M.; Gatard, S.; Payen, E.; Lins, L.; Nott, K.; Flore, C.; Thomas, R.; Paquot, 
M.; Bouquillon, S., D-xylose-based bolaamphiphiles: Synthesis and influence of the spacer nature on their interfacial and membrane properties. C. R. Chim. 2012, 15 (1), 68-74.

106. Gatard, S.; Nasir, M. N.; Deleu, M.; Klai, N.; Legrand, V.; Bouquillon, S., Bolaamphiphiles derived from alkenyl L-rhamnosides and alkenyl D-xylosides: importance of the hydrophilic head. Molecules 2013, 18 (5), 6101-6112.

107. Nasir, M. N.; Crowet, J.-M.; Lins, L.; Akong, F. O.; Haudrechy, A.; Bouquillon, S.; Deleu, M., Interactions of sugar-based bolaamphiphiles with biomimetic systems of plasma membranes. Biochimie 2016, 130, 23-32.

108. Kobayashi, H.; Koumoto, K.; Jung, J. H.; Shinkai, S., Sol-gel phase transition induced by fiber-vesicle structural changes in sugar-based bolaamphiphiles. J. Chem. Soc. Perkin Trans. 2. 2002, (11), 1930-1936.

109. Santucci, L.; Gilman, H., Some Bromine-containing and Sulfur-containing Aromatic Bornic Acids. J. Am. Chem. Soc. 1958, 80 (1), 193-196.

110. Snyder, H.; Konecky, M. S.; Lennarz, W., Aryl boronic acids. ii. aryl boronic anhydrides and their amine complexes1. J. Am. Chem. Soc. 1958, 80 (14), 3611-3615.

111. Smith, M. K.; Northrop, B. H., Vibrational properties of boroxine anhydride and boronate ester materials: Model systems for the diagnostic characterization of covalent organic frameworks. Chemistry of Materials 2014, 26 (12), 3781-3795.

112.Rambo, B. M.; Lavigne, J. J., Defining self-assembling linear oligo (dioxaborole) s. Chemistry of materials 2007, 19 (15), 3732-3739.

113.Khan, M. A.; Siddiqui, M. R.; Otero, M.; Alshareef, S. A.; Rafatullah, M., Removal of rhodamine $\mathrm{b}$ from water using a solvent impregnated polymeric dowex $5 \mathrm{wx} 8$ resin: Statistical optimization and batch adsorption studies. Polymers 2020, 12 (2), 500.

114.Wang, S.; Zhang, K., Glycosylated cellulose derivatives with regioselective distributions of pendant glucose moieties. Carbohydr. Polym. 2018, 196, 154-161.

115.Levit, S. L.; Walker, R. C.; Tang, C., Rapid, Single-Step Protein Encapsulation via Flash NanoPrecipitation. Polymers 2019, 11 (9), 1406.

116.Nishiyabu, R.; Kubo, Y.; James, T. D.; Fossey, J. S., Boronic acid building blocks: tools 
for sensing and separation. Chem. Commun. 2011, 47 (4), 1106-1123. 


\section{Appendix}

Author's peer-reviewed publications 


\section{Publication 1}

Glycosylated cellulose derivatives with regioselective distributions of pendant glucose moieties

Shuang Wang, Kai Zhang*

Wood Technology and Wood Chemistry, Georg-August-Universität Göttingen, Büsgenweg 4, D-37077 Göttingen, Germany.

*Corresponding authors. E-mail: kzhang1@uni-goettingen.de

\section{Originally published in:}

Carbohydrate Polymers

Doi.org/10.1016/j.carbpol.2018.05.036

Received: March 7, 2018; Revised: April 26, 2018; Accepted: May 12, 2018; Available online: May 17, 2018. 


\title{
Glycosylated cellulose derivatives with regioselective distributions of pendant glucose moieties
}

\author{
Shuang Wang, Kai Zhang* \\ Wood Technology and Wood Chemistry, Georg-August-Universität Göttingen, Büsgenweg 4, D-37077 Göttingen, Germany
}

\section{A R T I C L E I N F O}

\section{Keywords:}

Cellulose derivatives

Oxidation

Glucosyl

One-pot reaction

\begin{abstract}
A B S T R A C T
Inspired by the presence of diverse carbohydrates on the surface of biological systems, we present herein a method for the synthesis of sugar-bearing polymers derived from renewable cellulose. In this paper, novel glycosylated cellulose derivatives were successfully synthesized containing a series of subsequent reactions: (1) synthesis of cellulose derivatives with pendant hydroxyl groups via nucleophilic substitution; (2) further sequential reactions containing a novel TEMPO/[bis(acetoxy)iodo]benzene (BAIB)-mediated oxidation of pendant hydroxyl groups, Schiff base formation and reduction in one-pot reaction; and (3) thiol-ene click reaction as an efficient tool to generate cellulose derivatives with pendant glucosyl groups. Furthermore, the glucosyl groups were only linked with the C6 position of anhydroglucose units (AGUs) of cellulose. Moreover, the glycosylated cellulose derivatives could be reversibly cross-linked by 1,4-phenylenediboronic acid at pH 10 and dissociated into single polymer chains by using glucose, which allow such glycolated cellulose derivatives to be interesting responsive materials.
\end{abstract}

\section{Introduction}

In nature, carbohydrates on the cell surface perform key regulatory functions in biological and pathological processes, including innate immunity, cell adhesion, cellular communications, cancer metastasis, and so on (Paszek et al., 2014; Takano, Muchmore, \& W-Dennis, 1994). Over the past decades, carbohydrate-containing polymers mimicking native glycosylated macromolecules have been successfully synthesized, which are referred to as "glycopolymers" (Wang, Dordick, \& Linhardt, 2002). These glycopolymers have wide potential applications in biomedicine and materials science, such as for binding to lectins, for specific self-assembled nanostructures, for stimuli-responsive materials, and so on (Diaz-Dussan et al., 2017; Geng et al., 2007; Godula \& Bertozzi, 2010; Ladmiral et al., 2006; Muller, Despras, \& Lindhorst, 2016). Glycopolymers are mainly synthesized in two facile manners: via polymerization of sugar-containing monomers (Grande, Baskaran, Baskaran, Gnanou, \& Chaikof, 2000; Gupta, Raja, Kaltgrad, Strable, \& Finn, 2005; Pati et al., 2012) and through conjugation of pre-modified sugars to polymer backbones (Godula et al., 2009; Wu et al., 2017; You \& Schlaad, 2006). In the latter method, the polymer backbones mostly refer to synthetic polymers, while only few contained native molecules as backbone, such as peptides (Sprengard, Schudok, Schmidt, Kretzschmar, \& Kunz, 1996; Toyokuni et al., 1994; Wang \& Kiick, 2005) and oligosaccharide (Kamitakahara et al., 1998). Only as an example, a series of cyclodextrin-based glycoconjugates have been reported, which showed promising applications in biomedicine (Zhang et al., 2014). However, only very few reports about using polysaccharides as backbone for the introduction of pendant sugar moieties are known, e.g. using chitosan as backbone (Koshiji et al., 2016).

As the most abundant renewable biopolymer on earth, cellulose has been broadly used for more than one century (Klemm, Heublein, Fink, \& Bohn, 2005). In recent years, scientists around the world have devoted themselves to seeking new methods to covalently conjugate fluorescent dyes and other moieties onto cellulose and cellulose-derived nanostructures, while maintaining their favorable characteristics (Nielsen, Eyley, Thielemans, \& Aylott, 2010). Cellulosic materials with sensing capabilities have charming biomedical applications such as for bioimaging, drug delivery and gene transfection (Czaja, Young, Kawecki, \& Brown, 2007; Dong \& Roman, 2007; Song et al., 2010).

Cellulose is a polysaccharide with $\beta$ - $(1 \rightarrow 4)$-linked AGUs and three hydroxyl groups are present in each AGU (Heinze, 1998). Chemical derivatization demonstrates an important approach for tuning the physical and chemical properties of cellulose. Traditional modification methods generally involve esterification, etherification, oxidation reaction and nucleophilic displacement reaction, taking the advantage of easy access to reagents and the straightforwardness of the reactions (Dong \& Roman, 2007; Heinze, Koschella, Magdaleno-Maiza, \& Ulrich, 2001; Heinze et al., 2011). However, harsh conditions, long reaction

\footnotetext{
* Corresponding author.

E-mail address: kzhang1@uni-goettingen.de (K. Zhang).
} 
times and modest yields are associated with these conventional methods. In comparison, formation of Schiff base and "click chemistry" that was firstly proposed by K. B. Sharpless and his coworkers in 2001 (Kolb, Finn, \& Sharpless, 2001) represent two groups of efficient reactions under mild conditions. In particular, "click chemistry" techniques including thiol-ene, thiol-Michael addition and azide-alkyne Huisgen cycloaddition, have been widely used in polysaccharide chemistry due to its high chemoselectivity in mild surroundings (Breitenbach, Schmid, \& Wich, 2017; Jirawutthiwongchai, Krause, Draeger, \& Chirachanchai, 2013; Maleki, Edlund, \& Albertsson, 2015; Meng \& Edgar, 2016).

Herein, we describe a newly designed approach to construct novel glycosylated cellulose derivatives via nucleophilic displacement $\left(S_{N}\right)$ reaction, TEMPO/BAIB-mediated oxidation and subsequent UV-initiated thiol-ene click reaction. Due to the insolubility of cellulose in most solvents, homogenous esterification including carbanilation was used to enhance the solubility of cellulose derivatives. The primary hydroxyl groups were introduced in C6 position by nucleophilic substitution on the tosyl groups, which further allowed the one-pot reaction containing oxidation, Schiff base formation and reduction leading to free thiol groups. After further thiol-ene click reaction, glucosyl groups were introduced onto cellulose backbone, leading to glycosylated cellulose derivatives with reversible responsive properties.

\section{Experimental}

\subsection{Materials}

Microcrystalline cellulose (MCC) with the average size of $50 \mu \mathrm{m}$ from Sigma-Aldrich (Steinheim, Germany) was dried at $80^{\circ} \mathrm{C}$ under the vacuum of less than $133 \mathrm{~Pa}$ for $24 \mathrm{~h}$ before use. $p$-Toluenesulfonyl chloride, 2,2,6,6-tetramethylpiperidine 1-oxyl (TEMPO), phenyl isocyanate, cysteamine and sodium borohydride were obtained from Sigma-Aldrich (Steinheim, Germany). Ethanolamine, [bis(acetoxy) iodo]benzene (BAIB), triethylamine and lithium chloride ( $\mathrm{LiCl}$ ) were received from VWR International $\mathrm{GmbH}$ (Darmstadt, Germany). Anhydrous $\mathrm{LiCl}$ was dried at $80^{\circ} \mathrm{C}$ for $2 \mathrm{~h}$ under vacuum. Dimethylsulfoxide (DMSO), $\mathrm{N}, \mathrm{N}$-dimethylacetamide (DMA), $\mathrm{N}, \mathrm{N}$-dimethylformamide (DMF) and tetrahydrofuran (THF) were purchased from Carl Roth International GmbH. Ethanol was obtained from $\mathrm{TH}$. GEYER International $\mathrm{GmbH}$. All other reagents were analytical grade and used as received. Deionized water (DI water) was used in all experiments.

\subsection{Syntheses of cellulose derivatives}

\section{3. $p$-Toluenesulfonylation of cellulose leading to tosylcellulose (TosC)}

According to existing synthesis method (Heinze, Genco, PetzoldWelcke, \& Wondraczek, 2012), dried MCC (1 g, 6.2 mmol AGUs) was suspended in $40 \mathrm{~mL}$ of $N, N$-dimethylacetamide (DMA) and stirred at $130^{\circ} \mathrm{C}$ for $2 \mathrm{~h}$. After the slurry cooled down to $100^{\circ} \mathrm{C}, 2 \mathrm{~g}$ of anhydrous $\mathrm{LiCl}$ were added. By further cooling to room temperature under stirring, cellulose dissolved completely. Then, a mixture of $3.1 \mathrm{~mL}$ triethylamine and $2.2 \mathrm{~mL}$ DMA (10:7, v:v) was added to this solution under stirring. After cooling to $4{ }^{\circ} \mathrm{C}$ in the ice-bath, a solution of $p$-toluenesulfonyl chloride $(2.5 \mathrm{~g}, 12.4 \mathrm{mmol})$ in $4 \mathrm{~mL}$ DMA was added drop by drop within $10 \mathrm{~min}$. The homogeneous mixture was stirred at $4{ }^{\circ} \mathrm{C}$ for another $24 \mathrm{~h}$. After that, the mixture was slowly poured into $250 \mathrm{~mL}$ ice water. The precipitate was filtered off, washed carefully with about $750 \mathrm{~mL}$ of distilled water and $100 \mathrm{~mL}$ of ethanol, suspended in $50 \mathrm{~mL}$ of acetone and re-precipitated in $150 \mathrm{~mL}$ of distilled water. After further filtration and repeated washing with ethanol, the sample was dried at $50{ }^{\circ} \mathrm{C}$ under vacuum.

Yield: $90 \%$, degree of substitution (DS) ascribed to tosyl groups $\mathrm{DS}_{\text {tosyl }}=1.3$ determined by means of ${ }^{1} \mathrm{H}$ NMR spectroscopy (Fig. S1).

FT-IR $\left(\mathrm{cm}^{-1}\right)$ : $3474 v(\mathrm{O}-\mathrm{H}) ; 2900 \nu(\mathrm{CH}) ; 1599,1499 v\left(\mathrm{C}-\mathrm{C}_{\text {arom. }}\right.$; $1356 \nu_{\text {as }}\left(\mathrm{SO}_{2}\right) ; 1172 v_{\text {sy }}\left(\mathrm{SO}_{2}\right) ; 1043 \nu(\mathrm{C}-\mathrm{O}) ; 812 \nu\left(\mathrm{C}-\mathrm{H}_{\text {arom. }}\right)$.

\subsection{Carbanilation of tosylcellulose leading to tosylcellulose carbanilate (TosCC)}

According to previous report (Heinze, Rahn, Jaspers, \& Berghmans, 1996), tosylcellulose ( $1 \mathrm{~g}, 2.8 \mathrm{mmol}$ repeating units) was dissolved in $10 \mathrm{~mL}$ DMF. The temperature of the solution was elevated to $80^{\circ} \mathrm{C}$ before phenyl isocyanate $(1.5 \mathrm{~mL}, 12.6 \mathrm{mmol})$ was added to the solution. The mixture was kept at $80^{\circ} \mathrm{C}$ for $10 \mathrm{~h}$ under stirring. After the reaction, the solution was cooled down to room temperature and precipitated in $200 \mathrm{~mL}$ ethanol. After repeated dissolution in THF and precipitation in ethanol for several times, a brown product was separated and dried at $50{ }^{\circ} \mathrm{C}$ under vacuum.

Yield: $90 \%, \mathrm{DS}_{\text {tosyl }}=1.3$ and degree of substitution ascribed to carbanilate groups $\mathrm{DS}_{\text {carbanilate }}=1.6$ determined by means of ${ }^{1} \mathrm{H}$ NMR spectroscopy (Fig. S2).

FT-IR $\left(\mathrm{cm}^{-1}\right): 3310 \nu(\mathrm{O}-\mathrm{H}) ; 2884 \nu(\mathrm{CH}) ; 1720 \nu(\mathrm{C}=\mathrm{O}) ; 1599$, $1499 v\left(\mathrm{C}-\mathrm{C}_{\text {arom }}\right) ; 1536 v(\mathrm{C}-\mathrm{N}-\mathrm{H}) ; 1448 v(\mathrm{C}-\mathrm{N}) ; 1373 v_{\text {as }}\left(\mathrm{SO}_{2}\right) ; 1214$ $\nu(\mathrm{C}-\mathrm{O}-\mathrm{C}) ; 1043 \nu(\mathrm{C}-\mathrm{O}) ; 1180 v_{\text {sy }}\left(\mathrm{SO}_{2}\right) ; 812,752,691$ ( $\left.\nu \mathrm{C}-\mathrm{H}_{\text {arom. }}\right)$.

\subsection{Synthesis of 6-deoxy-6-ethanolamino cellulose carbanilate (EaCC)}

EaCC was synthesized according to a previous report with modifications (Tiller, Berlin, \& Klemm, 2000). TosCC (1 g, $1.8 \mathrm{mmol}$ repeating units) was dissolved in $10 \mathrm{~mL}$ DMSO, and ethanolamine $(4 \mathrm{~mL}$, $66 \mathrm{mmol}$ ) was added to the solution at room temperature. Then, the temperature was raised to $100^{\circ} \mathrm{C}$ and the solution was kept at this temperature for $6 \mathrm{~h}$. After that, the solution was precipitated in $200 \mathrm{~mL}$ ethanol and the product was purified by repeated dissolution in DMSO and precipitation in ethanol for several times. Thereafter, the precipitated product was dried at $50^{\circ} \mathrm{C}$ under vacuum.

Yield: $60 \%, \mathrm{DS}_{\text {tosyl }}=0.2, \mathrm{DS}_{\text {carbanilate }}=0.5$ and degree of substitution ascribed to ethanolamino groups $\mathrm{DS}_{\mathrm{EA}}=0.8$ determined by means of ${ }^{1} \mathrm{H}$ NMR spectroscopy.

FT-IR $\left(\mathrm{cm}^{-1}\right)$ : $3307 \nu(\mathrm{O}-\mathrm{H}) ; 2880 \nu(\mathrm{CH}) ; 1716 \nu(\mathrm{C}=\mathrm{O}) ; 1599$, $1499 v\left(\mathrm{C}-\mathrm{C}_{\text {arom. }}\right) ; 1536 \nu(\mathrm{C}-\mathrm{N}-\mathrm{H}) ; 1445 \nu(\mathrm{C}-\mathrm{N}) ; 1218 v(\mathrm{C}-\mathrm{O}-\mathrm{C})$; $1043 \nu(\mathrm{C}-\mathrm{O}) ; 812,755,691 \nu\left(\mathrm{C}-\mathrm{H}_{\text {arom. }}\right)$.

\subsection{Synthesis of 6-deoxy-6-(2-thiolethylamino)ethylamino cellulose carbanilate (ThiolCC)}

ThiolCC was synthesized according to modified methods (De Mico, Margarita, Parlanti, Vescovi, \& Piancatelli, 1997; Sokolsky-Papkov, Domb, \& Golenser, 2006). EaCC (1 g, $3.3 \mathrm{mmol}$ repeating units) was dissolved in $10 \mathrm{~mL}$ DMSO, before TEMPO ( $30 \mathrm{mg}, 0.19 \mathrm{mmol}$ ) was added. Thereafter, BAIB $(0.673 \mathrm{~g}, 1.98 \mathrm{mmol})$ was added to the solution. The mixture was further stirred at room temperature for $24 \mathrm{~h}$. Thereafter, cysteamine $(0.6 \mathrm{~g}, 7.6 \mathrm{mmol})$ was added to the solution, and the solution was kept at room temperature under an atmosphere of $\mathrm{N}_{2}$ for up to $20 \mathrm{~h}$. After that, $\mathrm{NaBH}_{4}(0.3 \mathrm{~g}, 7.6 \mathrm{mmol})$ was slowly added to the solution at $0{ }^{\circ} \mathrm{C}$, and the solution was stirred at ambient temperature for another $5 \mathrm{~h}$. After the reaction, the solution was precipitated in $200 \mathrm{~mL}$ ethanol and the product was purified by repeated dissolution in DMSO and precipitation in ethanol for several times, before the product was dried at $50{ }^{\circ} \mathrm{C}$ under vacuum.

Yield: $50 \%, \mathrm{DS}_{\text {tosyl }}=0.2, \mathrm{DS}_{\text {carbanilate }}=0.5$ and degree of substitution ascribed to thiol groups $\mathrm{DS}_{\mathrm{SH}}=0.6$ determined by means of ${ }^{1} \mathrm{H}$ NMR spectroscopy.

FT-IR $\left(\mathrm{cm}^{-1}\right): 3298 \nu(\mathrm{O}-\mathrm{H}) ; 2897 \nu(\mathrm{CH}) ; 2600 \nu(\mathrm{SH}) ; 1720 \nu(\mathrm{C}=$ O); 1599, $1499 v\left(\mathrm{C}-\mathrm{C}_{\text {arom. }}\right) ; 1532 v(\mathrm{C}-\mathrm{N}-\mathrm{H}) ; 1445 v(\mathrm{C}-\mathrm{N}) ; 1215$ $v(\mathrm{C}-\mathrm{O}-\mathrm{C}) ; 1043 \nu(\mathrm{C}-\mathrm{O}) ; 813,753,691 \nu\left(\mathrm{C}-\mathrm{H}_{\text {arom. }}\right)$.

\subsection{Synthesis of glycosylated 6-deoxy-6-(2-thiolethylamino)ethylamino} cellulose carbanilate (GlcThiolCC)

Glucose-terminated eugenol $(1.3 \mathrm{~g}, \quad 3.9 \mathrm{mmol}$, Supporting Information) and DMPA ( $153 \mathrm{mg}, 0.65 \mathrm{mmol}$ ) as photo-initiator were 


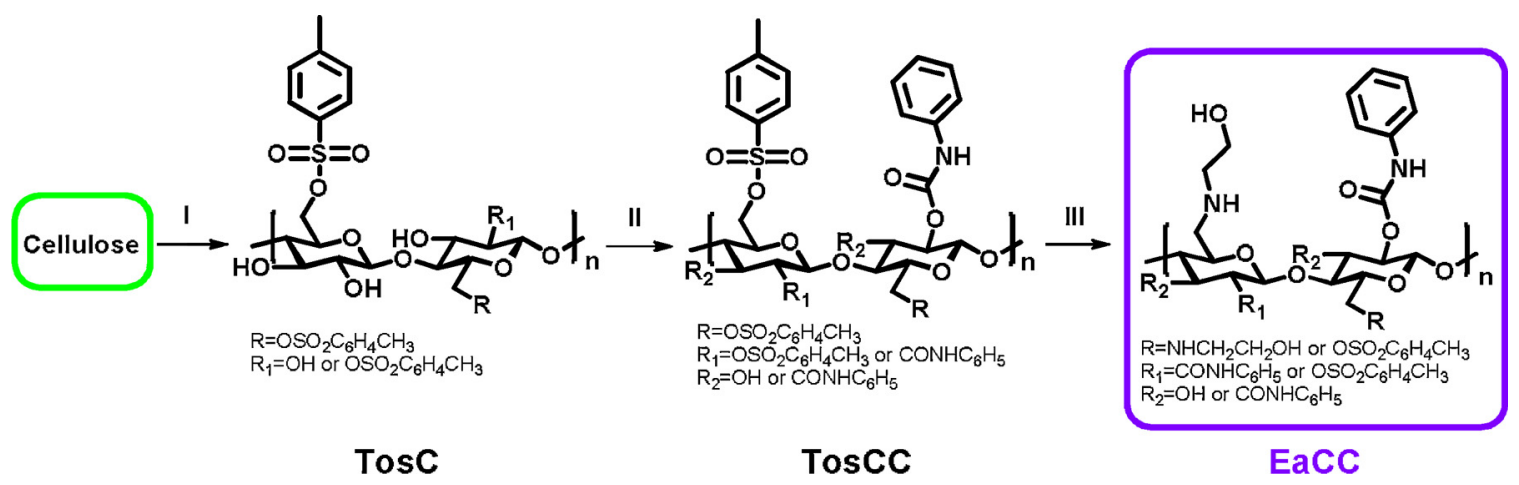

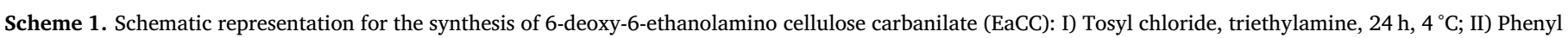
isocyanate, DMF, $10 \mathrm{~h}, 80^{\circ} \mathrm{C}$; III) Ethanolamine, DMSO, $6 \mathrm{~h}, 100{ }^{\circ} \mathrm{C}$.

added to the solution of ThiolCC ( $1 \mathrm{~g}, 3.1 \mathrm{mmol}$ repeating units) in $20 \mathrm{~mL}$ DMSO under $\mathrm{N}_{2}$ atmosphere. Then, the solution was thoroughly mixed until complete dissolution, before it was irradiated with UV light of $320-400 \mathrm{~nm}$ in a UV irradiation chamber for $10 \mathrm{~h}$ under stirring. After the reaction, the solution was precipitated in $200 \mathrm{~mL}$ ethanol and the product was purified by repeated dissolution in DMSO and precipitation in ethanol for several times, before the precipitated product was dried at $50{ }^{\circ} \mathrm{C}$ under vacuum.

Yield: $80 \%, \mathrm{DS}_{\text {tosyl }}=0.2, \mathrm{DS}_{\text {carbanilate }}=0.5$, degree of substitution ascribed to glucose groups $\mathrm{DS}_{\text {glucose }}=0.6$ determined by means of ${ }^{1} \mathrm{H}$ NMR spectroscopy.

FT-IR $\left(\mathrm{cm}^{-1}\right)$ : $3340 \nu(\mathrm{O}-\mathrm{H}) ; 2905 \nu(\mathrm{CH}) ; 1733 \nu(\mathrm{C}=\mathrm{O}) ; 1649$ $\nu(\mathrm{N}-\mathrm{H}) ; 1599,1499 v\left(\mathrm{C}-\mathrm{C}_{\text {arom. }}\right), 1541 v(\mathrm{C}-\mathrm{N}-\mathrm{H}), 1445 v(\mathrm{C}-\mathrm{N}) ; 1270$ $\nu\left(\mathrm{CH}_{2}-\mathrm{S}-\right)$; $1218 v(\mathrm{C}-\mathrm{O}-\mathrm{C}), 1043 \nu(\mathrm{C}-\mathrm{O}) ; 815,753,693 \nu\left(\mathrm{C}-\mathrm{H}_{\text {arom. }}\right)$.

\subsection{Cross-linking and dissociation of GlcThiolCC}

For the cross-linking of GlcThiolCC, it $(10 \mathrm{mg}, 0.02 \mathrm{mmol})$ was dissolved in $1 \mathrm{~mL}$ DMSO. At the same time, 1,4-phenylenediboronic acid $(6.6 \mathrm{mg}, 0.04 \mathrm{mmol})$ was dissolved in $2 \mathrm{~mL}$ DMSO. Then, the 1,4phenylenediboronic acid solution was added to the GlcThiolCC solution and saturated $\mathrm{NaOH}$ solution $(0.05 \mathrm{~mL})$ was added drop by drop to increase the $\mathrm{pH}$ value to $\sim 10$. After stirring for $15 \mathrm{~min}$, the solution became turbid and obvious aggregations formed. For the dissociation of cross-linked polymers, glucose $(360 \mathrm{mg}, 2 \mathrm{mmol})$ dissolved in $1 \mathrm{~mL}$ DMSO was added to the suspension and the system was stirred for $15 \mathrm{~min}$, leading to a clear solution again.

\subsection{Nanoprecipitation using GlcThiolCC}

$1 \mathrm{~mL}$ GlcThiolCC solution (10 mg in $4 \mathrm{~mL}$ DMSO) and $1 \mathrm{~mL}$ of the newly formed clear GlcThiolCC solution undergoing a cross-linking and dissociation cycle were separately added drop by drop into $10 \mathrm{~mL}$ water under stirring of $800 \mathrm{rpm}$ at ambient temperature. After the complete addition, opaque nanoparticle suspensions were obtained.

\subsection{Characterization}

Liquid-state ${ }^{13} \mathrm{C}$ NMR spectra of all polymer samples in DMSO- $d_{6}$ were obtained at $25^{\circ} \mathrm{C}$ on Bruker DRX 500 spectrometer (Bruker, Biospin $\mathrm{GmbH}$, Ettlingen) with a frequency of $125.8 \mathrm{MHz}, 1.0 \mathrm{~s}$ acq. Time, $30^{\circ}$ pulse length and a relaxation delay of $0.5 \mathrm{~s}$. Scans of up to 15000 were accumulated. Liquid-state ${ }^{1} \mathrm{H}$ NMR spectra of all polymer samples in DMSO- $d_{6}$ were obtained at $50{ }^{\circ} \mathrm{C}$ on Bruker DRX 500 spectrometer (Bruker, Biospin $\mathrm{GmbH}$, Ettlingen) with a frequency of $500.3 \mathrm{MHz}, 5.0 \mathrm{~s}$ acq. Time and a relaxation delay of $0.1 \mathrm{~s}$. Scans of up to 16 were accumulated. FTIR spectra were recorded on Alpha FTIR Spectrometer (Bruker, Germany) at room temperature. All samples were measured between 4000 and $600 \mathrm{~cm}^{-1}$ with a resolution of
$4 \mathrm{~cm}^{-1}$ using Platnum ATR and accumulated 23 scans. The dynamic light scattering (DLS) measurements were performed on a Zetasizer Nano ZS (Malvern Instruments Ltd., UK) using $5 \mathrm{~mW}$ laser with the incident beam of $633 \mathrm{~nm}$ (He-Ne laser). For the particle size measurement, the suspensions were diluted with water to a concentration of $\sim 0.25 \mathrm{mg} / \mathrm{mL}$ of in a disposable cuvette (IDL GmbH, Gießen, Germany). The sizes were measured three times with 15 runs for each measurement and the average sizes from three measurements were used as results. The analysis of the data in this work was executed with OriginPro 8.5 (OriginLab Corporation, MA, US).

\section{Results and discussion}

Regioselective location of functional groups within anhydroglucose units has been used to construct cellulose derivatives with well-defined supramolecular architectures (Kadla, Asfour, \& Bar-Nir, 2007) and promising adjustable properties (Kamitakahara, Funakoshi, Nakai, Takano, \& Nakatsubo, 2010). In order to synthesize glycosylated cellulose derivatives with pendant glucosyl groups at C6 position, we started with tosyl cellulose for $\mathrm{S}_{\mathrm{N}} 2$ substitution to introduce a relatively long-chain hydroxyl groups at $\mathrm{C} 6$ for further consecutive oxidation and thiol-ene reaction (Schemes 1 and 2).

A three-step synthesis route was carried out to prepare EaCC, as shown in Scheme 1. In the first step, a cellulose solution in DMA/LiCl was allowed to react with $p$-toluenesulfonyl chloride in the presence of triethylamine to synthesize TosC under homogenous conditions. Due to the similar DSs obtained from elemental analysis and NMR spectroscopy (Liu \& Baumann, 2002; Xu, Voiges, Elder, Mischnick, \& Edgar, 2012), ${ }^{1} \mathrm{H}$ NMR spectroscopy was used for determining DS, in order to maintain consistent results in the whole work. The DS ascribed to tosyl groups $\left(\mathrm{DS}_{\text {tosyl }}\right.$ ) was determined to be 1.3 by applying 2 molar equivalent of $p$-toluenesulfonyl chloride to AGUs, as confirmed by ${ }^{1} \mathrm{H}$ NMR spectroscopy (Fig. S1). TosC was further converted into tosylcellulose carbanilate (TosCC) in DMF at $80^{\circ} \mathrm{C}$. In order to maintain the good solubility of the product in organic solvent for subsequent homogeneous reactions, a molar equivalent of 4.5:1 (phenyl isocyanate:modified AGUs of TosC) was chosen. After the reaction, TosCC with a high DS $S_{\text {tosyl }}$ (1.3) and DS $S_{\text {carbanilate }}$ (1.6) was obtained, which was soluble in organic solvents including THF and DMSO.

The nucleophilic substitution of tosyl groups by ethanolamine was further performed in DMSO at $100{ }^{\circ} \mathrm{C}$, leading to 6-deoxy-6-ethanolamino cellulose carbanilate (EaCC). The structure of EaCC was confirmed by FTIR and ${ }^{13} \mathrm{C}$ NMR spectroscopy. The signal of $\nu(\mathrm{C}-\mathrm{N}-\mathrm{H})$ and $\nu(C-N)$ could be observed separately at 1536 and $1445 \mathrm{~cm}^{-1}$, respectively. The ${ }^{13} \mathrm{C}$ NMR spectrum of EaCC in DMSO- $d_{6}$ showed peaks at $51.4 \mathrm{ppm}$ for $\mathrm{C} 17$ and $60.2 \mathrm{ppm}$ for $\mathrm{C} 18$ (Fig. 1), in comparison to the ${ }^{13} \mathrm{C}$ NMR spectra of TosC and TosCC (Figs. S5 and S6). The signals for the modified positions $\mathrm{C}_{\mathrm{Tos}}$ and $\mathrm{C}_{\mathrm{NH}}$ with desoxyamino groups were found at 66.8 and $49.1 \mathrm{ppm}$, respectively (Heinze et al., 2012; Heinze 


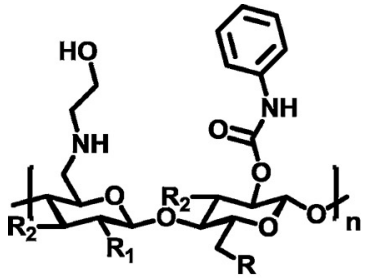

$\mathrm{R}=\mathrm{NHCH}_{2} \mathrm{CH}_{2} \mathrm{OH}$ or $\mathrm{OSO}_{2} \mathrm{C}_{6} \mathrm{H}_{4} \mathrm{CH}_{3}$ $\mathrm{R}_{1}=\mathrm{CONHC}_{6} \mathrm{H}_{5}$ or $\mathrm{OSO}_{2} \mathrm{C}_{6} \mathrm{H}_{4} \mathrm{CH}_{3}$ $\mathrm{R}_{2}=\mathrm{OH}$ or $\mathrm{CONHC}_{6} \mathrm{H}_{5}$

EaCC

TEMPO, BAIB, DMSO, rt

Cysteamine, DMSO, $\mathrm{MgSO}_{4}$ overnight

$\mathrm{NaBH}_{4}, \mathrm{O}^{\circ} \mathrm{C}, 5 \mathrm{~h}$

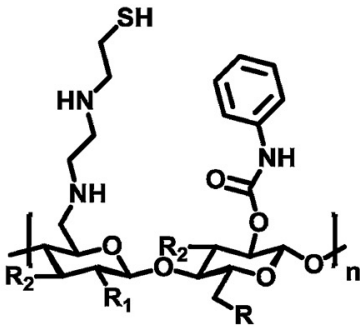

$\mathrm{R}=\mathrm{NHCH}_{2} \mathrm{CH}_{2} \mathrm{OH}$ or $\mathrm{OSO}_{2} \mathrm{C}_{6} \mathrm{H}_{4} \mathrm{CH}_{3}$ $\mathrm{R}_{1}=\mathrm{CONHC}_{6} \mathrm{H}_{5}$ or $\mathrm{OSO}_{2} \mathrm{C}_{6} \mathrm{H}_{4} \mathrm{CH}_{3}$

$\mathbf{R}_{2}=\mathrm{OH}$ or $\mathrm{CONHC}_{6} \mathrm{H}_{5}$

ThiolCC

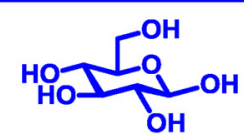

$\mathrm{CH}_{3} \mathrm{COONa},\left(\mathrm{CH}_{3} \mathrm{CO}\right)_{2} \mathrm{O}$ reflux, $4 \mathrm{~h}$

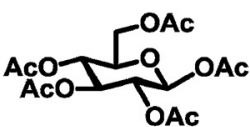<smiles>C=CCc1ccc(O)c(OC)c1</smiles>

$\mathrm{ZnCl}_{2}, \mathrm{BF}_{3} \cdot \mathrm{Et}_{2} \mathrm{O}, \mathrm{DCM}$ $\mathbf{N}_{2}, \mathrm{rt}, 6 \mathrm{~h}$

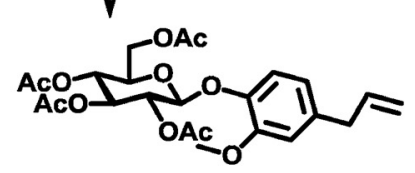

NaOMe, MeOH, rt, 2h

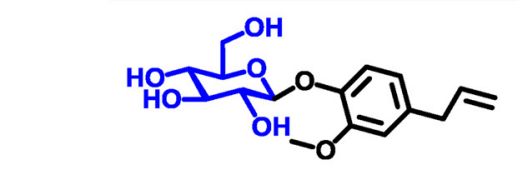

DMAP, DMSO, UV, 10h

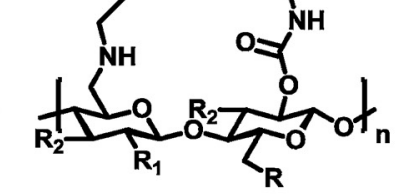

$\mathrm{R}=\mathrm{NHCH}_{2} \mathrm{CH}_{2} \mathrm{OH}$ or $\mathrm{OSO}_{2} \mathrm{C}_{6} \mathrm{H}_{4} \mathrm{CH}_{3}$ $\mathrm{R}_{1}=\mathrm{CONHC}_{6} \mathrm{H}_{5}$ or $\mathrm{OSO}_{2} \mathrm{C}_{6} \mathrm{H}_{4} \mathrm{CH}_{3}$ $\mathrm{R}_{2}=\mathrm{OH}$ or $\mathrm{CONHC}_{6} \mathrm{H}_{5}$

\section{GIcThiolCC}

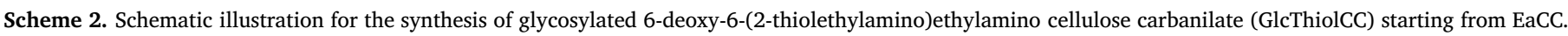
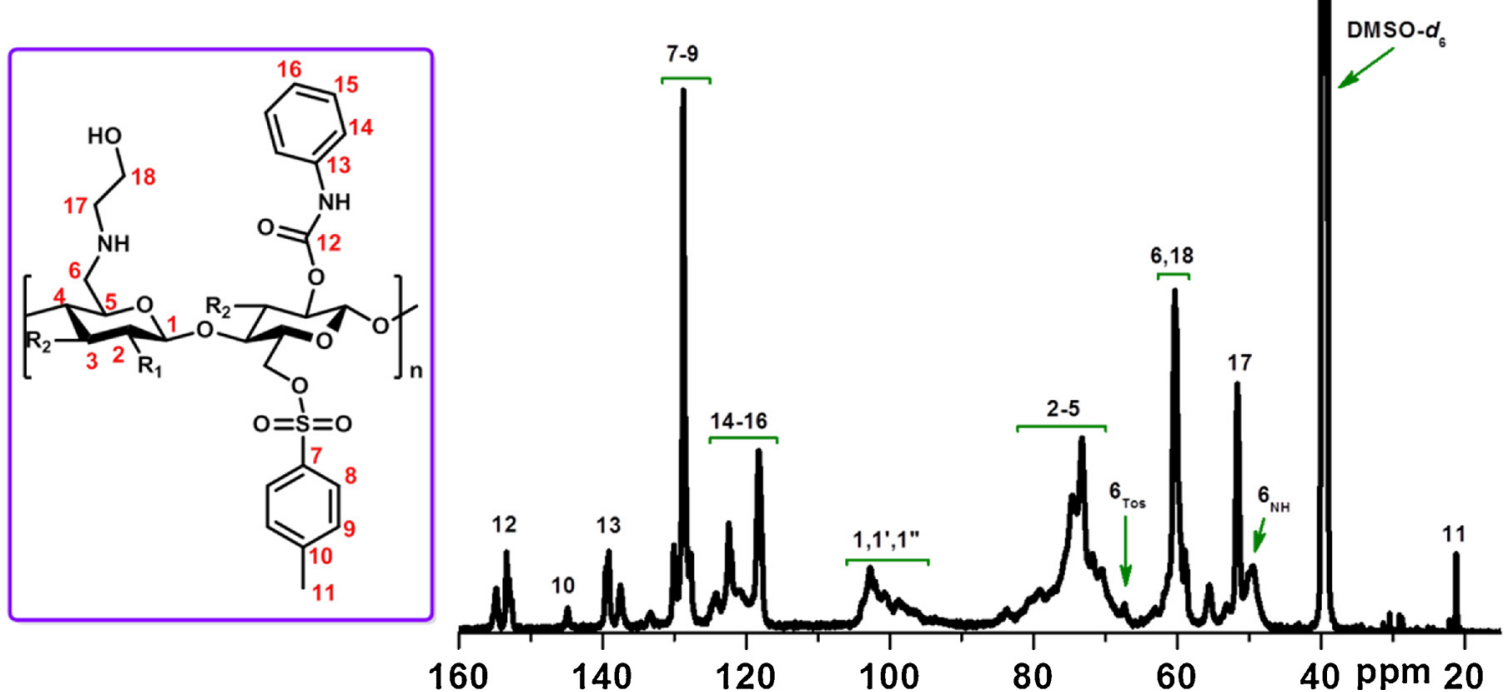

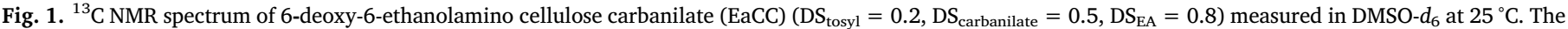
numbers in the structural formula demonstrate the carbons within EaCC. 


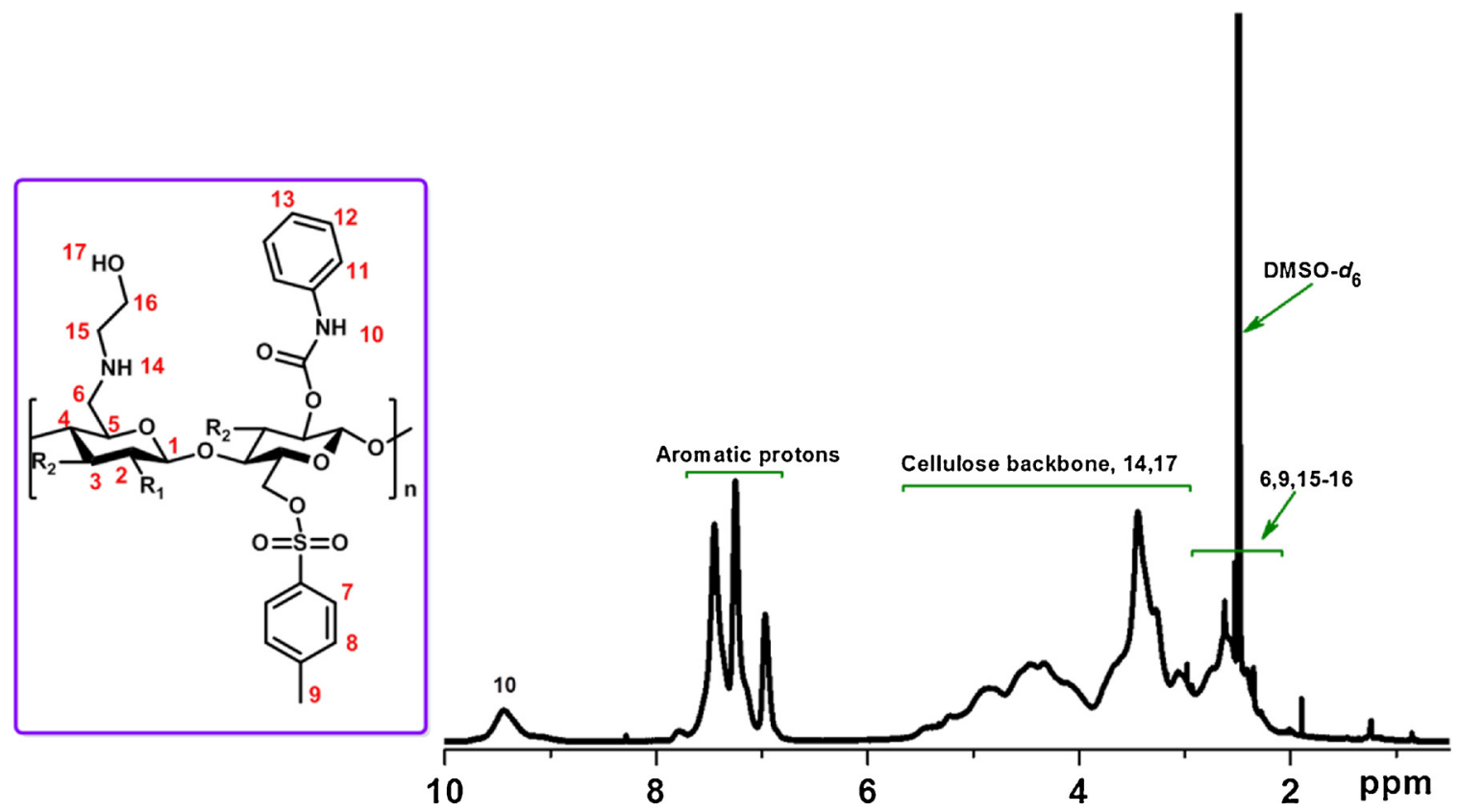

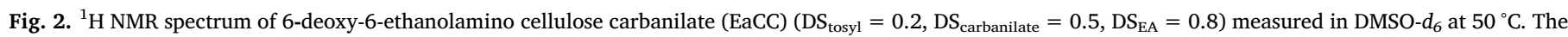
numbers in the structural formula demonstrate the protons within EaCC.

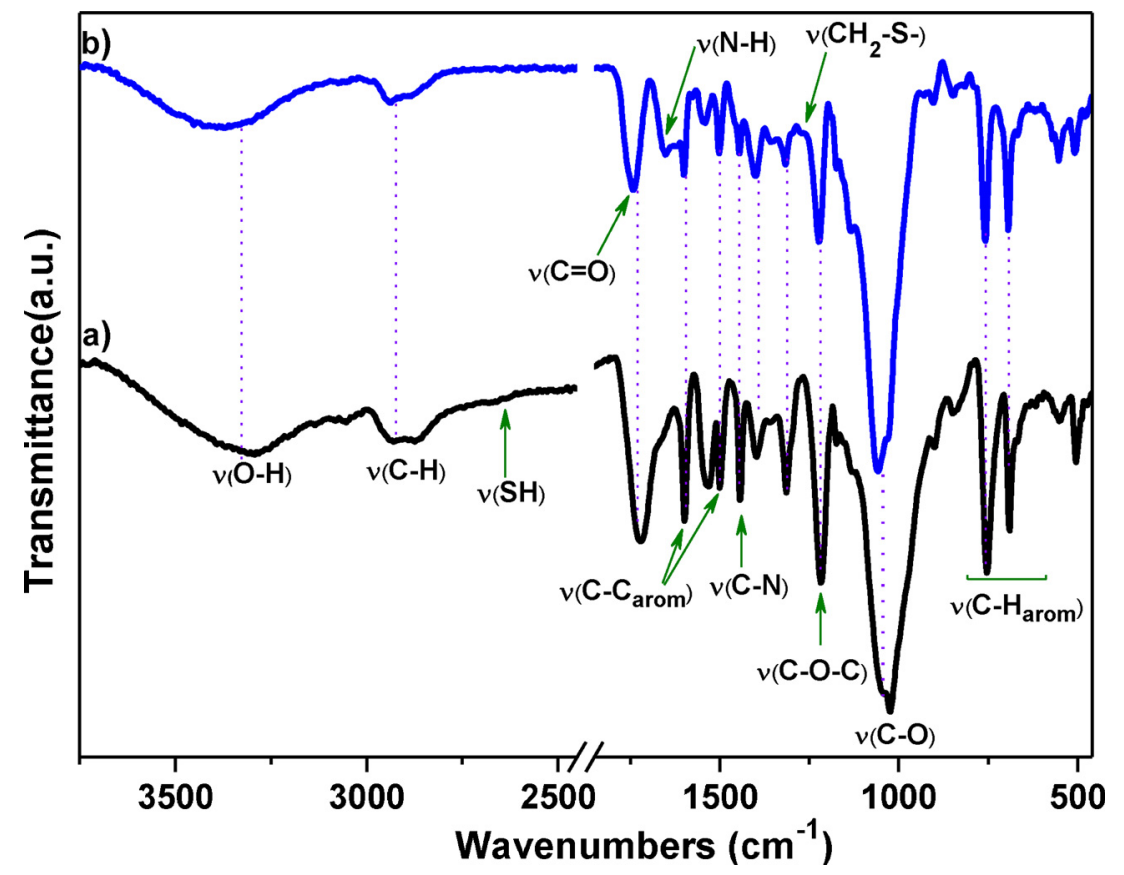

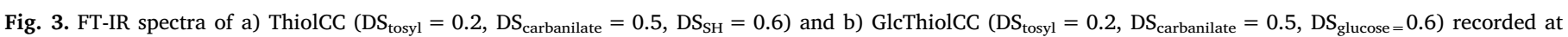
room temperature.

\section{et al., 2001).}

The degree of substitution attributed to ethanolamino groups ( $\left.\mathrm{DS}_{\mathrm{EA}}\right)$ was determined to be 0.8 based on ${ }^{1} \mathrm{H}$ NMR spectroscopy (Figs. 2 and S3). A high ratio of ethanolamine in comparison to repeating units of TosC of 36:1 had to be used to achieve this high $\mathrm{DS}_{\mathrm{EA}}$. Even though, a small portion of tosyl moieties with a low $\mathrm{DS}_{\text {tosyl }}$ of 0.2 is still detectable in EaCC. Due to the high amount of ethanolamine and high temperature of $100{ }^{\circ} \mathrm{C}$ for $6 \mathrm{~h}$, a part of carbanilate groups was removed, resulting in

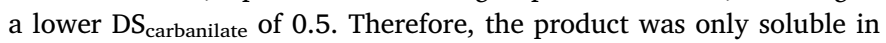
polar aprotic solvents, such as DMSO, DMF and DMA.

The pendant primary hydroxyl groups were further oxidized to introduce clickable thiol moieties, so that glycosylated 6-deoxy-6-(2- thiolethylamino)ethylamino cellulose carbanilate (GlcThiolCC) was synthesized after subsequent two steps (Scheme 2).

In polysaccharide chemistry, aldehyde groups could be a perfect bridge to connect cellulose with other striking structures. Two major methods for the introduction of aldehyde groups into cellulose by direct oxidation are firmly established: periodate oxidation (Kim, Kuga, Wada, Okano, \& Kondo, 2000; Sirvio, Hyvakko, Liimatainen, Niinimaki, \& Hormi, 2011) and TEMPO-mediated oxidation (Saito \& Isogai, 2004, 2007). The latter approach particularly converts the primary hydroxyls groups into aldehyde groups, but the synthesis generally suffers from the low efficiency for aldehyde groups (of up to $0.225 \mathrm{mmol} / \mathrm{g}$ ), because the aldehyde groups were immediately further oxidized to 
carboxyl groups under aqueous conditions (Saito \& Isogai, 2006). By studying the mechanism of TEMPO-oxidation under aqueous conditions, we found that the huge amount of water was potentially crucial to continuously oxidize aldehyde groups to carboxylate groups (Bragd, Van Bekkum, \& Besemer, 2004). Thus, we performed the TEMPO/BAIBmediate oxidation under non-aqueous condition, i.e. to use a catalytic amount of TEMPO and a stoichiometric amount of oxidant BAIB in DMSO solution (De Mico et al., 1997).

Furthermore, a one-pot reaction containing oxidation, Schiff base formation and reduction sequentially was carried out. First, EaCC was oxidized by TEMPO/BAIB-mediated reaction in DMSO at room temperature. The resulting aldehyde groups were allowed to immediately react with cysteamine via the formation of Schiff base. After further treatment with reducing agents, thiols groups were assured to be present at $\mathrm{C6}$ position. Glucose-terminated eugenol was further introduced via the thiol-ene reaction leading to GlcThiolCC.

Representative FTIR spectra of ThiolCC and GlcThiolCC showed typical signals for the functional groups (Fig. 3), e.g. cellulose backbone at $3300 \mathrm{~cm}^{-1} \mathrm{v}(\mathrm{O}-\mathrm{H}), 2930 \mathrm{~cm}^{-1} \mathrm{v}(\mathrm{C}-\mathrm{H}), 1733 \mathrm{~cm}^{-1} \mathrm{v}(\mathrm{C}=\mathrm{O})$, $1445 \mathrm{~cm}^{-1} \nu(\mathrm{C}-\mathrm{N})$ as well as $1060 \mathrm{~cm}^{-1} \nu(\mathrm{C}-\mathrm{O}-\mathrm{C})$. In GlcThiolCC, the signals of $\nu\left(\mathrm{CH}_{2}-\mathrm{S}-\right)$ and $\nu(\mathrm{N}-\mathrm{H})$ are also visible at 1270 and $1649 \mathrm{~cm}^{-1}$, respectively (Fig. 3b) (Marks, Fox, \& Edgar, 2016; Yang, Li, Dou, \& Sun, 2008).

NMR spectroscopy further confirmed the synthesis and was used for calculating DS attributed to functional groups. The signal attributed to the thiol protons could be strongly affected by water, e.g. the tiny amount of water in DMSO- $d_{6}$ (Persson \& Jannasch, 2005). However, the signal of secondary amine groups $\left(-\mathrm{NHCH}_{2} \mathrm{CH}_{2} \mathrm{SH}\right)$ at $1.0-1.5 \mathrm{ppm}$ is generally obvious (Marks et al., 2016). Based on this signal, the degree of substitution of thiol groups $\left(\mathrm{DS}_{\mathrm{SH}}\right)$ was determined to be 0.6 by means of ${ }^{1} \mathrm{H}$ NMR spectroscopy (Fig. 4a and S4). As well, ${ }^{13} \mathrm{C}$ NMR spectrum of ThiolCC showed characteristic signals confirming the successful reaction: the peak at $28 \mathrm{ppm}$ assigned to the methylene carbon next to the $-\mathrm{SH}$ group $\left(-\mathrm{NHCH}_{2} \mathrm{CH}_{2} \mathrm{SH}\right.$ ) (Feng et al., 1997); the peak at $38 \mathrm{ppm}$ ascribed to the other methylene carbon $\left(-\mathrm{SCH}_{2} \mathrm{CH}_{2} \mathrm{NH}-\right)$ probably overlapped by the solvent peak of DMSO- $d_{6}$ (Fig. 5a) (Marks et al., 2016).

In order to introduce pendant glucose units, ThiolCC was converted into GlcThiolCC via UV-initiated thiol-ene click reaction with glucose- terminated eugenol at room temperature. Based on the integrals of signal at $9.5 \mathrm{ppm}$ and signals at $6.8-8.0$ ascribed to aromatic protons within the ${ }^{1} \mathrm{H}$ NMR spectrum (Figs. $4 \mathrm{~b}$ and S7), thiol groups in ThiolCC should have completely reacted with vinyl groups in glucose-terminated eugenol, yielding GlcThiolCC with a degree of substitution ascribed to glucosyl moieties ( $\mathrm{DS}_{\text {glucose }}$ ) of 0.6. The ${ }^{13} \mathrm{C}$ NMR spectrum of GlcThiolCC (Fig. 5b) in DMSO- $d_{6}$ showed characteristic signals for C20/ 21 at $28 \mathrm{ppm}$ (Feng et al., 1997), C22/23 at $34.1 \mathrm{ppm}, \mathrm{C} 66_{\mathrm{NH}}$ with desoxyamino groups at $49.1 \mathrm{ppm}$ (Heinze et al., 2012; Heinze et al., 2001) and C30/36 around $60.5 \mathrm{ppm}$. Due to the structural similarity of glucose and AGUs of cellulose chains, the signals attributed to carbon atoms of glucose groups are highly overlapped by the signals of carbon atoms of AGUs.

Due to the presence of glucosyl groups with free 4,6-diols at the polymer backbone, it demonstrated responsive property against phenylboronic acid (Fig. 6a). The boronic acid unit should mainly bind to 4,6-diol of hexopyranosides (Dowlut \& Hall, 2006), due to the nonavailability of the 1,2-diol in GlcThiolCC. While the solution of GlcThiolCC was transparent at ambient temperatures, it became turbid and strong aggregates gradually formed with the addition of 1,4-phenylenediboronic acid at $\mathrm{pH} 10$. The turbid suspensions turned into a transparent solution again, when sufficient amount of glucose was added at $\mathrm{pH}$ 10. This optically visible phase transition was reversible, indicating that excess glucose in the base condition can displace GlcThiolCC by binding with 1,4-phenylenediboronic acid. Moreover, because the glucosyl groups should be the only possible groups providing the diols for binding with 1,4-phenylenediboronic acid (Kuralay et al., 2012), the reversible linkages further confirmed the applicable functionality of glucose groups at the cellulose derivative chains.

These polymers without the presence of cross-linkages can be transformed into uniform nanoparticles. The initial solution of GlcThiolCC (10 mg in $4 \mathrm{~mL}$ DMSO) could be transformed into nanoparticles with an average dimameter of $44 \pm 0.2 \mathrm{~nm}$ and a relatively low polydisperisty index (PDI) of 0.158 (Fig. 6b) through a nanoprecipitation process (Zhang, Geissler, \& Heinze, 2015). After the crosslinking and dissociation by the 1,4-phenylenediboronic acid, polymer chains of GlcThiolCC can be transformed into nanoparticles with a similar average diameter of $40 \pm 1.2 \mathrm{~nm}$ and a slightly higher polydisperisty index (PDI) of 0.285 . The slight increase of the nanoparticle

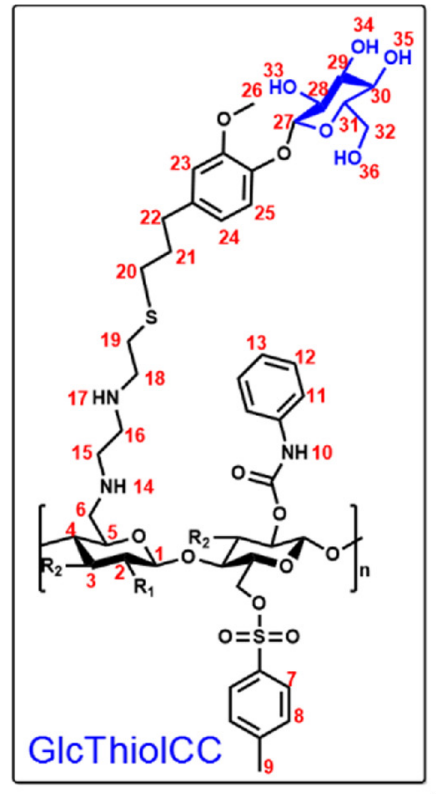

10

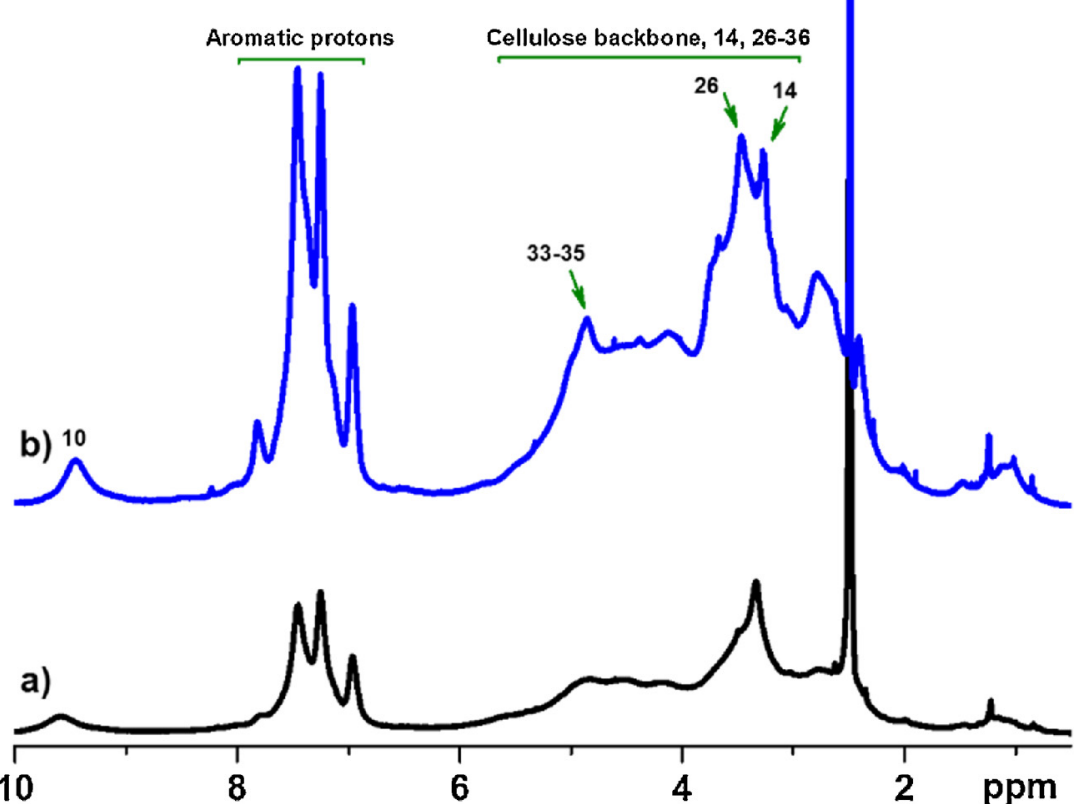

$\left.=0.5, \mathrm{DS}_{\mathrm{SH}}=0.6\right)$ and $\left.\mathrm{b}\right)$ GlcThiolCC $\left(\mathrm{DS}_{\text {tosyl }}=0.2, \mathrm{DS}_{\text {carbanilate }}=0.5, \mathrm{DS}_{\text {glucose }}=0.6\right)$ measured Fig. 4. ${ }^{1} \mathrm{H}$ NMR spectrum of a) ThiolCC $\left(\mathrm{DS}_{\text {tosyl }}=0.2, \mathrm{DS}_{\text {carbanilate }}=0.5, \mathrm{DS}_{\mathrm{SH}}=0.6\right)$ and b) Glc
in DMSO- $d_{6}$ at $50{ }^{\circ} \mathrm{C}$. The numbers in the structural formula of GlcThiolCC display the protons. 


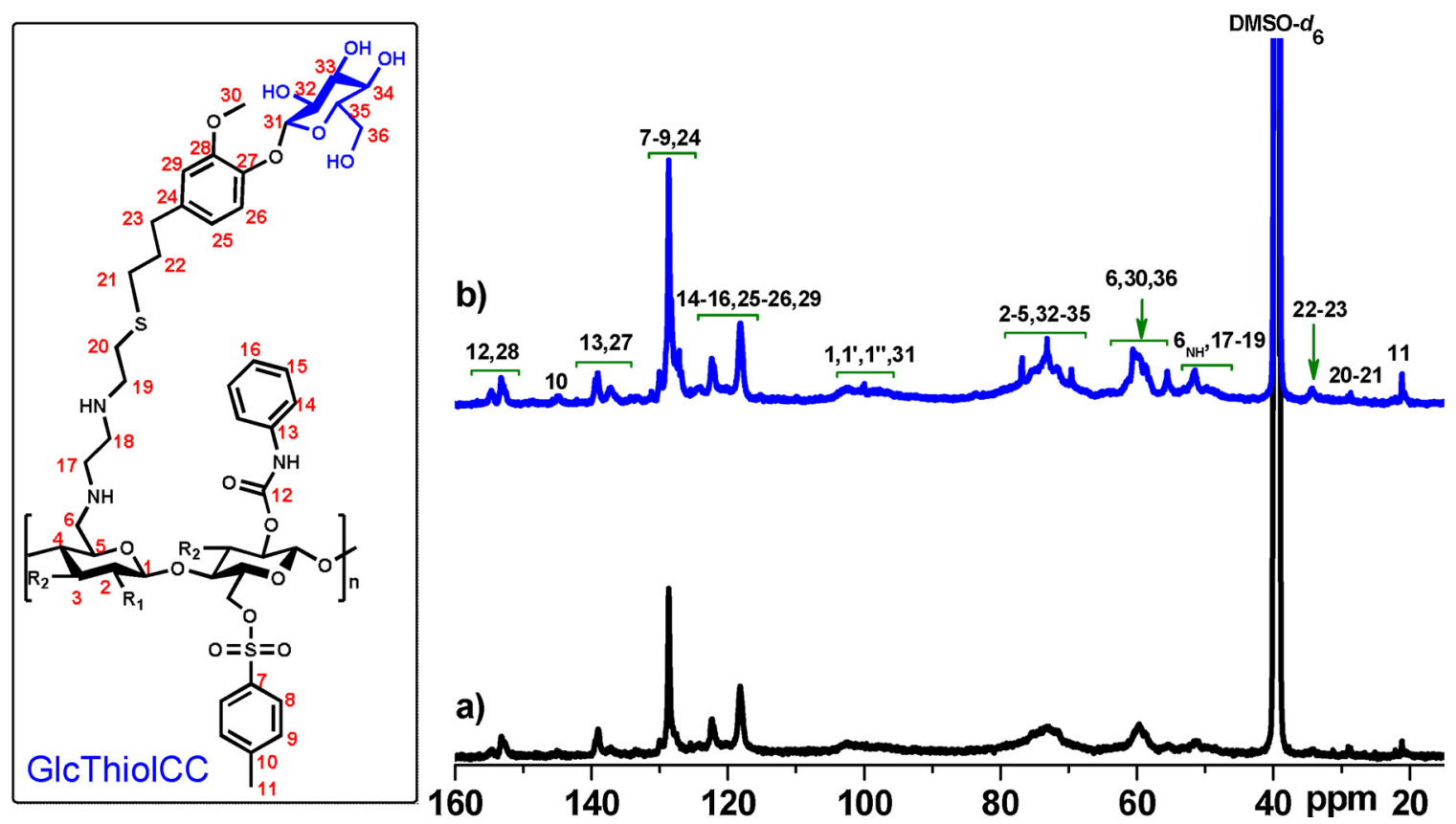

Fig. 5. ${ }^{13} \mathrm{C}$ NMR spectrum of a) ThiolCC $\left(\mathrm{DS}_{\text {tosyl }}=0.2, \mathrm{DS}_{\text {carbanilate }}=0.5, \mathrm{DS}_{\mathrm{SH}}=0.6\right)$ and b) GlcThiolCC $\left(\mathrm{DS}_{\text {tosyl }}=0.2, \mathrm{DS}_{\text {carbanilate }}=0.5\right.$, $\left.\mathrm{DS}_{\text {glucose }}=0.6\right)$ measured in DMSO- $d_{6}$ at $25^{\circ} \mathrm{C}$ with 15000 scans. The numbers in the structural formula of GlcThiolCC display the carbons.

a)
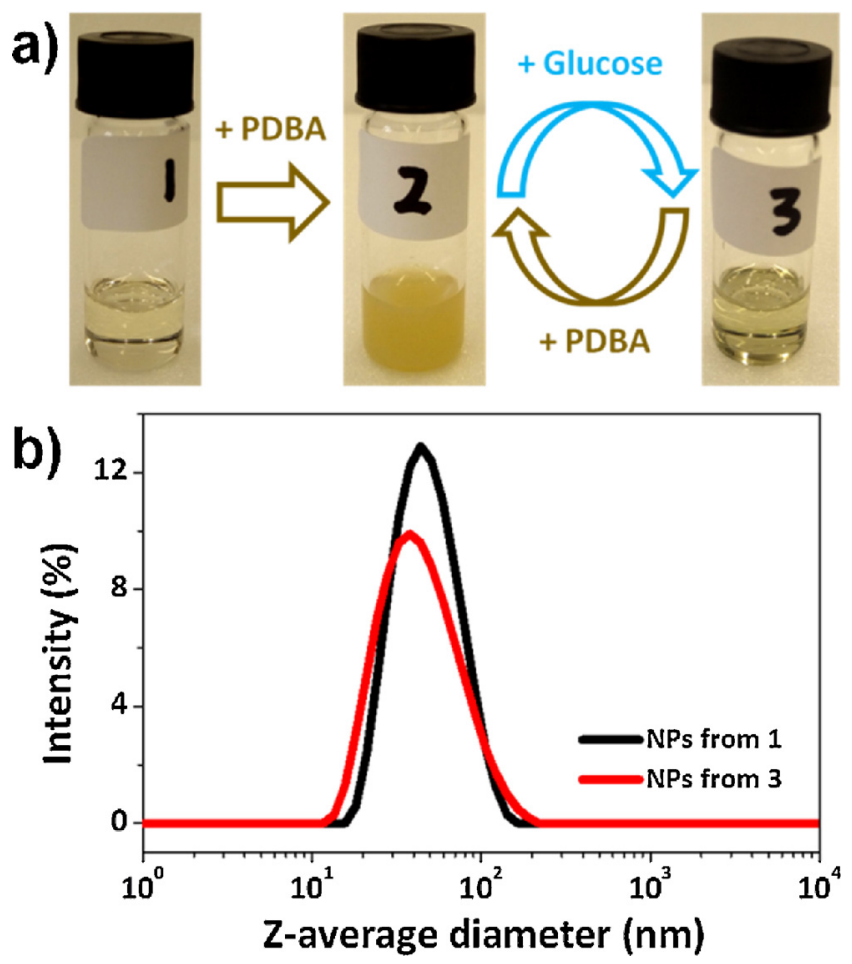

Fig. 6. (a) Schematic demonstration of the reversible covalent bonding of GlcThiolCC with 1,4-phenylenediboronic acid: (1) GlcThiolCC in DMSO; (2) the cross-linking of GlcThiolCC and 1,4-phenylenediboronic acid (PDBA) and (3) glucose-induced dissociation of the cross-linking complex. (b) DLS curves of NPs.

diameters should be due to the presence of the other compounds in the solution and the increased viscosity of the solution (Geissler, Biesalski, Heinze, \& Zhang, 2014).

Thus, we could show the synthesis of novel glycosylated cellulose derivatives showing stimuli-responsive properties. In particular, these responsive properties can also be further expanded to other fields by transforming them into nanoparticles or introducing more functions into compounds.

\section{Conclusion}

In this work, we demonstrated a novel synthesis strategy containing a sequential synthesis steps for glucosylated and phenylboronic acidsensitive cellulose derivatives. The synthesis of cellulose derivatives started with the nucleophilic substitution via tosylcellulose, further one-pot reaction with consecutive TEMPO/BAIB-mediated oxidation, Schiff base formation and reduction to free thiol groups, and subsequent thiol-ene click reaction. In particular, we showed that a modified TEMPO/BAIB-mediated oxidation system was realized on the cellulose derivative containing pendant hydroxyl groups. This whole synthetic procedure containing the one-pot reaction avoided the potential oxidation of aldehyde groups and thiol groups, and the loss of products due to repeated washing. In addition, the thiol-ene click reaction was conducted under mild condition, which is also beneficial to protect cellulose backbone. These glycosylated cellulose derivatives displayed significant responsive properties by binding with 1,4-phenylenediboronic acid at $\mathrm{pH} 10$, and easy dissociation by extra glucose. These novel glycosylated cellulose derivatives demonstrate a novel group of stimuli-responsive modified biopolymer derivatives.

\section{Acknowledgements}

S.W. thanks the Chinese Scholarship Council (CSC) for the financial support. The financial support from Fonds der Chemischen Industrie (FCI) and the Funding for the Promotion of Young Academics of University of Goettingen is gratefully acknowledged.

\section{Appendix A. Supplementary data}

Supplementary data associated with this article can be found, in the online version, at https://doi.org/10.1016/j.carbpol.2018.05.036.

\section{References}

Bragd, P., Van Bekkum, H., \& Besemer, A. (2004). TEMPO-mediated oxidation of 
polysaccharides: Survey of methods and applications. Topics in Catalysis, 27(1-4), $49-66$.

Breitenbach, B. B., Schmid, I., \& Wich, P. R. (2017). Amphiphilic polysaccharide block copolymers for $\mathrm{pH}$-responsive micellar nanoparticles. Biomacromolecules, 18(9), 2839-2848.

Czaja, W. K., Young, D. J., Kawecki, M., \& Brown, R. M. (2007). The future prospects of microbial cellulose in biomedical applications. Biomacromolecules, 8(1), 1-12.

De Mico, A., Margarita, R., Parlanti, L., Vescovi, A., \& Piancatelli, G. (1997). A versatile and highly selective hypervalent iodine (III)/2, 2, 6, 6-tetramethyl-1-piperidinyloxylmediated oxidation of alcohols to carbonyl compounds. The Journal of Organic Chemistry, 62(20), 6974-6977.

Diaz-Dussan, D., Nakagawa, Y., Peng, Y.-Y., Leslie V. Sanchez, C., Ebara, M., Kumar, P., \& Narain, R. (2017). Effective and specific gene silencing of epidermal growth factor receptors mediated by conjugated oxaborole and galactose-based polymers. ACS Macro Letters, 6(7), 768-774.

Dong, S., \& Roman, M. (2007). Fluorescently labeled cellulose nanocrystals for bioimaging applications. Journal of the American Chemical Society, 129(45), 13810-13811.

Dowlut, M., \& Hall, D. G. (2006). An improved class of sugar-binding boronic acids, soluble and capable of complexing glycosides in neutral water. Journal of the American Chemical Society, 128(13), 4226-4227.

Feng, X., Fryxell, G., Wang, L.-Q., Kim, A. Y., Liu, J., \& Kemner, K. (1997). Functionalized monolayers on ordered mesoporous supports. Science, 276(5314), 923-926.

Geissler, A., Biesalski, M., Heinze, T., \& Zhang, K. (2014). Formation of nanostructured cellulose stearoyl esters via nanoprecipitation. Journal of Materials Chemistry A, 2(4), 1107-1116.

Geng, J., Mantovani, G., Tao, L., Nicolas, J., Chen, G., Wallis, R., \& Haddleton, D. M. (2007). Site-directed conjugation of clicked glycopolymers to form glycoprotein mimics: Binding to mammalian lectin and induction of immunological function. Journal of the American Chemical Society, 129(49), 15156-15163.

Godula, K., \& Bertozzi, C. R. (2010). Synthesis of glycopolymers for microarray applications via ligation of reducing sugars to a poly(acryloyl hydrazide) scaffold. Journal of the American Chemical Society, 132(29), 9963-9965.

Godula, K., Umbel, M. L., Rabuka, D., Botyanszki, Z., Bertozzi, C. R., \& Parthasarathy, R. (2009). Control of the molecular orientation of membrane-anchored biomimetic glycopolymers. Journal of the American Chemical Society, 131(29), 10263-10268.

Grande, D., Baskaran, S., Baskaran, C., Gnanou, Y., \& Chaikof, E. L. (2000). Glycosaminoglycan-mimetic biomaterials. 1. Nonsulfated and sulfated glycopolymers by cyanoxyl-mediated free-radical polymerization. Macromolecules, 33(4), 1123-1125.

Gupta, S. S., Raja, K. S., Kaltgrad, E., Strable, E., \& Finn, M. G. (2005). Virus-glycopolymer conjugates by copper(i) catalysis of atom transfer radical polymerization and azidealkyne cycloaddition. Chemical Communications, 34, 4315-4317.

Heinze, T., Rahn, K., Jaspers, M., \& Berghmans, H. (1996). p-Toluenesulfonyl esters in cellulose modifications: Acylation of remaining hydroxyl groups. Macromolecular Chemistry and Physics, 197(12), 4207-4224.

Heinze, T., Koschella, A., Magdaleno-Maiza, L., \& Ulrich, A. (2001). Nucleophilic displacement reactions on tosyl cellulose by chiral amines. Polymer Bulletin, 46(1), 7-13.

Heinze, T., Nikolajski, M., Daus, S., Besong, T., Michaelis, N., Berlin, P., \& Harding, S. E. (2011). Protein-like oligomerization of carbohydrates. Angewandte Chemie International Edition, 50(37), 8602-8604.

Heinze, T., Genco, T., Petzold-Welcke, K., \& Wondraczek, H. (2012). Synthesis and characterization of aminocellulose sulfates as novel ampholytic polymers. Cellulose, 19(4), 1305-1313.

Heinze, T. (1998). New ionic polymers by cellulose functionalization. Macromolecular Chemistry and Physics, 199(11), 2341-2364.

Jirawutthiwongchai, J., Krause, A., Draeger, G., \& Chirachanchai, S. (2013). Chitosanoxanorbornadiene: A convenient chitosan derivative for click chemistry without metal catalyst problem. ACS Macro Letters, 2(3), 177-180.

Kadla, J. F., Asfour, F. H., \& Bar-Nir, B. (2007). Micropatterned thin film honeycomb materials from regiospecifically modified cellulose. Biomacromolecules, 8(1), 161-165.

Kamitakahara, H., Suzuki, T., Nishigori, N., Suzuki, Y., Kanie, O., \& Wong, C. H. (1998). A lysoganglioside/poly-L-glutamic acid conjugate as a picomolar inhibitor of influenza hemagglutinin. Angewandte Chemie International Edition, 37(11), 1524-1528.

Kamitakahara, H., Funakoshi, T., Nakai, S., Takano, T., \& Nakatsubo, F. (2010). Synthesis and Structure/property relationships of regioselective 2-O-, 3-O- and 6-O-ethyl celluloses. Macromolecular Bioscience, 10(6), 638-647.

Kim, U.-J., Kuga, S., Wada, M., Okano, T., \& Kondo, T. (2000). Periodate oxidation of crystalline cellulose. Biomacromolecules, 1(3), 488-492.

Klemm, D., Heublein, B., Fink, H. P., \& Bohn, A. (2005). Cellulose: Fascinating biopolymer and sustainable raw material. Angewandte Chemie International Edition, 44(22), 3358-3393.

Kolb, H. C., Finn, M., \& Sharpless, K. B. (2001). Click chemistry: Diverse chemical function from a few good reactions. Angewandte Chemie International Edition, 40(11), 2004-2021.

Koshiji, K., Nonaka, Y., Iwamura, M., Dai, F., Matsuoka, R., \& Hasegawa, T. (2016). C6Modifications on chitosan to develop chitosan-based glycopolymers and their lectinaffinities with sigmoidal binding profiles. Carbohydrate Polymers, 137, 277-286.

Kuralay, F., Sattayasamitsathit, S., Gao, W., Uygun, A., Katzenberg, A., \& Wang, J. (2012). Self-propelled carbohydrate-sensitive microtransporters with built-in boronic acid recognition for isolating sugars and cells. Journal of the American Chemical Society, 134(37), 15217-15220.
Ladmiral, V., Mantovani, G., Clarkson, G. J., Cauet, S., Irwin, J. L., \& Haddleton, D. M. (2006). Synthesis of neoglycopolymers by a combination of click chemistry and living radical polymerization. Journal of the American Chemical Society, 128(14), 4823-4830.

Liu, C., \& Baumann, H. (2002). Exclusive and complete introduction of amino groups and their N-sulfo and N-carboxymethyl groups into the 6-position of cellulose without the use of protecting groups. Carbohydrate Research, 337(14), 1297-1307.

Maleki, L., Edlund, U., \& Albertsson, A.-C. (2015). Thiolated hemicellulose as a versatile platform for one-pot click-type hydrogel synthesis. Biomacromolecules, 16(2), 667-674.

Marks, J. A., Fox, S. C., \& Edgar, K. J. (2016). Cellulosic polyelectrolytes: Synthetic pathways to regioselectively substituted ammonium and phosphonium derivatives. Cellulose, 23(3), 1687-1704.

Meng, X., \& Edgar, K. J. (2016). Click reactions in polysaccharide modification. Progress in Polymer Science, 53, 52-85.

Muller, C., Despras, G., \& Lindhorst, T. K. (2016). Organizing multivalency in carbohydrate recognition. Chemical Society Reviews, 45(11), 3275-3302.

Nielsen, L. J., Eyley, S., Thielemans, W., \& Aylott, J. W. (2010). Dual fluorescent labelling of cellulose nanocrystals for $\mathrm{pH}$ sensing. Chemical Communications, 46(47), 8929-8931.

Paszek, M. J., DuFort, C. C., Rossier, O., Bainer, R., Mouw, J. K., Godula, K., \& Weaver, V. M. (2014). The cancer glycocalyx mechanically primes integrin-mediated growth and survival. Nature, 511, 319.

Pati, D., Kalva, N., Das, S., Kumaraswamy, G., Sen Gupta, S., \& Ambade, A. V. (2012) Multiple topologies from glycopolypeptide-dendron conjugate self-assembly: Nanorods, micelles, and organogels. Journal of the American Chemical Society, 134(18), 7796-7802.

Persson, J. C., \& Jannasch, P. (2005). Intrinsically proton-conducting benzimidazole units tethered to polysiloxanes. Macromolecules, 38(8), 3283-3289.

Saito, T., \& Isogai, A. (2004). TEMPO-mediated oxidation of native cellulose. The effect of oxidation conditions on chemical and crystal structures of the water-insoluble fractions. Biomacromolecules, 5(5), 1983-1989.

Saito, T., \& Isogai, A. (2006). Introduction of aldehyde groups on surfaces of native cellulose fibers by TEMPO-mediated oxidation. Colloids and Surfaces A: Physicochemical and Engineering Aspects, 289(1-3), 219-225.

Saito, T., \& Isogai, A. (2007). Wet strength improvement of TEMPO-oxidized cellulose sheets prepared with cationic polymers. Industrial \& Engineering Chemistry Research, 46(3), 773-780.

Sirvio, J., Hyvakko, U., Liimatainen, H., Niinimaki, J., \& Hormi, O. (2011). Periodate oxidation of cellulose at elevated temperatures using metal salts as cellulose activators. Carbohydrate Polymers, 83(3), 1293-1297.

Sokolsky-Papkov, M., Domb, A. J., \& Golenser, J. (2006). Impact of aldehyde content on amphotericin B- dextran imine conjugate toxicity. Biomacromolecules, 7(5), 1529-1535.

Song, Y., Wang, H., Zeng, X., Sun, Y., Zhang, X., Zhou, J., \& Zhang, L. (2010). Effect of molecular weight and degree of substitution of quaternized cellulose on the efficiency of gene transfection. Bioconjugate Chemistry, 21(7), 1271-1279.

Sprengard, U., Schudok, M., Schmidt, W., Kretzschmar, G., \& Kunz, H. (1996). Multiple sialyl lewisx N-glycopeptides: Effective ligands for E-selectin. Angewandte Chemie International Edition, 35(3), 321-324.

Takano, R., Muchmore, E., \& W-Dennis, J. (1994). Sialylation and malignant potential in tumour cell glycosylation mutants. Glycobiology, 4(5), 665-674.

Tiller, J., Berlin, P., \& Klemm, D. (2000). Novel matrices for biosensor applications by structural design of redox-chromogenic aminocellulose esters. Journal of Applied Polymer Science, 75(7), 904-915.

Toyokuni, T., Dean, B., Cai, S., Boivin, D., Hakomori, S., \& Singhal, A. K. (1994). Synthetic vaccines: Synthesis of a dimeric Tn antigen-lipopeptide conjugate that elicits immune responses against Tn-expressing glycoproteins. Journal of the American Chemical Society, 116(1), 395-396.

Wang, Y., \& Kiick, K. L. (2005). Monodisperse protein-based glycopolymers via a combined biosynthetic and chemical approach. Journal of the American Chemical Society, 127(47), 16392-16393.

Wang, Q., Dordick, J. S., \& Linhardt, R. J. (2002). Synthesis and application of carbohydrate-containing polymers. Chemistry of Materials, 14(8), 3232-3244.

Wu, L., Zhang, Y., Li, Z., Yang, G., Kochovski, Z., Chen, G., \& Jiang, M. (2017). Sweet architecture-dependent uptake of glycocalyx-mimicking nanoparticles based on biodegradable aliphatic polyesters by macrophages. Journal of the American Chemical Society, 139(41), 14684-14692.

Xu, D., Voiges, K., Elder, T., Mischnick, P., \& Edgar, K. J. (2012). Regioselective synthesis of cellulose ester homopolymers. Biomacromolecules, 13(7), 2195-2201.

Yang, W.-h., Li, W.-w., Dou, H.-j., \& Sun, K. (2008). Hydrothermal synthesis for highquality CdTe quantum dots capped by cysteamine. Materials Letters, 62(17-18), 2564-2566.

You, L., \& Schlaad, H. (2006). An easy way to sugar-containing polymer vesicles or glycosomes. Journal of the American Chemical Society, 128(41), 13336-13337.

Zhang, Q., Su, L., Collins, J., Chen, G., Wallis, R., Mitchell, D. A., \& Becer, C. R. (2014). Dendritic cell lectin-targeting sentinel-like unimolecular glycoconjugates to release an anti-HIV drug. Journal of the American Chemical Society, 136(11), 4325-4332.

Zhang, K., Geissler, A., \& Heinze, T. (2015). Reversibly crystalline nanoparticles from cellulose alkyl esters via nanoprecipitation. Particle \& Particle Systems Characterization, 32(2), 258-266. 


\section{Publication 1}

(Supporting information)

Glycosylated cellulose derivatives with regioselective distributions of pendant glucose moieties

Shuang Wang, Kai Zhang* 


\title{
Suppl. Information
}

Glycosylated cellulose derivatives with regioselective distributions of pendant glucose moieties

\author{
Shuang Wang, Kai Zhang
}

\section{General Information}

All commercially available reagents were used without further purification. All solvents were purchased from Carl Roth International GmbH (Germany) and used without further purification. Thin-layer chromatography (TLC) was performed on aluminum backed precoated silica gel plate $\left(60 \mathrm{~F}_{254}\right.$, VWR International $\mathrm{GmbH}$, Germany). Nuclear magnetic resonance (NMR) spectroscopy was performed at $300 \mathrm{MHz}\left({ }^{1} \mathrm{H}-\mathrm{NMR}\right)$ and $75 \mathrm{MHz}\left({ }^{13} \mathrm{C}\right.$ NMR) on Bruker Avance III HD 300 instruments. NMR data were analyzed with MestRe Nova software. $\mathrm{CDCl}_{3}$ and DMSO- $d_{6}$ were generally used as solvents. ${ }^{13} \mathrm{C}$ NMR data were recorded relative to the solvent signals of $\mathrm{CDCl}_{3}$ (at $77.23 \mathrm{ppm}$ ) or DMSO- $d_{6}$ (at $39.5 \mathrm{ppm}$ ) and all chemical shift values of ${ }^{1} \mathrm{H}$ NMR were referenced using the solvent peak of $\mathrm{CDCl}_{3}$ (at $7.27 \mathrm{ppm}$ ) or DMSO-d $d_{6}$ (at $2.5 \mathrm{ppm}$ ).

\section{${ }^{1} \mathrm{H}$ NMR spectra (DMSO- $d_{6}$ ) of cellulose derivatives}
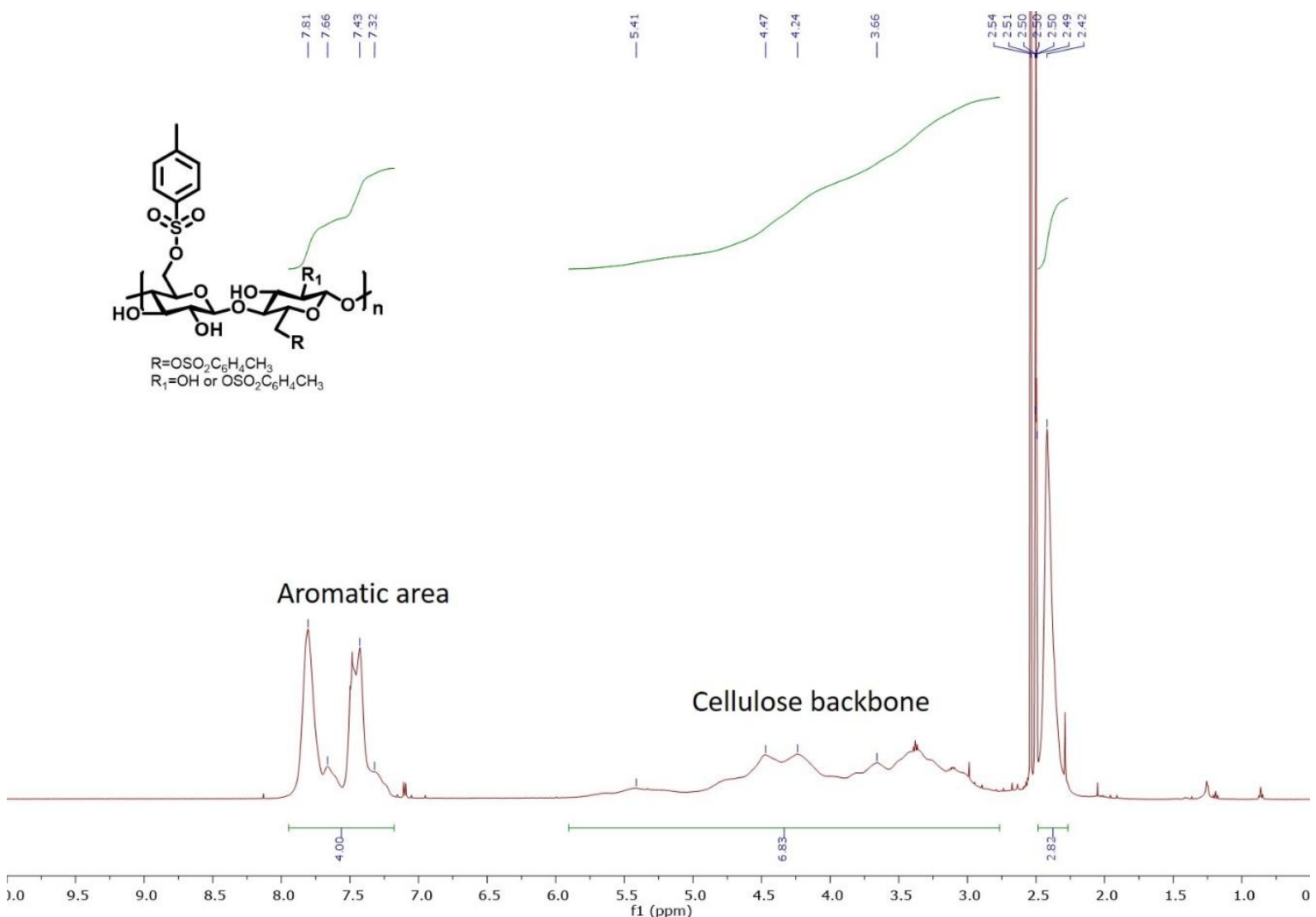

Fig. S1. ${ }^{1} \mathrm{H}$ NMR spectrum of TosC $\left(\mathrm{DS}_{\mathrm{tosyl}}=1.3\right)$ in DMSO- $d_{6}$. 


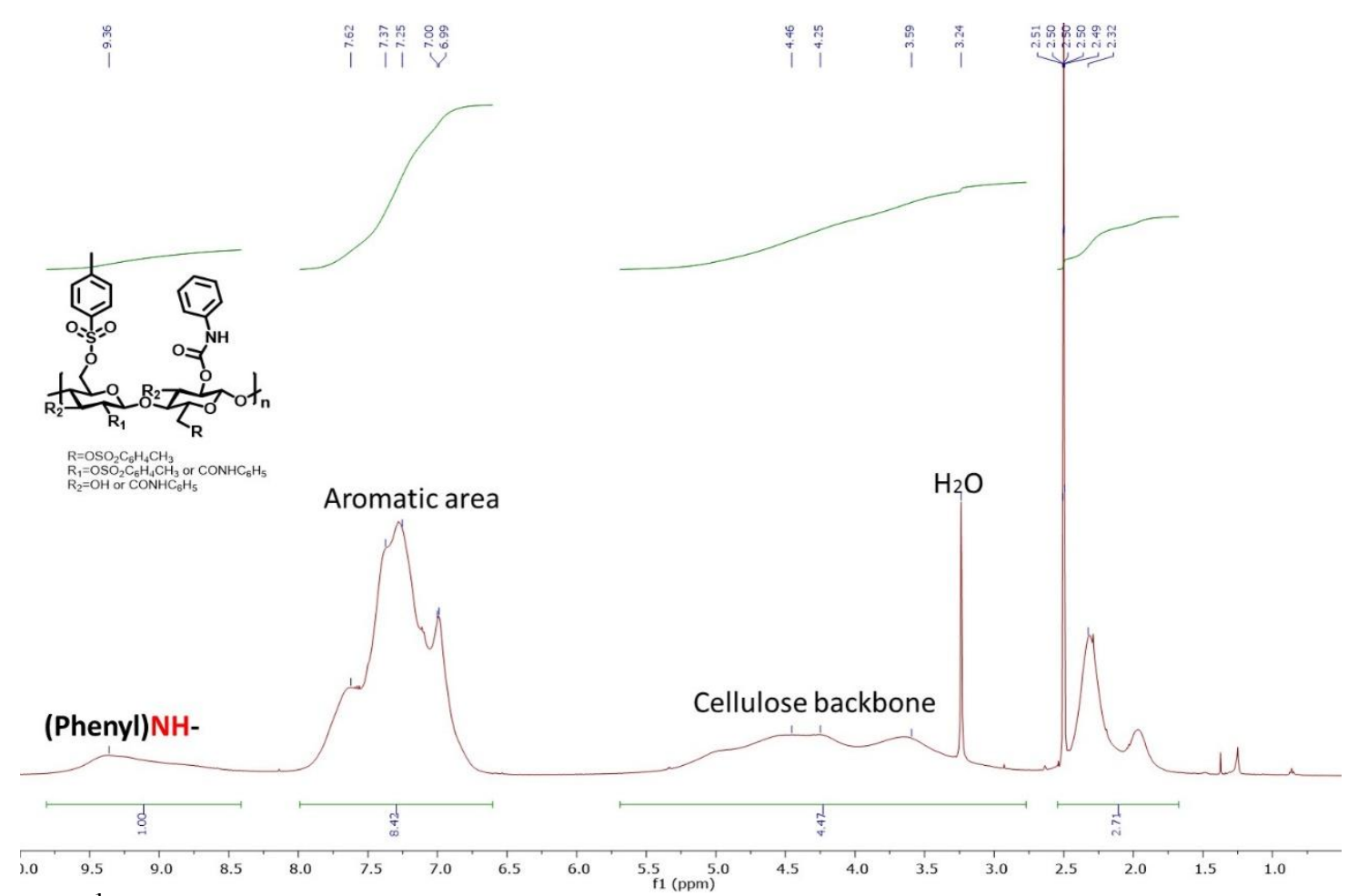

Fig. S2. ${ }^{1} \mathrm{H}$ NMR spectrum of TosCC $\left(\mathrm{DS}_{\mathrm{tosyl}}=1.3, \mathrm{DS}_{\text {carbanilate }}=1.6\right)$ in DMSO- $d_{6}$.

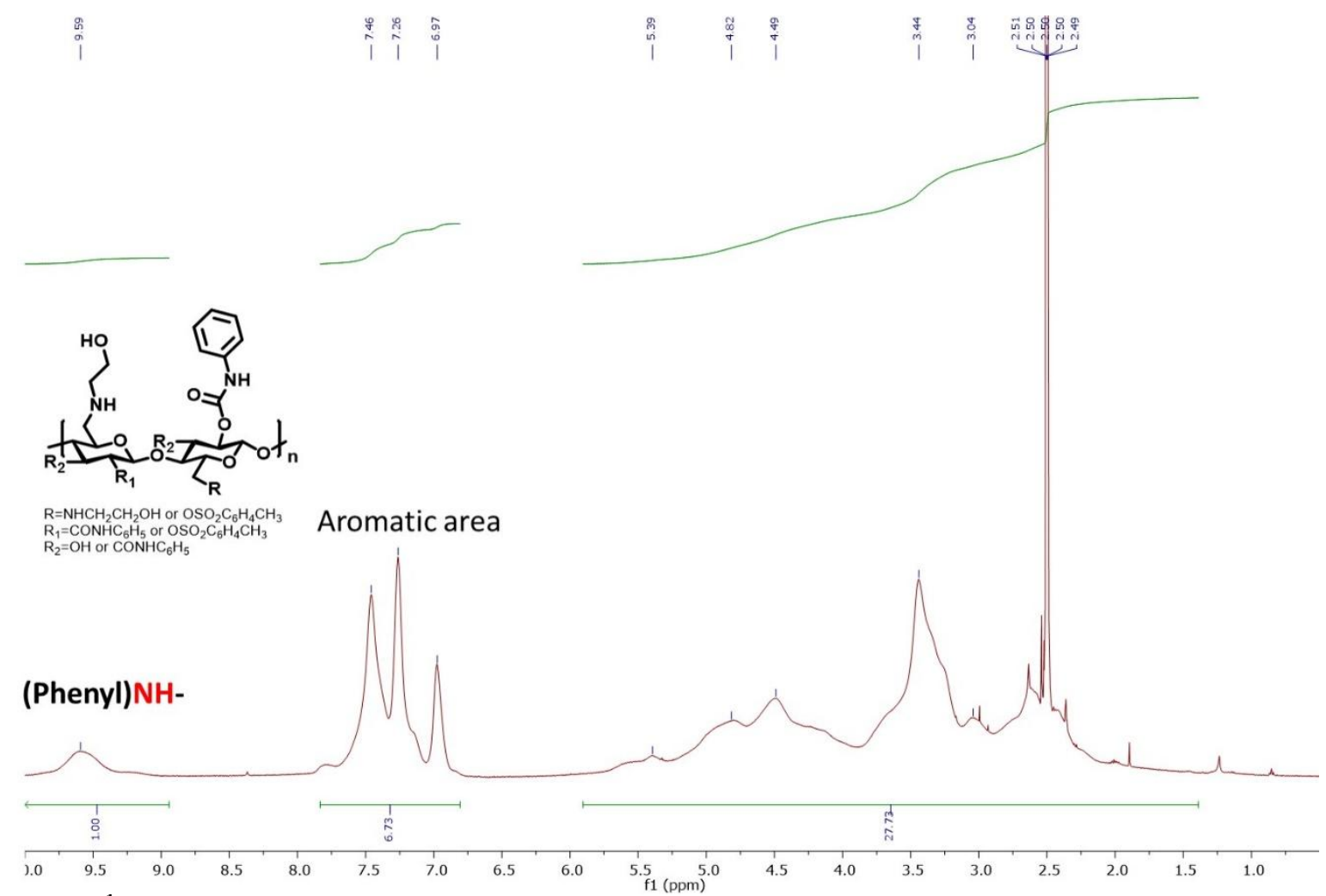

Fig. S3. ${ }^{1} \mathrm{H}$ NMR spectrum of EaCC $\left(\mathrm{DS}_{\text {tosyl }}=0.2, \mathrm{DS}_{\text {carbanilate }}=0.5, \mathrm{DS}_{\mathrm{EA}}=0.8\right)$ in DMSO- $d_{6}$. 


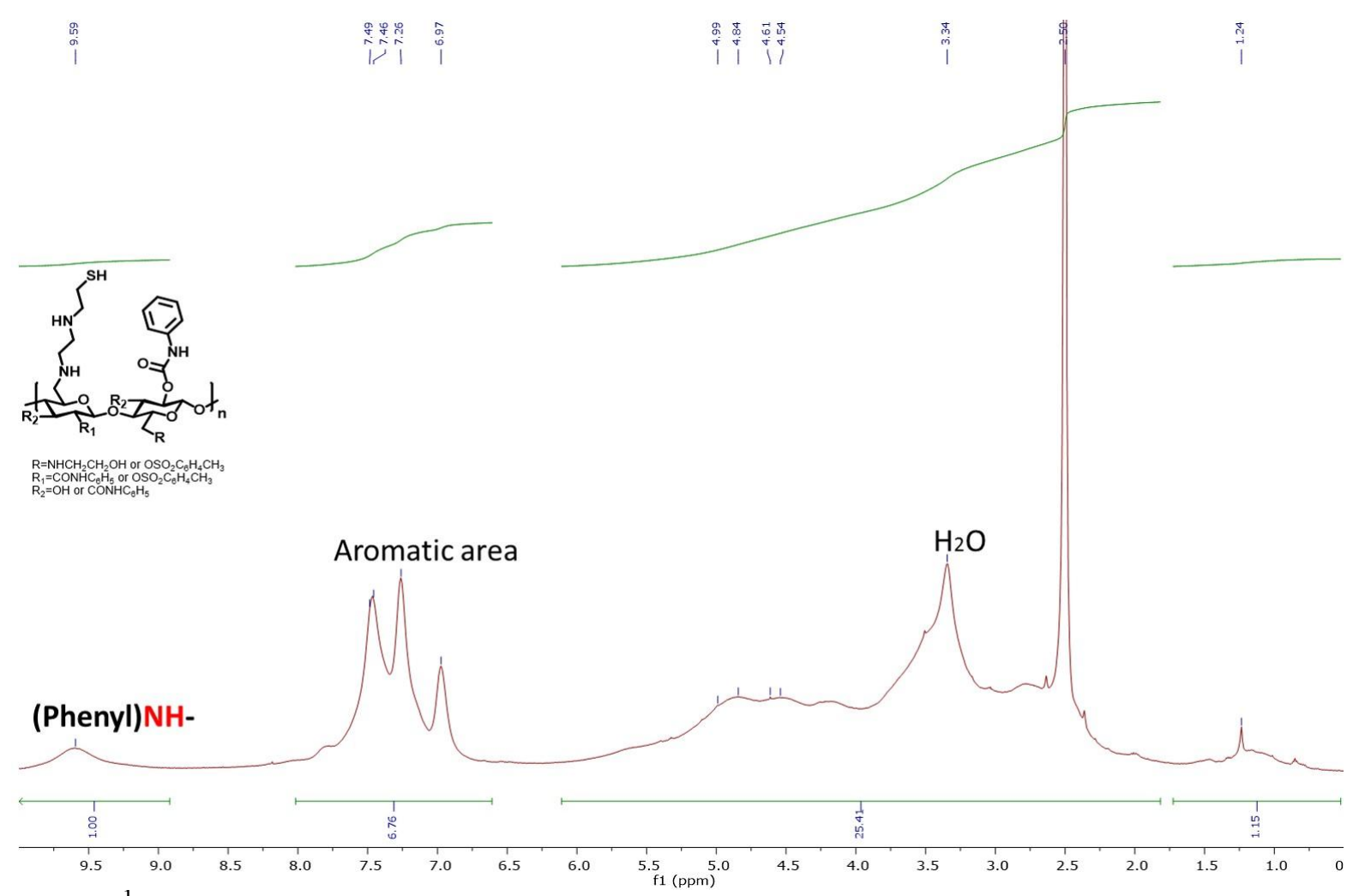

Fig. S4. ${ }^{1} \mathrm{H}$ NMR spectrum of ThiolCC $\left(\mathrm{DS}_{\text {tosyl }}=0.2, \mathrm{DS}_{\text {carbanilate }}=0.5, \mathrm{DS}_{\mathrm{SH}}=0.6\right)$ in DMSO- $d_{6}$.

${ }^{13}$ C NMR spectra (in DMSO- $d_{6}$ ) of cellulose derivatives
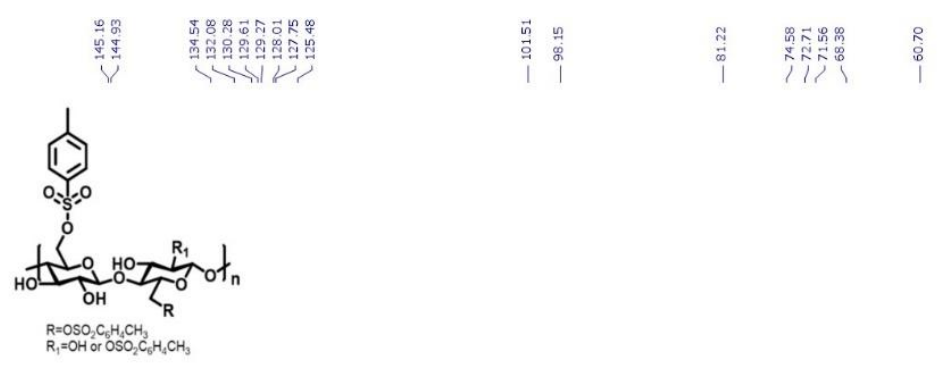

Aromatic area

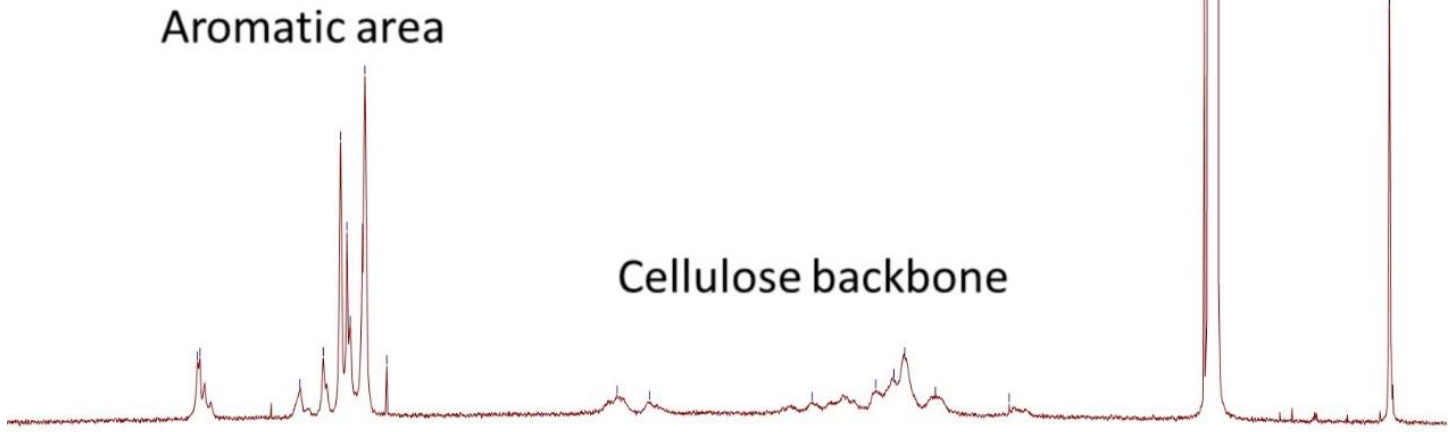

$\begin{array}{lllllllllllllllllllllllllllllll}160 & 155 & 150 & 145 & 140 & 135 & 130 & 125 & 120 & 115 & 110 & 105 & 100 & 95 & 90 & 85 & 80 & 75 & 70 & 65 & 60 & 55 & 50 & 45 & 40 & 35 & 30 & 25 & 20\end{array}$

Fig. S5. ${ }^{13} \mathrm{C}$ NMR spectrum of TosC $\left(\mathrm{DS}_{\mathrm{tosyl}}=1.3\right)$ in $\mathrm{DMSO}-d_{6}$. 


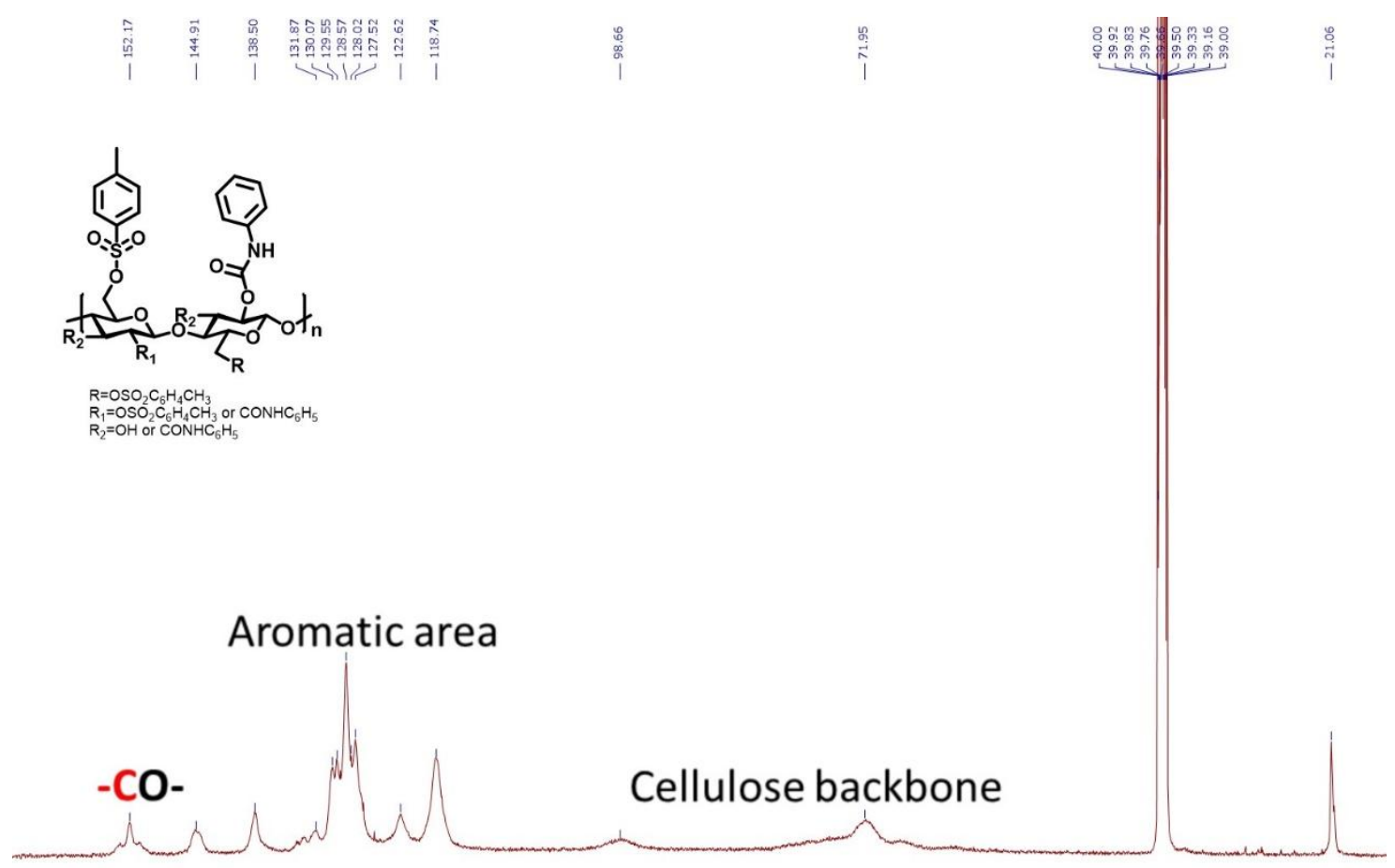

\begin{tabular}{lllllllllllllllllllllllllllllllllllllllllll}
\hline 65 & 160 & 155 & 150 & 145 & 140 & 135 & 130 & 125 & 120 & 115 & 110 & 105 & 100 & 95 & 90 & 85 & 80 & 75 & 70 & 65 & 60 & 55 & 50 & 45 & 40 & 35 & 30 & 25 & 20 & 1
\end{tabular}

Fig. S6. ${ }^{13} \mathrm{C}$ NMR spectrum of TosCC $\left(\mathrm{DS}_{\text {tosyl }}=1.3, \mathrm{DS}_{\text {carbanilate }}=1.6\right)$ in $\mathrm{DMSO}-d_{6}$.

\section{Synthesis of glucose-terminated eugenol}

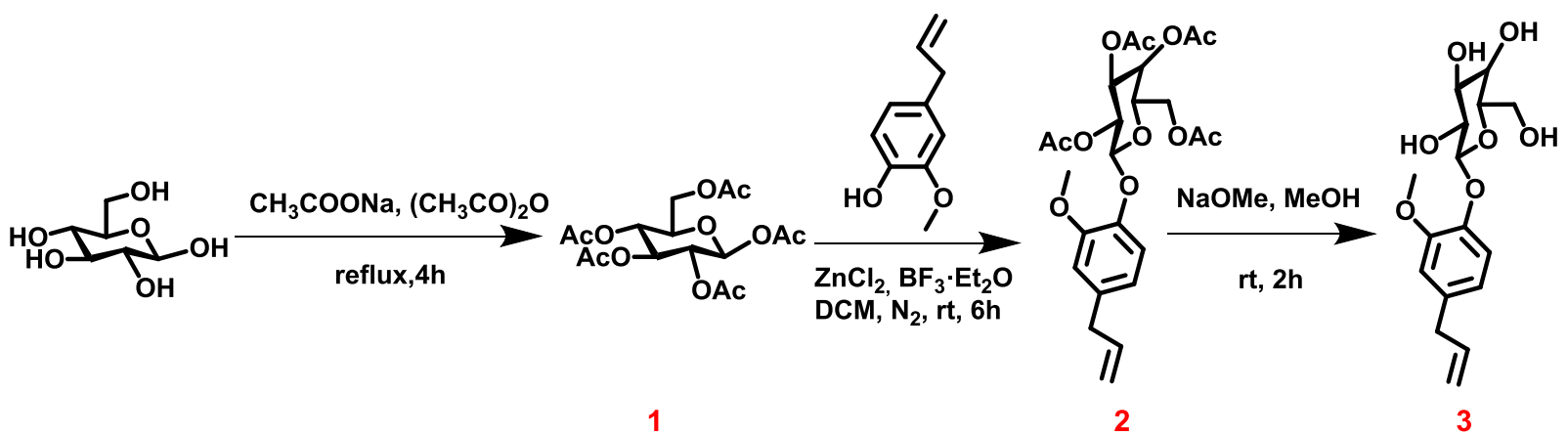

Scheme S1. Schematic illustration for the synthesis of glucose-terminated eugenol.

(2S,3R,4S,5R,6R)-6-(acetoxymethyl)tetrahydro-2H-pyran-2,3,4,5-tetrayl tetraacetate, 1 The synthesis was conducted according to previous report with slight modification (Li et al., 2016; Pulsipher \& Yousaf, 2011). Sodium acetate (5.4 g, $66.6 \mathrm{mmol}$ ) was added to a solution of acetic anhydride $(50 \mathrm{~mL})$, and the mixture was refluxed at $90{ }^{\circ} \mathrm{C}$ for 20 minutes. Then, glucose $(4.00 \mathrm{~g}, 22.2 \mathrm{mmol})$ was added to the mixture, and the reaction mixture was refluxed for 4 hours under stirring. The mixture was then diluted with DCM and washed against saturated $\mathrm{NaHCO}_{3}$ aqueous solution, brine and water. The extract was concentrated and dried 
over $\mathrm{MgSO}_{4}$, before the product was dissolved in methanol and recrystallized using cold water. A white solid was finally filtered and dried to afford product $\mathbf{1}$.

Yield: $7.25 \mathrm{~g}, 83.7 \%$.

${ }^{1} \mathrm{H}$ NMR (300 MHz, $\mathrm{CDCl}_{3}, \delta$ in ppm): 2.01 (s, 3H), 2.02 (s, 3H), 2.04 (s, 3H), 2.09 (s, 3H), $2.18(\mathrm{~s}, 3 \mathrm{H}), 4.06-4.14(\mathrm{~m}, 2 \mathrm{H}), 4.27(\mathrm{dd}, 1 \mathrm{H}, J=3.0 \mathrm{~Hz}), 5.07-5.17(\mathrm{~m}, 2 \mathrm{H}), 5.47(\mathrm{t}, 1 \mathrm{H}, J=$ $9.0 \mathrm{~Hz}), 6.33(\mathrm{~d}, 1 \mathrm{H}, J=3.0 \mathrm{~Hz}) ;{ }^{13} \mathrm{C} \mathrm{NMR}\left(75 \mathrm{MHz}, \mathrm{CDCl}_{3}, \delta\right.$ in ppm): 20.39, 20.51, 20.61, 20.64, 20.82, 61.43, 67.87, 69.16, 69.79, 89.03, 168.69, 169.33, 169.59, 170.16, 170.56 .

\section{(2R,3R,4S,5R,6S)-2-(acetoxymethyl)-6-(4-allyl-2-methoxyphenoxy)tetrahydro-2H- pyran-3,4,5-triyl triacetate, 2}

$\mathrm{ZnCl}_{2}$ (catalytic amount) and eugenol $(0.51 \mathrm{~mL}, 3.33 \mathrm{mmol})$ were added to a solution of compound 1 ( $1 \mathrm{~g}, 2.5 \mathrm{mmol})$ in anhydrous dichloromethane $(15 \mathrm{~mL})$, followed by the addition of boron trifluoride diethyl etherate $(0.41 \mathrm{~mL}, 3.33 \mathrm{mmol})$ drop by drop at $0{ }^{\circ} \mathrm{C}$ (Wei et al., 2016). The mixture was stirred under $\mathrm{N}_{2}$ gas at room temperature for 10 hours. Then, water ( 2 $\mathrm{mL}$ ) was added and the organic layer was separated and washed with $5 \% \mathrm{Na}_{2} \mathrm{CO}_{3}$ solution (2 $\mathrm{mL})$ as well as $5 \% \mathrm{NaCl}$ solution $(2 \mathrm{~mL})$. The extract was then concentrated and dried over $\mathrm{MgSO}_{4}$ under reduced pressure. Finally, the residue was purified using column chromatography with DCM/n-hexane $(1 / 3, \mathrm{v} / \mathrm{v})$ to give compound 2.

Yield: $0.74 \mathrm{~g}, 58.7 \%$.

${ }^{1} \mathrm{H}$ NMR (300 MHz, $\mathrm{CDCl}_{3}, \delta$ in ppm): 2.04-2.06 (m, 9H), $2.12(\mathrm{~s}, 3 \mathrm{H}), 3.34(\mathrm{~d}, 2 \mathrm{H}, J=9.0$ $\mathrm{Hz}), 3.8(\mathrm{~s}, 3 \mathrm{H}), 4.10(\mathrm{dd}, 1 \mathrm{H}, J=3.0 \mathrm{~Hz}), 4.27(\mathrm{dd}, 1 \mathrm{H}, J=3.0 \mathrm{~Hz}), 4.45(\mathrm{dd}, 1 \mathrm{H}, J=3.0$ $\mathrm{Hz}), 4.98(\mathrm{dd}, 1 \mathrm{H}, J=3.0 \mathrm{~Hz}), 5.05-5.17(\mathrm{~m}, 3 \mathrm{H}), 5.64(\mathrm{~d}, 1 \mathrm{H}, J=6.0 \mathrm{~Hz}), 5.73(\mathrm{t}, 1 \mathrm{H}, J=$ $9.0 \mathrm{~Hz}), 5.87-6.00(\mathrm{~m}, 1 \mathrm{H}), 6.68-6.73(\mathrm{~m}, 2 \mathrm{H}), 6.94(\mathrm{~d}, 1 \mathrm{H}, J=9.0 \mathrm{~Hz}) ;{ }^{13} \mathrm{C} \mathrm{NMR}(75 \mathrm{MHz}$, $\mathrm{CDCl}_{3}, \delta$ in ppm): 20.62, 20.66, 20.68, 20.70, 39.88, 55.74, 61.87, 68.01, 68.63, 70.00, 70.83, $96.34,113.10,115.95,120.46,120.72,136.90,137.15,143.42,150.88,169.66,170.04$, 170.24, 170.59 .

\section{(2S,3R,4S,5S,6R)-2-(4-allyl-2-methoxyphenoxy)-6-(hydroxymethyl)tetrahydro-2H- pyran-3,4,5-triol, 3}

Compound 2 (1g, $2 \mathrm{mmol}$ ) was dissolved in $10 \mathrm{~mL}$ dry methanol, before NaOMe $(27 \mathrm{mg}, 0.5$ $\mathrm{mmol}$ ) was added. The mixture was stirred for $2 \mathrm{~h}$ at ambience temperature. Upon completion, the ion exchange resin $\left(\mathrm{H}^{+}\right.$-form) was added slowly for neutralization. After filtration, the resulting solution was evaporated under vacuum and purified by using column chromatography with methanol/ethyl acetate $(1 / 4, \mathrm{v} / \mathrm{v})$ to give compound $\mathbf{3}$ after drying.

Yield: $0.4 \mathrm{~g}, 57.7 \%$.

${ }^{1} \mathrm{H}$ NMR (300 MHz, $\mathrm{CDCl}_{3}, \delta$ in ppm): 3.17 (s, 2H), 3.24 (s, 2H), $3.28(\mathrm{~s}, 1 \mathrm{H}), 3.44(\mathrm{~d}, 1 \mathrm{H}, J$ $=12.0 \mathrm{~Hz}), 3.65(\mathrm{~d}, 1 \mathrm{H}, J=12.0 \mathrm{~Hz}), 3.74(\mathrm{~s}, 3 \mathrm{H}), 4.09(\mathrm{~s}, 1 \mathrm{H}), 4.52(\mathrm{~s}, 1 \mathrm{H}), 4.84(\mathrm{~d}, 1 \mathrm{H}, J=$ $9.0 \mathrm{~Hz}), 5.01-5.10(\mathrm{~m}, 3 \mathrm{H}), 5.20(\mathrm{~s}, 2 \mathrm{H}), 5.88-6.01(\mathrm{~m}, 1 \mathrm{H}), 6.65-6,68(\mathrm{~m}, 1 \mathrm{H}), 6.8(\mathrm{~d}, 1 \mathrm{H}, J$ $=3.0 \mathrm{~Hz}), 7.00(\mathrm{~d}, 1 \mathrm{H}, J=9.0 \mathrm{~Hz}) ;{ }^{13} \mathrm{C} \mathrm{NMR}\left(75 \mathrm{MHz}, \mathrm{CDCl}_{3}, \delta\right.$ in ppm): 48.55, 55.62, 60.66, 69.67, 73.22, 76.83, 76.98, 100.26, 112.95, 115.47, 115.50, 120.27, 133.38, 137.86, $144.87,148.85$.

\section{${ }^{1} \mathrm{H}$ and ${ }^{13} \mathrm{C}$ NMR spectra of glucose derivatives 1-3}




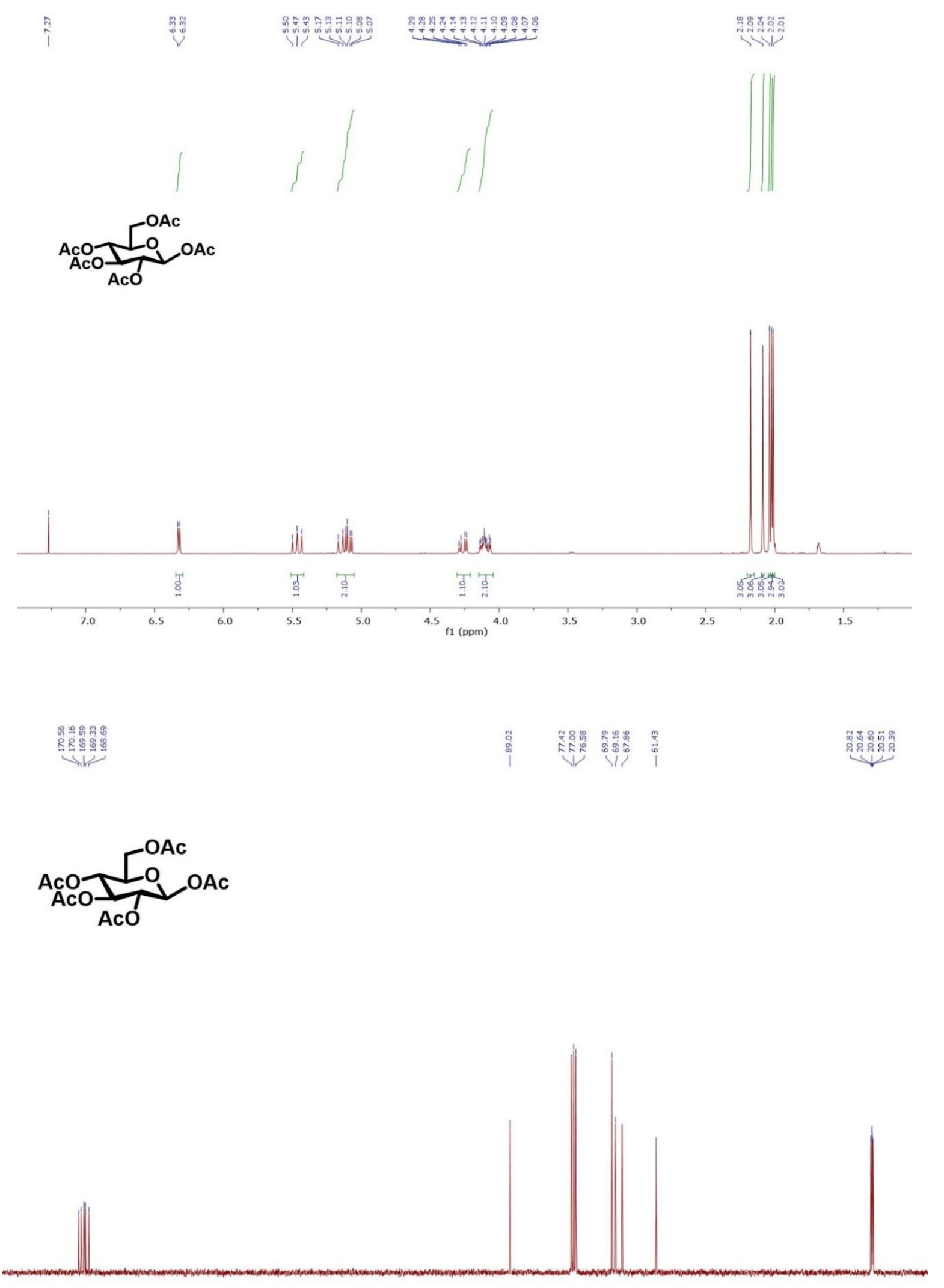

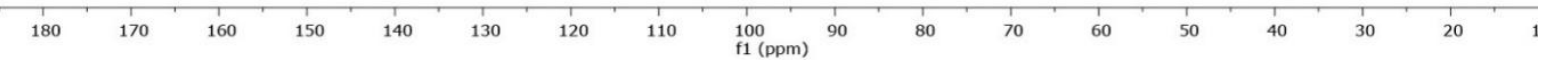



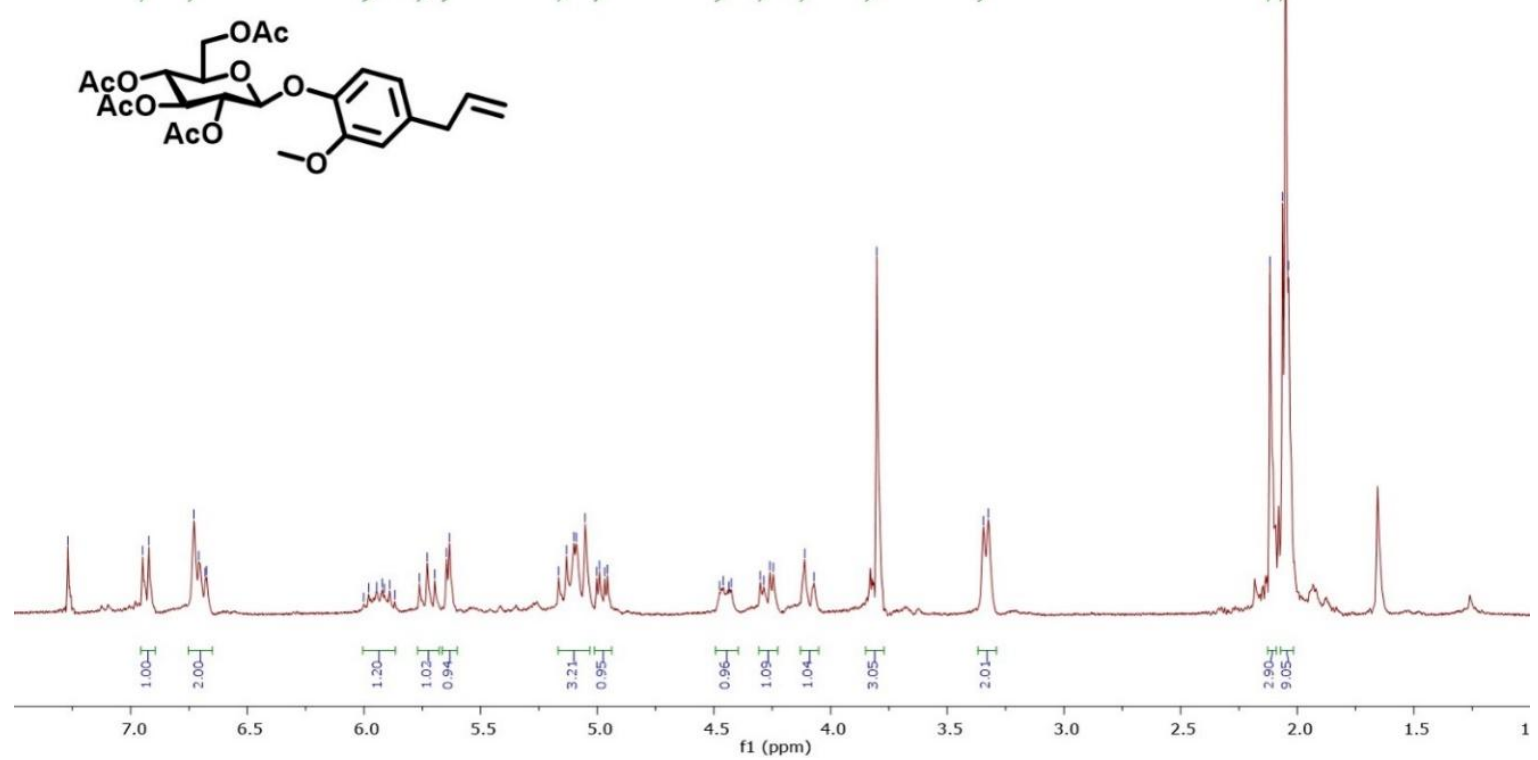

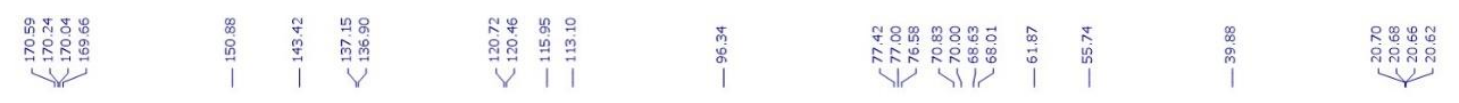<smiles>C=CCc1ccc(OC(=O)OC(C)C(C)(C)OC(C)=O)c(OC)c1</smiles> 


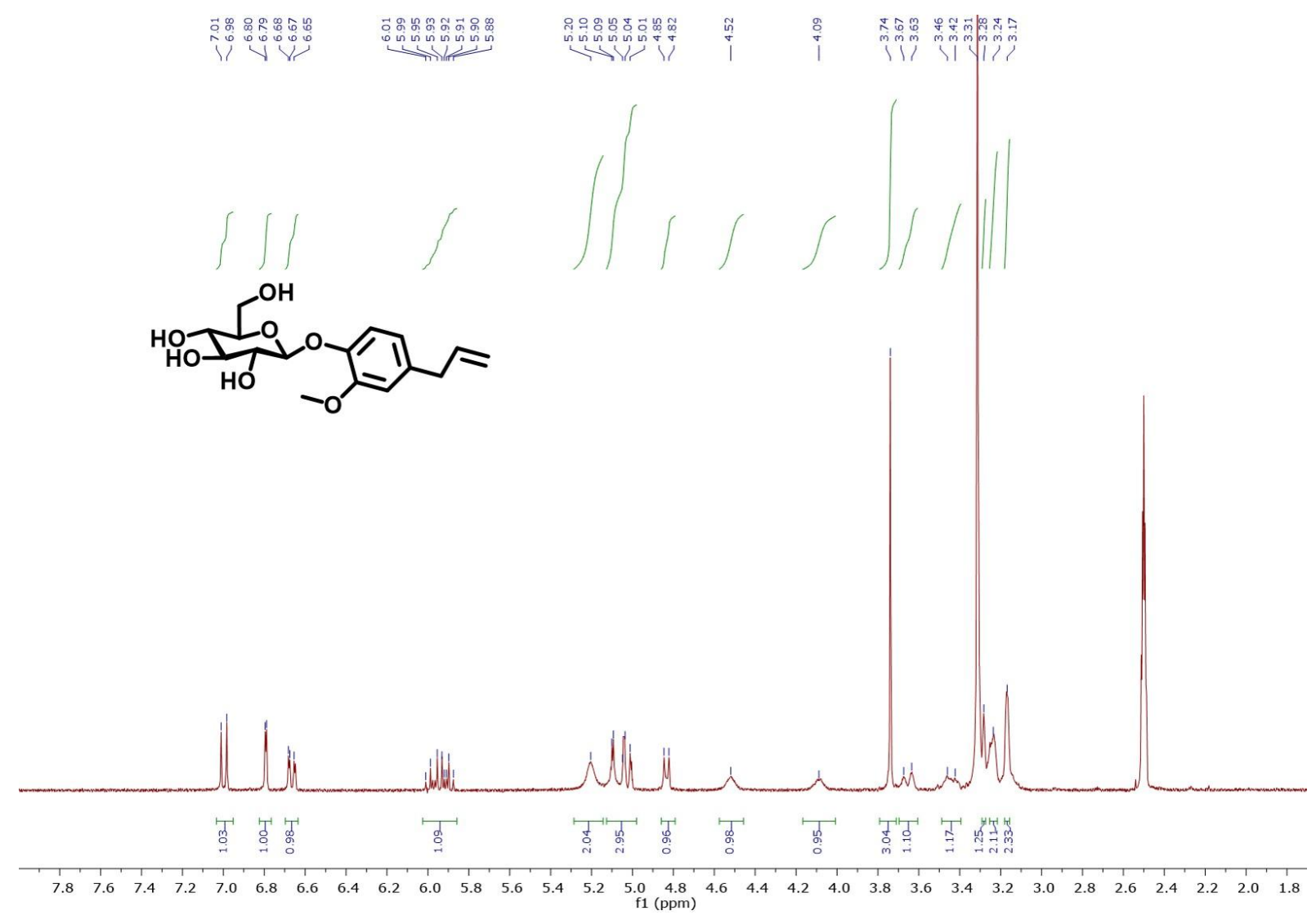

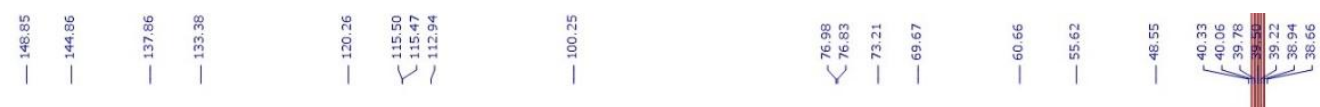

$$
\begin{aligned}
& \text { 管 }
\end{aligned}
$$

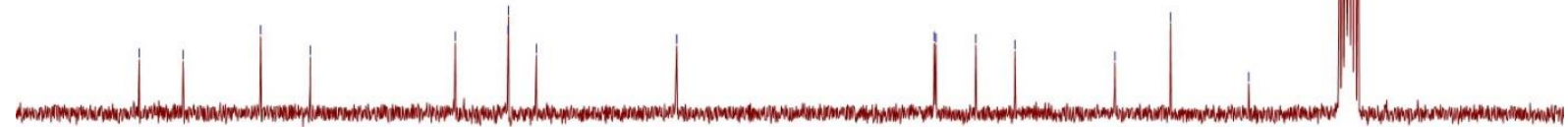

\begin{tabular}{lllllllllllllllllllllllllllllllllllllllllll}
\hline 50 & 155 & 150 & 145 & 140 & 135 & 130 & 125 & 120 & 115 & 110 & 105 & 100 & 95 & 90 & 85 & 80 & 75 & 70 & 65 & 60 & 55 & 50 & 45 & 40 & 35 & 30 & 25 & 2
\end{tabular} 


\section{${ }^{1}$ H NMR spectra (in DMSO- $d_{6}$ ) of GlcThiolCC}
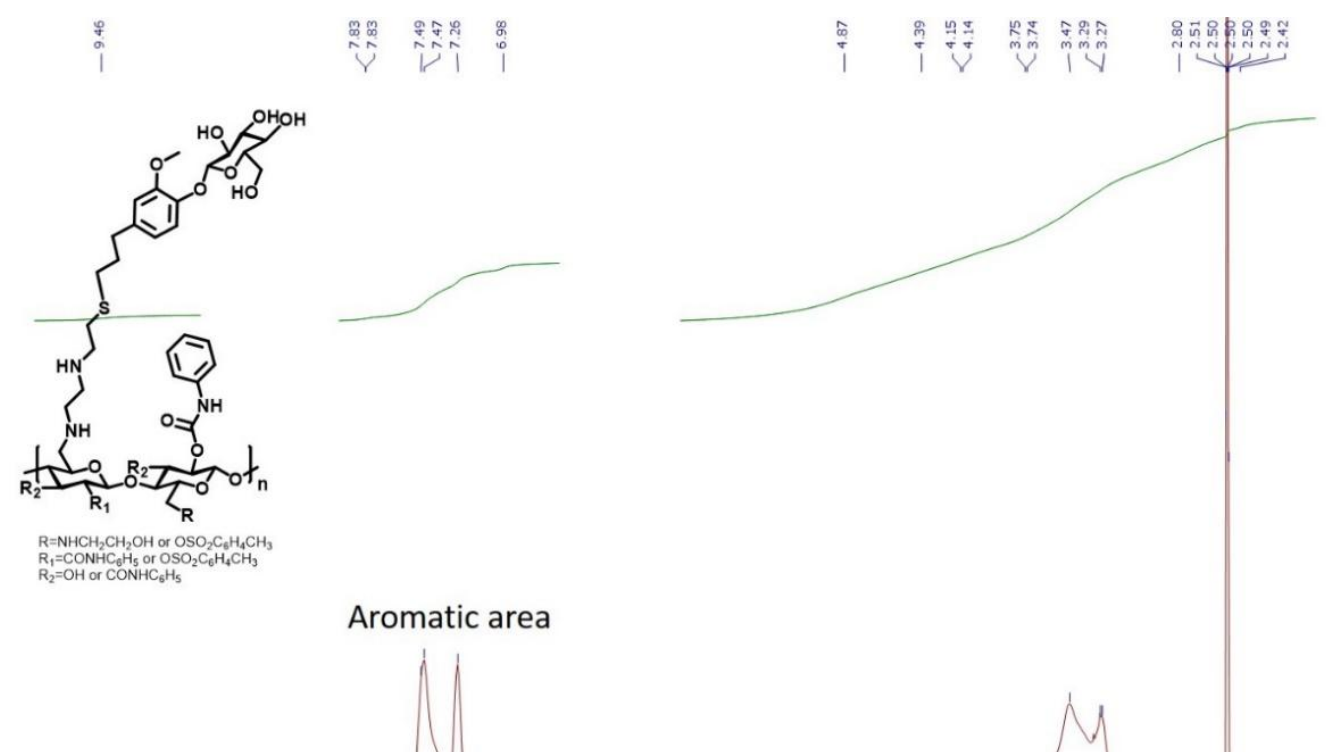

Aromatic area

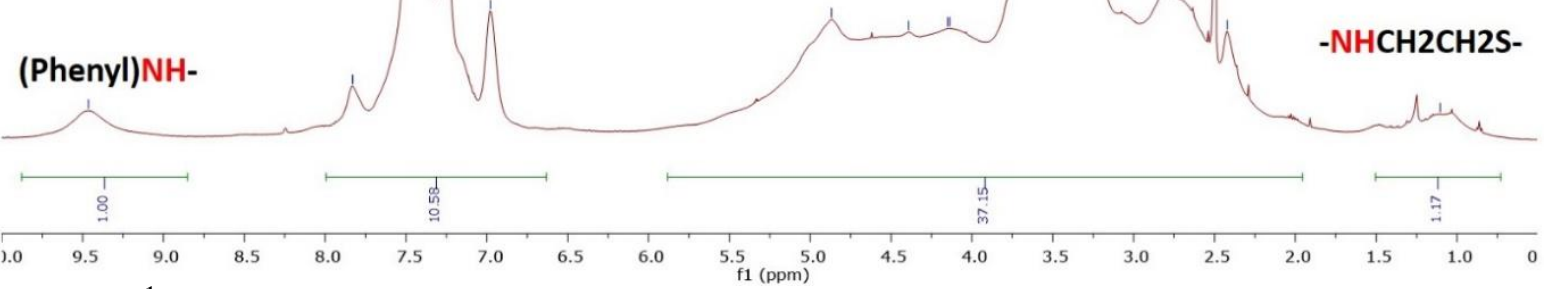

Fig. S7. ${ }^{1} \mathrm{H}$ NMR spectrum of GlcThiolCC $\left(\mathrm{DS}_{\text {tosyl }}=0.2, \mathrm{DS}_{\text {carbanilate }}=0.5, \mathrm{DS}_{\text {glucose }}=0.6\right)$ in DMSO- $d_{6}$.

\section{Reference}

Li, Z., Sun, L., Zhang, Y., Dove, A. P., O'Reilly, R. K., \& Chen, G. (2016). Shape effect of glyconanoparticles on macrophage cellular uptake and immune response. ACS Macro Letters, 5(9), 1059-1064.

Pulsipher, A., \& Yousaf, M. N. (2011). A renewable, chemoselective, and quantitative ligand density microarray for the study of biospecific interactions. Chemical Communications, 47(1), 523525.

Wei, J., Niikura, K., Higuchi, T., Kimura, T., Mitomo, H., Jinnai, H., . . Matsuo, Y. (2016). Yolk/Shell assembly of gold nanoparticles by size segregation in solution. Journal of the American Chemical Society, 138(10), 3274-3277. 


\section{Publication 2}

Macro-scale helices induced by temperature-responsive carbohydrate-based bolaamphiphiles from assembled phenylboronic acid

Shuang Wang, ${ }^{+}$Marcel C. Forster, ${ }^{+}$Kai Xue, Florian Ehlers, Bo Pang, Loren B. Andreas, Philipp Vana and Kai Zhang*

S. Wang, B. Pang, Prof. Dr. K. Zhang

Wood Technology and Wood Chemistry, Dept. Wood Technology and Wood-based Composites, Georg-August-University of Goettingen 37077 Goettingen, Germany.

E-mail: kai.zhang@uni-goettingen.de

M. C. Forster, Dr. K. Xue, Dr. L. B. Andreas

NMR-based Structural Biology, Max-Planck-Institute for Biophysical Chemistry, Am Fassberg 4, 37077 Goettingen, Germany

Dr. F. Ehlers, Prof. Dr. P. Vana

Institute of Physical Chemistry, Georg-August-University of Goettingen Tammannstraße 6, 37077 Goettingen, Germany

[+] These authors contributed equally to this work.

Originally submitted to:

XX 2020 


\begin{abstract}
Using small molecules to assemble well-controlled macro-sized helices is still a great challenge and highly desired for advanced materials. Here, we present the first example of the macro-scale helices co-assembled from temperature-responsive carbohydrate-based bolaamphiphiles (CHO-Bolas) and 1,4-benzenediboronic acid (BDBA). The CHO-Bolas containing hydrophilic glucose or mannose moieties and hydrophobic coumarin dimer showed temperature-responsive reversible micelle-to-vesicle transition (MVT) in aqueous solutions. Based on binding of carbohydrate moieties with boronic acids of BDBA in their alkaline solutions, right-handed helices were formed via the temperature-driven chirality transfer of D-glucose or D-mannose from molecular to supramolecular level. The co-assembled helices with the length of hundreds microns had helical pitches of 5.4-6.3 $\mu \mathrm{m}$ and lamellae thickness of $0.2-0.3 \mu \mathrm{m}$, containing unreacted BDBA, boronate esters and boroxine anhydrides. After heating treatment at $300{ }^{\circ} \mathrm{C}$ in nitrogen gas, helices displayed excellent morphological stability and emitted bright blue luminescence caused by huge self-condensation of BDBA and decomposition of coumarin dimers.
\end{abstract}

Keywords: bolaamphiphile; temperature-responsive; helices; assembly; chirality transfer

\title{
Introduction
}

In living systems, helical self-assemblies of biomacromolecules including nucleic acids, proteins and oligo-/polysaccharides are sophisticated and vital structures formed via non-covalent interactions. Inspired by the intriguing phenomena, chemists have devoted great efforts to mimic nano-/macro-scale helical architectures using designed polymer backbones or supramolecular systems. ${ }^{[1],[2]}$ Generally, the non-covalent forces utilized in preparing helical assemblies are diverse, including van der Waals interactions, hydrogen bonding, electrostatic interactions and $\pi-\pi$ stacking. ${ }^{[3],[4]}$ Both the specific chemical compositions of the molecules and environmental factors, such as solvents, temperature and $\mathrm{pH}$, greatly 
influence the formation of helical aggregates during the assembly process. ${ }^{[5],[6],[7],[8]}$ Well-controlled helices in the single/multiple-stranded form have potential applications in medicine and materials fields, such as drug delivery, gene delivery systems and asymmetric catalysis. ${ }^{[9],[10],[11]}$ However, it is still a great challenge to form macro-scale helices from small organic molecules, e.g. by using a chiral template.

Bolaamphiphiles (also known as bipolar amphiphiles) are defined as molecules, in which two polar functional headgroups are linked by one or more nonpolar hydrocarbon chains. The polar functional headgroups of synthetic bolaamphiphiles that can be either identical or different can be moieties of various types, such as phosphocholine, nucleotide, amino acid and sugar. ${ }^{[12],[13],[14]}$ In nature, there are typical bolaamphiphiles forming stable monolayer lipid membranes of thermophilic archaebacteria. ${ }^{[15],[16]}$ Over the past four decades, bolaamphiphiles have drawn a great deal of attention due to the formation of diverse supramolecular self-assemblies via non-covalent interactions, such as nanofibers, nanotubes and vesicles, ${ }^{[17],[18]}$ which find potential applications in various fields, e.g. pharmaceutics and biomaterials. ${ }^{[19],[20]}$ Among the nonionic ones, sugar-based bolaamphiphiles have outstanding properties, including abundance of chiral centers and recognition ability. ${ }^{[21],[22]}$ However, to our knowledge, there is no report about helical co-assembly of sugar-based chiral bolaamphiphiles and their achiral binding counterpart phenylboronic acids via chirality transfer.

Herein, we report the first macro-scale helices that were induced by temperature-responsive carbohydrate-based bolaamphiphiles by co-assembling with 1,4-benzenediboronic acid (BDBA). We first synthesized novel nonionic CHO-Bolas: CHO-Bolas with D-glucose moieties and a coumarin dimer (GCCG-12) $\mathbf{1}$ as well as CHO-Bolas with D-mannose moieties and a coumarin dimer (MCCM-12) 2. The CHO-Bolas had two sugar skeletons as hydrophilic heads for further boronic acid-binding sites and one dimer of 7-alkoxy-4-methylcoumarins as the hydrophobic motif. The temperature-responsive property of CHO-Bolas allowed their reversible micelle-to-vesicle transition (MVT) in aqueous 
solutions. Due to the chirality and boronic acid-binding ability of the carbohydrate moieties, the CHO-bolas induced macro-sized helices by co-assembling with BDBA in alkaline aqueous solutions with the assistance of temperature $\left(80^{\circ} \mathrm{C}\right)$.

\section{Results and Discussion}

Novel bolaamphiphiles 1-2 containing carbohydrates (glucose or mannose) as hydrophilic headgroups and coumarin dimers as the hydrophobic core were synthesized, which was realized through the simultaneous thiol-ene reaction of 2-allylethoxyl monosaccharide (7-8) and 7-mercaptohexyloxy-4-methylcoumarin (11) as well as [2+2]-photodimerization reaction of coumarin moieties in a one-pot reaction via 300-400 nm UV irradiation (Figure 1a and Schemes S1-S3). It was reported that direct excitation of 7-alkoxy-4-methylcoumarins in organic solvents readily gave the syn head-tail dimer and triplet sensitization resulted in the anti head-tail dimer. ${ }^{[23]}$ In our work, the photo-dimerization reactions worked out only under UV irradiation in dichloromethane via a singlet excited state, in the absence of photo-catalysis. The chemical shifts belonging to the cyclobutane protons and cyclobutane methyl protons were visible at 3.41 and $1.41 \mathrm{ppm}$ (See Supporting Information for ${ }^{1} \mathrm{H}$ NMR spectra). ${ }^{1} \mathrm{H}$ NMR spectra further confirmed the formation of primarily the syn head-tail product with minor quantity of the anti head-tail conformation, which is in agreement with previous reports. ${ }^{[23],[24]}$ 
a)

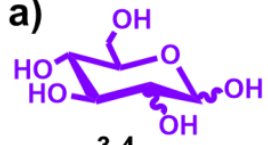

3-4

$\sqrt{2,}\left(\mathrm{CH}_{3} \mathrm{CO}\right)_{2} \mathrm{O}$

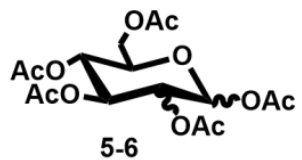

$\mathrm{BF}_{3} \cdot \mathrm{Et}_{2} \mathrm{O}$

2-allyloxyethanol

$\downarrow$ NaOMe, $\mathrm{H}^{+}$-form

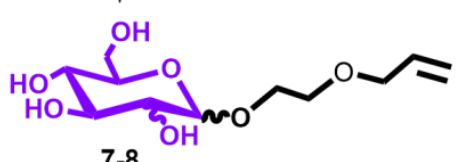

7-8<smiles>Cc1cc(=O)oc2cc(O)ccc12</smiles>

$\downarrow \mathrm{Br}\left(\mathrm{CH}_{2}\right)_{6} \mathrm{Br}$

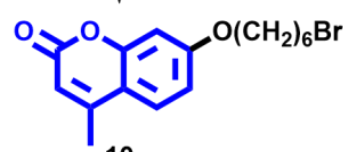

10

$\downarrow \mathrm{CH}_{3} \mathrm{COSK}$

NaOMe, $\mathrm{H}^{+}$-form

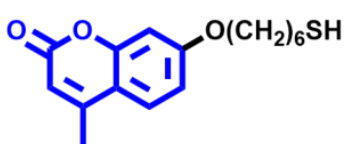

11

J

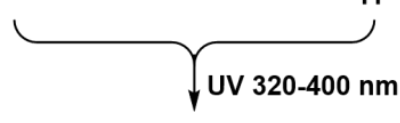

1. GCCG-12

2. MCCM-12

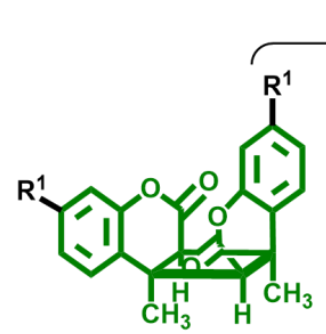

syn head-tail (major)

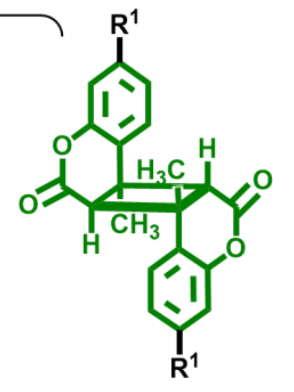

$R^{1}=\mathrm{O}\left(\mathrm{CH}_{2}\right)_{6} \mathrm{~S}\left(\mathrm{CH}_{2}\right)_{3} \mathrm{O}\left(\mathrm{CH}_{2}\right)_{2} \mathrm{O}-\mathrm{C}_{6} \mathrm{H}_{12} \mathrm{O}_{5}$

b)

GCCG-12

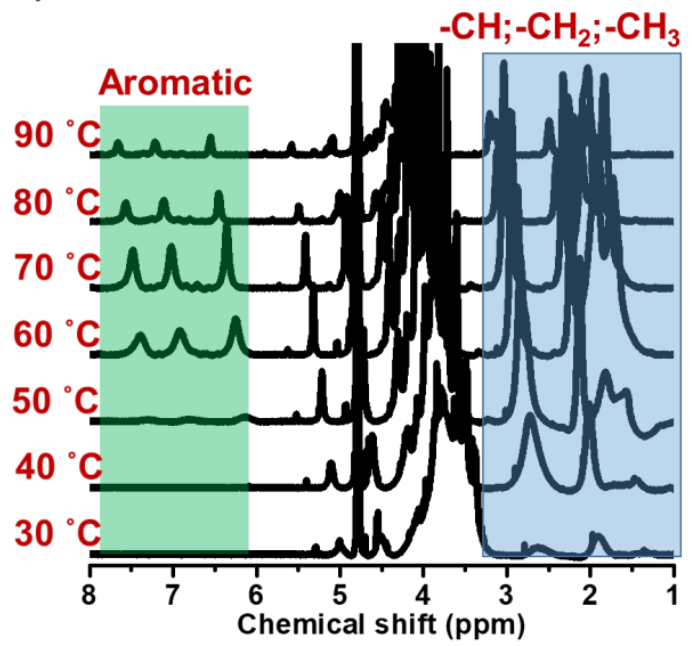

MCCM-12

c)

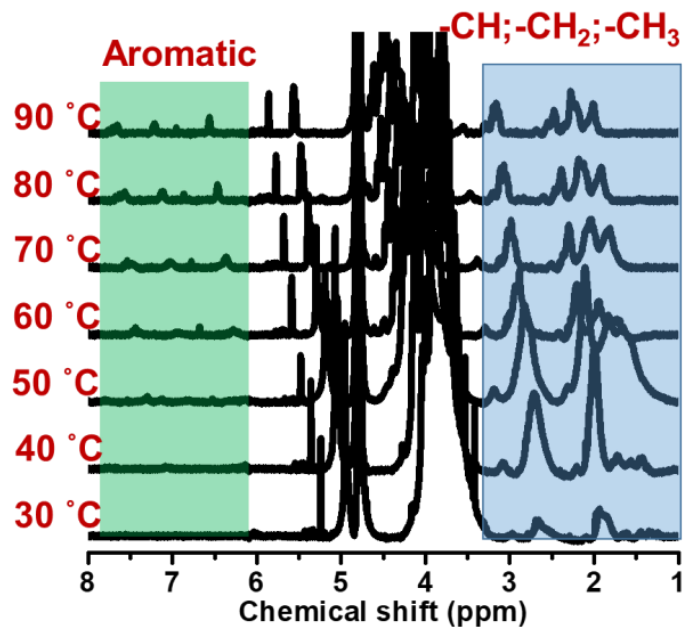

Figure 1. a) Synthesis route for CHO-Bolas containing glucose and a coumarin dimer (GCCG-12) 1 or mannose and a coumarin dimer (MCCM-12) 2. ${ }^{1} \mathrm{H}-\mathrm{NMR}$ spectra of b) GCCG-12 and c) MCCM-12 recorded in $\mathrm{D}_{2} \mathrm{O}$ at various temperatures between 30 and $90{ }^{\circ} \mathrm{C}$.

${ }^{1} \mathrm{H}$ NMR measurements of water-soluble CHO-Bolas in $\mathrm{D}_{2} \mathrm{O}$ at various temperatures showed their temperature-responsive properties at the molecular level. As shown in Figure 1b and c, the peaks in the aromatic region $(\delta \approx 6-7.5 \mathrm{ppm})$ were absent and the peaks in the alkyl region $(\delta \approx 1-3 \mathrm{ppm})$ were significantly diminished at $30{ }^{\circ} \mathrm{C}$, indicating the formation of aggregates via non-covalent interactions. ${ }^{[25]}$ When the temperature was raised to $60{ }^{\circ} \mathrm{C}$, the intensities of peaks in these regions were enhanced due to the increased molecular mobility and partial secession of these interactions. Slight downfield shift of signals of aromatic protons was 
observed during the temperature increase. This behavior can be ascribed to the increase of water-exposure and pressure-induced conformational changes. ${ }^{[26]-[28]}$ Furthermore, these peaks became gradually weaker with further increasing temperature to more than $80{ }^{\circ} \mathrm{C}$.
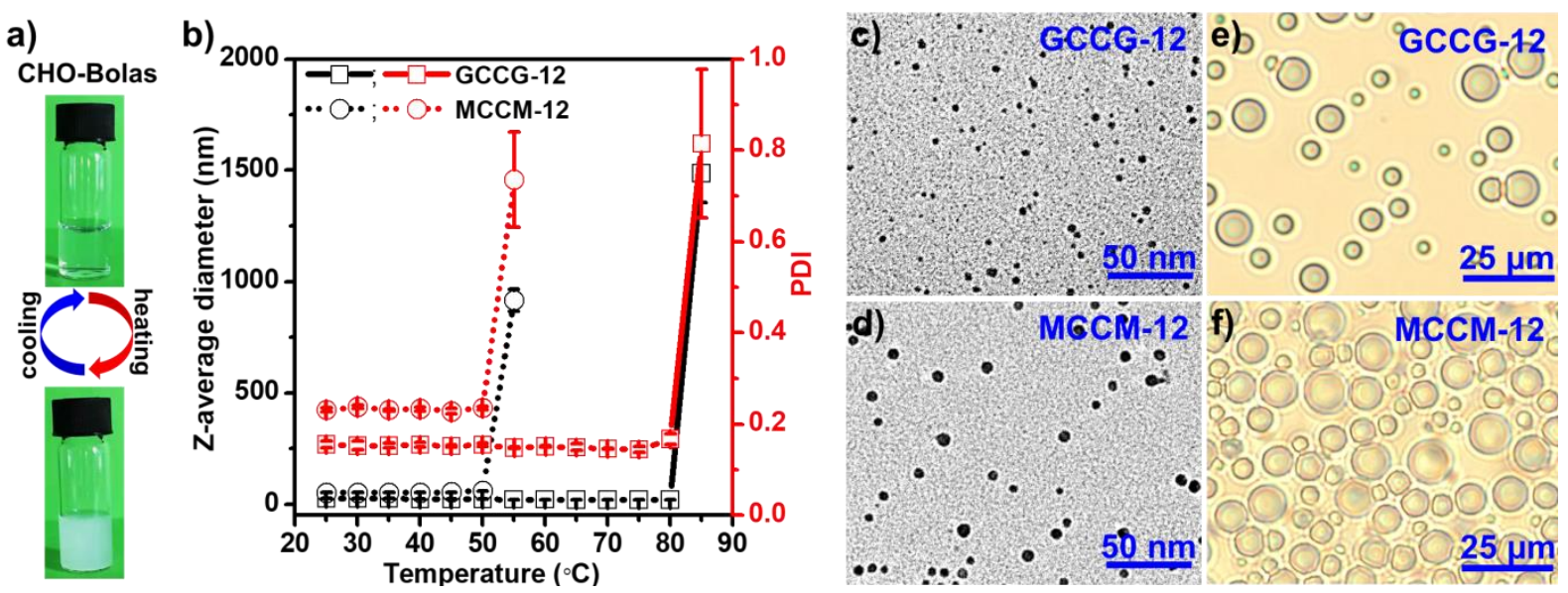

Figure 2. a) Photo images of reversible clear-turbid cycles during heating and cooling of CHO-Bolas in deionized (DI) water. b) Z-average diameters and polydispersity index (PDI) of aggregates formed by GCCG-12 and MCCM-12 in aqueous solutions in correlation with temperature. TEM images of micelles formed by: c) GCCG-12 and d) MCCM-12. Polarized light microscopy (PLM) images of vesicles formed by: e) $\mathrm{GCCG}-12$ at $98{ }^{\circ} \mathrm{C}$ and $\mathrm{f}$ ) MCCM-12 at $70{ }^{\circ} \mathrm{C}$.

The formation of aggregations of the temperature-responsive CHO-Bolas was optically visible and the solution changed from transparent to turbid with increasing temperature to $90{ }^{\circ} \mathrm{C}$ (Figure 2a). The turbid suspensions returned to the transparent solution when cooling down to room temperature. This reversible transparent-turbid-change is in fact a micelle-to-vesicle transition (MVT), which was further measured using dynamic light scattering (DLS) to analyse the temperature-dependent process and the size development of the aggregates (Figure 2b). In GCCG-12 aqueous solutions, the Z-average diameters of aggregates were $22.2 \pm 2.0 \mathrm{~nm}$ with a narrow size distribution (PDI of $0.152 \pm 0.008$ ) at a temperature below $80{ }^{\circ} \mathrm{C}$ and strongly increased to $1.5 \pm 0.1 \mu \mathrm{m}$ with a broad size 
distribution (PDI of $0.815 \pm 0.163$ ) by raising the temperature to $85{ }^{\circ} \mathrm{C}$, indicating the formation of vesicles from the initial micelles. Compared with GCCG-12, the MCCM-12 solution displayed MVT at a lower temperature. The Z-average diameters of aggregates in MCCM-12 solution were $54.2 \pm 2.9 \mathrm{~nm}$ with the PDI of $0.233 \pm 0.005$ at a temperature below $50{ }^{\circ} \mathrm{C}$ and notably increased to $917.7 \pm 49.3 \mathrm{~nm}$ with the PDI of $0.735 \pm 0.105$ after heating to $55^{\circ} \mathrm{C}$. The morphologies of micelles and vesicles formed by $\mathrm{CHO}$-Bolas were analysed with TEM and temperature-controlled PLM measurements, respectively. As shown in Figure 2c and $\mathbf{d}$, the average sizes of the predominantly spherical micelles were $5.4 \pm 1.0 \mathrm{~nm}$ for GCCG-12 and $7.1 \pm 1.1 \mathrm{~nm}$ for MCCM-12. By heating samples of CHO-Bolas solution, vesicles were clearly observed under PLM (Figure 2e and f, Movies S1 and S2). The average sizes of vesicles were $6.2 \pm 1.9 \mu \mathrm{m}$ for $\mathrm{GCCG}-12$ at $95{ }^{\circ} \mathrm{C}$ and $9.4 \pm 2.2 \mu \mathrm{m}$ for MCCM-12 at $70{ }^{\circ} \mathrm{C}$. Therefore, the $\mathrm{CHO}-$ Bolas exhibited temperature-responsive behaviors by forming reversible micelles and vesicles depending on the temperature.

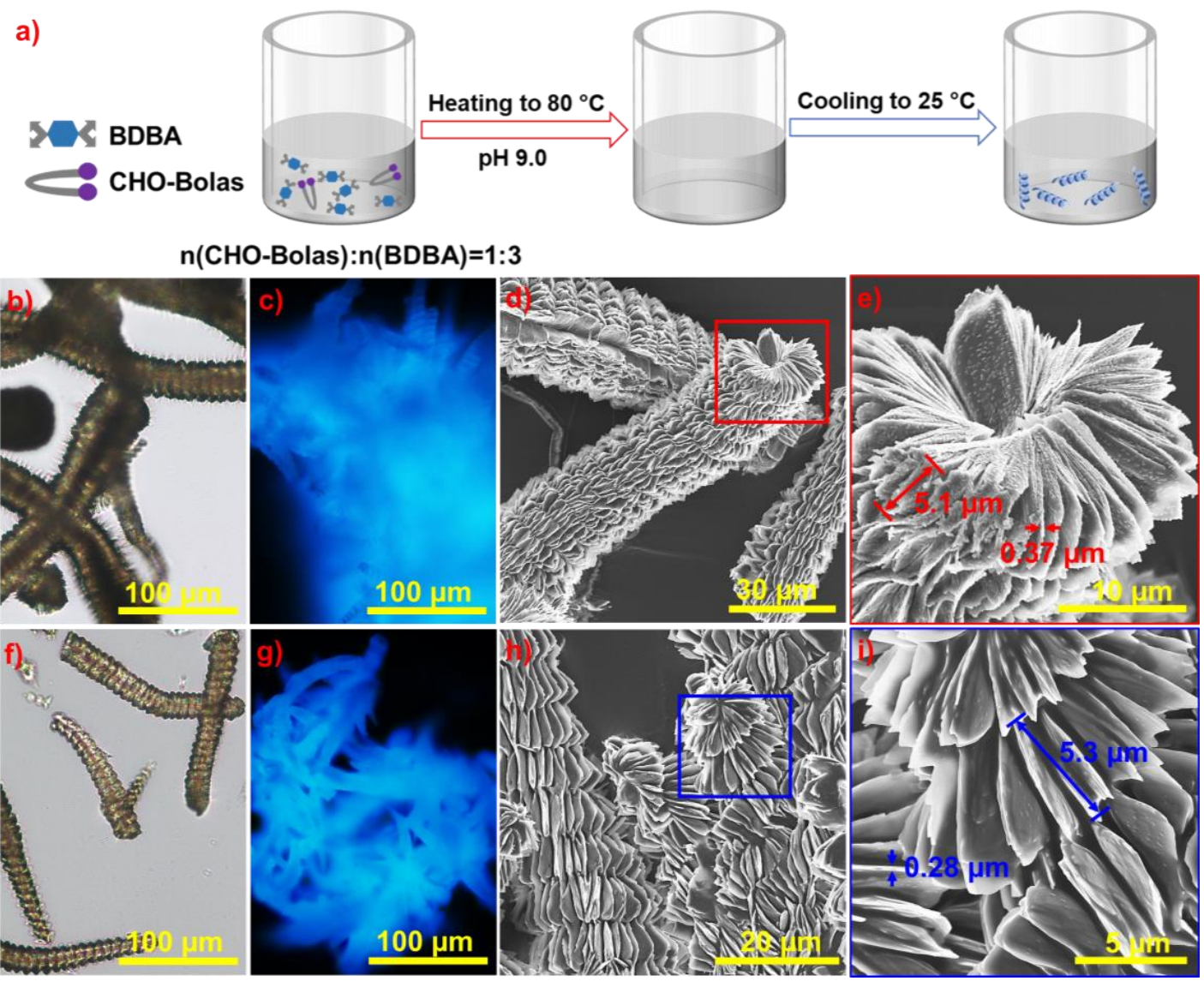


Figure 3. a) Schematic illustration for the formation of helical structures in alkaline aqueous solution of CHO-Bolas and 1,4-benzeneboronic acid (BDBA). Optical light and fluorescence microscopy as well as SEM images of the helices with diverse magnifications: b-e) formed by GCCG-12 and BDBA; f-i) formed by MCCM-12 and BDBA.

Apart from the temperature-responsive behavior of the reversible transition between micelles and vesicles, $\mathrm{CHO}-$ Bolas had other characteristic properties, such as chirality and recognition via bonding with lectins or boronic acids through the carbohydrate moieties. ${ }^{[21],[22]}$ It is known that boronic acids have the potential to covalently and non-covalently interact with diverse molecular motifs in aqueous media, such as reversibly bonding with diols to form boronic esters, self-condensation to form boroxines and hydrogen bonding with other active molecules. ${ }^{[29],[30]}$

As shown in Figure 3a, helices were obtained from the mixture of the CHO-Bolas and BDBA with the molar ratio of 1:3. These were dissolved in alkaline aqueous solution ( $\mathrm{pH} 9$ ) at $80{ }^{\circ} \mathrm{C}$. After cooling the solutions slowly down to room temperature, co-assembled helical aggregates of several hundred microns in length were obtained (Figure $3 \mathbf{b}$ and f). The assembled solid-state helical structures emitted blue luminescence, as observed under the fluorescence microscope with a UV lamp $(\lambda=365 \mathrm{~nm}$ ) (Figure 3c and g). Moreover, the SEM images of the air-dried samples showed right-handed helices containing packed thin layers (Figure 3d-e and h-i). The helices of co-assembled BDBA/GCCG-12 had helical pitches of $5.4 \pm 1.1 \mu \mathrm{m}$ and lamellae thickness of $0.3 \pm 0.1 \mu \mathrm{m}$ (Figure 3e). In comparison, co-assembled helices of BDBA/MCCM-12 had larger helical pitches of $6.3 \pm 1.0 \mu \mathrm{m}$ and thinner lamellae with a thickness of $0.2 \pm 0.1 \mu \mathrm{m}$ (Figure 3i). In contrast to the co-assembled helices by CHO-Bolas and BDBA, BDBA alone only self-assembled into brick-shaped structures under equal conditions, as revealed by optical light and fluorescence microscopy as well as SEM images (Figure S1). It should be noted that the mixture of CHO-Bolas and BDBA in neutral aqueous solutions produced sporadic macro-sized helices and a large 
amount of brick-shaped structures when decreasing the temperature from $80{ }^{\circ} \mathrm{C}$ to room temperature. Therefore, well-ordered helices should be formed by the chirality transfer from the CHO-Bolas to co-assemblies and simultaneously via covalent interactions among cis-diols and boronic acids as well as non-covalent interactions including hydrogen bonding interaction and $\pi-\pi$ stacking during cooling to room temperature. Without the CHO-Bolas, brick-shaped structures constituting only of benzeneboronic acids did not form helical structures.
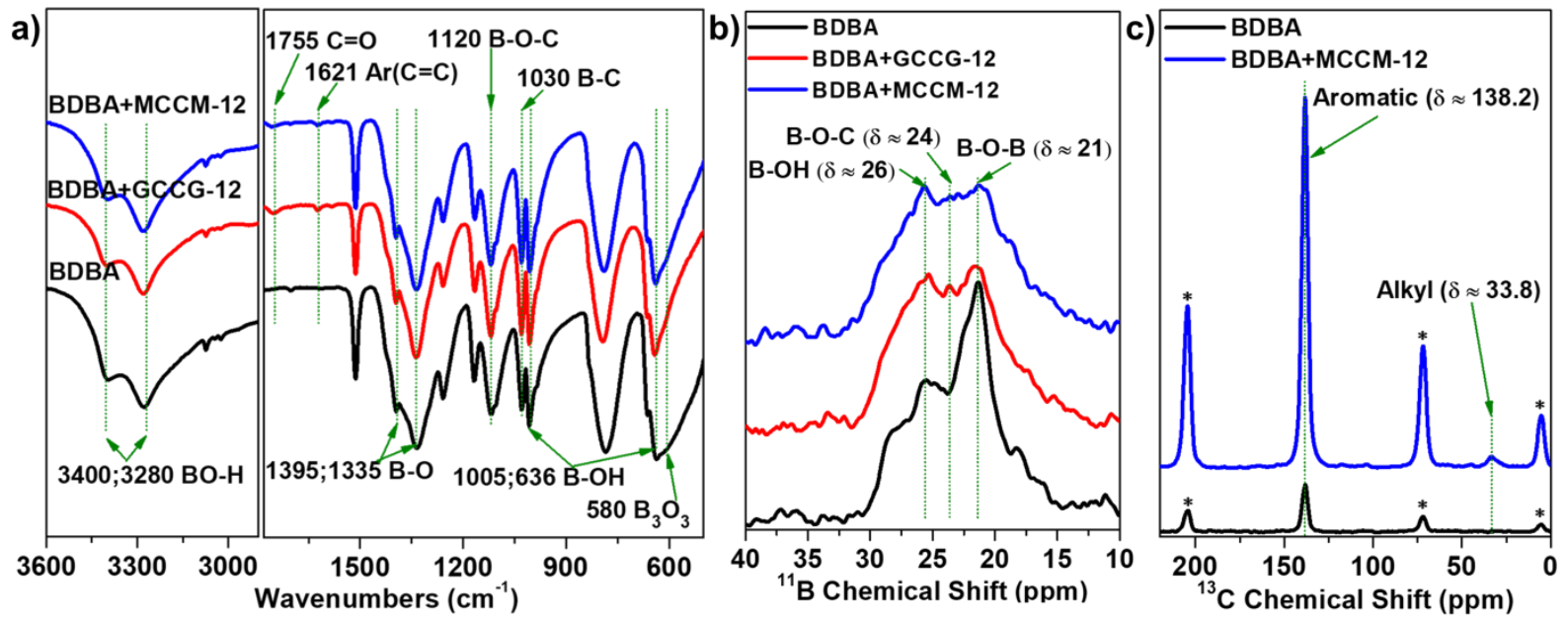

Figure 4. a) FTIR spectra and b) Solid-state ${ }^{11}$ B NMR spectra of the helical structures formed by the $\mathrm{CHO}$-Bolas and BDBA, as well as brick-shaped structure formed by BDBA alone. c) Solid-state ${ }^{13} \mathrm{C}$ NMR spectra of the helical assembly formed by MCCM-12 and BDBA, as well as brick-shaped structure formed by BDBA alone. Asterisks indicate spinning side-band peaks.

To reveal the chemical compositions of co-assembled helices, they were further analysed with FTIR and solid-state ${ }^{11} \mathrm{~B} /{ }^{13} \mathrm{C}$ NMR spectroscopy. According to the FTIR spectra of the helices and brick-shaped aggregates (Figure 4a), the peaks ascribed to unreacted BDBA were predominant and strong, e.g. the peaks assigned to the BO-H stretching vibration at 3280 and $3400 \mathrm{~cm}^{-1}$, the peaks attributed to B-O at 1335 and $1395 \mathrm{~cm}^{-1}$, the peak of B-C(aryl) at 1030 $\mathrm{cm}^{-1}$, and the peaks corresponding to B-OH stretching vibrations at 636 and $1005 \mathrm{~cm}^{-1}$. [31],[32] 
Within the FTIR spectra of helices, the new emerging peaks at 1621 and $1755 \mathrm{~cm}^{-1}$ were assigned to aromatic rings and $\mathrm{C}=\mathrm{O}$ groups of coumarin dimers, respectively. Moreover, the greatly increased peak at $1120 \mathrm{~cm}^{-1}$ was attributed to the symmetric C-O-B-O-C stretching vibration. ${ }^{[33]}$ All these results indicated the formation of boronate esters between BDBA and CHO-Bolas within the helices. Moreover, brick-shaped aggregates contained much more boroxine anhydrides according to the peak at $580 \mathrm{~cm}^{-1}$ attributed to boroxine anhydrides, ${ }^{[34]}$ while it should be marginal within helices based on their very weak peaks.

The solid-state ${ }^{11} \mathrm{~B}$ NMR spectrum of the self-assembled helices exhibited overlapping multiplets due to the boron atoms in different structural environments (Figure 4b). Compared to the brick-shaped aggregates formed by BDBA alone, the helical structures formed by BDBA and CHO-Bolas showed a much broader peak, consisting of multiple peaks with roughly the same intensity. This can be explained with the overlap boroxine anhydride at around $21 \mathrm{ppm}$, new emerging boronate ester at around $24 \mathrm{ppm}$ and boronic acid at around 26 ppm, in agreement with the FTIR results shown above. The solid-state ${ }^{13} \mathrm{C}$ NMR spectrum of brick-shaped aggregates exhibited one single and weak resonance for aromatic rings of BDBA at 138 ppm (Figure 4c). In comparison, the solid-state ${ }^{13} \mathrm{C}$ NMR spectrum of helices formed by MCCM-12 and BDBA displayed one stronger and broader resonance at $138 \mathrm{ppm}$ and one weak resonance for alkyl chains of MCCM-12 at $34 \mathrm{ppm}$. Therefore, the helical structures contained high amounts of bulk BDBA, reversible boronate esters formed between BDBA and CHO-Bolas, and boroxine anhydrides by self-condensation of BDBA.

In addition, adding excess of glucose or mannose into the suspension of these helices led to their gradual disassembly and finally complete dissolution in aqueous solutions. This phenomenon also indicated the pivotal role of reversible boronate esters between BDBA and CHO-Bolas in chirally guiding the formation of right-handed helical structures. 

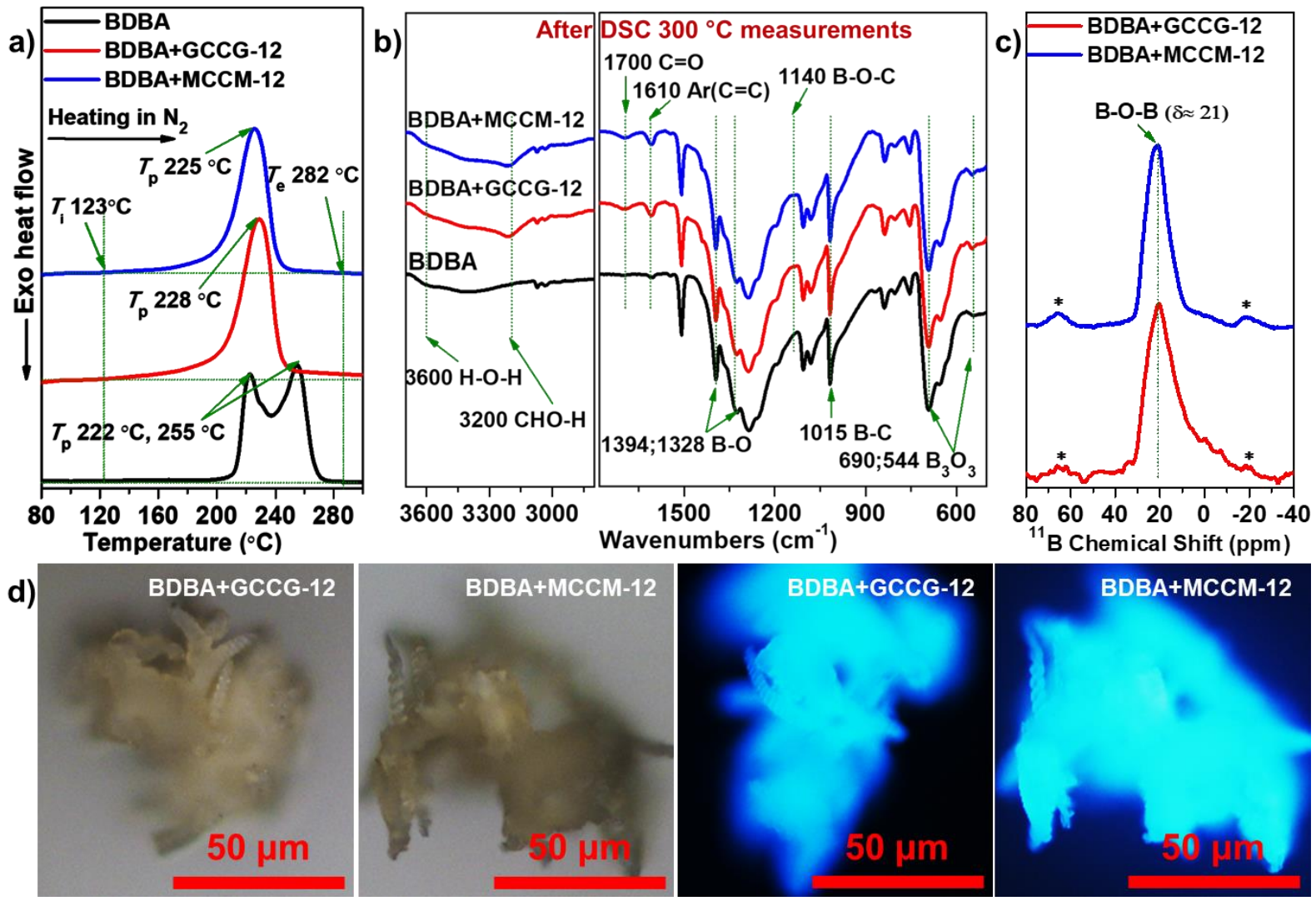

Figure 5. a) DSC curves of assembled structures heated from $20{ }^{\circ} \mathrm{C}$ to $300{ }^{\circ} \mathrm{C}$ at a heating rate of $5 \mathrm{~K} / \mathrm{min}$ under a nitrogen atmosphere. b) FTIR spectra of assembled structures after the treatments at $300{ }^{\circ} \mathrm{C}$ in nitrogen gas. c) Solid-state ${ }^{11} \mathrm{~B}$ NMR spectra of helical structure formed by $\mathrm{CHO}$-Bolas and BDBA after the treatment at $300{ }^{\circ} \mathrm{C}$ in nitrogen gas. Asterisks indicate spinning side-band peaks. d) Optical and fluorescence microscopy images of helices formed by $\mathrm{CHO}-\mathrm{Bolas}$ and BDBA after treatment at $300{ }^{\circ} \mathrm{C}$ in nitrogen gas.

The helices were further treated at high temperature to analyse their thermal properties and compositions. It is well known that the six-membered boroxine anhydrides can be easily formed by dehydrative self-condensation of boronic acid, when the temperature exceeds $100{ }^{\circ} \mathrm{C} \cdot{ }^{[35]}$ According to the FTIR and solid-state ${ }^{11} \mathrm{~B}$ NMR spectra of the assembled helical structures (Figure 4), there were excessive active groups of B-OH in comparison to hydroxyl groups of carbohydrate moieties. As shown in Figure 5a, the DSC curves of the self-assembled helices showed the endothermic processes, starting at around $123{ }^{\circ} \mathrm{C}$ (initial temperature, $T_{\mathrm{i}}$ ) and ending at around $282{ }^{\circ} \mathrm{C}$ (end temperature, $T_{\mathrm{e}}$ ). The helical structures 
formed by both CHO-Bolas and BDBA exhibited only one single endothermic peak at 225-228 ${ }^{\circ} \mathrm{C}$. In comparison, the brick-shaped structures formed by BDBA alone showed two partially overlapping endothermic peaks at $222^{\circ} \mathrm{C}$ and $255^{\circ} \mathrm{C}$. Since all DSC measurements of assembled aggregates were carried out in sealed crucibles, no peaks corresponding to water evaporation were observed.

The endothermic processes involved multiple reactions and physical changes, such as self-condensation of $\mathrm{B}-\mathrm{OH}$ groups into boroxine anhydrides, decomposition of coumarin dimers into coumarin monomers, ${ }^{[36]}$ esterification of $\mathrm{B}-\mathrm{OH}$ groups with hydroxyl groups of mannose moieties and melting. After the heat treatment with accompanying boroxine anhydride formation by self-condensation of BDBA, the strong bands at 3000-3580, 1005 and $636 \mathrm{~cm}^{-1}$ ascribed to $\mathrm{BO}-\mathrm{H}$ and $\mathrm{B}-\mathrm{OH}$ vibrations sharply decreased (Figure 5b). In comparison, the bands at 690 and $544 \mathrm{~cm}^{-1}$ attributed to B-O-B of boroxine anhydrides greatly increased. ${ }^{[32],[31],[37]}$ Due to the self-condensation and esterification of B-OH groups with hydroxyl groups of mannose moieties, the signal at $3600 \mathrm{~cm}^{-1}$ ascribed to free hydroxyl groups of resulting water was observed. Interestingly, the band at $1755 \mathrm{~cm}^{-1}$ attributed to the saturated ketones and the band at $1621 \mathrm{~cm}^{-1}$ due to aromatic rings of coumarin dimers disappeared. New stronger bands at 1700 and $1610 \mathrm{~cm}^{-1}$ for the unsaturated ketones and aromatic rings of coumarins appeared, indicating the decomposition of coumarin dimers into coumarin monomers after heat treatment. ${ }^{[36]}$ Besides, signals emerged at 1140 and $1015 \mathrm{~cm}^{-1}$ corresponding to B-O-C of boronate esters and B-C bonds, respectively.

As shown in Figure 5c and Figure S2, the solid-state ${ }^{11}$ B NMR spectra of co-assembled structures formed by $\mathrm{CHO}-$ Bolas and BDBA as well as self-assembled by BDBA alone after the treatment at $300{ }^{\circ} \mathrm{C}$ under nitrogen atmosphere exhibited only one single broad peak at around $21 \mathrm{ppm}$. This peak is attributed to resulting B-O-B bonds in high quantities during the heat treatment, which was in good agreement with the FTIR results. Moreover, helices showed great morphological stability after the heat treatment at $300{ }^{\circ} \mathrm{C}$ (Figure 5d). Their luminescence also changed to a bright blue from blue due to the formation of more $\pi-\pi$ 
stacking in the boroxine network upon heating and decomposition of coumarin dimers in helices, which is similar as the brick-shaped structure of BDBA alone (Figure 5d and S1-d).

\section{Conclusion}

In summary, we found a new approach to prepare macro-sized right-handed helices via chirality transfer from novel carbohydrate-based bolaamphiphiles (CHO-Bolas) using co-assembled 1,4-benzenediboronic acid (BDBA) as building blocks. The CHO-Bolas containing chiral glucose/mannose headgroups were synthesized via simultaneous thiol-ene click and [2+2]-photodimerization of coumarins reactions in one-pot reacton after UV irradiation. The CHO-Bolas displayed temperature-responsive behaviour by showing reversible micelle-to-vesicle transition. Furthermore, the $\mathrm{CHO}-$ Bolas had other characteristic properties including chirality and recognition ability. When mixing with BDBA in alkaline solution at $80{ }^{\circ} \mathrm{C}$, the carbohydrate moieties of $\mathrm{CHO}$-Bolas transferred chirality to macro-scale right-handed helices in a co-assembly process. The resulting helical structures constructed by BDBA were induced by $\mathrm{CHO}$-Bolas via covalent interactions among CHO-Bolas and BDBA, as demonstrated by FTIR spectra and solid-state NMR measurements. After treatment at $300{ }^{\circ} \mathrm{C}$ in nitrogen gas, the fluorescence of the helices was enhanced due to the enhanced self-condensation of BDBA and decomposition of coumarin dimers. This work paves the way to realize the chirality transfer from small organic molecules to assembled supramolecular structures using carbohydrate as chirality templates.

\section{Acknowledgements}

K.Z. thanks Fonds der Chemischen Industrie (FCI) for the financial support and Georg-August-University of Goettingen for the Department Start-up funding. S.W. and B.P. gratefully acknowledge their PhD scholarship from the Chinese Scholarship Council (CSC). 


\section{Reference}

[1] A. E. Rowan, R. J. Nolte, Angew. Chem. Int. Ed. 1998, 37, 63-68.

[2] C. Schmuck, Angew. Chem. Int. Ed. 2003, 42, 2448-2452.

[3] F. J. Hoeben, P. Jonkheijm, E. Meijer, A. P. Schenning, Chem. Rev. 2005, 105, 1491-1546.

[4] Y. Yang, Y. Zhang, Z. Wei, Adv. Mater. 2013, 25, 6039-6049.

[5] K. Murata, M. Aoki, T. Suzuki, T. Harada, H. Kawabata, T. Komori, F. Ohseto, K. Ueda, S. Shinkai, J. Am. Chem. Soc. 1994, 116, 6664-6676.

[6] A. Brizard, C. Aimé, T. Labrot, I. Huc, D. Berthier, F. Artzner, B. Desbat, R. Oda, J. Am. Chem. Soc. 2007, 129, 3754-3762.

[7] X. Zhang, J. Zou, K. Tamhane, F. F. Kobzeff, J. Fang, Small 2010, 6, 217-220.

[8] T. D. Nguyen, S. C. Glotzer, Small 2009, 5, 2092-2098.

[9] E. R. Gillies, F. Deiss, C. Staedel, J. M. Schmitter, I. Huc, Angew. Chem. Int. Ed. 2007, 46, 4081-4084.

[10] T. Nakano, Y. Okamoto, Chem. Rev. 2001, 101, 4013-4038.

[11] T. Kimmerlin, K. Namoto, D. Seebach, Helv. Chim. Acta 2003, 86, 2104-2109.

[12]M. Ambrosi, E. Fratini, V. Alfredsson, B. W. Ninham, R. Giorgi, P. Lo Nostro, P. Baglioni, Journal of the American Chemical Society 2006, 128, 7209-7214.

[13]K. Köhler, G. Förster, A. Hauser, B. Dobner, U. F. Heiser, F. Ziethe, W. Richter, F. Steiniger, M. Drechsler, H. Stettin, Journal of the American Chemical Society 2004, 126, 16804-16813.

[14]R. Iwaura, K. Yoshida, M. Masuda, K. Yase, T. Shimizu, Chemistry of materials 2002, 14, 3047-3053.

[15] G. H. Escamilla, G. R. Newkome, Angewandte Chemie International Edition in English 1994, 33, 1937-1940.

[16] J. H. Fuhrhop, D. Fritsch, Accounts of Chemical Research 1986, 19, 130-137.

[17]R. Iwaura, K. Yoshida, M. Masuda, M. Ohnishi-Kameyama, M. Yoshida, T. Shimizu, 
Angew. Chem. Int. Ed. 2003, 42, 1009-1012.

[18] J. Jiang, Y. Meng, L. Zhang, M. Liu, J. Am. Chem. Soc. 2016, 138, 15629-15635.

[19] N. Nuraje, H. Bai, K. Su, Progress in Polymer Science 2013, 38, 302-343.

[20] J.-H. Fuhrhop, T. Wang, Chemical Reviews 2004, 104, 2901-2938.

[21]M. N. Nasir, J.-M. Crowet, L. Lins, F. O. Akong, A. Haudrechy, S. Bouquillon, M. Deleu, Biochimie 2016, 130, 23-32.

[22]H. Kobayashi, K. Koumoto, J. H. Jung, S. Shinkai, J. Chem. Soc. Perkin Trans. 2. 2002, $1930-1936$.

[23] K. Muthuramu, N. Ramnath, V. Ramamurthy, The Journal of Organic Chemistry 1983, $48,1872-1876$.

[24]B. Kiskan, Y. Yagci, Journal of Polymer Science Part A: Polymer Chemistry 2007, 45, $1670-1676$.

[25] W. Yuan, H. Zou, W. Guo, A. Wang, J. Ren, J. Mater. Chem. 2012, 22, 24783-24791.

[26] S. R. McAlpine, M. A. Garcia-Garibay, J. Am. Chem. Soc. 1996, 118, 2750-2751.

[27]J. C. Morales, S. Penadés, Angew. Chem. Int. Ed. 1998, 37, 654-657.

[28]H. R. Kalbitzer, A. Görler, H. Li, P. V. Dubovskii, W. Hengstenberg, C. Kowolik, H. Yamada, K. Akasaka, Protein Sci. 2000, 9, 693-703.

[29] R. Pizer, C. Tihal, Inorg. Chem. 1992, 31, 3243-3247.

[30] A. L. Korich, P. M. Iovine, Dalton Trans. 2010, 39, 1423-1431.

[31]L. Santucci, H. Gilman, J. Am. Chem. Soc. 1958, 80, 193-196.

[32] H. Snyder, M. S. Konecky, W. Lennarz, J. Am. Chem. Soc. 1958, 80, 3611-3615.

[33]M. K. Smith, B. H. Northrop, Chemistry of Materials 2014, 26, 3781-3795.

[34]B. M. Rambo, J. J. Lavigne, Chemistry of materials 2007, 19, 3732-3739.

[35]H. Snyder, J. Kuck, J. R. Johnson, J. Am. Chem. Soc. 1938, 60, 105-111.

[36] N. Yonezawa, Y. Ikebe, T. Yoshida, T. Hirai, K. Saigo, M. Hasegawa, Bull. Chem. Soc. Jpn. 1984, 57, 1608-1611.

[37] C. Bao, Y. J. Jiang, H. Zhang, X. Lu, J. Sun, Adv. Funct. Mater. 2018, 28, 1800560. 


\section{Publication 2}

(Supporting information)

Macro-scale helices induced by temperature-responsive carbohydrate-based bolaamphiphiles from assembled phenylboronic acid

Shuang Wang $^{+}$, Marcel C. Forster ${ }^{+}$, Kai Xue, Florian Ehlers, Bo Pang, Loren Andreas, Philipp Vana and Kai Zhang* 


\section{Table of Content}

1. General Remarks

1.1 Materials

1.2 Characterizations

2. General Procedures

3. Assembly Experiments

4. ${ }^{1} \mathrm{H}$ NMR and ${ }^{13} \mathrm{C}$ NMR Spectra

5. References 


\section{General Remarks}

\subsection{Materials}

All starting materials were obtained from commercial suppliers and were used without further purification. D-(+)-Glucose, acetic anhydride, sodium bicarbonate and 1,12-dibromododecane were obtained from VWR (Germany). D-(+)-Mannose, boron trifluoride-ethyl ether complex, iodine, sodium methylate, 7-hydroxy-4-methylcoumarin, 1,6-dibromohexane and potassium thioacetate were purchased from Sigma-Aldrich (USA). 2,2-Dimethoxy-2-phenylacetophenone (DMPA), benzene-1,4-diboronic acid (BDBA), sodium sulfite and thioacetic acid were bought from TH. Geyer (Germany). The organic solvents including dichloromethane (DCM), ethyl acetate and hexane were obtained from $\mathrm{TH}$. Geyer (Germany). Deionized water (DI water) was purified on a Millipore system.

\subsection{Characterizations}

\section{FTIR spectroscopy}

FTIR spectra were recorded on Alpha FTIR Spectrometer (Bruker, Germany) at room temperature. All samples were measured between 4000 and $400 \mathrm{~cm}^{-1}$ with a resolution of 4 $\mathrm{cm}^{-1}$ using Platinum ATR and accumulated 32 scans.

\section{Electrospray mass spectrometry (ESI-MS)}

The ESI-MS was recorded on Bruker Daltonik micrOTOF and maXis instruments. The samples were analyzed in positive ionization mode by direct perfusion in the ESI-MS interface $($ ESI capillary voltage $=4200 \mathrm{~V}$, end plate offset voltage $=-500 \mathrm{~V})$. Samples were scanned from 50 to $1600 \mathrm{~m} / \mathrm{z}$. All systems are equipped with time-of-flight (TOF) analyzers. 


\section{Differential scanning calorimetry (DSC)}

DSC scans were recorded on a NETZSCH DSC/200/F3 (NETZSCH, Germany) under a constant nitrogen flow $(20 \mathrm{~mL} / \mathrm{min})$ with a heating/cooling rate of $5 \mathrm{~K} / \mathrm{min}$.

\section{Dynamic Light Scattering Measurement (DLS)}

The DLS measurements were performed on a Zetasizer Nano ZS (Malvern Instruments Ltd., UK) using $5 \mathrm{~mW}$ laser with the incident beam of $633 \mathrm{~nm}$ (He-Ne laser). For the size measurement (Z-average diameter), aqueous solutions of GCCG-12 and MCCM-12 at a concentration of $8 \mathrm{mg} / \mathrm{mL}$ DI water were filtered through $0.45 \mu \mathrm{m}$ Millipore filters before each measurement. $1 \mathrm{~mL}$ of each sample was sealed inside a glass cuvette and the programmed temperature trend measurements were performed automatically from $25{ }^{\circ} \mathrm{C}$ to $90{ }^{\circ} \mathrm{C}$ and from $90{ }^{\circ} \mathrm{C}$ to $25^{\circ} \mathrm{C}$, taking a measurement at every $5{ }^{\circ} \mathrm{C}$ after equilibrating for 2 min, once the measurement temperature was achieved. The average sizes from three repeated measurements were used as results.

\section{Transmission electron microscopy (TEM)}

TEM measurement was performed on a CM 12 Transmission Electron Microscope (Philips, Netherland). A droplet (total volume $7 \mu \mathrm{L}$ ) of GCCG-12/ MCCM-12 aqueous solution at a concentration of $2 \mathrm{mg} / \mathrm{mL}$ was placed onto a carbon-coated 300 mesh copper grids (Plano $\mathrm{GmbH}$, Germany) that was previously glow-discharged with $40 \mathrm{~mA}$ electric current for $90 \mathrm{~s}$ to ensure hydrophilicity.

\section{Scanning electron microscopy (SEM)}

The SEM images were captured with an electron beam acceleration voltage of $5 \mathrm{kV}$ on a LEO Supra-35 high-resolution field emission scanning electron microscope (Carl Zeiss AG, Germany). Before the measurement, a layer of carbon was coated on the surface of samples before SEM measurements. 


\section{Polarized light microscopy (PLM)}

The PLM images were taken on Olympus BX51 with temperature control unit (CI94). All the samples were measured on glass slides with single concave and coverslip, and the temperature was controlled with a hot stage (Linkam LTS350).

\section{Light microscopy with fluorescence}

The images were recorded on ZEISS Axioplan 2 imaging microscope and the camera type of Nikon DS-Fi2. The samples were washed with DI water and put on glass slides before the observation.

\section{Liquid-state nuclear magnetic resonance (NMR)}

Nuclear magnetic resonance (NMR) spectroscopy was performed at 300 or $400 \mathrm{MHz}$ $\left({ }^{1} \mathrm{H}-\mathrm{NMR}\right)$ and $75 \mathrm{MHz}\left({ }^{13} \mathrm{C}-\mathrm{NMR}, \mathrm{APT}\right)$ on Bruker Avance III 300 and Avance III 400 instruments in the solvent indicated. Chemical shifts $(\delta)$ were given in parts per million $(\mathrm{ppm})$ with respect to the residual solvent signal $\mathrm{CDCl}_{3}$ containing $0.5 \mathrm{wt}$ \% silver foil as stabilizer and $0.03 \%(\mathrm{v} / \mathrm{v})$ TMS $\left({ }^{1} \mathrm{H}\right.$ NMR: $\delta=7.26 ;{ }^{13} \mathrm{C}$ NMR: $\left.\delta=77.00\right)$ and $\mathrm{D}_{2} \mathrm{O}\left({ }^{1} \mathrm{H}\right.$ NMR: $\delta=$ 4.79). Peak multiplicities were reported as follows: $\mathrm{s}=$ singlet, $\mathrm{d}=$ doublet, $\mathrm{t}=$ triplet, $\mathrm{dd}=$ doublet of doublets, $\mathrm{m}=$ multiplet.

\section{Solid-state MAS NMR spectroscopy}

Solid-state ${ }^{11} \mathrm{~B}$ magic angle spinning (MAS) NMR spectra were recorded on a Bruker AVIIIHD 600 UltraShield spectrometer with a field strength of 14.1 Tesla (corresponding to a proton Larmor frequency of $600 \mathrm{MHz}$ ), equipped with a $1.3 \mathrm{~mm}$ HXY probe. Samples were packed in $1.3 \mathrm{~mm}$ rotors and spun at the magic angle with $8 \mathrm{kHz}$. Temperature for data collection was set to $275 \mathrm{~K} .{ }^{11} \mathrm{~B}$ direct excitation spectra were acquired for 254 milliseconds with $100 \mathrm{kHz}$ continuous wave proton decoupling at $4.6 \mathrm{ppm}$ carrier frequency. ${ }^{11} \mathrm{~B}$ excitation power was $35.7 \mathrm{kHz}$ with a carrier frequency of $0 \mathrm{ppm}$. For sample containing brick-shaped 
structure formed by BDBA alone, 64 scans were accumulated with a recycle delay of 30 seconds; for samples containing helices formed by BDBA and GCCG-12 (MCCM-12), 3072 scans were accumulated with a recycle delay of 1 second. For sample (containing helices formed by BDBA and MCCM-12) after DSC $300{ }^{\circ} \mathrm{C}$ measurement, the recording conditions were changed to a recording time of 22 milliseconds and a recycle delay of 8 seconds, with 1024 scans; for samples (containing helices formed by GCCG-12 and BDBA, and brick-shaped structures formed by BDBA alone) after DSC $300{ }^{\circ} \mathrm{C}$ measurement, the recording conditions were changed to a recording time of 22 milliseconds and a recycle delay of 8 seconds, with 7168 scans.

${ }^{13} \mathrm{C}$ MAS NMR spectra were recorded on a Bruker Ascend 600DNP spectrometer with a field strength of 14.1 Tesla, equipped with a $4 \mathrm{~mm}$ HXY probe. Samples were packed in $4 \mathrm{~mm}$ rotors and spun with $10 \mathrm{kHz}$. Temperature for data collection was set to $290 \mathrm{~K} .{ }^{13} \mathrm{C}$ detected spectra were recorded using cross polarization (CP) from ${ }^{1} \mathrm{H}$. Initial ${ }^{1} \mathrm{H}$ excitation was $83 \mathrm{kHz}$ at a carrier frequency of $4 \mathrm{ppm}$. The $\mathrm{CP}$ length was 3 milliseconds, with ${ }^{1} \mathrm{H}$ power of $57 \mathrm{kHz}$ at $4 \mathrm{ppm}$ carrier frequency and ${ }^{13} \mathrm{C}$ power of $35 \mathrm{kHz}$ at $110 \mathrm{ppm}$ carrier frequency. A linear ramp from $90-100 \%$ power was applied on ${ }^{1} \mathrm{H}$, making the average power during CP $54 \mathrm{kHz}$. Acquisition on ${ }^{13} \mathrm{C}$ was 24.5 milliseconds with SPINAL64 heteronuclear decoupling of 83 $\mathrm{kHz}$. The recycle delay was 15 seconds and 5120 scans were recorded. Spectra were processed with Bruker TopSpin 4.0.8 and the data were analyzed using OriginPro software (OriginLab, OriginPro 8.5G, USA). Exponential apodization of 100, 200 or $300 \mathrm{~Hz}$ was applied to all ${ }^{11} \mathrm{~B}$ spectra (according to sensitivity considerations), and $200 \mathrm{~Hz}$ to all ${ }^{13} \mathrm{C}$ spectra.

\section{General Procedures}

\section{Synthesis of 2-allylethoxyl-D-monosaccharides}


2-Allylethoxyl-D-monosaccharides were synthesized from commercially available D-glucose and D-mannose in 3 steps. The steps are described below (Scheme S1).

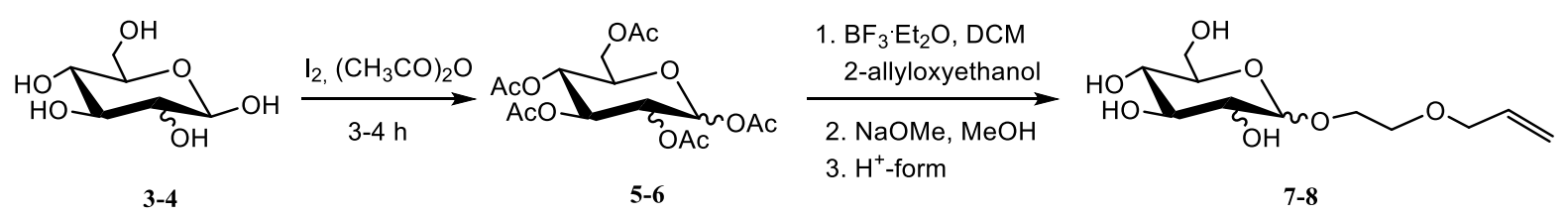

Scheme S1. Synthesis of 2-allylethoxyl-D-glucose (7) and 2-allylethoxyl-D-mannose (8).

\section{General procedure for the synthesis of fully acetylated monosaccharides (6-7)}

The fully acetylated monosaccharides were synthesized according to the literature. ${ }^{[1]}$ Catalytic amount of iodine $(0.2 \mathrm{~g})$ was added to a stirred mixture of acetic anhydride $(30 \mathrm{~mL})$ and monosaccharide (3 glucose or 4 mannose) (5.0 g, $27.8 \mathrm{mmol})$. About 3-4 hours, the reaction mixture stirring at room temperature was completely dissolved. Then, the mixture was added to saturated $\mathrm{Na}_{2} \mathrm{SO}_{3}$ aqueous solution and saturated $\mathrm{NaHCO}_{3}$ aqueous solution in ice-bath. The mixture was extracted with dichloromethane. At last, the solvent was evaporated under reduced pressure to give the pentaacetate $5(\mathbf{6})$.

Penta-O-acetate-D-glucose, 5, ${ }^{1} \mathrm{H}$ NMR $\left(300 \mathrm{MHz}^{\mathrm{CDCl}} \mathrm{CD}_{3}, \delta\right.$ in ppm): 2.01 (s, 3H), 2.02 (s, 3H), $2.04(\mathrm{~s}, 3 \mathrm{H}), 2.09$ (s, 3H), $2.18(\mathrm{~s}, 3 \mathrm{H}), 4.06-4.14(\mathrm{~m}, 2 \mathrm{H}), 4.27(\mathrm{dd}, 1 \mathrm{H}, J=3.0 \mathrm{~Hz}, J=$ $12.0 \mathrm{~Hz}), 5.07-5.17(\mathrm{~m}, 2 \mathrm{H}), 5.47(\mathrm{t}, 1 \mathrm{H}, J=9.0 \mathrm{~Hz}), 6.33(\mathrm{~d}, 1 \mathrm{H}, J=3.0 \mathrm{~Hz}) ;{ }^{13} \mathrm{C} \mathrm{NMR}(75$ $\mathrm{MHz}, \mathrm{CDCl}_{3}, \delta$ in ppm): 20.39, 20.51, 20.61, 20.64, 20.82, 61.43, 67.87, 69.16, 69.79, 89.03, $168.69,169.33,169.59,170.16,170.56$; HR-MS (ESI) $\mathrm{m} / \mathrm{z}$ calcd for $\mathrm{C}_{16} \mathrm{H}_{22} \mathrm{NaO}_{11}[\mathrm{M}+\mathrm{Na}]^{+}$ 413.1060, found: 413.1054 .

Penta-O-acetate-D-mannose, 6, ${ }^{1} \mathrm{H}$ NMR (300 MHz, $\mathrm{CDCl}_{3}, \delta$ in ppm): 1.99 (s, 3H), 2.04 (s, $3 \mathrm{H}), 2.08(\mathrm{~s}, 3 \mathrm{H}), 2.16(\mathrm{~s}, 6 \mathrm{H}), 4.02-4.11(\mathrm{~m}, 2 \mathrm{H}), 4.24-4.30(\mathrm{~m}, 1 \mathrm{H}), 5.25(\mathrm{~d}, 1 \mathrm{H}, J=3.0$ $\mathrm{Hz}), 5.33(\mathrm{t}, 2 \mathrm{H}, J=3.0 \mathrm{~Hz}), 6.07(\mathrm{~s}, 1 \mathrm{H}) ;{ }^{13} \mathrm{C} \mathrm{NMR}\left(75 \mathrm{MHz}, \mathrm{CDCl}_{3}, \delta\right.$ in ppm): 20.55, $20.58,20.63,20.69,20.78,62.03,65.46,68.26,68.66,70.52,90.52,167.99,169.46,169.66$, 169.91, 170.57; HR-MS (ESI) $m / z$ calcd for $\mathrm{C}_{16} \mathrm{H}_{22} \mathrm{O}_{11}[\mathrm{M}+\mathrm{Na}]^{+} 413.1060$, found: 413.1054 . 


\section{General procedure for the synthesis of 2-allylethoxyl monosaccharides (7-8)}

2-Allylethoxyl monosaccharides were generated via a published route with adaptation. ${ }^{[2]}$ To a solution of the fully acetylated monosaccharide $5(6)(1 \mathrm{~g}, 2.5 \mathrm{mmol})$ in dichloromethane was added 2-allyloxyethanol $(0.35 \mathrm{~mL}, 3.3 \mathrm{mmol})$, followed by the addition of boron trifluoride diethyl etherate $(0.41 \mathrm{~mL}, 3.33 \mathrm{mmol})$ in the ice-bath under $\mathrm{N}_{2}$ protection. Then, the mixture was stirred overnight at room temperature. After that, cold water was added and the mixture was washed with $\mathrm{NaHCO}_{3}$ solution. After the solvent was removed under reduced pressure, an oily residue was obtained without further purification. Then, the oily residue was dissolved in $10 \mathrm{~mL}$ methanol, and $50 \mathrm{mg} \mathrm{NaOMe}$ were added. The mixture was stirred for overnight and then added to the ion exchange resin $\left(\mathrm{H}^{+}\right.$-form $)$for separation by adjusting the $\mathrm{pH}$ to neutral. Finally, purification by column chromatography on silica gel led to oil compounds as product $7(\mathbf{8})$.

2-Allylethoxyl-D-glucose, 7, ${ }^{1} \mathrm{H}$ NMR (300 MHz, $\mathrm{D}_{2} \mathrm{O}, \delta$ in ppm): 3.27-3.90 (m, 9H), 4.03-4.10 (m, 3H), 4.49 (d, 1H, $J=9.0 \mathrm{~Hz}), 5.25-5.39(\mathrm{~m}, 2 \mathrm{H}), 5.90-6.03(\mathrm{~m}, 1 \mathrm{H}) ;{ }^{13} \mathrm{C} \mathrm{NMR}$ (75 MHz, $\mathrm{D}_{2} \mathrm{O}, \delta$ in ppm): $60.36,68.68,69.59,70.77,71.75,73.08,75.62,75.86,102.22$, 118.61, 133.48; HR-MS (ESI) $m / z$ calcd for $\mathrm{C}_{11} \mathrm{H}_{21} \mathrm{O}_{7}[\mathrm{M}+\mathrm{H}]^{+}$265.1287, found: 265.1282.

2-Allylethoxyl-D-mannose, 8, ${ }^{1} \mathrm{H}$ NMR (300 MHz, $\mathrm{D}_{2} \mathrm{O}, \delta$ in ppm): $3.65-3.75$ (m, 5H), 3.78-3.92 (m, 4H), $3.98(\mathrm{t}, 1 \mathrm{H}, J=3.0 \mathrm{~Hz}), 4.11(\mathrm{dd}, 2 \mathrm{H}, J=3.0 \mathrm{~Hz}, J=6.0 \mathrm{~Hz}), 4.90(\mathrm{~d}, 1 \mathrm{H}$, $J=3.0 \mathrm{~Hz}), 5.28-5.40(\mathrm{~m}, 2 \mathrm{H}), 5.91-6.04(\mathrm{~m}, 1 \mathrm{H}) ;{ }^{13} \mathrm{C} \mathrm{NMR}\left(75 \mathrm{MHz}, \mathrm{D}_{2} \mathrm{O}, \delta\right.$ in ppm): $60.89,66.38,66.70,68.59,69.96,70.49,71.69,72.69,99.90,118.37,133.67$; HR-MS (ESI) $m / z$ calcd for $\mathrm{C}_{11} \mathrm{H}_{21} \mathrm{O}_{7}[\mathrm{M}+\mathrm{H}]^{+}$265.1287, found: 265.1282 .

\section{Synthesis of 7-mercaptohexyloxy-4-methylcoumarins}

7-Mercaptohexyloxy-4-methylcoumarins were synthesized from commercially available 7-hydroxy-4-methylcoumarin in 3 steps. The steps are described below (Scheme S2). 


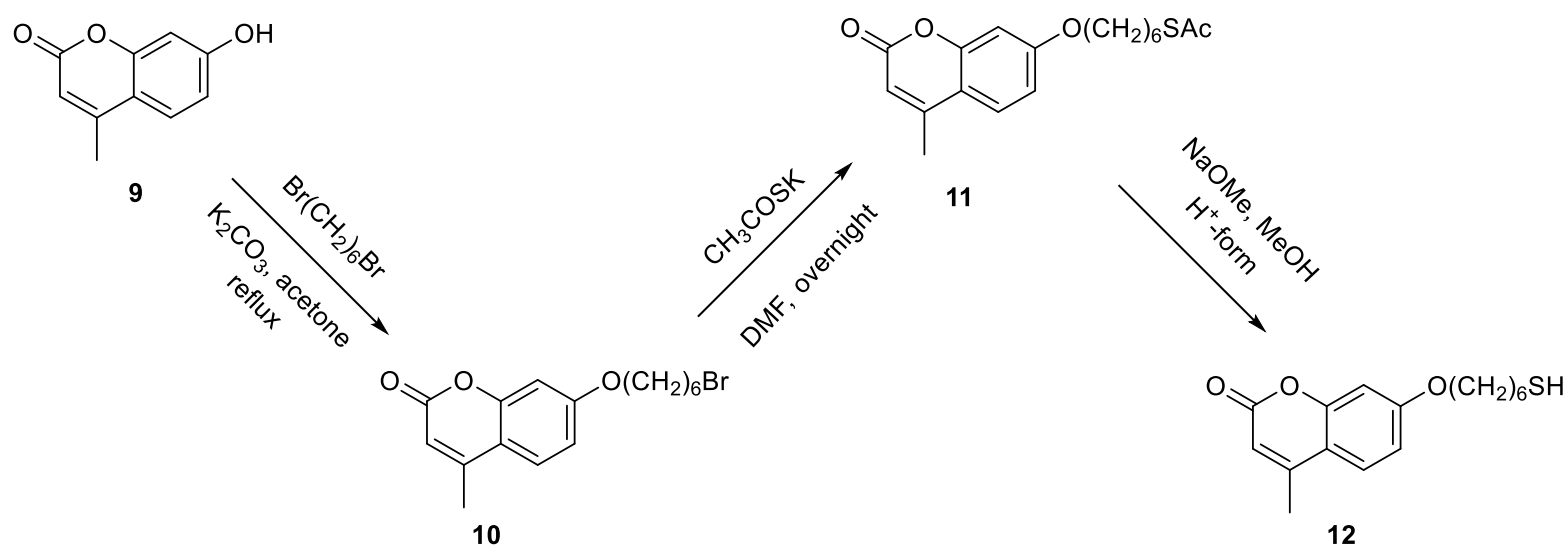

Scheme S2. Synthesis of 7-mercaptohexyloxy-4-methylcoumarin (12)

\section{The synthesis of 7-bromoalkyloxy-4-methylcoumarins (10)}

According to the literature, ${ }^{[3]}$ anhydrous $\mathrm{K}_{2} \mathrm{CO}_{3}(0.78 \mathrm{~g}, 5.68 \mathrm{mmol})$ and 1,6-dibromohexane (11.35 mmol) were added to a solution of 7-hydroxy-4-methylcoumarin (0.5 g, $2.84 \mathrm{mmol})$ in acetone $(5 \mathrm{~mL})$, and the mixture was refluxed for 10 hours. After cooling, the reaction mixture was filtered, and the filtrate was evaporated under reduced pressure. The residue was purified on silica gel chromatography to afford solid product $\mathbf{1 0}$.

7-bromohexyloxy-4-methylcoumarin, 10, ${ }^{1} \mathrm{H} \mathrm{NMR}\left(300 \mathrm{MHz}, \mathrm{CDCl}_{3}, \delta\right.$ in ppm): 1.52-1.59 $(\mathrm{m}, 4 \mathrm{H}), 1.80-1.96(\mathrm{~m}, 4 \mathrm{H}), 2.41(\mathrm{~d}, 3 \mathrm{H}, J=3.0 \mathrm{~Hz}), 3.44(\mathrm{t}, 2 \mathrm{H}, J=6.0 \mathrm{~Hz}), 4.03(\mathrm{t}, 2 \mathrm{H}, J=$ $6.0 \mathrm{~Hz}), 6.14(\mathrm{~d}, 1 \mathrm{H}, J=3.0 \mathrm{~Hz}), 6.81(\mathrm{~d}, 1 \mathrm{H}, J=3.0 \mathrm{~Hz}), 6.84-6.87(\mathrm{~m}, 1 \mathrm{H}), 7.50(\mathrm{~d}, 1 \mathrm{H}, J$ $=9.0 \mathrm{~Hz}) ;{ }^{13} \mathrm{C} \mathrm{NMR}\left(75 \mathrm{MHz}, \mathrm{CDCl}_{3}, \delta\right.$ in ppm): 18.65, 25.16, 27.81, 28.68, 32.57, 33.45, $68.26,101.27,111.85,112.64,113.42,125.76,152.65,155.08,160.98,162.48 ;$ HR-MS (ESI) $m / z$ calcd for $\mathrm{C}_{16} \mathrm{H}_{20} \mathrm{BrO}_{3}[\mathrm{M}+\mathrm{H}]^{+} 339.0596$, found: 339.0590 .

\section{The synthesis of 7-acetylmercaptohexyloxy-4-methylcoumarins (11)}

According to previously reported substitution reaction, ${ }^{[4]}$ potassium thioacetate $(4.5 \mathrm{mmol})$ was added to a solution of $\mathbf{1 0}(3 \mathrm{mmol})$ in DMF $(5 \mathrm{~mL})$. The mixture was stirred at room temperature for 1 day. When finished, the mixture was poured to water and extracted with ethyl acetate. The solvent was removed by rotary evaporation and the crude product was purified on silica gel chromatography to afford solid compound $\mathbf{1 1 .}$ 
7-acetylmercaptohexyloxy-4-methylcoumarin, 11, ${ }^{1} \mathrm{H} \mathrm{NMR}\left(300 \mathrm{MHz}, \mathrm{CDCl}_{3}, \delta\right.$ in ppm): 1.39-1.54 (m, 4H), 1.55-1.67 (m, 2H), 1.78-1.87 (m, 2H), $2.33(\mathrm{~s}, 3 \mathrm{H}), 2.40(\mathrm{~s}, 3 \mathrm{H})$, 2.87-2.92 (m, 2H), 3.99-4.04 (m, 2H), $6.14(\mathrm{~d}, 1 \mathrm{H}, J=3.0 \mathrm{~Hz}), 6.81(\mathrm{~d}, 1 \mathrm{H}, J=3.0 \mathrm{~Hz}), 6.85$ $(\mathrm{dd}, 1 \mathrm{H}, J=3.0 \mathrm{~Hz}, J=9.0 \mathrm{~Hz}), 7.50(\mathrm{~d}, 1 \mathrm{H}, J=9.0 \mathrm{~Hz}) ;{ }^{13} \mathrm{C} \mathrm{NMR}\left(75 \mathrm{MHz}, \mathrm{CDCl}_{3}, \delta\right.$ in ppm): 18.60, 25.46, 28.39, 28.77, 28.93, 29.29, 30.52, 68.44, 101.18, 111.87, 112.63, 113.64, $125.45,152.06,155.36,160.99,162.17,195.91$; HR-MS (ESI) $\mathrm{m} / \mathrm{z}$ calcd for $\mathrm{C}_{18} \mathrm{H}_{23} \mathrm{O}_{4} \mathrm{~S}$ $[\mathrm{M}+\mathrm{H}]^{+}$335.1317, found: 355.1312 .

\section{The synthesis of 7-mercaptohexyloxy-4-methylcoumarins (12)}

Under protection with $\mathrm{N}_{2}$ gas, $\mathrm{NaOMe}(6 \mathrm{mmol})$ was added to a solution of 11 (3 mmol) in methanol. Then, the mixture was stirred overnight and added to the ion exchange resin $\left(\mathrm{H}^{+}\right.$-form $)$to adjust the $\mathrm{pH}$ to neutral. Finally, purification by column chromatography on silica gel led to white solid compound $\mathbf{1 2}$.

7-mercaptohexyloxy-4-methylcoumarin, 12, ${ }^{1} \mathrm{H}$ NMR $\left(300 \mathrm{MHz}, \mathrm{CDCl}_{3}, \delta\right.$ in ppm): 1.29-1.34 (m, 1H), 1.43-1.46 (m, 4H), 1.58-1.67 (m, 2H), 1.74-1.83 (m, 2H), 2.35 (s, 3H), 2.48-2.55 (m, 2H), 3.95-4.00 (m, 2H), $6.07(\mathrm{~s}, 1 \mathrm{H}), 6.74(\mathrm{~d}, 1 \mathrm{H}, J=3.0 \mathrm{~Hz}), 6.81(\mathrm{dd}, 1 \mathrm{H}, J$ $=3.0 \mathrm{~Hz}, J=9.0 \mathrm{~Hz}), 7.45(\mathrm{~d}, 1 \mathrm{H}, J=9.0 \mathrm{~Hz}) ;{ }^{13} \mathrm{C} \mathrm{NMR}\left(75 \mathrm{MHz}, \mathrm{CDCl}_{3}, \delta\right.$ in ppm): 18.50, $24.36,25.33,27.87,28.72,33.68,68.25,101.17,111.62,112.40,113.26,125.36,152.43$, 155.09, 161.09, 161.97; HR-MS (ESI) $m / z$ calcd for $\mathrm{C}_{16} \mathrm{H}_{21} \mathrm{O}_{3} \mathrm{~S}[\mathrm{M}+\mathrm{H}]^{+}$293.1211, found: 293.1206.

\section{Synthesis of sugar-based bolaamphiphiles}

Sugar-based bolaamphiphiles were synthesized from synthesized intermediate compounds 2-allylethoxyl-D-monosaccharides (7-8) and 7-mercaptohexlyoxy-4-methylcoumarins (12) using thiol-ene click reaction and photo-dimerization in one-pot. The synthesis route is described below (Scheme S3). 


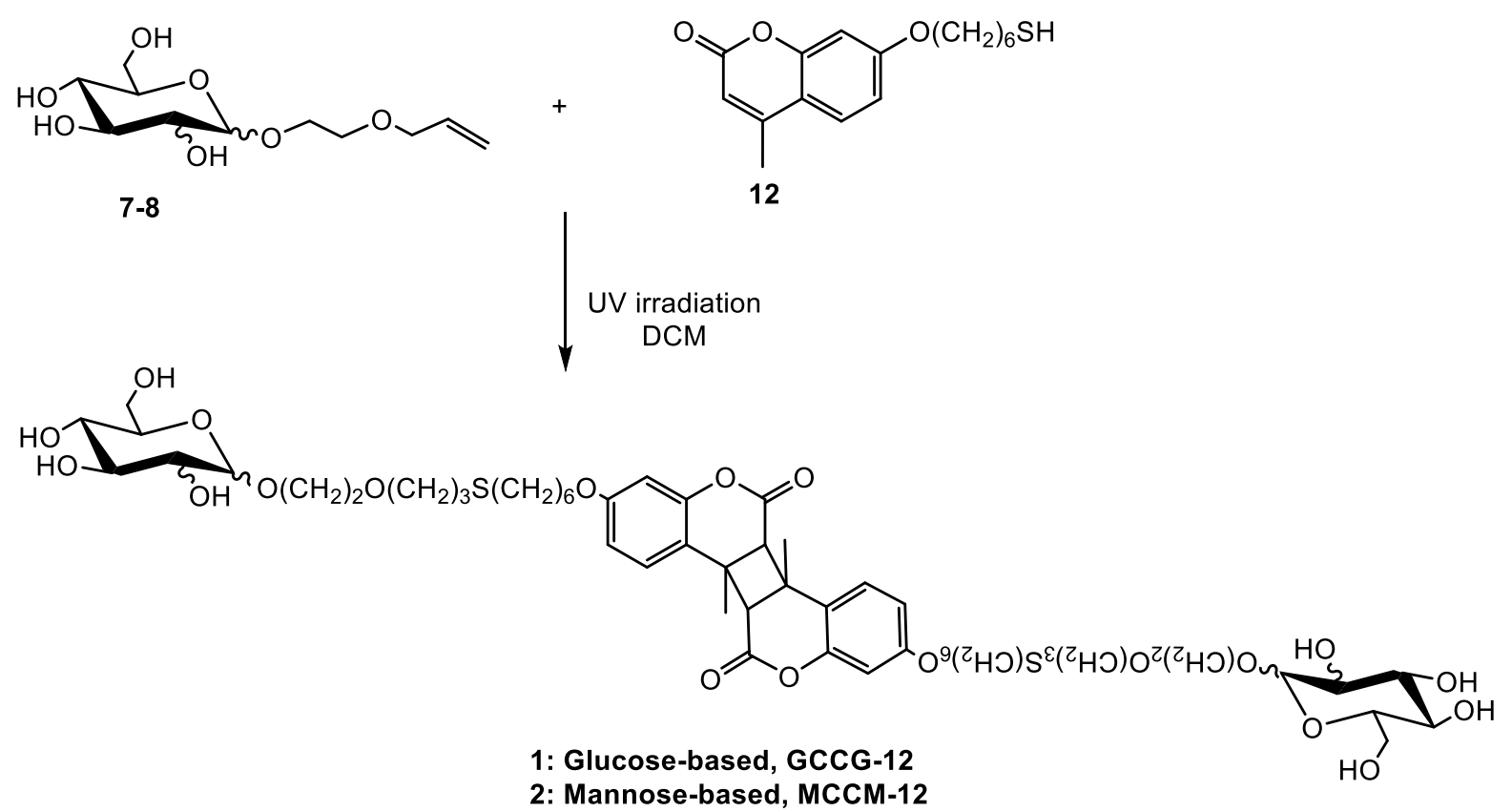

Scheme S3. Synthesis of glucose-based 1 and mannose-based $\mathbf{2}$ bolaamphiphiles.

General procedure: 2-allylethoxyl-D-monosaccharide $\left.\quad \begin{array}{lllll}\mathbf{7} & (\mathbf{8}) & (4.5 & \mathrm{mmol}\end{array}\right)$ and 7-mercaptohexlyoxy-4-methylcoumarin $\mathbf{1 2}(3 \mathrm{mmol})$ were dissolved in $5 \mathrm{~mL}$ dichloromethane. The solution was purged with argon gas for 3 min and then exposed to UV light (wavelength from 300-400 nm, $8 \mathrm{~W}$ ) for several days. When finished, the solvent was removed on rotary evaporator and the crude product was purified on silica gel chromatography to afford solid compound $\mathbf{1}(\mathbf{2})$.

Glucose-based bolaamphiphile, 1, ${ }^{1} \mathrm{H}$ NMR (300 $\mathrm{MHz}, \mathrm{CDCl}_{3}, \delta$ in ppm): 1.41-1.91 (m, $28 \mathrm{H}), 2.50-2.61(\mathrm{~m}, 8 \mathrm{H}), 3.31-3.44(\mathrm{~m}, 5 \mathrm{H}), 3.56-3.86(\mathrm{~m}, 24 \mathrm{H}), 3.98-4.10(\mathrm{~m}, 4 \mathrm{H}), 4.37(\mathrm{~s}$, 1H), 4.91-5.37 (m, 4H), $6.01(\mathrm{~d}, 2 \mathrm{H}, J=3.0 \mathrm{~Hz}), 6.63(\mathrm{~d}, 2 \mathrm{H}, J=9.0 \mathrm{~Hz}), 7.07(\mathrm{~d}, 2 \mathrm{H}, J=$ $9.0 \mathrm{~Hz}) ;{ }^{13} \mathrm{C}$ NMR $\left(125 \mathrm{MHz}, \mathrm{CDCl}_{3}, \delta\right.$ in ppm): 25.69, 28.64, 28.70, 28.95, 29.30, 29.49, $31.43,32.04,41.14,55.24,61.28,68.16,68.68,69.35,69.76,69.89,73.29,75.80,76.27$, 102.08, 102.97, 112.33, 113.70, 127.31, 150.24, 159.68, 164.83; HR-MS (ESI) $\mathrm{m} / \mathrm{z}$ calcd for $\mathrm{C}_{54} \mathrm{H}_{80} \mathrm{NaO}_{20} \mathrm{~S}_{2}[\mathrm{M}+\mathrm{Na}]^{+}$1135.4582, found: 1135.4577 .

Mannose-based bolaamphiphile, $2,{ }^{1} \mathrm{H}$ NMR (300 $\mathrm{MHz}, \mathrm{CDCl}_{3}, \delta$ in ppm): 1.41-1.49 (m, 
$10 \mathrm{H}), 1.59-1.72(\mathrm{~m}, 14 \mathrm{H}), 1.83-1.87(\mathrm{~m}, 4 \mathrm{H}), 2.50-2.60(\mathrm{~m}, 8 \mathrm{H}), 2.87(\mathrm{~s}, 2 \mathrm{H}), 3.41(\mathrm{~s}, 2 \mathrm{H})$, 3.53-3.62 (m, 12H), 3.72-4.02 (m, 18H), 4.87-5.31 (m, 4H), $6.02(\mathrm{~d}, 2 \mathrm{H}, J=3.0 \mathrm{~Hz}), 6.63$ $(\mathrm{dd}, 2 \mathrm{H}, J=3.0 \mathrm{~Hz}, J=9.0 \mathrm{~Hz}), 7.07(\mathrm{~d}, 2 \mathrm{H}, J=9.0 \mathrm{~Hz}) ;{ }^{13} \mathrm{C} \mathrm{NMR}\left(125 \mathrm{MHz}, \mathrm{CDCl}_{3}, \delta\right.$ in ppm): 25.68, 28.67, 28.70, 28.94, 29.49, 29.51, 31.48, 32.03, 41.12, 55.23, 60.84, 66.21, $66.62,68.15,69.81,70.66,71.27,72.11,72.37,102.11,112.31,113.67,127.33,134.52$, 150.23, 159.68, 164.81; HR-MS (ESI) $\mathrm{m} / z$ calcd for $\mathrm{C}_{54} \mathrm{H}_{80} \mathrm{NaO}_{20} \mathrm{~S}_{2}[\mathrm{M}+\mathrm{Na}]^{+} 1135.4582$, found: 1135.4577 .

\section{Assembly Experiments}

All assembly experiments were performed in 5-fold diluted buffer solution by mixing $0.1 \mathrm{~mL}$ pH 10 buffer solution with $0.4 \mathrm{~mL}$ DI water. In a $4 \mathrm{~mL}$ capped bottle, the mixture compounds were dispersed in $0.5 \mathrm{~mL}$ diluted buffer solution using a 1:3 mole ratio of GCCG-12/MCCM-12 (10 mg) to BDBA (4.5 mg), and then sonicated for 10 minutes. A control experiment was conducted by only dispersing $4.5 \mathrm{mg}$ BDBA in $0.5 \mathrm{~mL}$ diluted buffer solution and following sonication at room temperature for 10 minutes. Then, all three capped bottles were placed in pre-heated oil bath at $80{ }^{\circ} \mathrm{C}$ until clear solutions were obtained. The solutions were slowly cooled to room temperature and the aggregates were generated after 3-4 hours. Afterwards, the assembled aggregates were purified by washing three times with DI water to remove buffer solution, followed by filtration through $0.45 \mu \mathrm{m}$ membrane (PVDF hydrophilic, Carl-Roth, Germany).
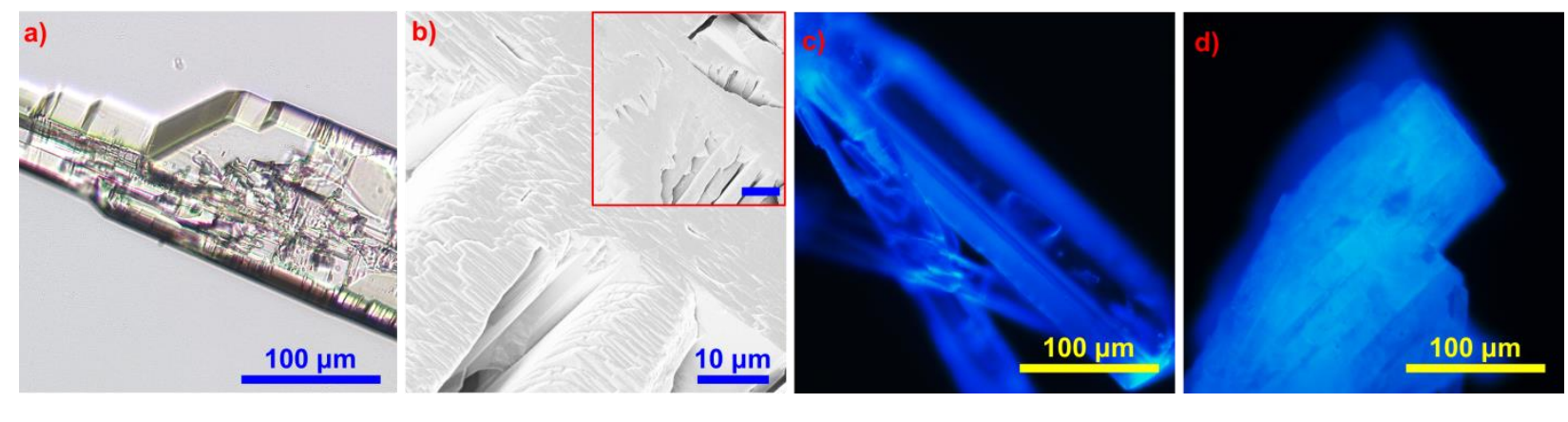
Figure S1. The brick-shaped structures self-assembled by BDBA alone: a) Optical light microscopy image; b) SEM image. The inset shows more typical stack structure with the scale bar of $50 \mu \mathrm{m}$; c) Fluorescence microscopy image of as-prepared sample; d) Fluorescence microscopy image after the treatment at $300{ }^{\circ} \mathrm{C}$ in nitrogen gas.

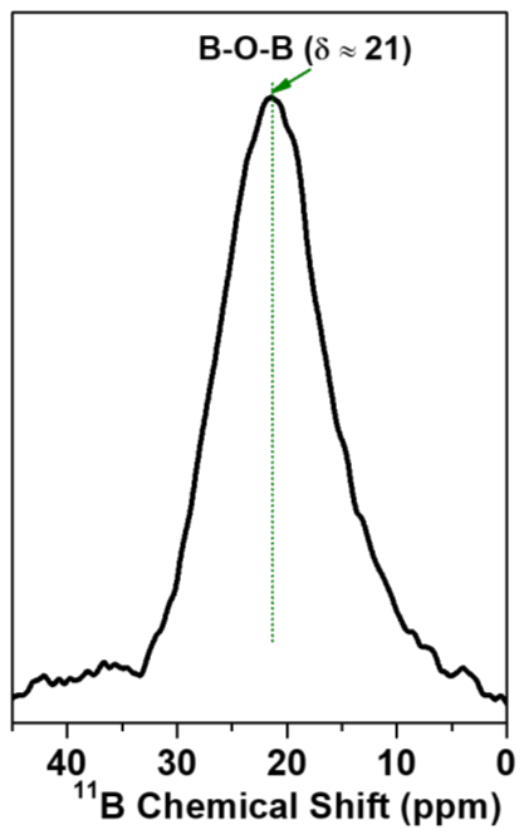

Figure S2. Solid-state ${ }^{11}$ B NMR spectra of brick-shaped structure formed by BDBA alone after the treatment at $300{ }^{\circ} \mathrm{C}$ in nitrogen gas. 


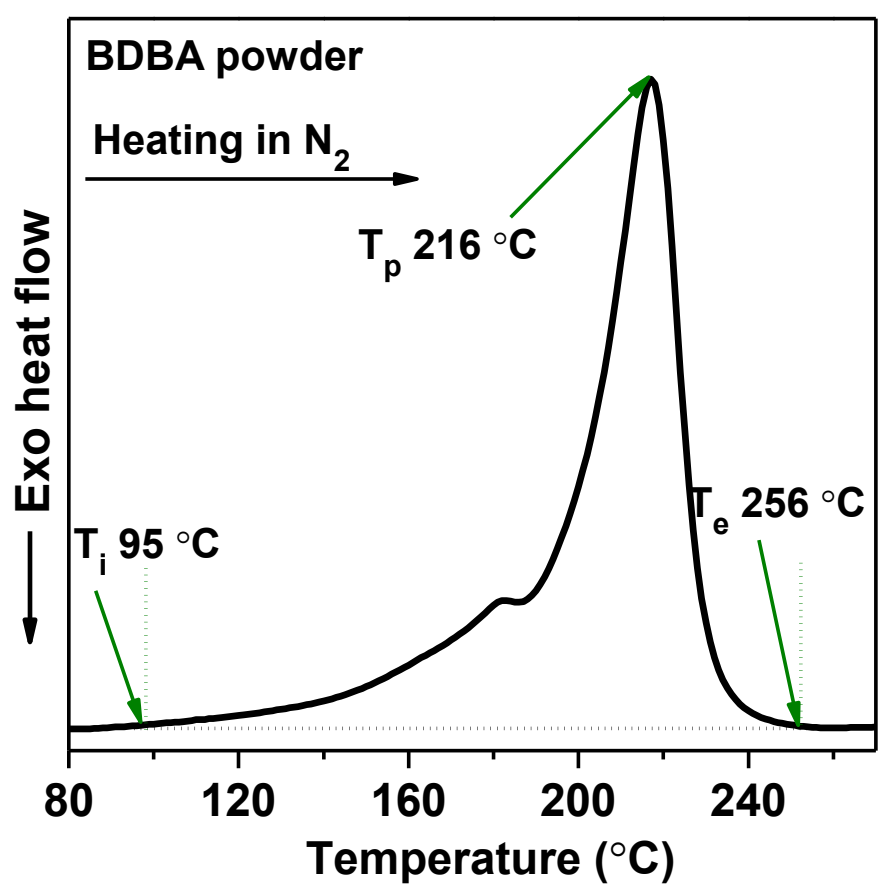

Figure S3. DSC curves of BDBA powder brought from company heated from $20{ }^{\circ} \mathrm{C}$ to $300{ }^{\circ} \mathrm{C}$ at a heating rate of $5 \mathrm{~K} / \mathrm{min}$ under a nitrogen atmosphere.

4. ${ }^{1} \mathrm{H}$ NMR and ${ }^{13} \mathrm{C}$ NMR Spectra 

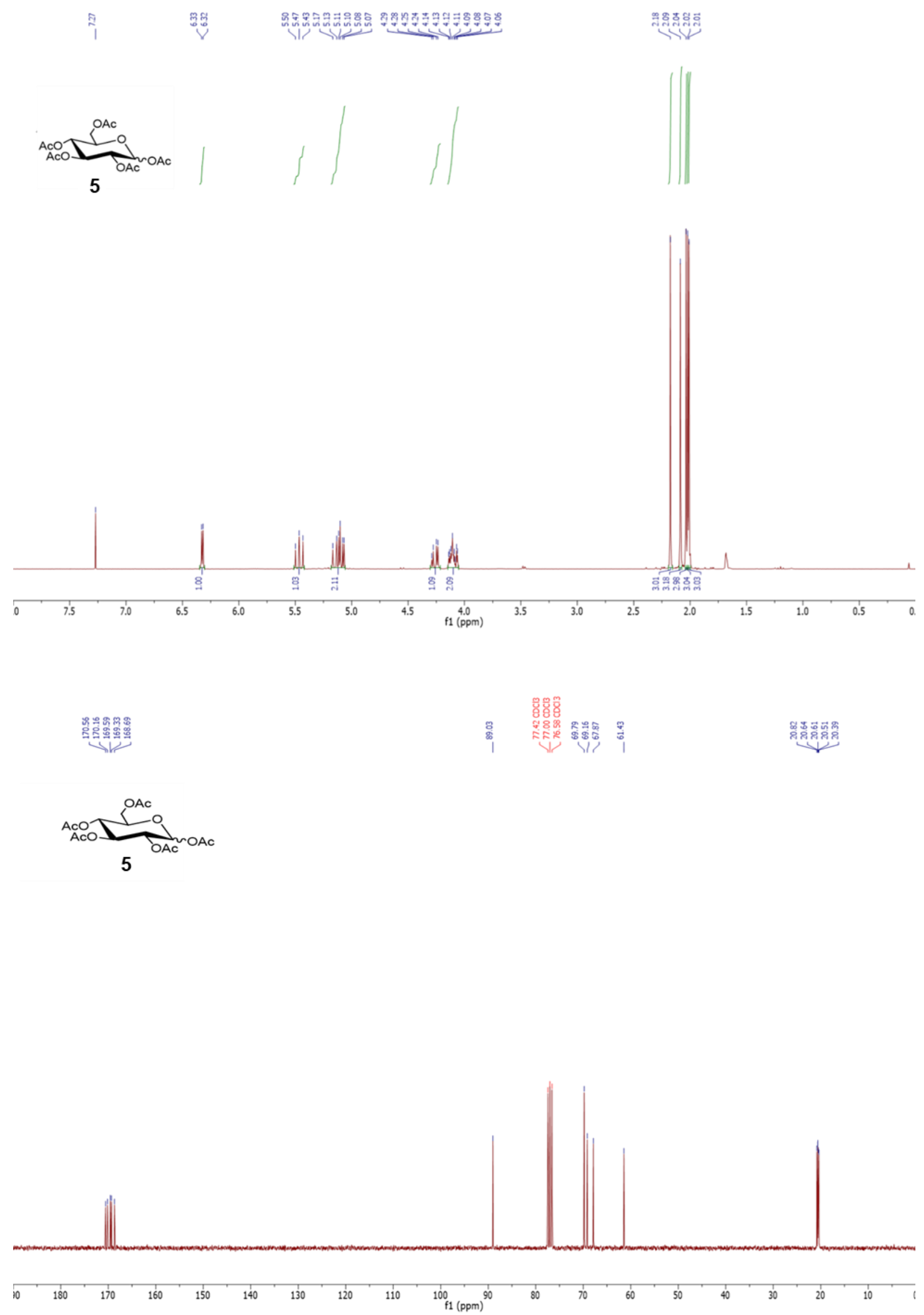


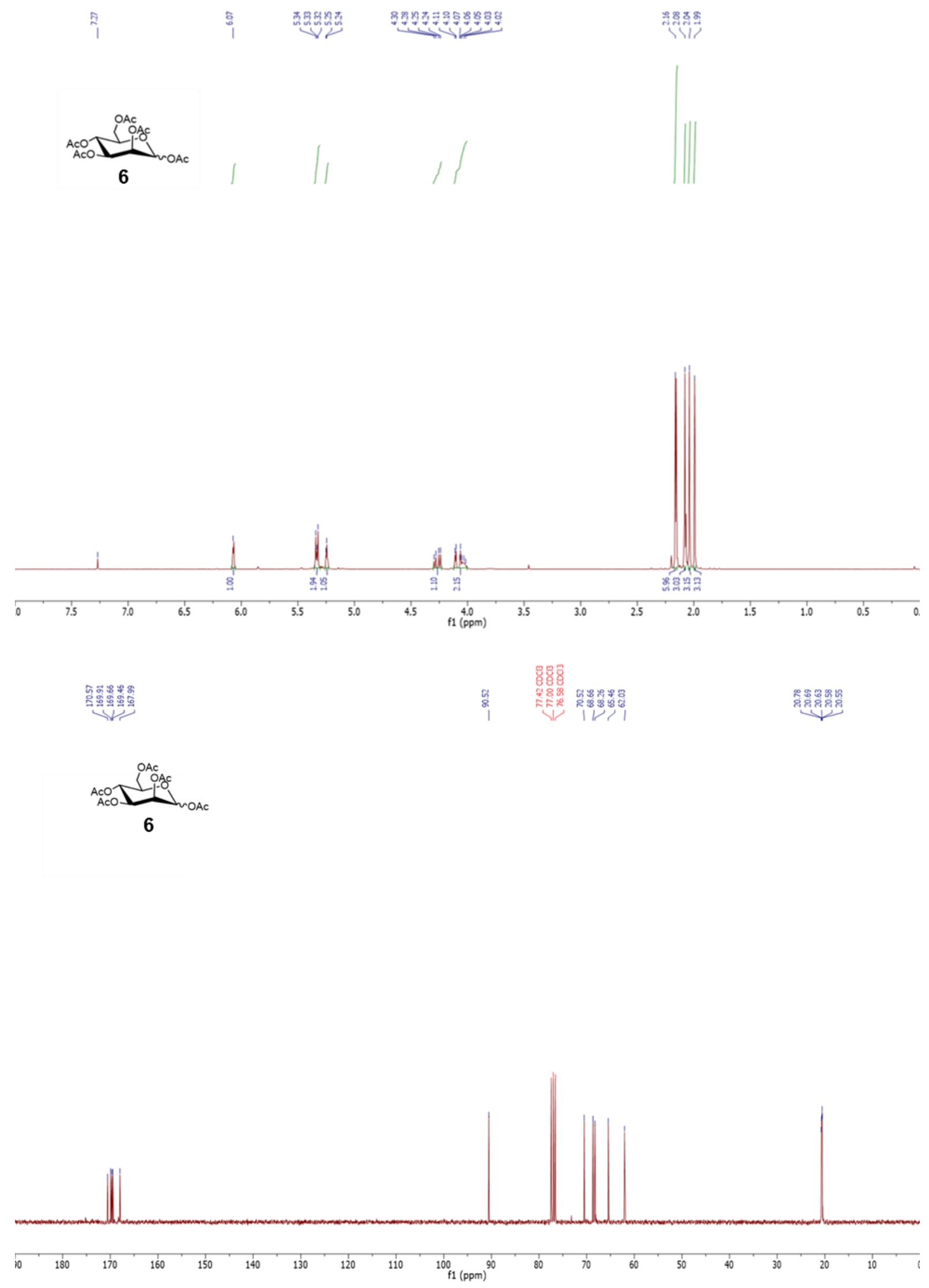




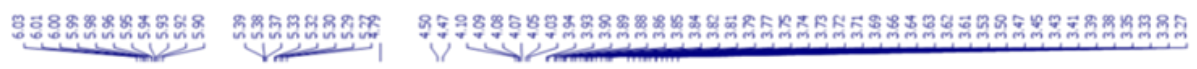

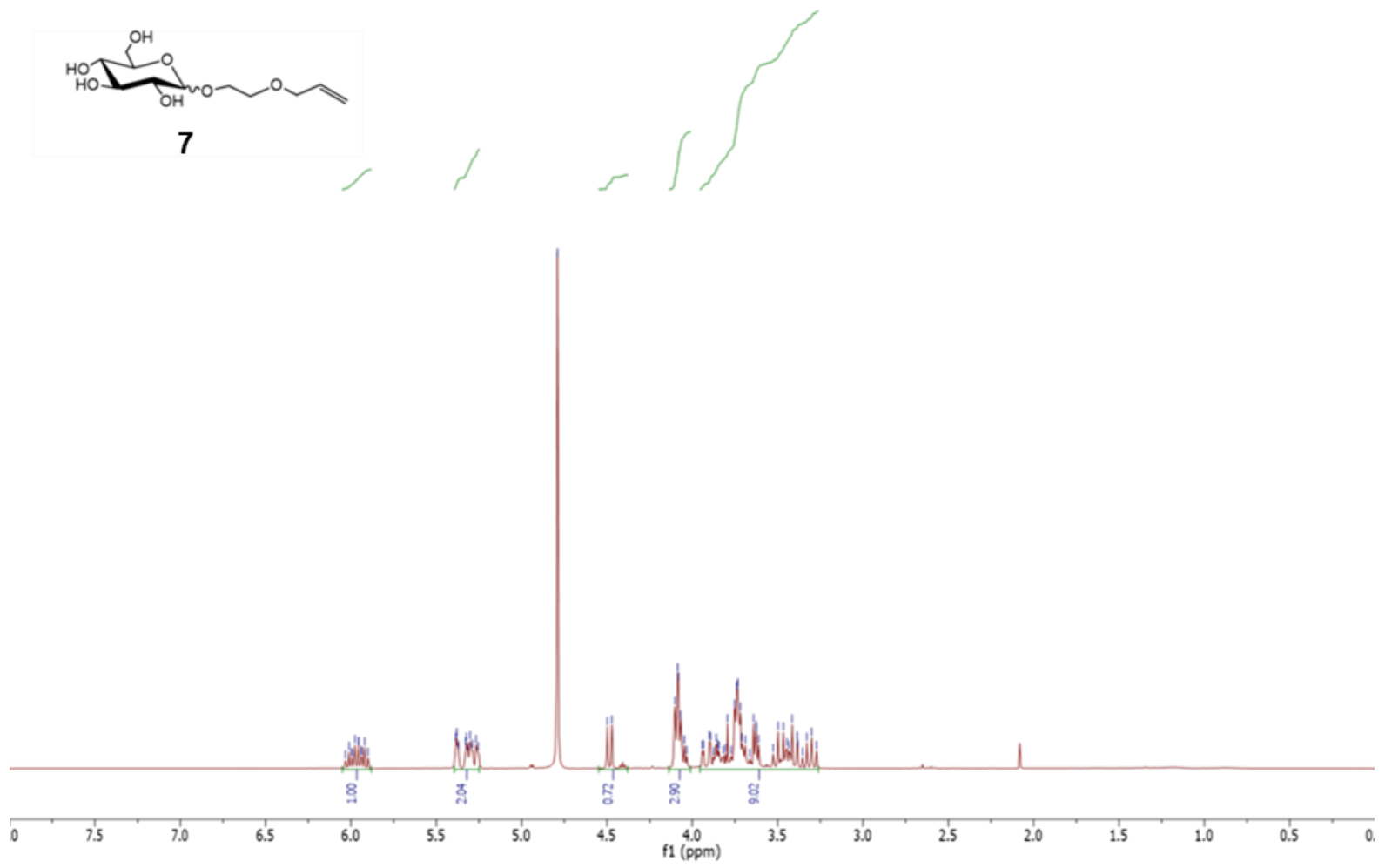

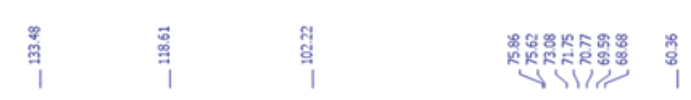
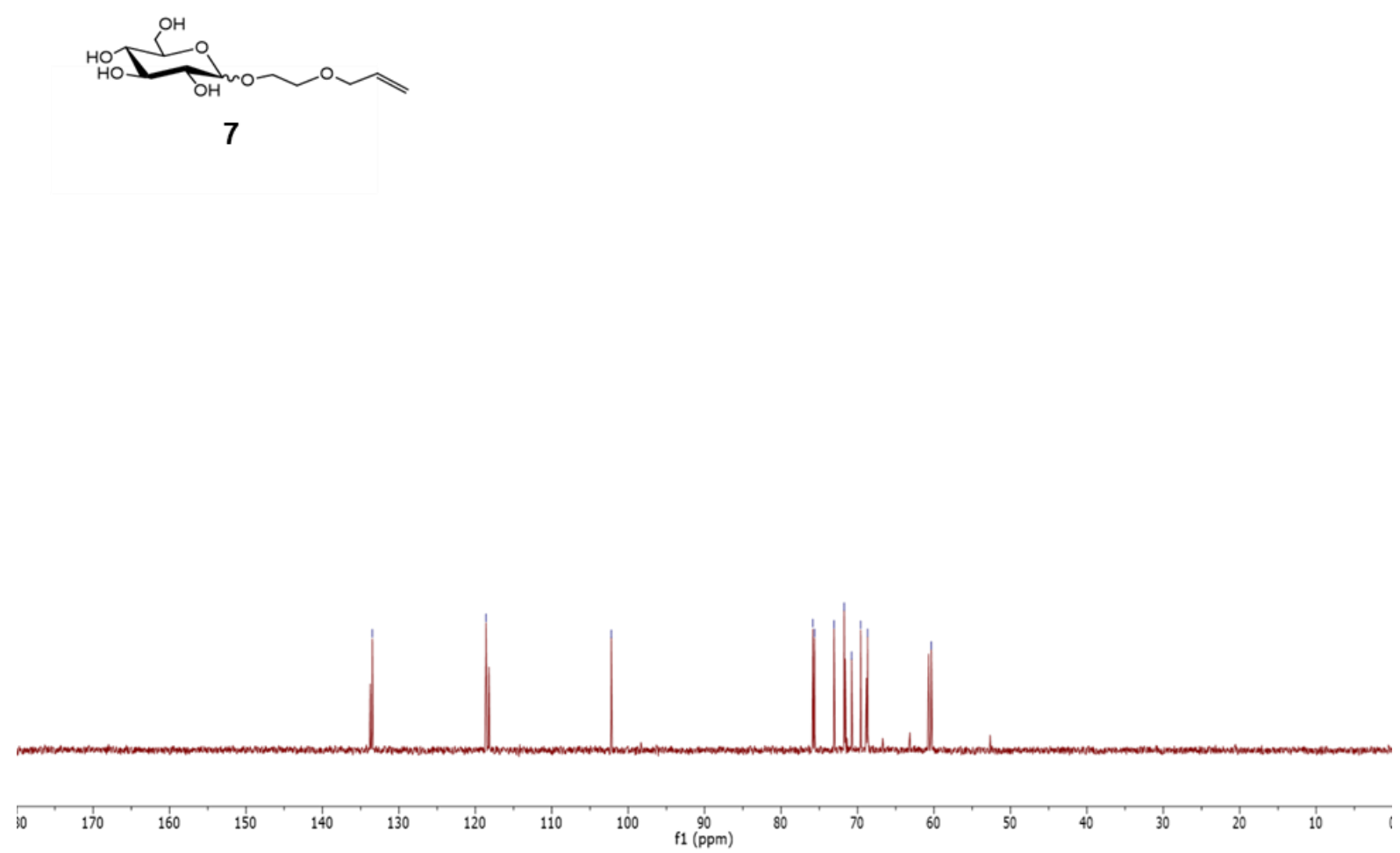
$\underbrace{3}$
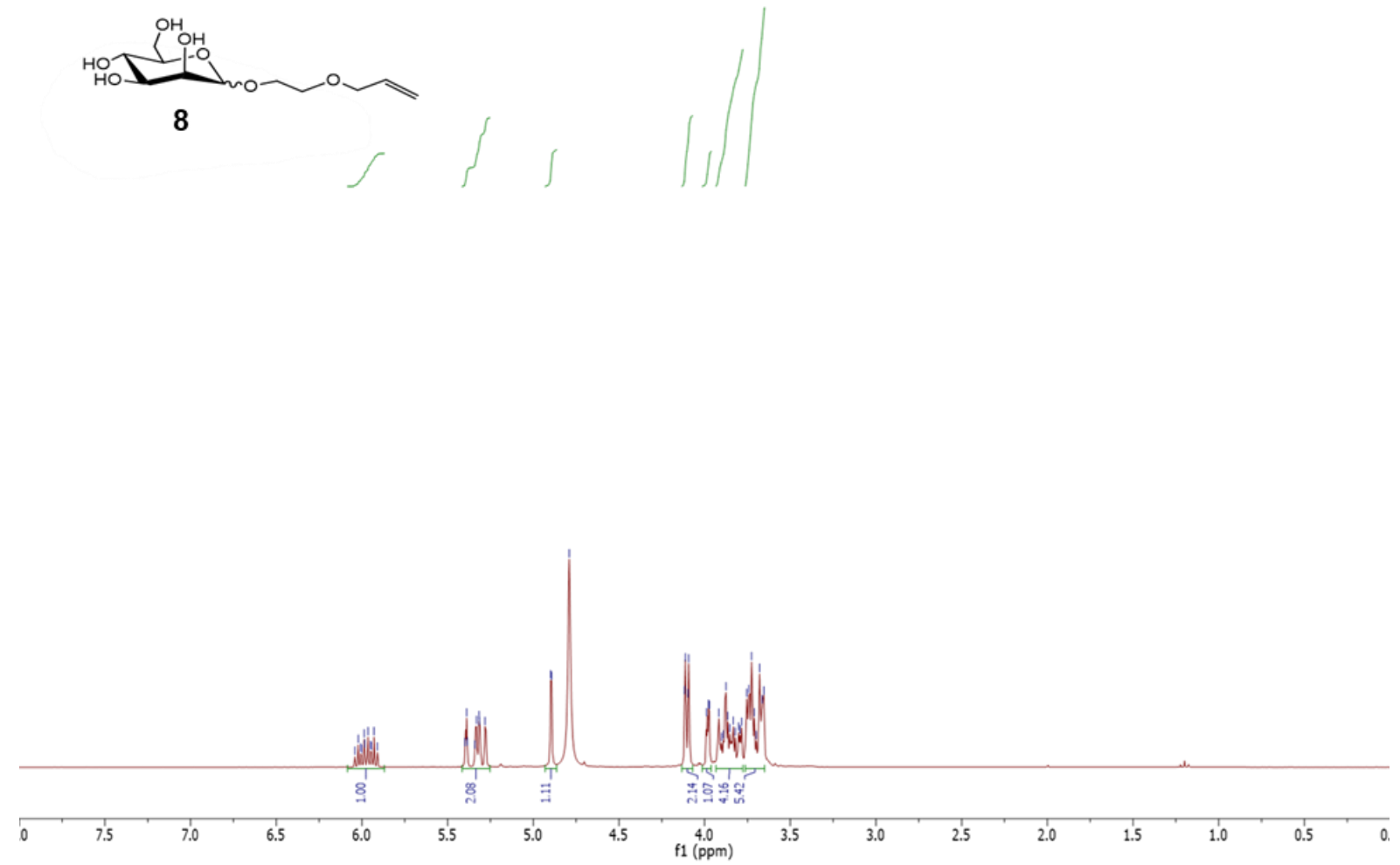

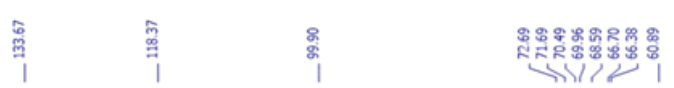
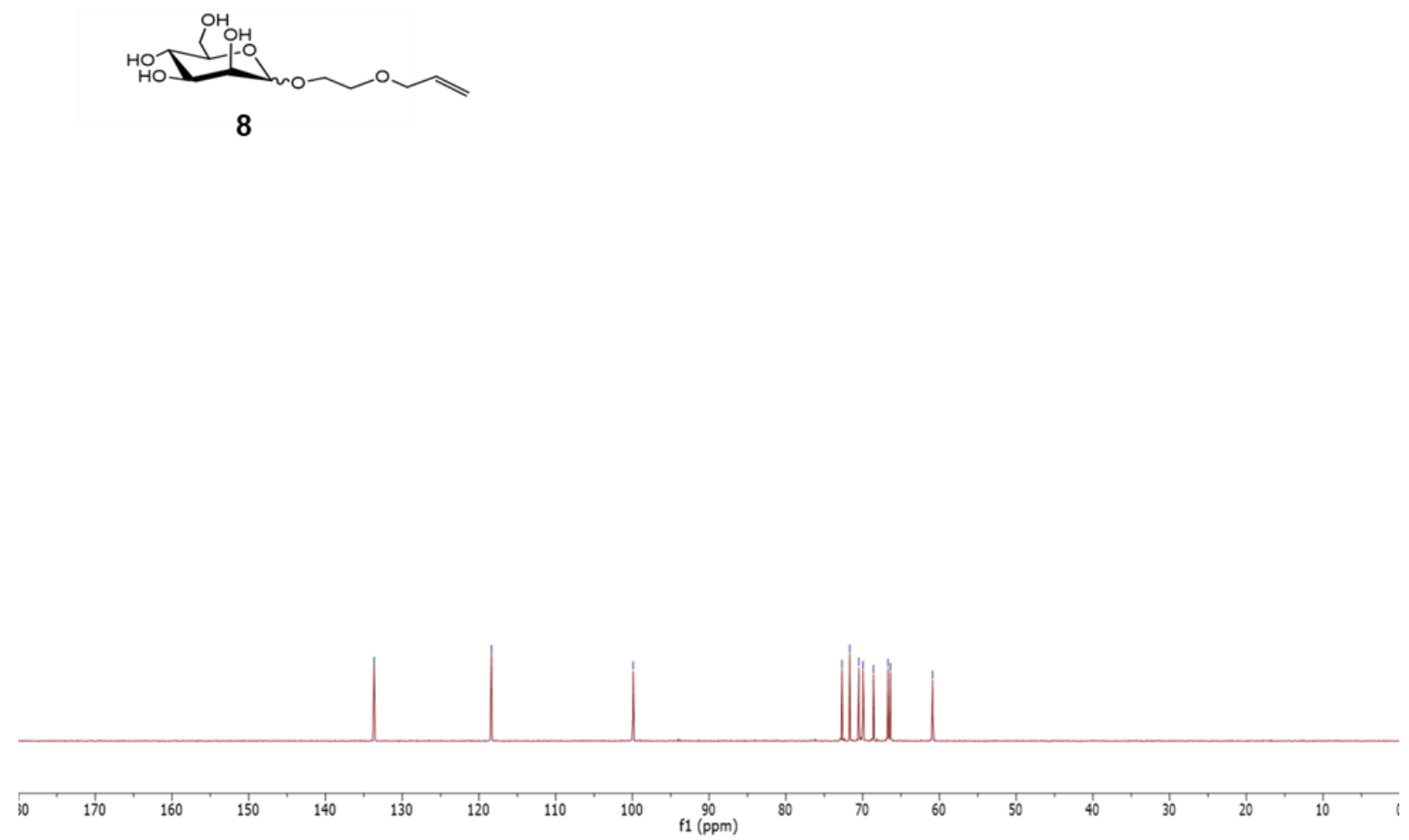

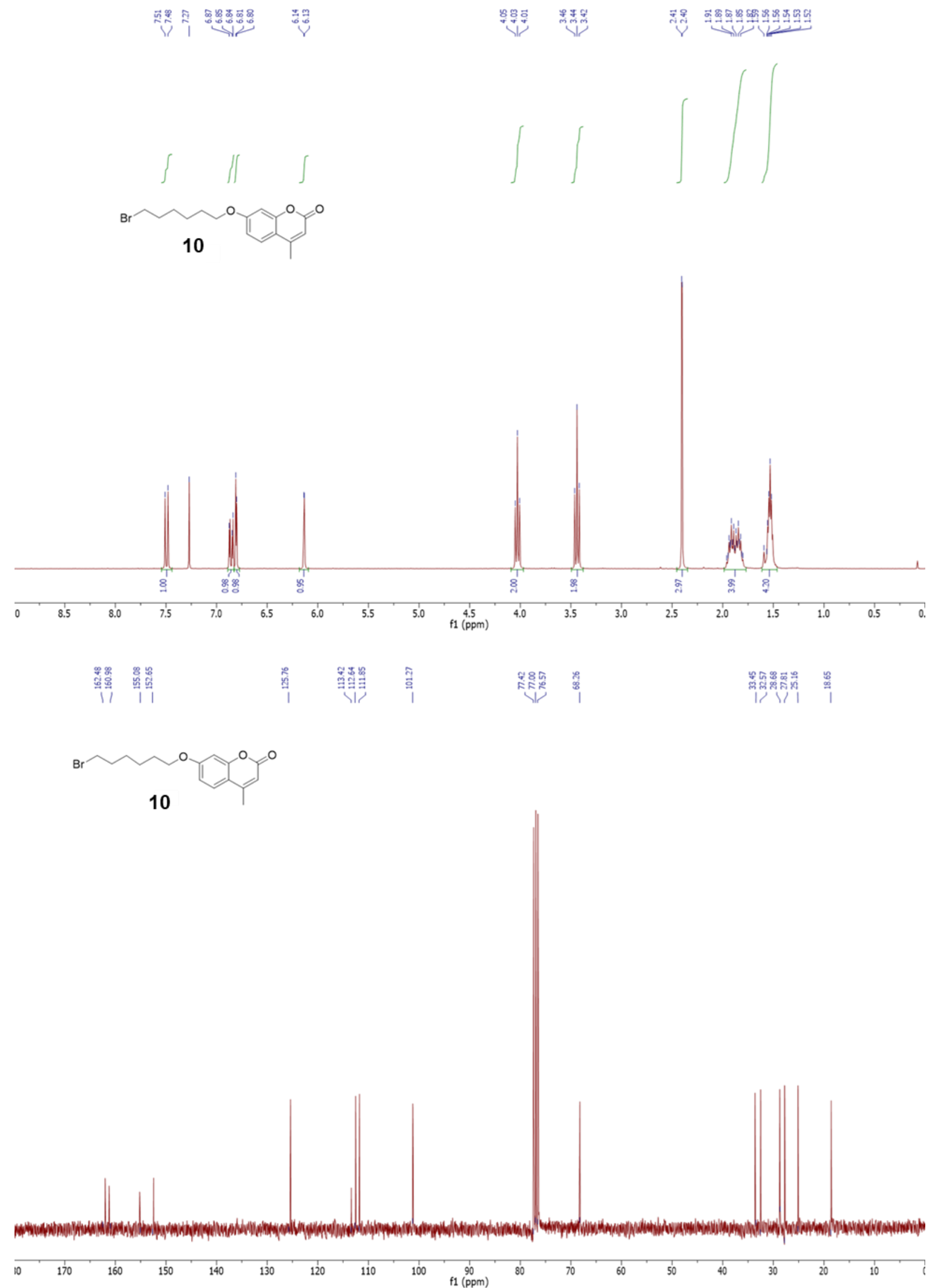


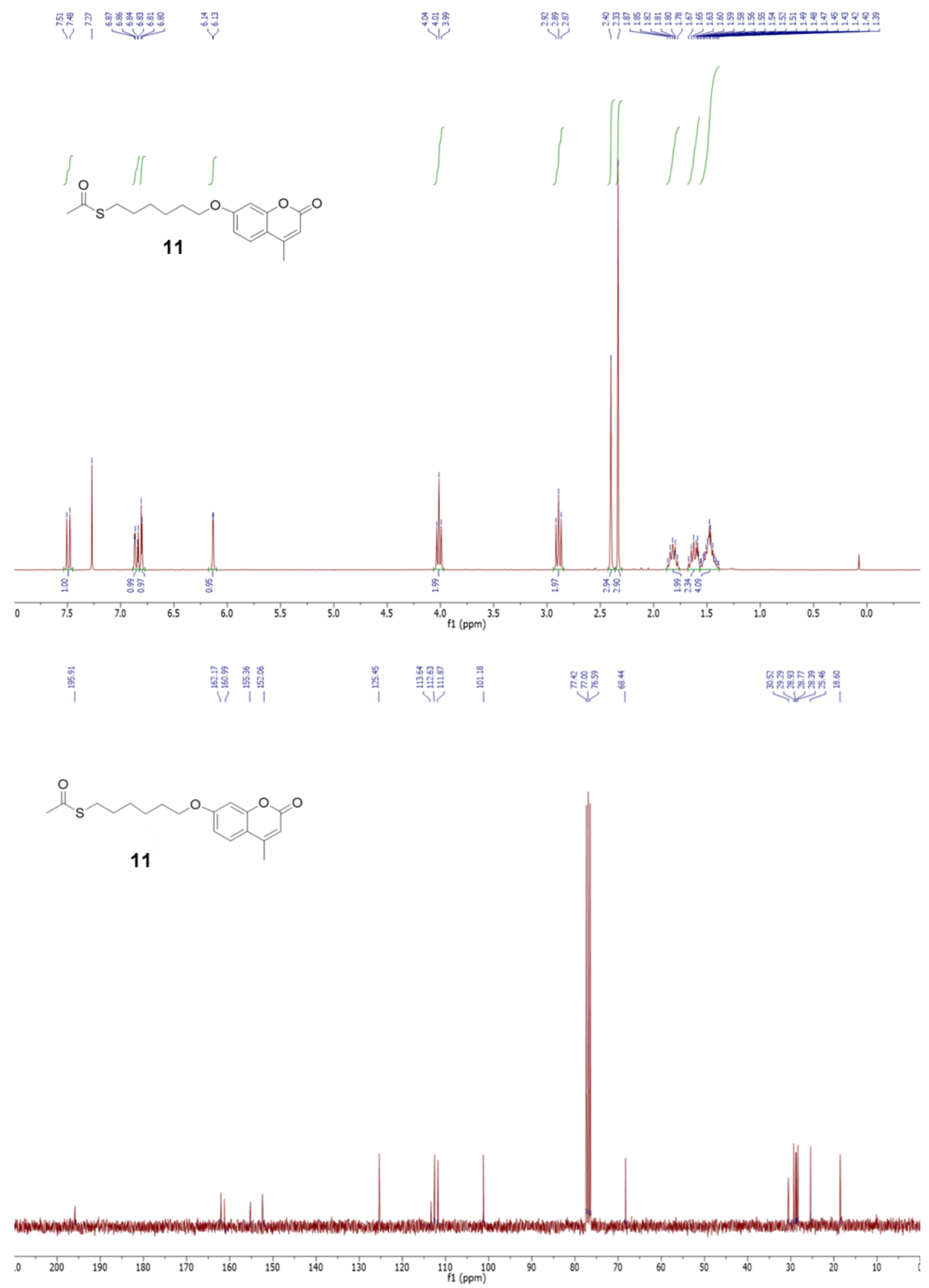


是巽

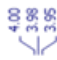

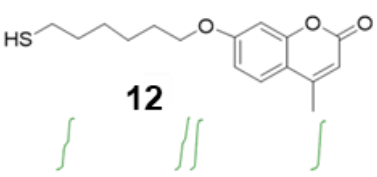

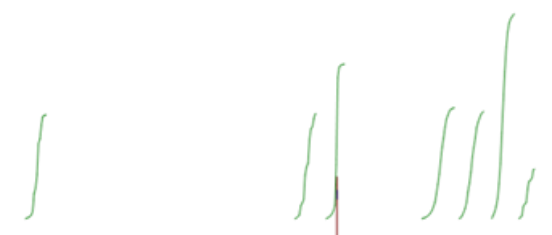

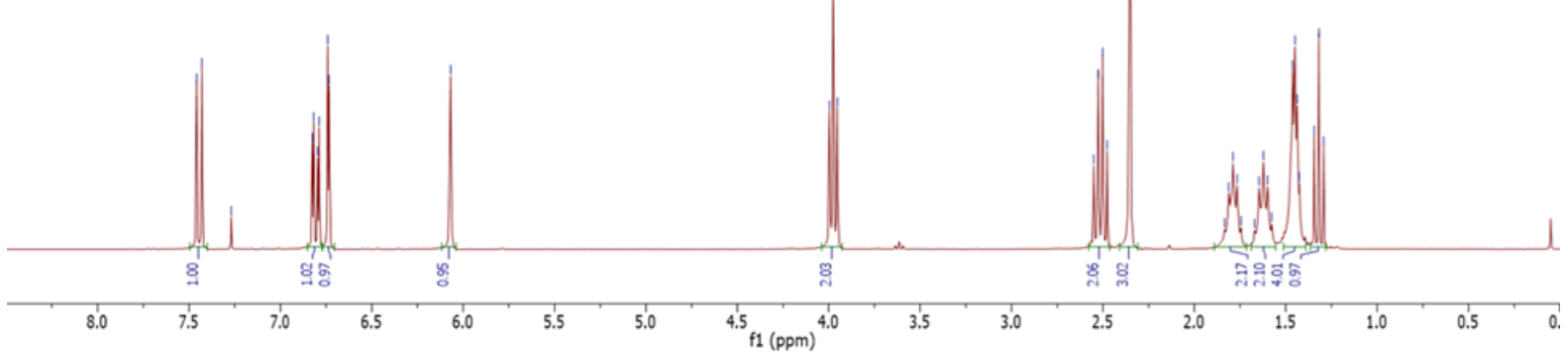

要总

ช్

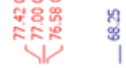

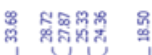<smiles></smiles>

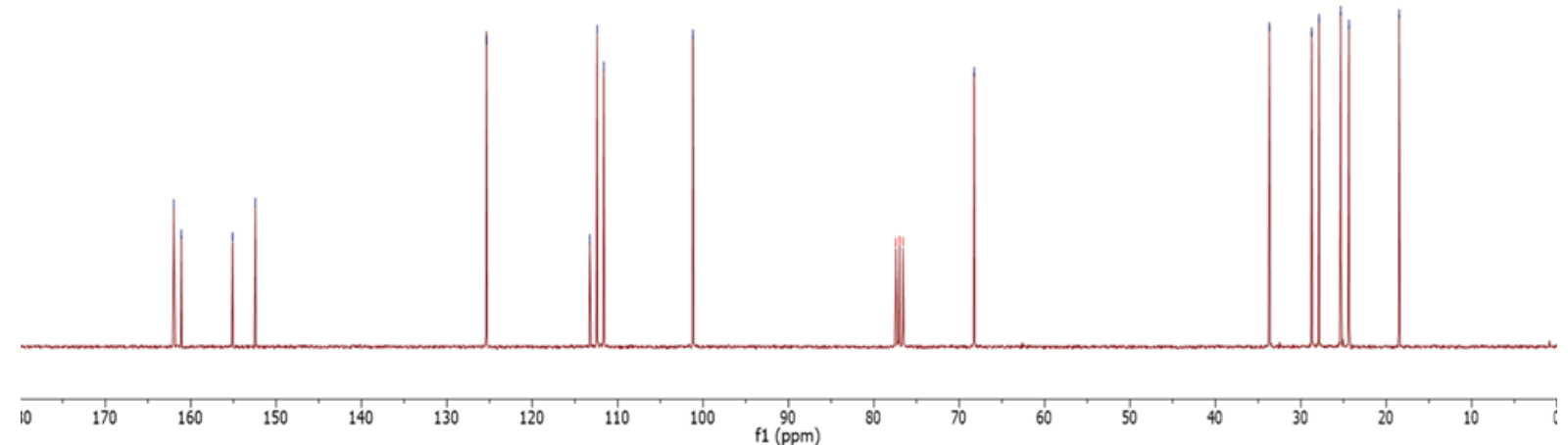


|
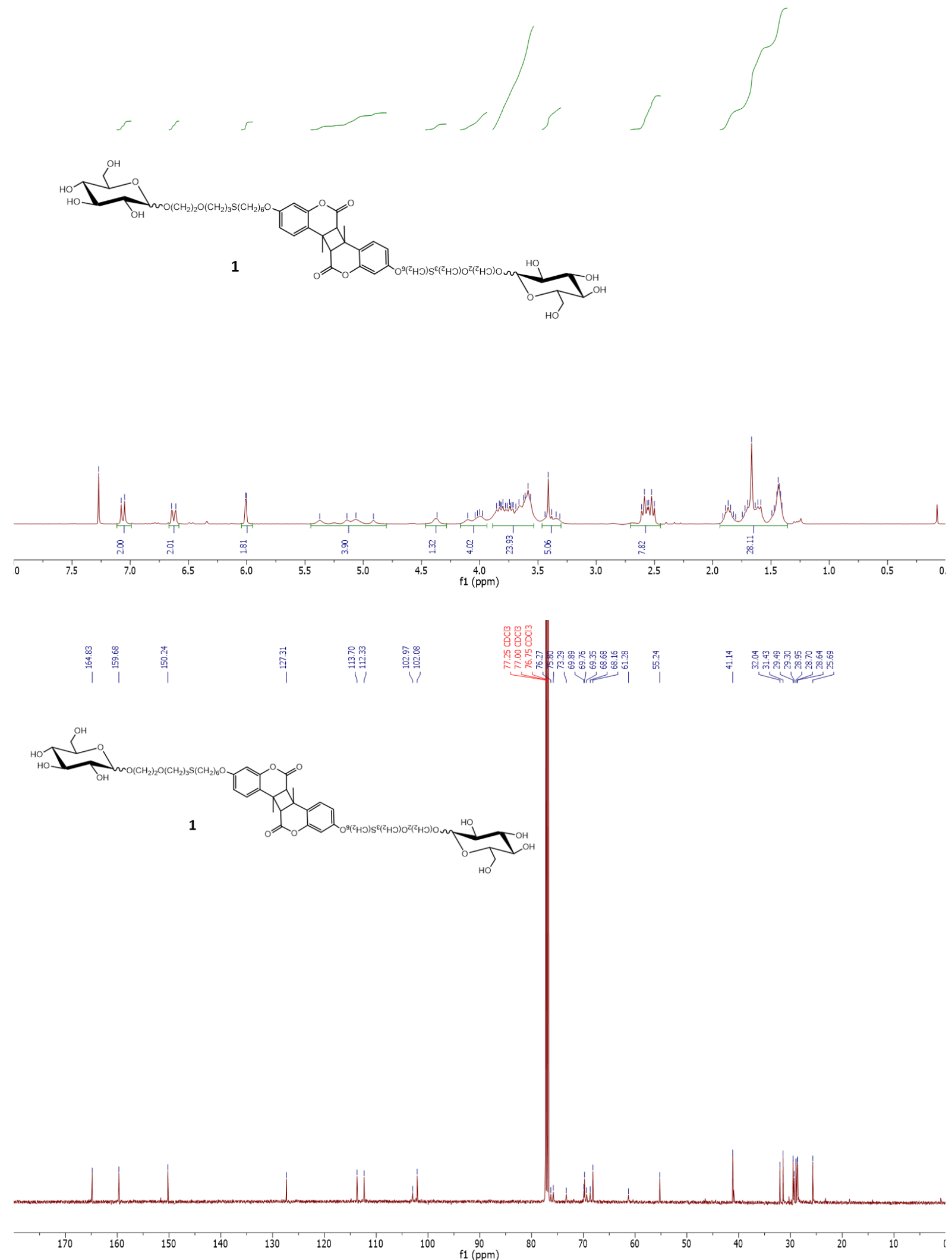


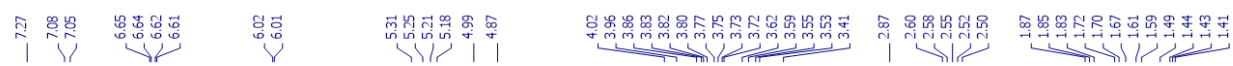
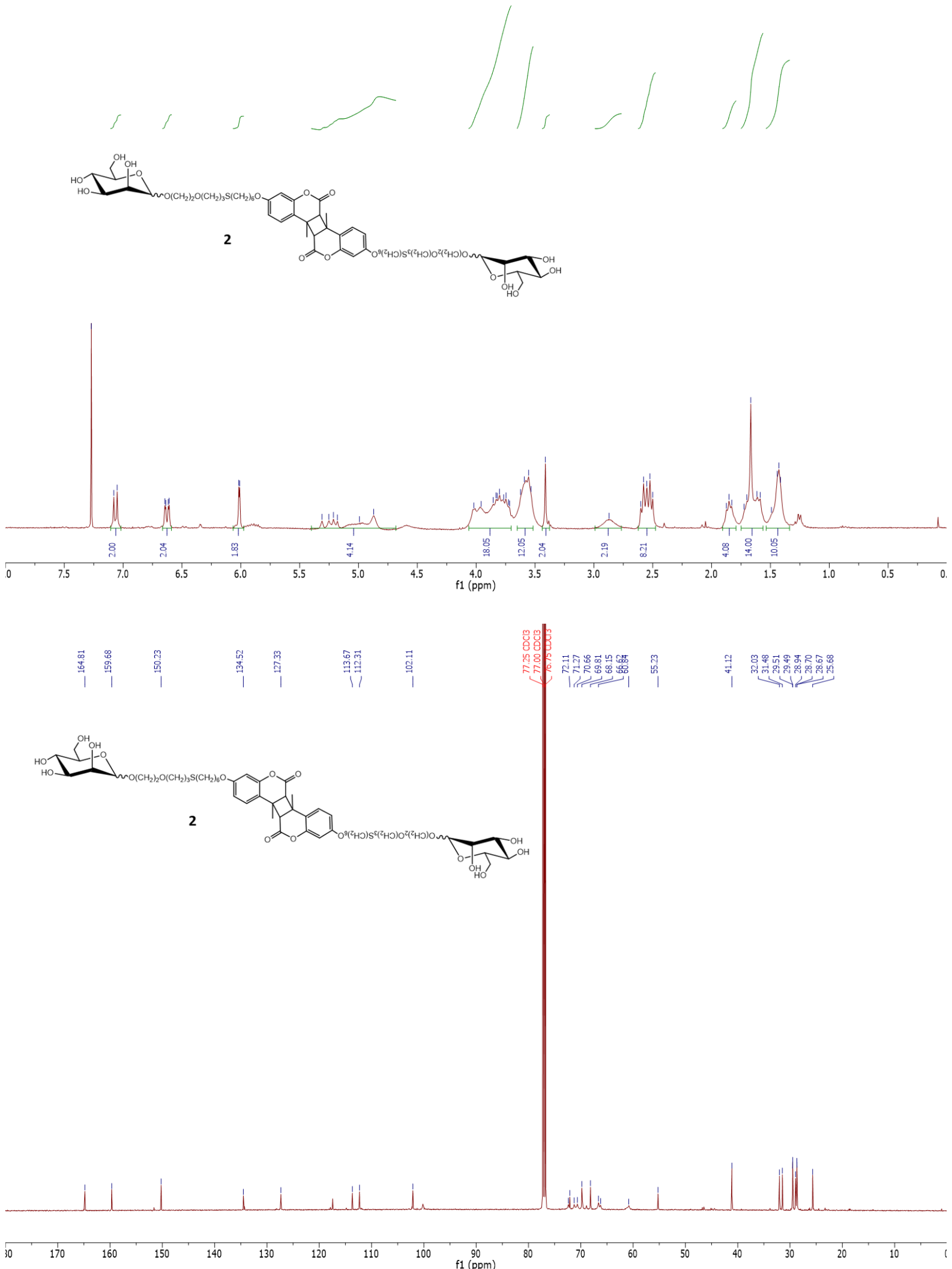


\section{References}

[1] Z. Li, L. Sun, Y. Zhang, A. P. Dove, R. K. O’Reilly, G. Chen, ACS Macro Lett. 2016, 5, 1059-1064.

[2] Z. Cai, A. Sasmal, X. Liu, S. A. Asher, ACS Sens. 2017, 2, 1474-1481.

[3] N. Jiang, Q. Huang, J. Liu, N. Liang, Q. Li, Q. Li, S.-S. Xie, Eur. J. Med. Chem. 2018, $146,287-298$.

[4] Y. Chen, H. Zhou, Y. Wang, W. Li, J. Chen, Q. Lin, C. Yu, Chem. Commun. 2013, 49, 9821-9823. 


\section{Publication 3}

Mannosylated fluorescent cellulose-based glycopolymers for stable uniform nanoparticles

Shuang Wang, Philipp Vana, Kai Zhang*

Wood Technology and Wood Chemistry, Department Wood Technology and Wood-based Composites, Georg-August-University of Göttingen, Büsgenweg 4, D-37077 Göttingen, Germany

E-mail: kai.zhang@uni-goettingen.de

Institute of Physical Chemistry, Georg-August-University of Göttingen, Tammannstraße 6, D-37077 Göttingen, Germany

Originally submitted to:

XX 2020 


\begin{abstract}
In living organisms, carbohydrate-protein interactions play key roles in physiological and pathological processes, which are amplified by the "glycol-cluster effect". In this work, we synthesized novel fluorescent cellulose derivatives bearing mannose moieties via thiol-ene click reactions by sequentially conjugating hydrophilic mannose-oxyethoxylpropane-thiol (Mann-SH) and fluorescent coumarin-oxyhexyl-thiol (Coum-SH) and rhodamine B-ethyl-thiol (RhB-SH) to cellulose undecenoate with terminal double bonds. The amphiphilic fluorescent cellulose derivatives were converted into nanoparticles (NPs) by dropping into low ionic strength solutions $(<0.085 \mathrm{M})$. Obtained NPs have average sizes between 240-554 $\mathrm{nm}$ depending on the solution concentrations, exhibiting uniform size distributions (PDI values < 0.12). These uniform NPs exhibited excellent dispersion stability even at elevated temperatures. The mannose moieties were accessible to 1,4-benzendiboronic acid (BDBA) in $\mathrm{NaOH}$ aqueous solutions. Under irradiation with UV light of 320-400 nm, the fluorescence of NPs increased by the formation of open-ring rhodamine spiroamide, which could be a promising candidate for biomedical application.
\end{abstract}

Keywords: Cellulose derivative, mannose moieties, thiol-ene click reaction, ionic strength, nanoparticles

\title{
1. Introduction
}

Carbohydrate-protein interactions participate in numerous biological activities, such as cellular recognition, adhesion, infection of pathogen and cancer cell metastasis. ${ }^{[1] ;[2]}$ The interactions between clustered saccharides and proteins are strong due to the so-called "glycol-cluster effect" or "multivalent effect". ${ }^{[3]}$ Synthetic glycopolymers containing pendant saccharides have been commonly used to mimic biological recognition events, such as biosensing and diagnosis, targeting cells, drug delivery and gene delivery. ${ }^{[4] ;[5] ;[6] ;[7] ;[8]}$ 
Generally, glycopolymers carrying saccharide moieties have been prepared via polymerization of glyco-monomers or post-polymerization modification favored by the highly efficient and selective click reactions. ${ }^{[9] ;[10]}$

Cellulose is the most abundant polysaccharide of $\beta$-(1 $\rightarrow 4)$-linked anhydroglucose units (AGUs) and widely distributes in plants, algae and some bacteria. ${ }^{[11]}$ Cellulose derivatives with diverse functional groups can be obtained by regioselectively chemical modifications of three hydroxyl groups presenting in each AGU. ${ }^{[12]}$ Certain cellulose derivatives can formed nanoparticles with high surface/volume ratio via nanoprecipitation also called "Ouzo effect" or "solvent exchange process", which include dropping and dialysis techniques. ${ }^{[12]}$ In the past decades, bio-nano/microparticles produced from cellulose derivatives have attracted great attentions due to their potential applications in biomedicine field, such as drug delivery, gene transfection and bioimaging. ${ }^{[13] ;[14] ;[15]}$ However, cellulose derivatives with carbohydrate pendants have been rarely reported, which could be a group of interesting biomaterials due to many superiorities, such as biocompatibility, nontoxicity and specific recognition ability. ${ }^{[16] ;[17]}$

For medical and biological applications, fluorescent dyes offer a platform to visualize and track molecular interactions during cellular internalization process. ${ }^{[18]}$ Among them, rhodamine and coumarin fluorophores are commonly used due to their excellent and favorable properties, such as high fluorescent quantum yields, biocompatibility, stable fluorescent emission and sharp fluorescence emissions. ${ }^{[18] ;[19]}$ Besides, the florescence of rhodamine can be greatly enhanced via structural change from the non-fluorescent spirocyclic state to fluorescent open-ring state induced by different stimulus, such as UV light, metal ions and $\mathrm{pH}^{[20] ;[21]}$

In the present study, we prepared fluorescent glycopolymers by chemical modification of renewable cellulose. At first, three kinds of mercapto-containing compounds were synthesized: hydrophilic mannose-oxyethoxylpropane-thiol (Mann-SH) and fluorescent coumarin-oxyhexyl-thiol (Coum-SH) and rhodamine B-ethyl-thiol (RhB-SH). Then, they 
were conjugated to cellulose undecenoate with terminal double bonds via sequentially photoand thermal-initiated thiol-ene click reactions. The final product 11-(mannose-oxyethoxylpropane)(coumarin-oxyhexyl)(rhodamine-ethyl)thiolundecanoate 10-undecenoyl ester of cellulose (CUE-MCR) was well soluble in organic solvents and further converted into NPs. The properties of NPs bearing mannose moieties were investigated regarding their thermal stability, binding with phenylboronic acid and fluorescence sensitivity.

\section{Results and Discussion}

\section{$\begin{array}{lllll}2.1 & \text { Synthesis } & \text { of } & \text { fluorescent } & \text { amphiphilic }\end{array}$}

11-(mannose-oxyethoxylpropane)(coumarin-oxyhexyl)(rhodamine-ethyl)thiolundecanoa te 10-undecenoyl ester of cellulose (CUE-MCR) via thiol-ene click reaction

In this work, "thiol-ene click chemistry" technique as a highly efficient and practical reaction to fabricate multifunctional polymers was used to attach different mercapto-containing compounds to cellulose backbones with terminal double bonds under mild reaction conditions. At first, three mercapto-containing compounds were synthesized via reactions including glycosylation, acetylation, deacetylation and substitution reactions: mannose-oxyethoxylpropane-thiol (Mann-SH), coumarin-oxyhexyl-thiol (Coum-SH) and rhodamine B-ethyl-thiol (RhB-SH) (Scheme 1a-c). Besides, compound Mann-SH was hydrophilic and compounds Coum-SH and $\mathrm{RhB}-\mathrm{SH}$ were hydrophobic and fluorescent. At the same time, we prepared cellulose 10-undecenoyl ester (CUE) under homogenous conditions, which was easily dissolved in THF due to the high degree of substitution $\left(\mathrm{DS}_{\mathrm{C}=\mathrm{C}}\right.$ = 2.6) according to elemental analysis (Scheme 1d). Due to the highly hydrophilic property of Mann-SH and UV-sensitive property of Coum-SH and RhB-SH, we used photo-initiated thiol-ene click reaction between Mann-SH and CUE in the mixture solvents of THF and DMAc for 6 hours and sequentially used thermal-initiated thiol-ene click reaction by adding 
Coum-SH and RhB-SH stirring at $70{ }^{\circ} \mathrm{C}$ for 10 hours. After the two-step thiol-ene click reactions, the final fluorescent amphiphilic product 11-(mannose-oxyethoxylpropane)(coumarin-oxyhexyl)(rhodamine-ethyl)thiolundecanoate 10-undecenoyl ester of cellulose (CUE-MCR) was obtained with $\mathrm{DS}_{\mathrm{Coum}}(1.0), \mathrm{DS}_{\mathrm{C}=\mathrm{C}}(0.9)$, low $\mathrm{DS}_{\text {Mann }}(0.5)$ and $\mathrm{DS}_{\mathrm{Rhod}}(0.2)$, according to elemental analysis and ${ }^{1} \mathrm{H}$ NMR spectroscopy. The polymer CUE-MCR was well soluble in several organic solvents, such as THF, DCM, DMAc and DMF.
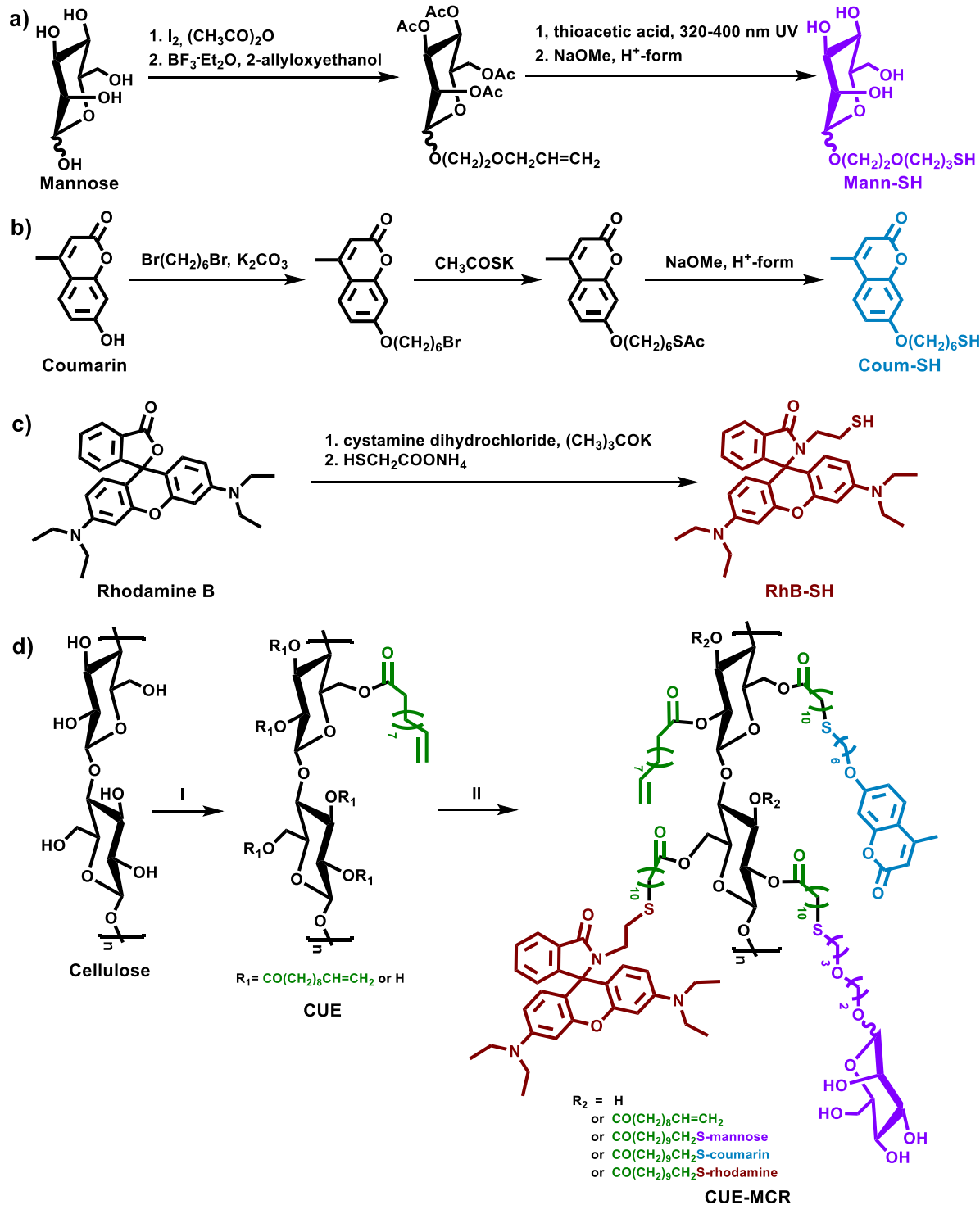

Scheme 1. Synthetic routes of a) Mann-SH; b) Coum-SH; c) RhB-SH and d) 11-(man 
nose-oxyethoxylpropane)(coumarin-oxyhexyl)(rhodamine-ethyl)thiolundecanoate 10-undece noyl ester of cellulose (CUE-MCR): I) 10-undecenoyl chloride, pyridine, heating at 50 ${ }^{\circ} \mathrm{C}$ for 4 hours; II) Mann-SH, 320-400 nm UV irradiation for 6 hours, DMPA; then Coum-SH, RhB-SH, heating at $70{ }^{\circ} \mathrm{C}$ for 10 hours, AIBN.
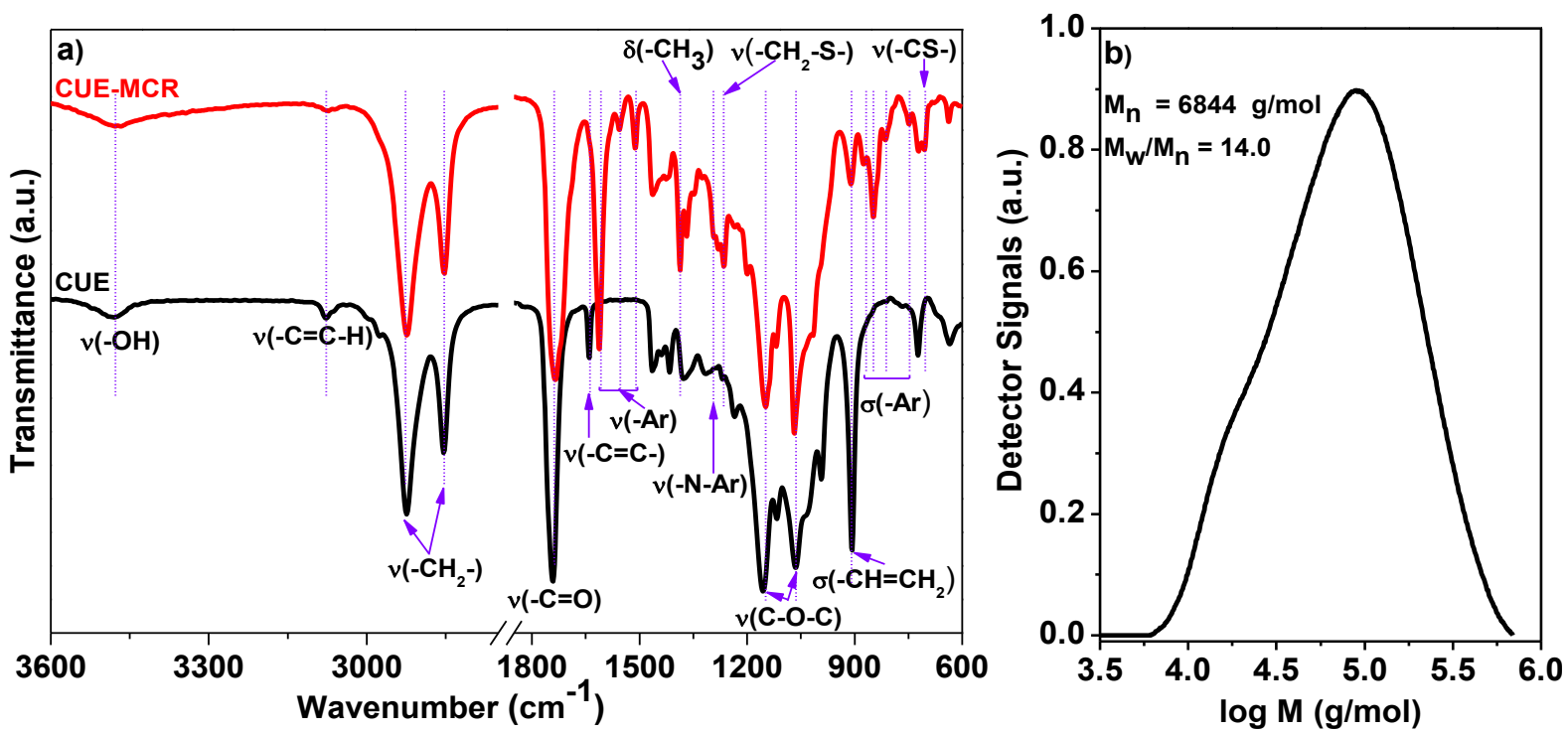

Figure 1. a) FTIR spectra of cellulose 10-undecenoyl ester $(\mathrm{CUE})\left(\mathrm{DS}_{\mathrm{C}=\mathrm{C}}=2.6\right)$ and 11-(mannose-oxyethoxylpropane)(coumarin-oxyhexyl)(rhodamine-ethyl)thiolundecanoate 10 -undecenoyl ester of cellulose $(\mathrm{CUE}-\mathrm{MCR})\left(\mathrm{DS}_{\mathrm{Mann}}=0.5, \mathrm{DS}_{\mathrm{Coum}}=1.0, \mathrm{DS}_{\mathrm{Rhod}}=0.2\right.$ and $\mathrm{DS}_{\mathrm{C}=\mathrm{C}}=0.9$ ). b) Size exclusion chromatographic curve of CUE-MCR measured in THF.

The representative FTIR spectra of CUE and CUE-MCR were displayed in Figure 1a. Compared to the FTIR spectra of CUE, the peaks of olefin C-H and C=C at 3077, 1639 and $907 \mathrm{~cm}^{-1}$ greatly decreased and the stretching vibration peaks of $\mathrm{O}-\mathrm{H}$ and $\mathrm{C}=\mathrm{O}$ (ester carbonyl group and enone carbonyl group) at 3483 and $1735 \mathrm{~cm}^{-1}$ broadly increased in the FTIR spectra of CUE-MCR. This fact indicates that the double bonds of CUE were partially consumed and three mercapto-containing compounds (Mann-SH, Coum-SH and RhB-SH) were attached to the CUE during the thiol-ene click reaction. Meanwhile, we observed characteristic absorption peaks for aromatic rings at $1610-1510 \mathrm{~cm}^{-1}$ (the $\mathrm{C}=\mathrm{C}$ stretching vibration) and $870-750 \mathrm{~cm}^{-1}$ (the aromatic $\mathrm{C}-\mathrm{H}$ deformation vibration out of plane), and peak 
at $1386 \mathrm{~cm}^{-1}$ (the $-\mathrm{CH}_{3}$ deformation vibration), indicating the existence of coumarin and rhodamine B structures. ${ }^{[22]}$ In addition, the new peak appeared at $1280 \mathrm{~cm}^{-1}$ which was ascribed to the tertiary aromatic amine $\mathrm{N}$-aryl bond of the rhodamine $\mathrm{B}$ moieties. The peaks at 1270 and $693 \mathrm{~cm}^{-1}$ were attributed to the $-\mathrm{CH}_{2}-\mathrm{S}_{-} \mathrm{CH}_{2}$ - bond. ${ }^{[16]}$ In addition, gel permeation chromatography (GPC) was used to measure the molecular weight of CUE-MCR. As shown in Figure 1b, the CUE-MCR had the number-average molecular weight $\left(M_{\mathrm{n}}\right)$ of $6844 \mathrm{~g} \cdot \mathrm{mol}^{-1}$ and a broad molecular weight distribution (PDI $=14.0)$.
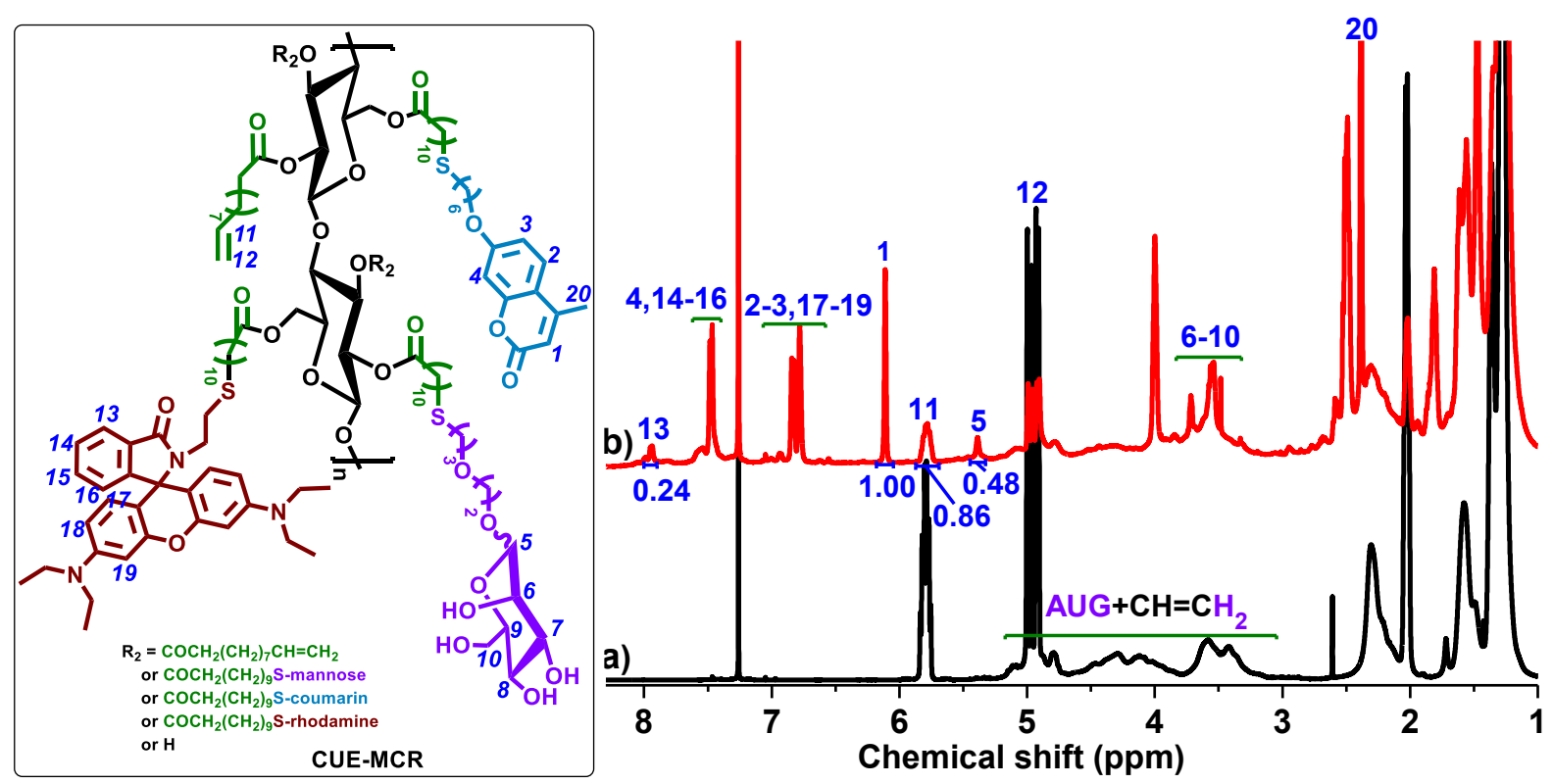

Figure 2. ${ }^{1} \mathrm{H}$ NMR spectra of a) cellulose 10-undecenoyl ester $(\mathrm{CUE})\left(\mathrm{DS}_{\mathrm{C}=\mathrm{C}}=2.6\right)$ and $\mathrm{b}$ ) 11-(mannose-oxyethoxylpropane)(coumarin-oxyhexyl)(rhodamine-ethyl)thiolundecanoate 10 -undecenoyl ester of cellulose $(\mathrm{CUE}-\mathrm{MCR})\left(\mathrm{DS}_{\mathrm{Mann}}=0.5, \mathrm{DS}_{\mathrm{Coum}}=1.0, \mathrm{DS}_{\mathrm{Rhod}}=0.2\right.$ and $\mathrm{DS}_{\mathrm{C}=\mathrm{C}}=0.9$ ) measured in $\mathrm{CDCl}_{3}$. The numbers in the structural formula of CUE-MCR display the protons of CUE-MCR.

${ }^{1} \mathrm{H}-\mathrm{NMR}$ was employed to further investigate the chemical structure of CUE-MCR, as shown in Figure 2. In the ${ }^{1} \mathrm{H}$ NMR spectrum of CUE, the terminal olefin peaks appeared at 4.9 and $5.8 \mathrm{ppm}$ and the signals from 3.0 to $5.3 \mathrm{ppm}$ can be assigned to the protons of the cellulose backbone, as shown in Figure 2a. After thiol-ene click reaction, a significant decrease of 
olefin resonances revealed the most thiol-ene addition. The new peaks at 8.0, 7.5-7.6, 6.8-7.1, $6.1 \mathrm{ppm}$ were assigned to the aromatic and enone protons of rhodamine and coumarin group, respectively. The new signals appeared at 5.4 and 3.3-3.8 ppm and were corresponding to the protons of mannose groups. The presence of these signals confirmed the successful incorporation of mannose, coumarin and rhodamine groups after the two-step thiol-ene click reaction. Moreover, ${ }^{1} \mathrm{H}$ NMR spectrum of CUE-MCR was also used for calculating DS ascribed to functional groups. Since the two-step thiol-ene click reactions were very mild, the double bonds of CUE ( $\mathrm{DS}_{\mathrm{C}=\mathrm{C}}=2.6$ ) should only be consumed by incorporation of three kinds of functional groups. The integration of typical aromatic peak of rhodamine group at $8.0 \mathrm{ppm}$, enone peak of coumarin group at $6.1 \mathrm{ppm}$, the terminal olefin peak at $5.8 \mathrm{ppm}$ and C-1 peak of mannose group at $5.4 \mathrm{ppm}$ yielded a ratio of 0.24:1.00:0.86:0.48, which was in good accordance with the result of elemental analysis.

In addition to the carbon signals assigned to terminal olefin at 114.15 and $138.97 \mathrm{ppm}$ as observed in ${ }^{13} \mathrm{C}$ NMR spectra of CUE, new characteristic signals emerged in the ${ }^{13} \mathrm{C}$ NMR spectra of CUE-MCR assigned to the mannose, coumarin and rhodamine groups (Figure 3). As shown in Figure 3b, the carbon signals at 61.66, 66.65, 67.89, 69.60, 71.81 and 99.93 ppm were assigned to the mannose ring, while the carbon signals at 18.61, 101.22, 111.71, $112.59,113.34,125.42,152.58,155.18,161.30$ and $162.08 \mathrm{ppm}$ were attributed to the methyl, cyclic enone and aromatic carbons of coumarin groups, respectively, as displayed in detail in Figure 3b. The weak carbon signals at 12.54, 50.69, 97.59, 107.99, 124.55, 125.15, 127.96, $128.47,128.81,131.40,148.69$ and 153.22 were assigned to the methyl and aromatic carbons of rhodamine group due to the low DS. 

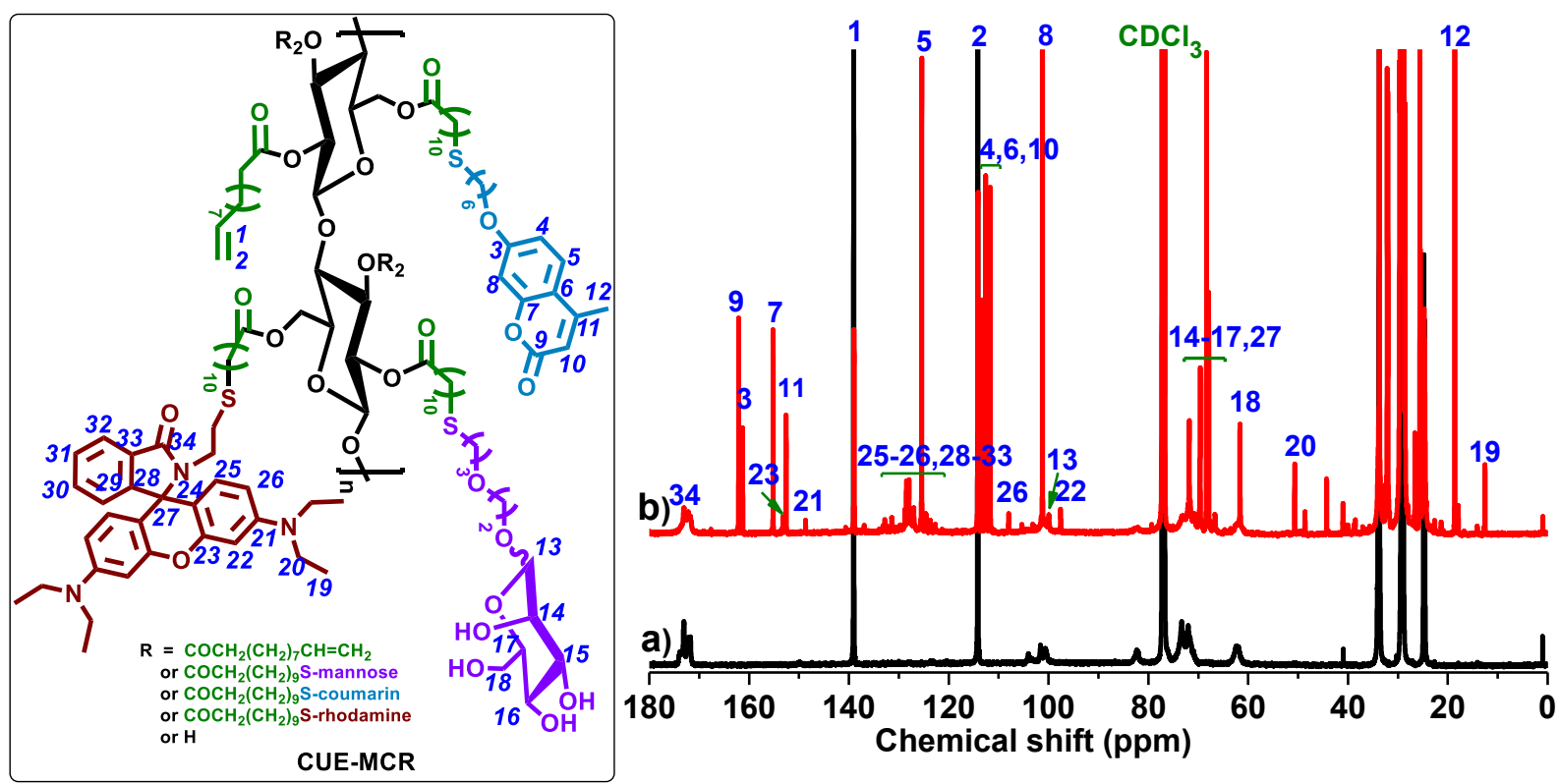

Figure 3. ${ }^{13} \mathrm{C}$ NMR spectra of a) cellulose 10-undecenoyl ester (CUE) $(\mathrm{DS} \mathrm{C}=\mathrm{C}=2.6)$ and $\mathrm{b}$ ) 11-(mannose-oxyethoxylpropane)(coumarin-oxyhexyl)(rhodamine-ethyl)thiolundecanoate 10 -undecenoyl ester of cellulose $(\mathrm{CUE}-\mathrm{MCR})\left(\mathrm{DS}_{\mathrm{Mann}}=0.5, \mathrm{DS}_{\mathrm{Coum}}=1.0, \mathrm{DS}_{\mathrm{Rhod}}=0.2\right.$ and $\mathrm{DS}_{\mathrm{C}=\mathrm{C}}=0.9$ ) measured in $\mathrm{CDCl}_{3}$ with 15000 scans. The numbers in the structural formula of CUE-MCR display the carbons of CUE-MCR.

\subsection{Formation of nanoparticles}

The NPs were formed via nanoprecipitation of CUE-MCR using dropping technique through a solvent exchange process (Figure 4a). In this work, the ionic strengths of non-solvent affecting average size and size distribution of NPs during nanoparticle formation process was investigated. Three electrolytes were chosen: monovalent salts $\mathrm{NH}_{4} \mathrm{Cl}, \mathrm{NaCl}$ and divalent salt $\mathrm{MgSO}_{4}$. After dropping CUE-MCR solution in THF with the concentration of $4 \mathrm{mg} \cdot \mathrm{mL}^{-1}$ into excessive aqueous solutions of electrolytes with various concentrations $(0,17 \mathrm{mM}, 51 \mathrm{mM}$, $85 \mathrm{mM}$ ), stable and milky NPs were only obtained in pure DI water and solutions of $17 \mathrm{mM}$ electrolytes $\left(\mathrm{NH}_{4} \mathrm{Cl}, \mathrm{NaCl}, \mathrm{MgSO}_{4}\right)$ as well as $51 \mathrm{mM}$ electrolytes $\left(\mathrm{NH}_{4} \mathrm{Cl}\right.$ and $\left.\mathrm{NaCl}\right)$. After the nanoprecipitation, NPs were dialysed against DI water for days to remove THF and electrolytes. 
a)

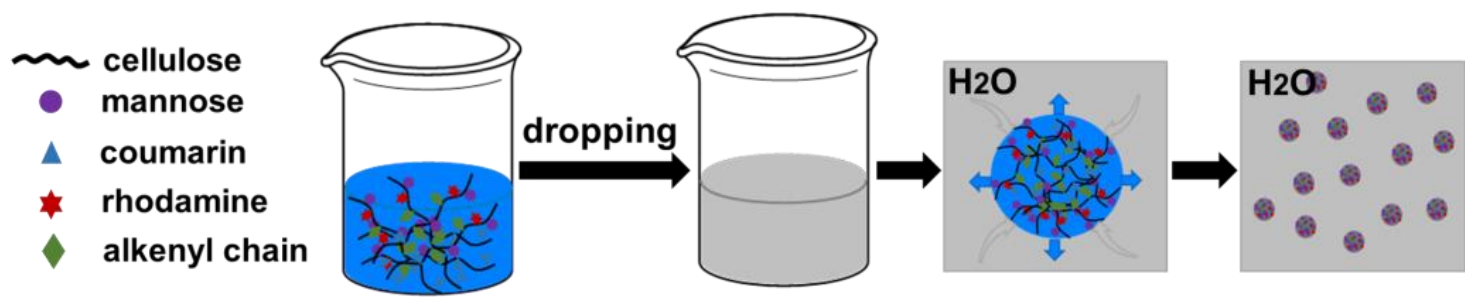

CUE-MCR in THF

NPs

b)

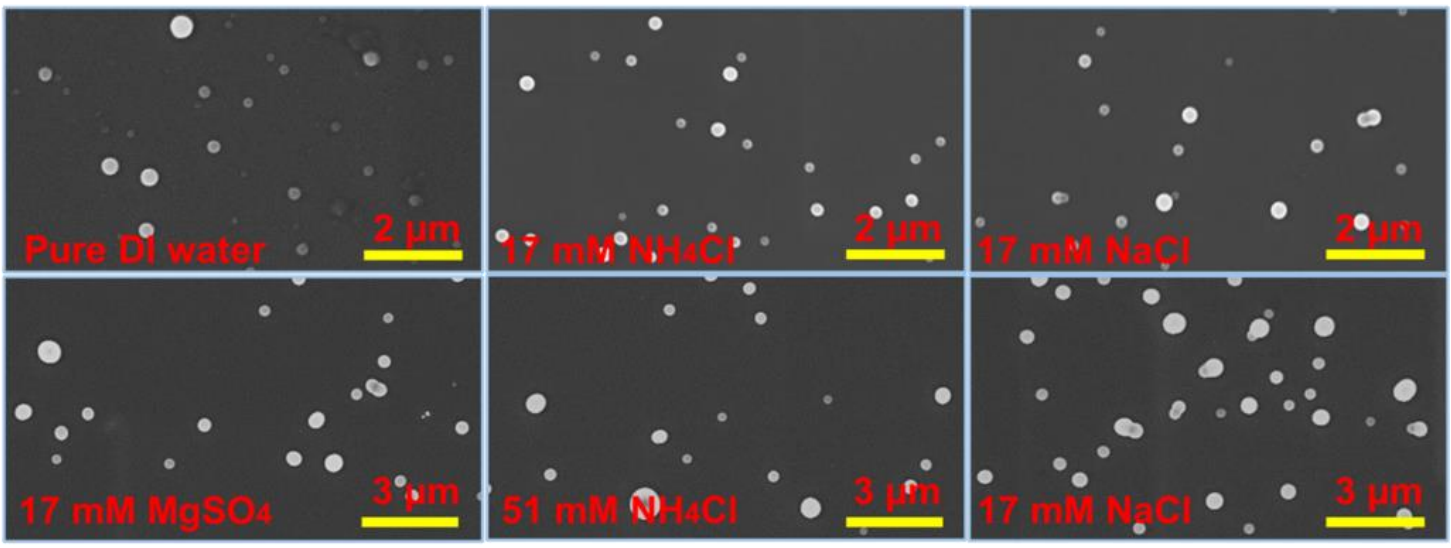

Figure 4. a) Schematic illustration for the nanoprecipitation of CUE-MCR solutions using dropping technique. Blue areas: THF, colorful chains: CUE-MCR chains. b) SEM images of obtained NPs prepared via dropping into aqueous electrolytes solutions of different concentrations after aging at $80{ }^{\circ} \mathrm{C}$ for 36 hours.

The average size, size distribution and zeta potential were essential parameters for NPs. The average diameters of the resulting NPs ranging from 118 to $560 \mathrm{~nm}$ were determined by DLS measurement (Table 1). When using pure DI water as no-solvent (dispersant), the average diameter of NPs was smaller with relatively broader size distribution. In comparison, the presence of electrolytes greatly increased the average sizes of NPs with a more uniform size distribution (PDI value $<0.12)$. At the same lower concentration of electrolytes $(17 \mathrm{mM})$, the average diameters of NPs formed in monovalent electrolyte solutions were smaller than in divalent electrolyte solution. The average diameter of NPs formed in $17 \mathrm{mM} \mathrm{MgSO} 4$ was 
similar to NPs formed in $51 \mathrm{mM} \mathrm{NaCl}$. Using the same electrolyte, the average diameter of NPs increased more than two-fold by increasing the concentration from $17 \mathrm{mM}$ to $51 \mathrm{mM}$. The ionic strength of divalent electrolyte $\mathrm{MgSO}_{4}$ was four times higher than an equivalent concentration of monovalent electrolyte $\mathrm{NaCl}$. The presence of low ion valences introduced small electrostatic screening and weakened the electrostatic interactions, leading to the growth of NPs according to nucleation-aggregation mechanism. ${ }^{[23]}$ Thus, stable NPs dispersions in $17 \mathrm{mM}$ solutions of all electrolytes but only in $51 \mathrm{mM}$ solutions of monovalent electrolytes were obtained. The zeta potentials of the stable NPs were between -30.9 to -35.2 $\mathrm{mV}$, confirming the negative surface charges and fairly good physical stability of NPs in these dispersions. With the ionic strength further increased up to $0.085 \mathrm{M}$, the NPs flocculated instantly upon formation. Therefore, the formation of stable particles is probably strongly limited at higher ionic strengths and/or ion valences $\left(51 \mathrm{mM} \mathrm{MgSO}_{4}, 85 \mathrm{mM} \mathrm{NH}_{4} \mathrm{Cl}\right.$ and 85 $\mathrm{mM} \mathrm{NaCl}$ ), which introduced greater electrostatic screening and strongly reduced surface negative charges.

Table 1. Z-average diameters (d), PDI and zeta potential of NPs formed in aqueous electrolytes solutions of different concentrations using the CUE-MCR solution of $4 \mathrm{mg} \cdot \mathrm{mL}^{-1}$ THF.

\begin{tabular}{cccccccc}
\hline Dispersan & Ionic & d of & PDI & Zeta & d of NPs & PDI & Zeta \\
$\mathrm{t}$ & strength & as-prepared & & potential & at $80{ }^{\circ} \mathrm{C}$ & & potential \\
& $(\mathrm{M})^{\mathrm{a}}$ & $\mathrm{NPs}$ & & $(\mathrm{mV})$ & for $36 \mathrm{~h}$ & & $(\mathrm{mV})$ \\
& & $(\mathrm{nm})$ & & & $(\mathrm{nm})$ & & \\
\hline DI water & 0 & $117.8 \pm 1.0$ & $0.29 \pm 0.04$ & $-31.9 \pm 0.4$ & $109.8 \pm 5.4$ & $0.26 \pm 0.01$ & $-41.2 \pm 0.6$ \\
& & & & & & & \\
$\mathrm{NH}_{4} \mathrm{Cl}$ & 0.017 & $239.3 \pm 1.2$ & $0.10 \pm 0.01$ & $-33.1 \pm 0.9$ & $221.9 \pm 1.2$ & $0.10 \pm 0.02$ & $-48.9 \pm 0.6$ \\
$(17 \mathrm{mM})$ & & & & & & & \\
$\mathrm{NaCl}$ & 0.017 & $196.2 \pm 0.6$ & $0.08 \pm 0.04$ & $-35.0 \pm 0.5$ & $187.8 \pm 4.1$ & $0.06 \pm 0.02$ & $-50.6 \pm 0.8$
\end{tabular}


(17 mM)

\begin{tabular}{cccccccc}
$\mathrm{MgSO}_{4}$ & 0.068 & $471.4 \pm 4.7$ & $0.05 \pm 0.01$ & $-30.9 \pm 0.1$ & $443.0 \pm 2.4$ & $0.05 \pm 0.02$ & $-39.4 \pm 0.4$ \\
$(17 \mathrm{mM})$ & & & & & & & \\
$\mathrm{NH}_{4} \mathrm{Cl}$ & 0.051 & $553.7 \pm 7.6$ & $0.12 \pm 0.01$ & $-35.2 \pm 0.2$ & $477.5 \pm 9.1$ & $0.08 \pm 0.04$ & $-53.3 \pm 0.8$ \\
$(51 \mathrm{mM})$ & & & & & & & \\
$\mathrm{NaCl}$ & 0.051 & $491.0 \pm 4.4$ & $0.10 \pm 0.02$ & $-34.6 \pm 0.6$ & $458.5 \pm 0.3$ & $0.02 \pm 0.02$ & $-49.5 \pm 1.1$ \\
$(51 \mathrm{mM})$ & & & & & & & \\
\hline
\end{tabular}

${ }^{\mathrm{a}}$ : the data calculated according the reference ${ }^{[23]}$.

To investigate the effect of temperature on the dispersion stability of NPs, NPs formed in different electrolytes concentration were incubated at $80{ }^{\circ} \mathrm{C}$ for 36 hours and used DLS to measure the corresponding average diameter and zeta potential of those NPs. After aging for 36 hours, NPs with excellent dispersion stability maintained stable and the dispersions stayed transparent. According to their SEM images (Figure 4b), spherical NPs of CUE-MCR with a smooth surface remained after aging at $80{ }^{\circ} \mathrm{C}$ for 36 hours. As summarized in Table 1, an increase in temperature resulted in a slight decrease in both the average size and size distribution of those NPs after aging at $80{ }^{\circ} \mathrm{C}$ compared to initial NPs. The average sizes of those NPs after aging were $225.3 \pm 101.7 \mathrm{~nm}, 260.3 \pm 51.0 \mathrm{~nm}, 253.2 \pm 69.0 \mathrm{~nm}, 473.7 \pm$ $121.1 \mathrm{~nm}, 477.6 \pm 158.2 \mathrm{~nm}$ and $538.4 \pm 103.5 \mathrm{~nm}$ for NPs formed in pure DI water, $17 \mathrm{mM}$ $\mathrm{NH}_{4} \mathrm{Cl}, 17 \mathrm{mM} \mathrm{NaCl}, 17 \mathrm{mM} \mathrm{MgSO}_{4}, 51 \mathrm{mM} \mathrm{NH} 4 \mathrm{Cl}$ and $51 \mathrm{mM} \mathrm{NaCl}$, respectively. Zeta potential measurements showed that those NPs after aging became more negatively charged. In particular, the zeta potentials of NPs formed in monovalent electrolyte solutions were similar (with the increase of $15-17 \mathrm{mV}$ to around $50 \mathrm{mV}$ ) and more than NPs formed in pure DI water or divalent electrolyte solutions (with the increase of 9-10 $\mathrm{mV}$ to around $40 \mathrm{mV}$ ). 
a)

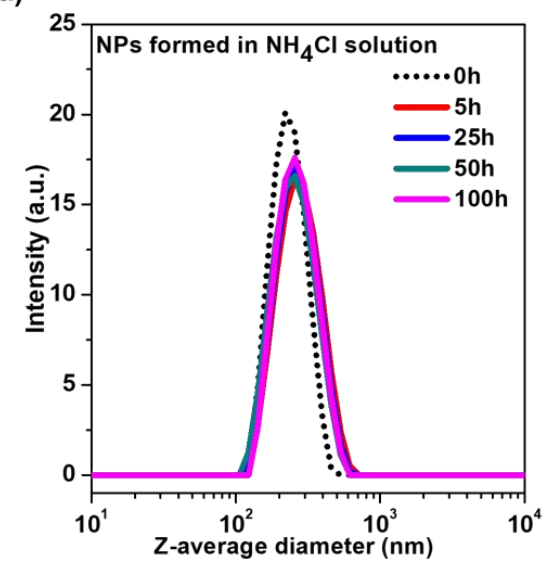

b)

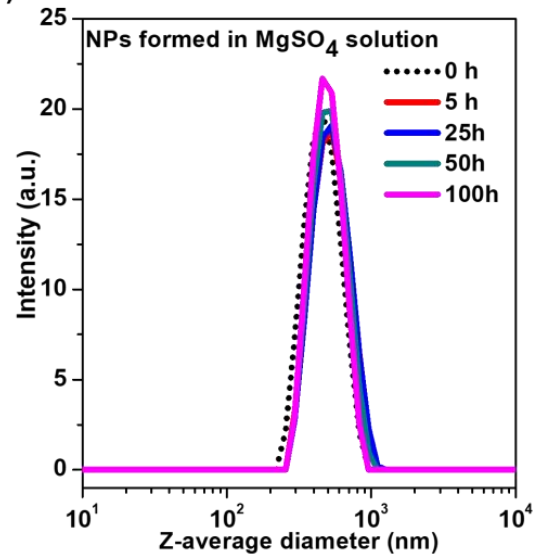

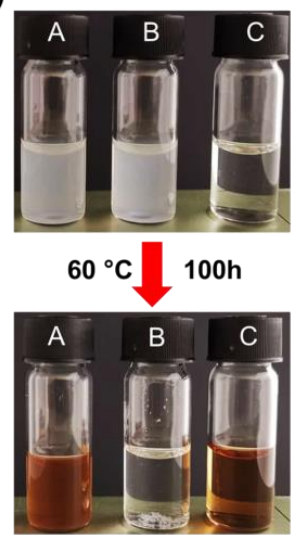

d)

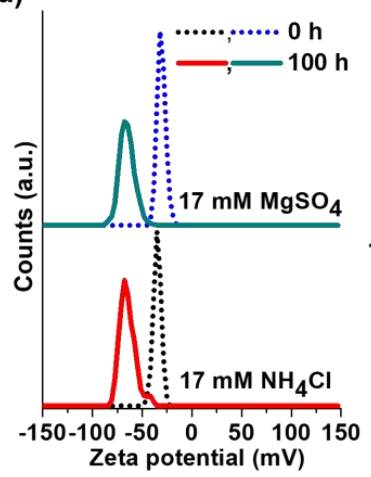

e) NPs formed in $\mathrm{NH}_{4} \mathrm{Cl}$ solution

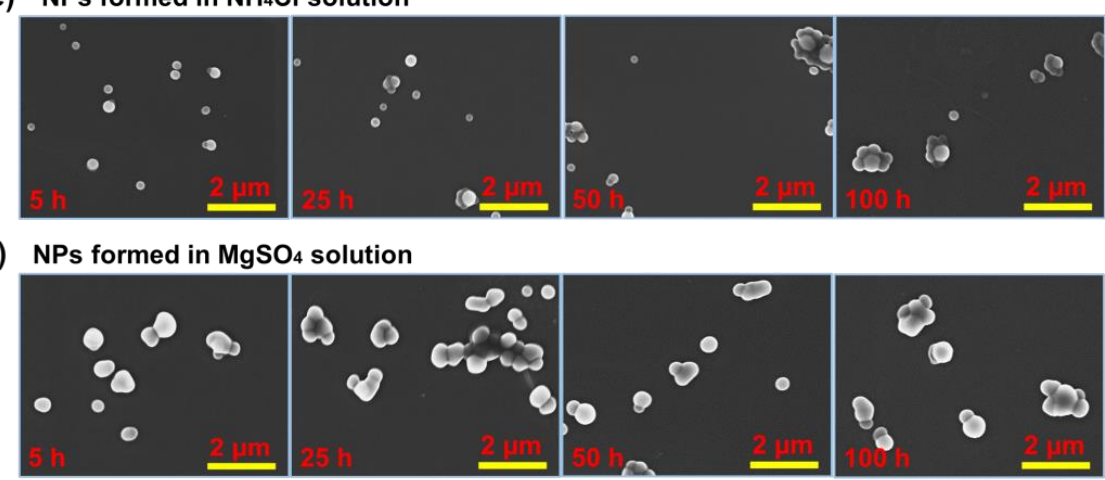

Figure 5. DLS curves and SEM images of NPs after incubation in excess BDBA alkaline solution at $60{ }^{\circ} \mathrm{C}$ for $5,25,50$ and 100 hours: a) and e) NPs formed in $17 \mathrm{mM} \mathrm{NH}_{4} \mathrm{Cl}$; b) and f) NPs formed in $17 \mathrm{mM} \mathrm{MgSO}_{4}$. c) Photo image after incubation in $\mathrm{NaOH}$ solution at $60{ }^{\circ} \mathrm{C}$ for 100 hours: sample A containing NPs with excess BDBA, sample B containing NPs without BDBA, and sample C containing BDBA without NPs. d) Zeta potential curves of NPs after incubation.

\subsection{Interaction of NPs bearing mannose moieties with BDBA}

The NPs bearing monosaccharide units have potential bio-medical applications via protein-clustered saccharides interactions. Besides, boronic acids are considered as synthetic lectins, which are extensively exploited to covalently bind to 1,2- or 1,3-diols of

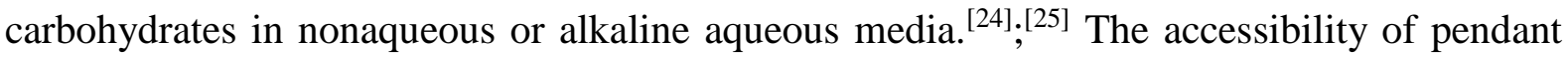
mannose moieties on NPs of CUE-MCR was further verified via the interaction of the NPs with BDBA in alkaline aqueous solutions. 
Interestingly, the NPs mixing with excess BDBA alkaline solution had good dispersion stability over a period of 100 hours. The average diameter of NPs after the incubation with BDBA was determined by DLS measurement. After the incubation for 5, 25, 50, 100 hours, the average diameter of $\mathrm{NPs}$ formed in $17 \mathrm{mM} \mathrm{NH}_{4} \mathrm{Cl}$ remained $246.6 \pm 5.7 \mathrm{~nm}$ with narrow size distribution $(\mathrm{PDI}=0.11 \pm 0.02)($ Figure 5a), which slightly increased compared to initial NPs with the average size $221.9 \pm 1.2 \mathrm{~nm}$ and narrow size distribution (PDI $=0.10 \pm 0.02$ ) As shown in Figure 5b, the average diameter of NPs formed in $17 \mathrm{mM} \mathrm{MgSO} 4$ remained $500.1 \pm 12.5 \mathrm{~nm}$ with narrow size distribution $(\mathrm{PDI}=0.08 \pm 0.03)$ after the incubation for 5 , 25, 50, 100 hours. These sizes also slightly increased compared to initial NPs with the average size $443.0 \pm 2.4 \mathrm{~nm}$ and narrow size distribution (PDI $=0.05 \pm 0.02$ ). The results supported the covalent bond between NPs bearing mannose moieties and BDBA under alkaline condition, forming boronic acid-cis diol complexes with strong boronate ester bonds. NPs together with excess BDBA in alkaline solutions of $\mathrm{NaOH}$ were incubated at $60{ }^{\circ} \mathrm{C}$ (Figure 5c, sample A). As comparison, NPs in alkaline solution without BDBA (sample B) and alkaline solutions of BDBA without NPs (sample C) were also incubated at $60{ }^{\circ} \mathrm{C}$. As shown in Figure 5c, the $\mathrm{NaOH}-$ induced aggregation of NPs was observed in sample B: NPs formed in $17 \mathrm{mM} \mathrm{MgSO} 4$ precipitated within 1 hour, which significantly faster than the sedimentation of NPs formed in $17 \mathrm{mM} \mathrm{NH}_{4} \mathrm{Cl}$ (about 6 hours). The reason was that larger average size nanoparticles were more unstable than smaller particles, due to the greater electrostatic screening introduced by $\mathrm{NaOH}$ (usually used as precipitation agent). Over the 100 hours, the color of sample A changed from milky to yellow and finally to reddish brown, also indicating the formation of tetrahedral boronate anions under alkaline aqueous condition, which was similar to the result observed in sample $\mathrm{C}$ only containing BDBA alkaline solution. ${ }^{[26]}$ The tetrahedral boronate anions multivalently bond with clustered mannoses existing on the surface of NPs, transforming nonionic NPs into anionic NPs. The negatively charged NPs had great electrostatic repulsion which can stabilize the NPs against electrostatic screening introduced by $\mathrm{NaOH}$. The slight increases of the average diameter of NPs were 
caused by the slight aggregation due to electrostatic screening introduced by $\mathrm{NaOH}$. As shown in Figure 5d, compared with initial NPs, the zeta potentials of NPs in sample A were both greatly increased: the zeta potential of NPs formed in $17 \mathrm{mM} \mathrm{NH} \mathrm{N}_{4} \mathrm{Cl}$ increased from $-33.1 \mathrm{mV}$ to $-63.1 \mathrm{mV}$, and the zeta potential of $\mathrm{NPs}$ formed in $17 \mathrm{mM} \mathrm{MgSO} 4$ increased from $-30.9 \mathrm{mV}$ to $-66.6 \mathrm{mV}$. Similar results can be obtained when incubated at room temperature over longer time. In addition, the elevated temperature was not necessary but accelerated the resulting aggregateion or binding behaviour.

SEM images of NPs incubating with BDBA at $60{ }^{\circ} \mathrm{C}$ under alkaline condition were shown in Figure 5e-f. After the incubation with BDBA in $\mathrm{NaOH}$ solution, the spherical morphology of mono-dispersion NPs maintained but those NPs had enhanced tendency to agglomerate over incubation time when dried.

\subsection{Fluorescent properties of NPs}

When NPs of CUE-MCR containing coumarin and rhodamine moieties was irradiated with UV light of 320-400 $\mathrm{nm}$ for 90 minutes, a significant decrease of the peak at $328 \mathrm{~nm}$ in the UV-Vis spectrum due to the dimerization of the coumarins. As well, there was an increase in the fluorescence intensity at $556 \mathrm{~nm}$ due to the formation of ring-opened structure of rhodamine from the corresponding non-fluorescent spirolactam structure (Figure 6a and c). Moreover, the strong fluorescence of NPs in dispersion and dry-state was observed by fluorescent microscopy after the irradiation with UV light of 320-400 nm, compared with as-prepared NPs (Figure 6b). However, the exposure to 320-400 nm UV light was not sufficient enough to change the average diameter of NPs significantly, but changed zeta potential of NPs. The average diameter of NPs determined by DLS measurement decreased from $239 \pm 1 \mathrm{~nm}$ to $218 \pm 1 \mathrm{~nm}$ after the irradiation with UV light of $320-400 \mathrm{~nm}$ for 90 minutes (Figure 6d). PDI greatly decreased simultaneously from $0.208 \pm 0.014$ to $0.083 \pm$ 0.013 , while the zeta potential value obviously increased from $-33.1 \pm 0.9 \mathrm{mV}$ to $-41.2 \pm 0.8$ $\mathrm{mV}$, as shown in Figure 6e. By irradiating the NPs solution with $254 \mathrm{~nm}$ UV light for 90 
minutes, an obvious peak increase at $328 \mathrm{~nm}$ in the UV-Vis spectrum due to the cleavage of coumarin dimer is notable. At the same time, the fluorescence intensity at $556 \mathrm{~nm}$ decreased due to the degradation of rhodamine under irradiation with UV light of $254 \mathrm{~nm}$ (Figure S1). The results showed that NPs of CUE-MCR was highly UV sensitive, which greatly enhanced the fluorescence of NPs by forming open-ring rhodamines. Besides, the coumarin moieties of NPs were photo-switchable, with accompanying fluorescence and stabilizing NPs by dimerization.

a)

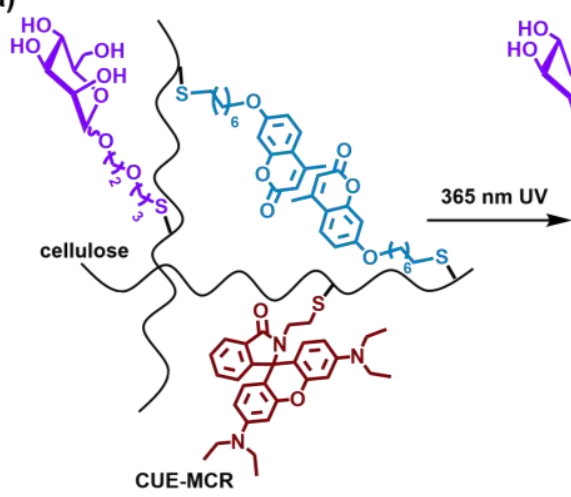

b)

c)

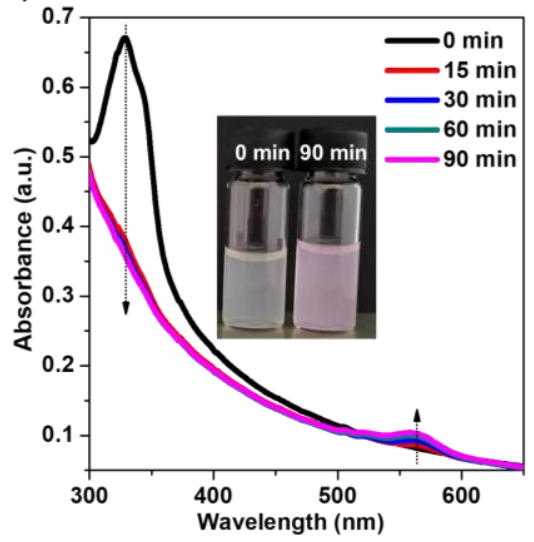

d)

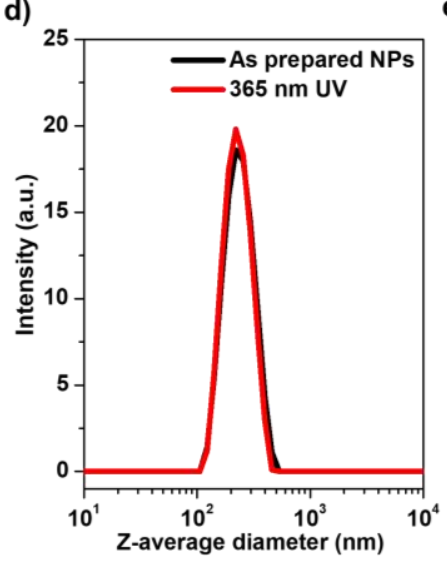

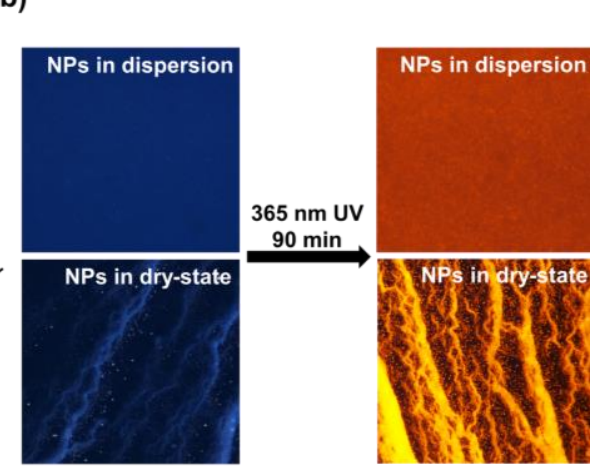

e)

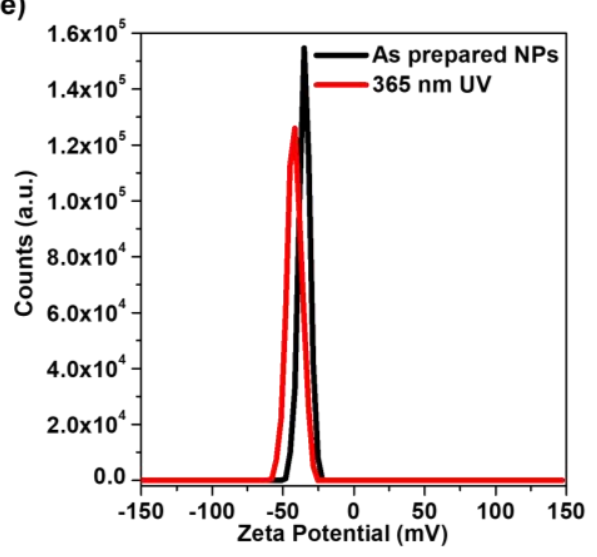

Figure 6. UV (365 nm) irradiation of $\mathrm{NPs}$ formed in $17 \mathrm{mM} \mathrm{NH}_{4} \mathrm{Cl}$ solution for $90 \mathrm{~min}$ : a) dimerization of coumarin and structure change of rhodamine; b) fluorescent microscopy images of NPs in dispersion and in dry-state; c) UV-vis spectra, the inset showing the corresponding photographs before and after treatments. d) DLS curves of NPs before and after treatments. e) Zeta potential curves of NPs before and after treatments.

\section{Conclusion}


In summary, we obtained uniform NPs of novel fluorescent cellulose derivatives bearing mannose moieties and coumarin as well as rhodamine moieties. The preparation of final product CUE-MCR started from esterification of cellulose to obtain cellulose backbone with terminal double bonds (CUE) and then two-step thiol-ene click reaction between three mercapto-compounds and CUE. The CUE-MCR with $\mathrm{DS}_{\mathrm{Mann}}=0.5, \mathrm{DS}_{\mathrm{Coum}}=1.0, \mathrm{DS}_{\mathrm{Rhod}}=$ 0.2 and $\mathrm{DS}_{\mathrm{C}=\mathrm{C}}=0.9$ was soluble in organic solvents, such as $\mathrm{THF}$, and were converted into stable NPs via nanoprecipitation. When dropping CUE-MCR solution into aqueous solutions with low ionic strengths $(<0.085 \mathrm{M})$, the average sizes of NPs with uniform size distribution (PDI < 0.12) increased along with ionic strength. The NPs were thermal stable due to the sufficiently high zeta potential. Furthermore, obtained NPs bearing mannose moieties can multivalently bind with BDBA in alkaline solution, stabilizing dispersions in $\mathrm{NaOH}$ solution even at elevated temperatures. Irradiation with UV light of $320-400 \mathrm{~nm}$ increased the fluorescence of the NPs bearing mannose moieties, which had potential application in biomedical fields.

\section{Experimental}

Materials: Microcrystalline cellulose (MCC) with the average size of $50 \mu \mathrm{m}$ was received from Sigma-Aldrich (Steinheim, Germany). 10-Undecenoyl chloride, pyridine, lithium chloride, D-Mannose, boron trifluoride-ethyl etherate $\left(\mathrm{BF}_{3} \cdot \mathrm{Et}_{2} \mathrm{O}\right)$, iodine, sodium methoxide, 2-allyloxyethanol, thioacetic acid, 7-hydroxy-4-methylcoumarin, 1,6-dibromohexane, potassium thioacetate, ion exchange resin $\left(\mathrm{H}^{+}\right.$-form $)$, rhodamine $\mathrm{B}$, cystamine dihydrochloride, potassium tert-butoxide, ammonium thioglycolate solution, 2,2-dimethoxy-2-phenylacetophenone (DMPA) and organic solvents including dichloromethane (DCM), ethyl acetate (EtOAc) and $n$-hexane were bought from Th. Geyer $\mathrm{GmbH}$ (Germany). Azobisisobutyronitrile (AIBN) was bought from TCI (Japan). Deionized water (DI water) was purified on a Merck Millipore system.

Synthesis of mannose-oxyethoxylpropane-thiol (Mann-SH): Mann-SH was synthesized 
from commercially available D-mannose in 3 steps according to previous report with a few modifications. ${ }^{[27] ;[28]}$ First step: iodine $(0.2 \mathrm{~g})$ was added to a stirred mixture of acetic anhydride $(30 \mathrm{~mL})$ and D-mannose $(5.0 \mathrm{~g}, 27.8 \mathrm{mmol})$. the reaction mixture was allowed to stir at room temperature until the solid was completely dissolved. Then, saturated $\mathrm{Na}_{2} \mathrm{SO}_{3}$ aqueous solution $(10 \mathrm{~mL})$ and saturated $\mathrm{NaHCO}_{3}$ aqueous solution $(50 \mathrm{~mL})$ were added sequentially. The mixture was then diluted with DCM (100 mL) and washed against brine solution. After the solvent was removed under reduced pressure, a yellow oily product $\mathbf{1}$ was obtained without further purification. Second step: a solution of compound 1 ( $1.0 \mathrm{~g}, 2.5 \mathrm{mmol})$ and 2-allyloxyethanol $(0.4 \mathrm{~mL}, 3.3 \mathrm{mmol})$ in $\mathrm{DCM}(30 \mathrm{~mL})$ was kept in ice-bath for 10 minutes under nitrogen protection. Then, $\mathrm{BF}_{3} \cdot \mathrm{Et}_{2} \mathrm{O}(0.4 \mathrm{~mL}, 3.3 \mathrm{mmol})$ was added dropwise. The mixture was allowed to stir in ice-bath for another 10 minutes and then at ambient temperature for overnight. The solution was added into ice water, extracted with DCM and washed with saturated $\mathrm{NaHCO}_{3}$ aqueous solution. The crude product was purified using silica gel column chromatography $(n$-hexane/EtOAc $=4: 1)$ and gave yellow oily product 2 . Third step: A solution of compound $2(1.0 \mathrm{~g}, 2.3 \mathrm{mmol})$ and thioacetic acid $(3.3 \mathrm{~mL}, 46.0 \mathrm{mmol})$ in DCM solution was stirred under UV irradiation for 2 days. After the extra thioacetic acid was removed by evaporation, sodium methoxide was added slowly until the $\mathrm{pH}$ was 10 by $\mathrm{pH}$ test paper. The mixture was stirred overnight at room temperature. Thereafter, ion exchange resin ( $\mathrm{H}^{+}$-form) was added to adjust the $\mathrm{pH}$ to neutral. The crude product was purification by silica gel column chromatography $($ EtOAc/methanol $=1: 4)$ to afford a red oily product 3 . Yield: $24 \%$

Synthesis of coumarin-oxyhexyl-thiol (Coum-SH): Coum-SH was synthesized from commercially available 7-hydroxy-4-methylcoumarin in 3 steps according to previous report with a few modifications. ${ }^{[29]}$ First step: anhydrous $\mathrm{K}_{2} \mathrm{CO}_{3}(0.8 \mathrm{~g}, 5.7 \mathrm{mmol})$ and 1,6-dibromohexane $(1.8 \mathrm{~mL}, 11.4 \mathrm{mmol})$ were added to a solution of 7-hydroxy-4-methylcoumarin $(0.5 \mathrm{~g}, 2.8 \mathrm{mmol})$ in acetone $(5 \mathrm{~mL})$, and the mixture was refluxed for 10 hours. After cooling down to room temperature, the reaction mixture was 
filtered and the filtrate was evaporated under reduced pressure. The crude product was purified on silica gel chromatography ( $n$-hexane/EtOAc $=4: 1)$ to afford white solid compound 4. Second step: potassium thioacetate $(0.5 \mathrm{~g}, 4.5 \mathrm{mmol})$ was added to a solution of compound 4 (1.0 g, $3 \mathrm{mmol})$ in DMF $(5 \mathrm{~mL})$. The mixture was stirred at room temperature for overnight. When finished, the mixture was poured to water and extracted with ethyl acetate. The solvent was removed by rotary evaporation and the crude product was purified on silica gel chromatography $(n$-hexane/EtOAc $=4: 1)$ to afford white solid compound $\mathbf{5}$. Third step: sodium methoxide was added slowly to a solution of compound $\mathbf{5}$ in methanol until the $\mathrm{pH}$ was 10 by $\mathrm{pH}$ test paper. The mixture was stirred overnight at room temperature. Then, ion exchange resin $\left(\mathrm{H}^{+}\right.$-form) was added to adjust the $\mathrm{pH}$ to neutral. The crude product was purification by silica gel column chromatography ( $n$-hexane/EtOAc $=4: 1$ ) to afford white solid compound 6 . Yield $50 \%$.

Synthesis of rhodamine B-ethyl-thiol (RhB-SH): RhB-SH was synthesized according to the literature with a few modifications. ${ }^{[30]}$ Under argon gas protection, cystamine dihydrochloride $(5.2 \mathrm{~g}, 33.8 \mathrm{mmol})$, potassium tert-butoxide (4.5 $\mathrm{g}, 40.0 \mathrm{mmol})$ and rhodamine B (1.2 g, $2.6 \mathrm{mmol})$ were dispersed in ethanol and refluxed for 24 hours. The solvent was removed by evaporation thereafter. Then, $10 \mathrm{~mL}$ ammonium thioglycolate aqueous solution $(60 \%)$ was added to the solution of crude product in DCM (20 mL). The mixture was stirred for overnight at room temperature. After that, the reaction mixture was extracted with DCM (100 mL) and washed against water for 3 times and the organic solvent was removed by evaporation and purified by silica gel column chromatography ( $n$-hexane/EtOAc $=4: 1)$ to yield yellow solid compound 7. Yield: $40 \%$.

Synthesis of polymeric cellulose 10-undecenoyl ester (CUE) under homogeneous condition: CUE was synthesized homogenously according to the previous report with a few modifications. ${ }^{[31]} \mathrm{MCC}$ was dried at $80{ }^{\circ} \mathrm{C}$ for 12 hours and lithium chloride was dried at $130{ }^{\circ} \mathrm{C}$ for 2 hours under the vacuum of less than $133 \mathrm{~Pa}$ before use. $1.0 \mathrm{~g}$ MCC was suspended in $40 \mathrm{~mL}$ DMAc and the mixture was kept at $130{ }^{\circ} \mathrm{C}$ for 2 hours under rigorous 
stirring. After removing the oil-bath and cooling down to $100{ }^{\circ} \mathrm{C}, 2 \mathrm{~g}$ lithium chloride was added. The mixture was stirred for overnight until a clear solution was obtained. Then, the cellulose solution was heated up to $50{ }^{\circ} \mathrm{C}$ and $4.1 \mathrm{~mL}$ of 10 -undecenoyl chloride ( $3 \mathrm{~mol}$ 10-undecenoyl chloride per mol anhydroglucose units in cellulose) was added. Thereafter, 4.9 $\mathrm{mL}$ pyridine was added under stirring. The mixture was then stirred for additional 4 hours at $50{ }^{\circ} \mathrm{C}$ and stopped by pouring the warm mixture into 5 volumes of methanol. Thereafter, the product was separated via centrifugation and purified by repeated dissolution in THF and precipitation in methanol. Yield: $\sim 3.0$ g CUE. Degree of substitution ascribed to double bonds $\mathrm{DS}_{\mathrm{C}=\mathrm{C}}$ is 2.6 according to elemental analysis: $\mathrm{C} 69.03 \%, \mathrm{H} 9.64 \%$.

Synthesis

of

11-(mannose-oxyethoxylpropane)(coumarin-oxyhexyl)(rhodamine-ethyl)thiolundecanoate 10-undecenoyl ester of cellulose (CUE-MCR) via thiol-ene click reaction: $0.7 \mathrm{~g}$ CUE was dissolved in $70 \mathrm{~mL}$ THF at room temperature and the solution of $1.9 \mathrm{~g}$ Mann-SH (2 mol per mol $\mathrm{C}=\mathrm{C}$ double bonds) and $0.5 \mathrm{~g}$ DMPA in $20 \mathrm{~mL}$ DMAc were added. Under argon protection, the mixture was stirred under UV irradiation $(320-400 \mathrm{~nm}$ with the intensity of $\sim 100 \mathrm{~mW} \cdot \mathrm{cm}^{-2}$ ) for 6 hours. Then $4.6 \mathrm{~g}$ Coum-SH ( $5 \mathrm{~mol}$ per $\mathrm{C}=\mathrm{C}$ double bonds), $0.9 \mathrm{~g}$ RhB-SH (0.6 mol per $\mathrm{C}=\mathrm{C}$ double bonds) and $1.5 \mathrm{~g}$ AIBN were added to the mixture solution and was stirred at $70{ }^{\circ} \mathrm{C}$ for 10 hours. The mixture was condensed by removing THF and poured into 5 volumes of methanol. the product was separated via centrifugation and purified by repeated dissolution in THF and precipitation in methanol. Yield: $\sim 0.9$ g CUE-MCR. Degrees of substitutions ascribed to mannose groups (DS $\mathrm{Dann}_{\text {n }}$, coumarin groups (DS $\mathrm{Doum}_{\text {), }}$ rhodamine groups $\left(\mathrm{DS}_{\mathrm{Rhod}}\right)$ and double bonds $\left(\mathrm{DS}_{\mathrm{C}=\mathrm{C}}\right)$ are $0.5,1.0,0.2$ and 0.9, respectively, according to elemental analysis and ${ }^{1} \mathrm{H}$ NMR spectra. Elemental analysis: C 66.90\%, H 8.6\%, N $0.78 \%$, S $4.85 \%$.

Fabrication of NPs from CUE-MCR: CUE-MCR was converted into NPs via nanoprecipitation using dropping technique. CUE-MCR was dissolved in THF at a concentration of $4 \mathrm{mg} \cdot \mathrm{mL}^{-1}$. Then, $1 \mathrm{~mL}$ CUE-MCR solution was added dropwise to $10 \mathrm{~mL}$ 
DI water or various electrolyte solutions of different concentrations $(17,51$ and $85 \mathrm{mM}$ of $\mathrm{NH}_{4} \mathrm{Cl} / \mathrm{NaCl} / \mathrm{MgSO}_{4}$ ) under a stirring of $600 \mathrm{rpm}$ at room temperature. After the complete addition, the samples were subsequently dialysed (molecular weight cut-off 3500) against DI water for 2 days to remove THF and electrolytes before further characterization.

Incubation NPs solution with BDBA in alkaline condition at $60{ }^{\circ} \mathrm{C}$ : BDBA alkaline solution was prepared by dissolving $30 \mathrm{mg}$ of BDBA in $1 \mathrm{~mL} \mathrm{NaOH}$ solution (containing 10 mg $\mathrm{NaOH}$ ) under sonication. Sample A: $1 \mathrm{~mL} \mathrm{NPs}$ (formed in $17 \mathrm{mM} \mathrm{NH} 4 \mathrm{Cl} / \mathrm{MgSO}_{4}$ solution and subsequently dialysed in DI water) was added to $1 \mathrm{~mL}$ BDBA alkaline solution and then incubated at $60{ }^{\circ} \mathrm{C}$ in oven for different periods of time. Sample B: $1 \mathrm{~mL}$ NPs (formed in $17 \mathrm{mM} \mathrm{NH}_{4} \mathrm{Cl} / \mathrm{MgSO}_{4}$ solution and subsequently dialysed in DI water) was added to $1 \mathrm{~mL} \mathrm{NaOH}$ solution (containing $10 \mathrm{mg} \mathrm{NaOH}$ ) and then incubated at $60{ }^{\circ} \mathrm{C}$ in oven for different periods of time. Sample C: $1 \mathrm{~mL}$ DI water was added to $1 \mathrm{~mL}$ BDBA alkaline solution and then incubated at $60{ }^{\circ} \mathrm{C}$ in oven for different periods of time.

Liquid-state ${ }^{1} \mathrm{H}$ and ${ }^{13} \mathrm{C}$ NMR spectra: All polymer samples in $\mathrm{CDCl}_{3}$ were obtained at $25{ }^{\circ} \mathrm{C}$ on Bruker DRX 500 spectrometer (Bruker, Biospin GmbH, Ettlingen). For ${ }^{1} \mathrm{H}$ NMR spectra, scans of up to 16 were accumulated with a frequency of $500.3 \mathrm{MHz}$. For ${ }^{13} \mathrm{C}$ NMR spectra, scans of up to 15000 were accumulated with a frequency of $125.8 \mathrm{MHz}$. Liquid-state NMR spectra were performed at $300 \mathrm{MHz}\left({ }^{1} \mathrm{H}-\mathrm{NMR}\right)$ and $75 \mathrm{MHz}\left({ }^{13} \mathrm{C}-\mathrm{NMR}, \mathrm{APT}\right)$ on Bruker Avance III 300 and Avance III 400 instruments in the solvent indicated. Chemical shifts $(\delta)$ were given in ppm and referenced to the residual solvent signal of $\mathrm{CDCl}_{3}$.

Elemental analysis: The contents of carbon, hydrogen, nitrogen and sulfur were determined with an Elemental Analyser 4.1 vario EL III (Elementar, Germany).

FTIR spectroscopy: FTIR spectroscopy was conducted on Bruker Alpha FTIR Spectrometer (Bruker, Germany) at room temperature. All polymer samples were measured between 4000 and $400 \mathrm{~cm}^{-1}$ with a resolution of $4 \mathrm{~cm}^{-1}$ using Platinum ATR and accumulated 24 scans.

Scanning electron microscopy (SEM): SEM images were obtained on a LEO supra-35 
high-resolution field emission scanning electron microscope (Carl Zeiss AG, Germany) with an electron beam acceleration voltage of $5 \mathrm{kV}$. A layer of carbon was coated on the surface of samples before SEM measurements.

Size exclusion chromatography (SEC): SEC characterization of CUE-MCR was measured with THF as the eluent on an Agilent 1260 Infinity system consisting of an autosampler (Agilent 1260 Infinity Standard Autosampler), an isocratic solvent pump (Agilent 1260 Infinity), a precolumn of the type $\operatorname{SDV}(8 \mathrm{~mm} \times 50 \mathrm{~mm}$, particle size $10 \mu \mathrm{m})$ from the company Polymer Standard Services (PSS), three separation columns of the type $\operatorname{SDV}\left(8 \mathrm{~mm} \times 300 \mathrm{~mm}\right.$, nominal particle size $10 \mu \mathrm{m}$, with pore sizes of $10^{6}, 10^{5}$, and $\left.10^{3} \AA\right)$ from PSS maintained at $35{ }^{\circ} \mathrm{C}$ in a column compartment and a refractive index detector. An injection volume of $50 \mu \mathrm{L}$ of CUE-MCR solution in THF at the concentration of $1 \mathrm{~g} \cdot \mathrm{L}^{-1}$ was measured and the flow rate of the mobile phase was $1 \mathrm{~mL} \cdot \mathrm{min}^{-1}$. Sample CUE-MCR was filter with the pore size of $0.45 \mu \mathrm{m}$ before the injection.

Dynamic light scattering (DLS): DLS measurements were performed on a Zetasizer Nano ZS (Malvern Instruments Ltd., UK) using $5 \mathrm{~mW}$ laser with the incident beam of $633 \mathrm{~nm}$ (He-Ne laser). $1.2 \mathrm{ml}$ of NPs suspensions $\left(4 \mathrm{mg} \cdot \mathrm{mL}^{-1}\right.$ different aqueous solutions) were used for the size measurement (Z-average diameter) in a disposable cuvette (IDL GmbH, Gießen, Germany), and were used for zeta potential measurement in disposable zeta cuvette (DTS1060C from Malvern Instruments Ltd.). The sizes and zeta potentials (mV) of NPs were measured three times with 15 and 20 runs for each measurement, respectively.

\section{Acknowledgements}

K.Z. thanks Georg-August-University of Goettingen for the Department Start-up funding and Fonds der Chemischen Industrie (FCI) for the financial support. S.W. gratefully acknowledges her PhD scholarship from the Chinese Scholarship Council (CSC).

\section{Conflict of Interest}


The authors declare no conflict of interest.

\section{Reference}

[1] I. Goldstein, R. Iyer, E. Smith, L. So, Biochemistry 1967, 6, 2373.

[2] H. Lis, N. Sharon, Chem. Rev. 1998, 98, 637.

[3] Y. C. Lee, R. T. Lee, Acc. Chem. Res. 1995, 28, 321.

[4] S. S. Ting, G. Chen, M. H. Stenzel, Polym. Chem. 2010, 1, 1392.

[5] Y. Miura, Y. Hoshino, H. Seto, Chem. Rev. 2016, 116, 1673.

[6] J. S. Basuki, L. Esser, H. T. Duong, Q. Zhang, P. Wilson, M. R. Whittaker, D. M. Haddleton, C. Boyer, T. P. Davis, Chem. Sci. 2014, 5, 715.

[7] F. Suriano, R. Pratt, J. P. Tan, N. Wiradharma, A. Nelson, Y.-Y. Yang, P. Dubois, J. L. Hedrick, Biomaterials 2010, 31, 2637.

[8] R. Jelinek, S. Kolusheva, Chem. Rev. 2004, 104, 5987.

[9] M. Okada, Prog. Polym. Sci. 2001, 26, 67.

[10] S. G. Spain, M. I. Gibson, N. R. Cameron, J. Polym. Sci. Polym. Chem. 2007, 45, 2059.

[11] Y. Habibi, L. A. Lucia, O. J. Rojas, Chem. Rev. 2010, 110, 3479.

[12] Y. Wang, T. Heinze, K. Zhang, Nanoscale 2016, 8, 648.

[13]F. Fayazpour, B. Lucas, C. Alvarez-Lorenzo, N. N. Sanders, J. Demeester, S. C. De Smedt, Biomacromolecules 2006, 7, 2856.

[14] S. Dong, M. Roman, J. Am. Chem. Soc. 2007, 129, 13810.

[15]E. Bulut, O. Şanl1, Artif. Cells Nanomed. Biotechnol. 2016, 44, 431.

[16] S. Wang, K. Zhang, Carbohydrate polymers 2018, 196, 154.

[17]K. Yoshida, M. Kaino, M. Sekiguchi, N. Chigira, Y. Amano, M. Inokuchi, Q. Li, T. Hasegawa, Carbohydr. Polym. 2019, 223, 115062.

[18]M. Sakabe, D. Asanuma, M. Kamiya, R. J. Iwatate, K. Hanaoka, T. Terai, T. Nagano, Y. Urano, J. Am. Chem. Soc. 2013, 135, 409. 
[19]D. Cao, Z. Liu, P. Verwilst, S. Koo, P. Jangjili, J. S. Kim, W. Lin, Chem. Rev. 2019, 119, 10403.

[20] S.-K. Ko, Y.-K. Yang, J. Tae, I. Shin, J. Am. Chem. Soc. 2006, 128, 14150.

[21]L. Zhao, W. Li, A. Plog, Y. Xu, G. Buntkowsky, T. Gutmann, K. Zhang, Phys. Chem. Chem. Phys. 2014, 16, 26322.

[22] M. A. Khan, M. R. Siddiqui, M. Otero, S. A. Alshareef, M. Rafatullah, Polymers 2020, $12,500$.

[23] S. L. Levit, R. C. Walker, C. Tang, Polymers 2019, 11, 1406.

[24] S. Tommasone, F. Allabush, Y. K. Tagger, J. Norman, M. Köpf, J. H. Tucker, P. M. Mendes, Chem. Soc. Rev. 2019, 48, 5488.

[25]S. A. Asher, V. L. Alexeev, A. V. Goponenko, A. C. Sharma, I. K. Lednev, C. S. Wilcox, D. N. Finegold, J. Am. Chem. Soc. 2003, 125, 3322.

[26] R. Nishiyabu, Y. Kubo, T. D. James, J. S. Fossey, Chem. Commun. 2011, 47, 1106.

[27]Z. Li, L. Sun, Y. Zhang, A. P. Dove, R. K. O’Reilly, G. Chen, ACS Macro Lett. 2016, 5, 1059.

[28]Z. Cai, A. Sasmal, X. Liu, S. A. Asher, ACS Sens. 2017, 2, 1474.

[29]N. Jiang, Q. Huang, J. Liu, N. Liang, Q. Li, Q. Li, S.-S. Xie, Eur. J. Med. Chem. 2018, $146,287$.

[30] W. Li, W. Wang, Y. Yang, K. Zhang, J. Mater. Chem. A 2014, 2, 13675.

[31] K. Zhang, A. Geissler, T. Heinze, Part. Part. Syst. Char. 2015, 32, 258. 


\section{Publication 3}

(Supporting information)

Mannosylated fluorescent cellulose-based glycopolymers for stable uniform nanoparticles

Shuang Wang, Philipp Vana, Kai Zhang* 


\section{General Remarks}

(3S,4S,5R,6R)-6-(acetoxymethyl)tetrahydro-2H-pyran-2,3,4,5-tetrayl tetraacetate, compound 1.

${ }^{1} \mathrm{H}$ NMR (300 MHz, $\mathrm{CDCl}_{3}, \delta$ in ppm): 1.99 (s, 3H), 2.04 (s, 3H), 2.08 (s, 3H), 2.16 (s, 6H), 4.01-4.11 (m, 2H), 4.24-4.30 (m, 1H), $5.25(\mathrm{~d}, 1 \mathrm{H}, J=3.0 \mathrm{~Hz}), 5.33(\mathrm{t}, 2 \mathrm{H}, J=3.0 \mathrm{~Hz}), 6.07$ (s, $1 \mathrm{H}) ;{ }^{13} \mathrm{C} \mathrm{NMR}\left(75 \mathrm{MHz}, \mathrm{CDCl}_{3}, \delta\right.$ in ppm): 20.59, 20.67, 20.76, 20.82, 20.92, 62.05, $65.50,68.42,68.83,70.70,90.74,168.13,169.60,169.82,170.06,170.73$; HR-MS (ESI) $\mathrm{m} / \mathrm{z}$ calcd for $\mathrm{C}_{16} \mathrm{H}_{22} \mathrm{O}_{11}[\mathrm{M}+\mathrm{Na}]^{+}$413.1060, found: 413.1054 .

(2R,3R,4S,5S)-2-(acetoxymethyl)-6-(2-(allyloxy)ethoxy)tetrahydro-2H-pyran-3,4,5-triyl triacetate, compound 2.

${ }^{1} \mathrm{H}$ NMR (300 MHz, $\mathrm{CDCl}_{3}, \delta$ in ppm): 1.99 (s, 3H), 2.04 (s, 3H), 2.10 (s, 3H), 2.16 (s, 3H), 3.61-3.72 (m, 3H), 3.80-3.86 (m, 1H), 4.01-4.12 (m, 4H), $4.29(\mathrm{dd}, 1 \mathrm{H}, J=6.0 \mathrm{~Hz}), 4.88(\mathrm{~s}$, $1 \mathrm{H}), 5.20(\mathrm{~d}, 1 \mathrm{H}, J=12.0 \mathrm{~Hz}), 5.25-5.32(\mathrm{~m}, 3 \mathrm{H}), 5.34-5.40(\mathrm{~m}, 1 \mathrm{H}), 5.84-5.97(\mathrm{~m}, 1 \mathrm{H}) ;{ }^{13} \mathrm{C}$ NMR (75 MHz, $\mathrm{CDCl}_{3}, \delta$ in ppm): 20.53, 20.58, 20.61, 20.81, 62.35, 66.11, 67.33, 68.23, $68.64,69.00,69.42,72.03,97.50,117.02,134.34,169.61,169.73,169.88,170.52$; HR-MS (ESI) $\mathrm{m} / \mathrm{z}$ calcd for $\mathrm{C}_{19} \mathrm{H}_{28} \mathrm{O}_{11}[\mathrm{M}+\mathrm{Na}]^{+} 455.3796$, found: 455.1524 .

(2R,3S,4S,5S)-2-(hydroxymethyl)-6-(2-(3-mercaptopropoxy)ethoxy)tetrahydro-2H-pyra n-3,4,5-triol, compound 3.

${ }^{1} \mathrm{H}$ NMR (300 MHz, D2O, $\delta$ in ppm): 1.85-2.04 (m, 2H), 2.60-2.86 (m, 2H), 3.65-3.76 (m, $7 \mathrm{H}), 3.78-3.92(\mathrm{~m}, 4 \mathrm{H}), 3.97(\mathrm{t}, 1 \mathrm{H}, J=3.0 \mathrm{~Hz}), 4.89(\mathrm{~s}, 1 \mathrm{H}) ;{ }^{13} \mathrm{C} \mathrm{NMR}(75 \mathrm{MHz}, \mathrm{D} 2 \mathrm{O}, \delta$ in ppm): 20.38, 32.47, 60.87, 66.33, 66.68, 68.92, 69.07, 69.96, 70.48, 72.70, 99.91; HR-MS (ESI) $\mathrm{m} / \mathrm{z}$ calcd for $\mathrm{C}_{11} \mathrm{H}_{23} \mathrm{O}_{7} \mathrm{~S}[\mathrm{M}+\mathrm{H}]^{+} 299.1164$, found: 259.1159 .

Thiolethyl rhodamine, compound 4. 
${ }^{1} \mathrm{H}$ NMR (300 MHz, $\mathrm{CDCl}_{3}, \delta$ in ppm): 1.15-1.22 (m, 12H), 1.24-1.27 (m, 1H), 2.26 (dd, 2H, $J=9.0 \mathrm{~Hz}, J=15.0 \mathrm{~Hz}), 3.28-3.37(\mathrm{~m}, 10 \mathrm{H}), 6.27(\mathrm{dd}, 2 \mathrm{H}, J=3.0 \mathrm{~Hz}, J=9.0 \mathrm{~Hz})$, 6.37-6.45 (m, 4H), 7.05-7.10 (m, 1H), 7.40-7.46 (m, 2H), 7.87-7.92 (m, 1H); HR-MS (ESI) $\mathrm{m} / \mathrm{z}$ calcd for $\mathrm{C}_{30} \mathrm{H}_{36} \mathrm{~N}_{3} \mathrm{O}_{2} \mathrm{~S}[\mathrm{M}+\mathrm{H}]^{+}$502.2528, found: 502.2523 .

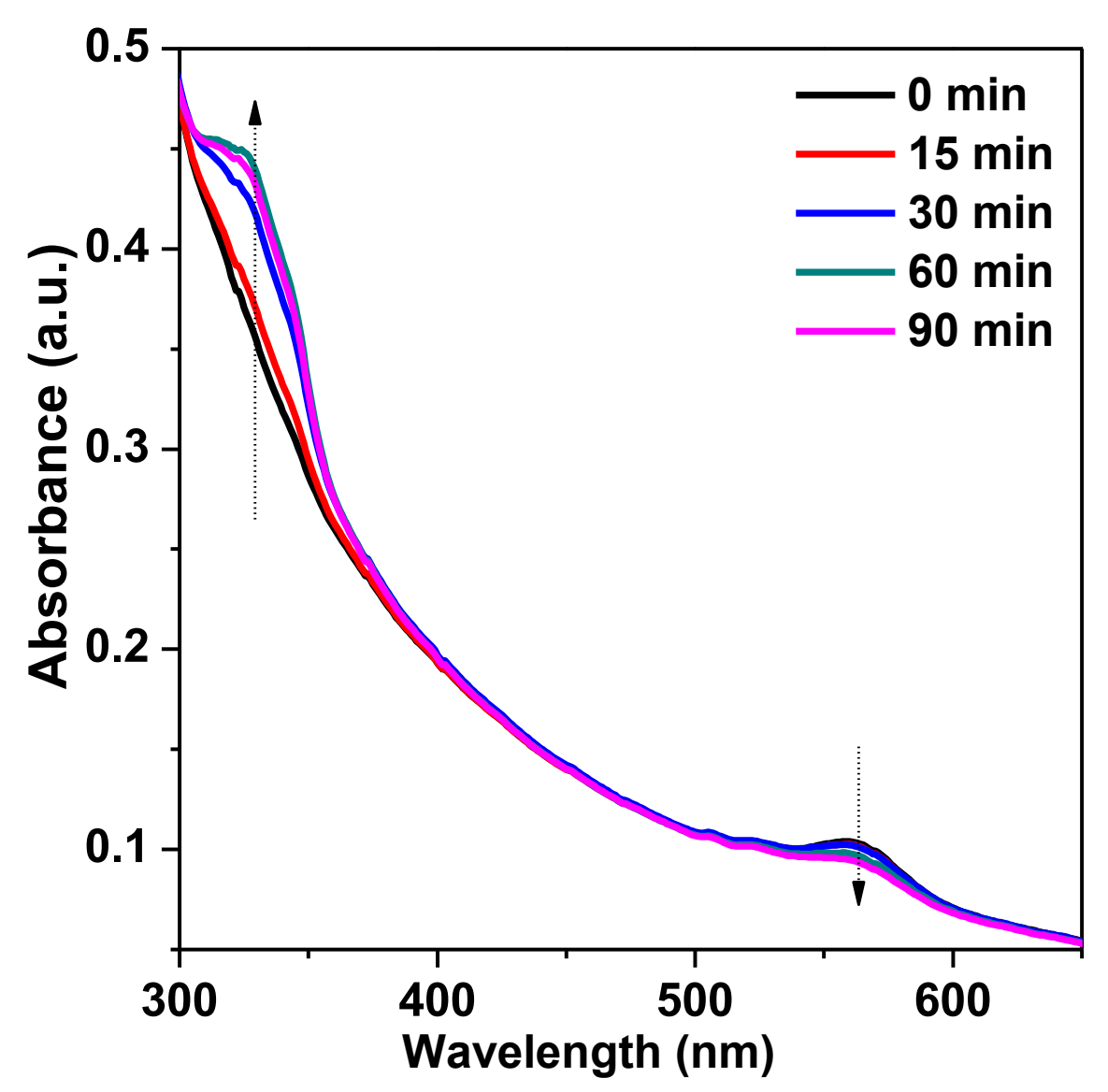

Figure S1. UV-vis spectra of NPs formed in $17 \mathrm{mM} \mathrm{NH}_{4} \mathrm{Cl}$ solution exposed to $254 \mathrm{~nm} \mathrm{UV}$ light for $90 \mathrm{~min}$.

${ }^{1} \mathrm{H}$ NMR and ${ }^{13} \mathrm{C}$ NMR Spectra 

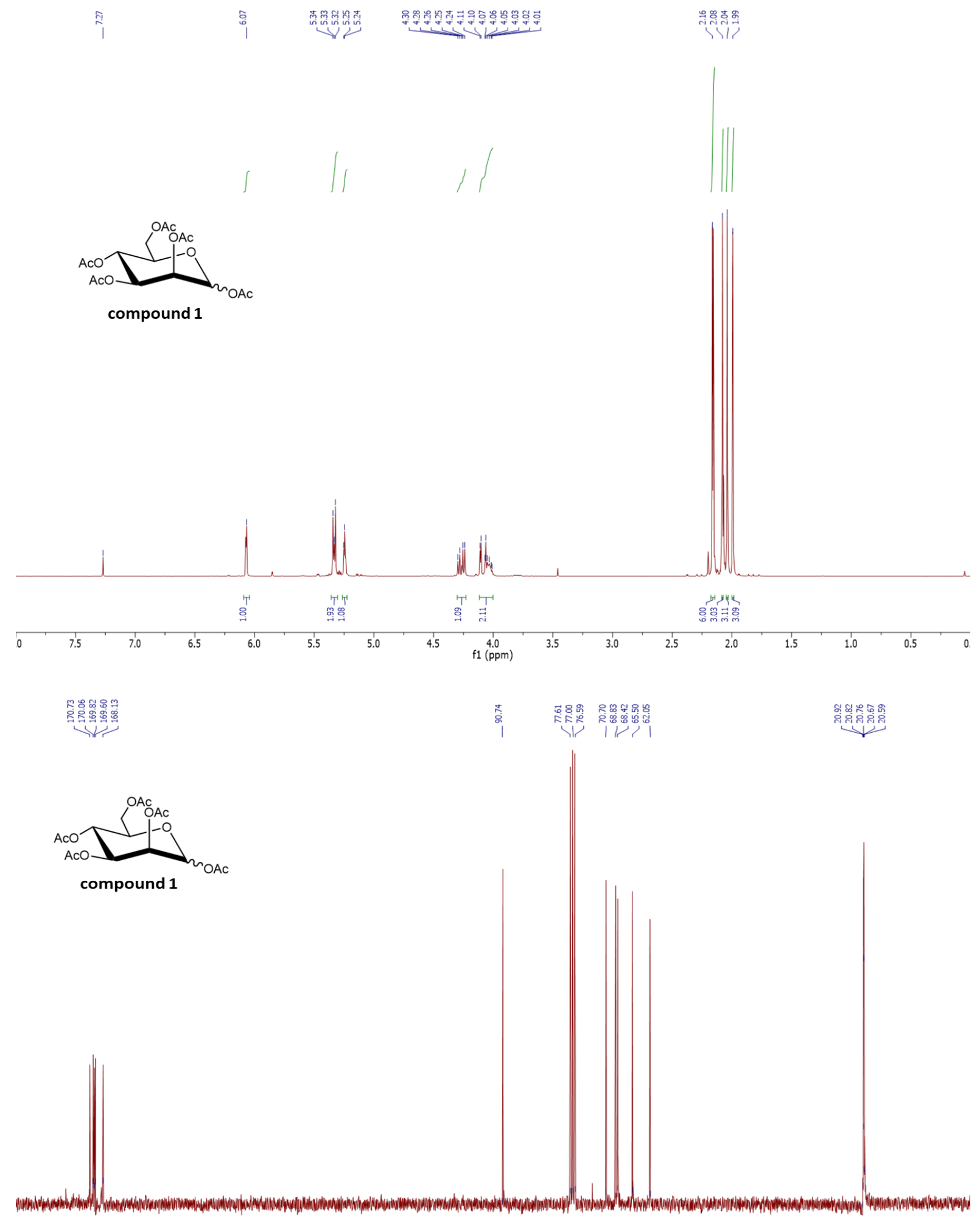

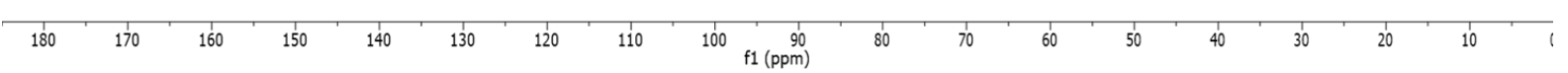



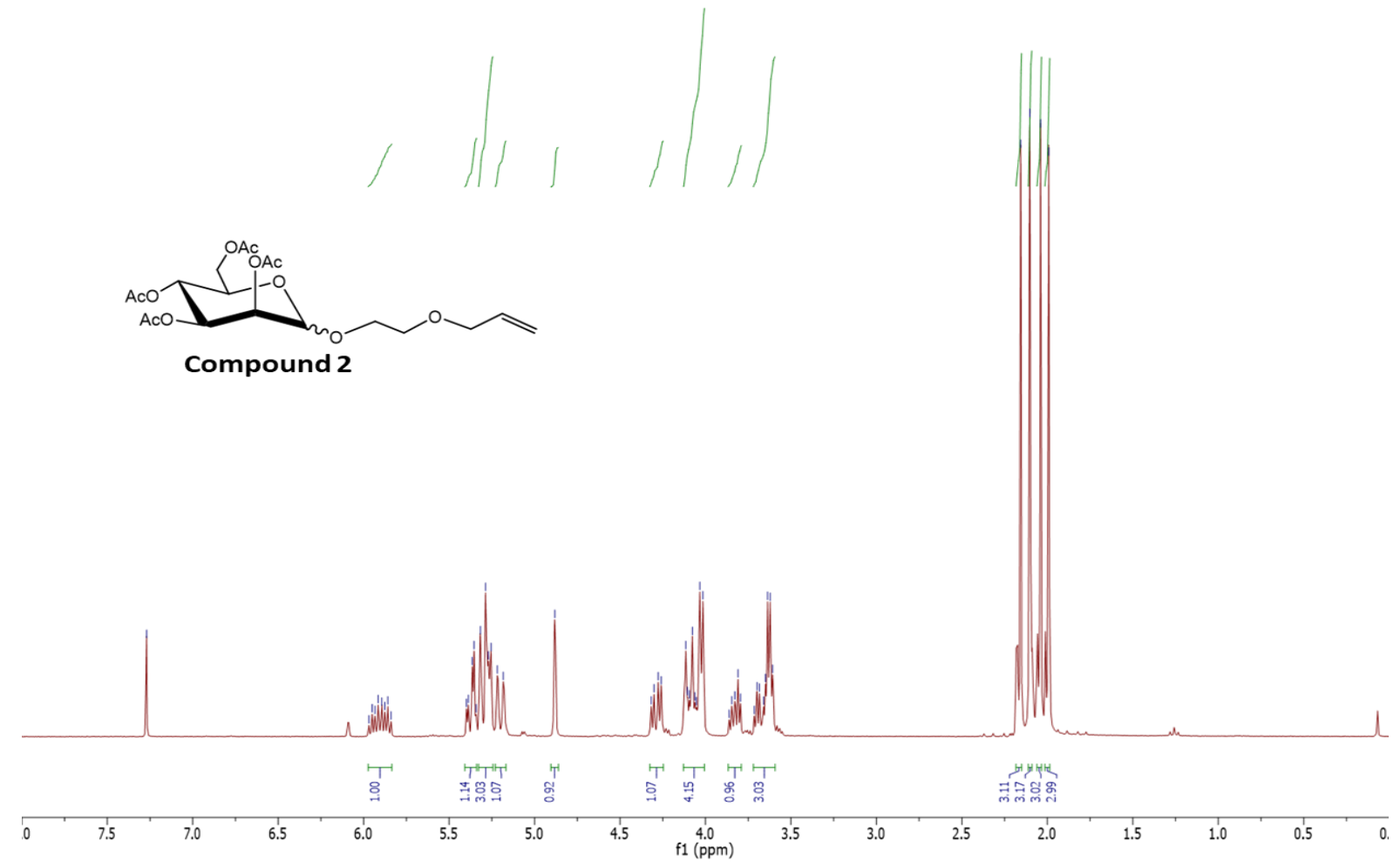

\begin{tabular}{|c|}
\hline 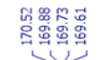 \\
\hline
\end{tabular}

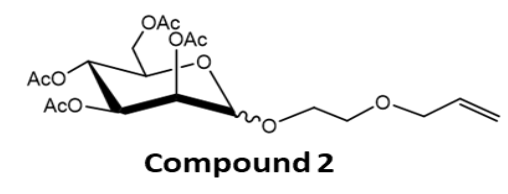

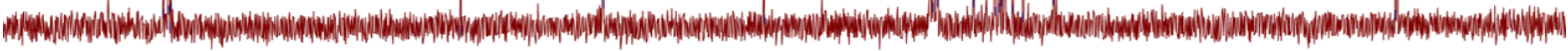

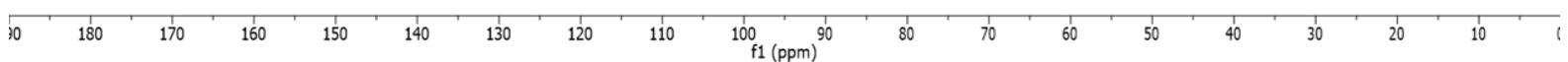



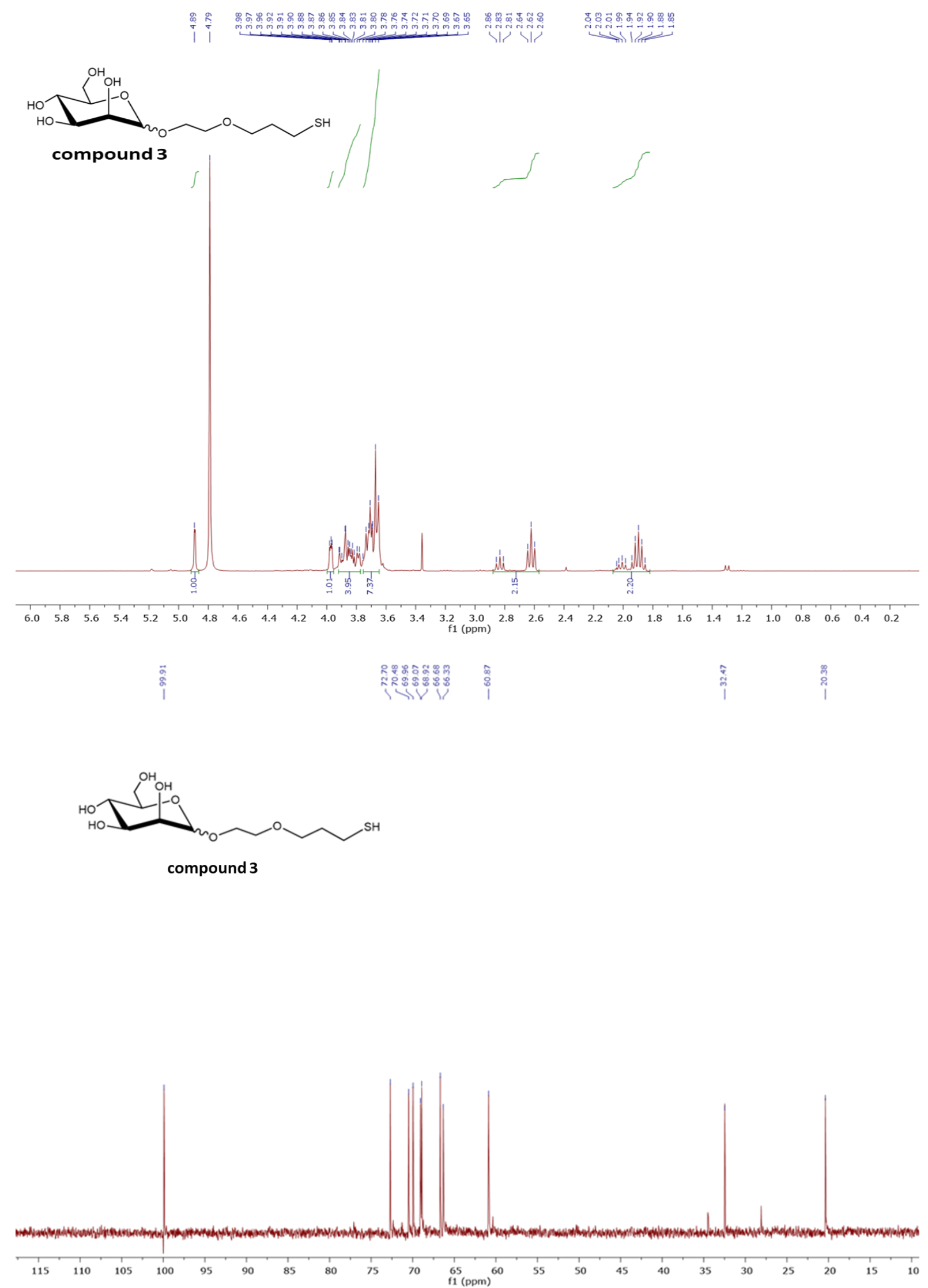


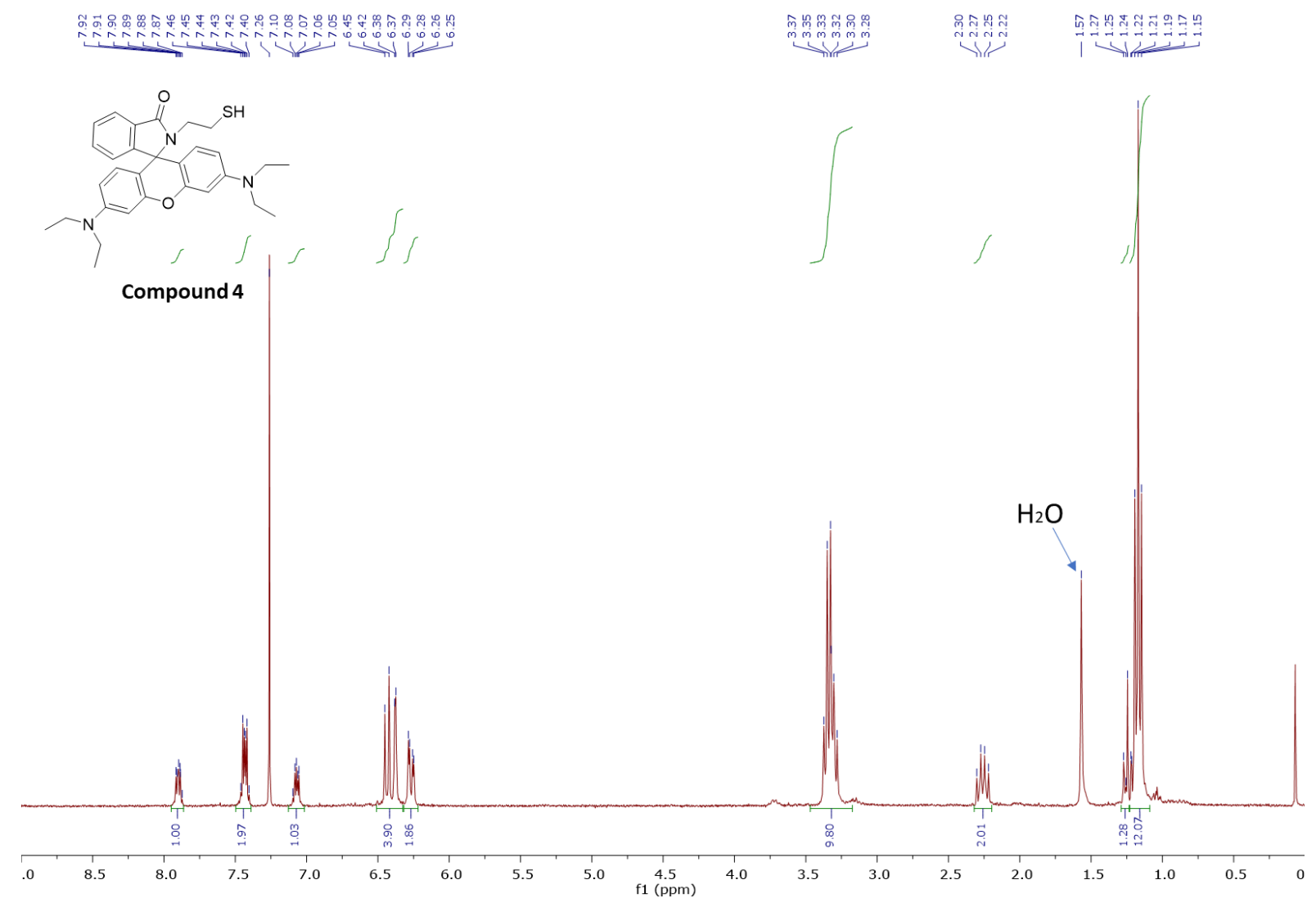

